Abstract Of 10 ${ }^{\text {th }}$ WRC, September 3 -6 2012, Sharm El-Sheikh, Egypt

\title{
BREEDING PROGRAMS FOR IMPROVING MALE REPRODUCTIVE PERFORMANCE AND EFFICIENCY OF AI DOSE PRODUCTION IN PATERNAL LINES: FEASIBILITY AND LIMITATIONS
}

\author{
Piles M. ${ }^{1 *}$, Baselga M. $^{2}$ \\ ${ }^{1}$ Unitat de Cunicultura, IRTA, Torre Marimon s/n, 08140, Caldes de Motbui, Barcelona, Spain \\ ${ }^{2}$ Depatment of Animal Science, Polytechnic University of Valencia, Camino de Vera s/n , 46022, \\ Valencia, Spain \\ *Corresponding author: miriam.piles@irta.es
}

\begin{abstract}
This paper aims at reviewing the current genetic knowledge of the issues related to the efficient use of bucks in artificial insemination (AI). Differences between lines have been found relevant in semen production and quality traits not necessarily related to their specialization as maternal or paternal lines. Accurate heritability estimates indicate that genetic selection for increasing semen production by improving male libido and reducing the number of rejected ejaculates may not be effective. However, total sperm produced per ejaculate appears to be as an interesting trait to select for, despite that genetic correlation between ejaculate volume and sperm concentration has not been yet accurately estimated. Semen $\mathrm{pH}$ has shown low to medium heritability estimates and a low coefficient of variation, therefore it is not advisable to attempt improvement by direct selection. In general, sperm motility traits have shown low heritabilities but, the rate of motile sperms per ejaculate has been considered as convenient to select for. Morphological characteristics of the spermatozoa have revealed as medium to highly heritable. There are evidences of high genetic correlations between sperm traits before and after freezing-thawing. There are few studies regarding the estimation of heterosis of seminal traits but results indicate important and favorable direct and maternal heterosis in crosses between maternal lines. However, this has not been confirmed in a cross between two paternal lines. Until now, attempts to find parametric or non-parametric functions to predict ejaculate fertility through seminal characteristics recorded in routinely evaluations have been very unsatisfactory. Hence, it may be necessary to find other semen quality markers, or to evaluate some of the currently used ones in a more precise manner or closer to the AI time in order to improve the ability to predict ejaculate fertility. Several seminal characteristics phenotypically correlated to male fertility, could be considered as potential traits to select for in order to genetically improving this trait. However, only the semen $\mathrm{pH}$ has been checked for this purpose, and a negative result has been obtained. Other traits can be studied in the future but bearing in mind that the required experiments will need large number of bucks for an accurate estimation of the genetic correlation of the trait with male fertility. This means that these experiments will be expensive and difficult to set up. The most common criterion to select paternal lines, average daily gain, seems not to be genetically correlated to male fertility and seminal traits. Thus, selection for average daily gain has no detrimental consequences on these
\end{abstract}


traits, and a multi-trait selection, including growth rate and seminal traits directly related to an efficient AI semen dose production, is feasible in paternal lines. The male contribution to fertility after natural mating and after AI with semen doses with high concentration is negligible, but it has been found that, under more restrictive conditions of AI, male contributions to fertility and litter size are low but higher in magnitude than the ones obtained after natural mating. The genetic correlation between the female and male contributions to fertility has been found to be moderate to high and positive.

Key words: Fertility, Genetics, Insemination, Male, Rabbits, Semen traits.

\title{
GENETIC SELECTION AND NUTRITIVE RESOURCES ALLOCATION IN REPRODUCTIVE RABBIT DOES
}

\author{
Pascual J.J., Cervera C., Baselga M. \\ Institute for Animal Science and Technology, Universidad Politécnica de Valencia, \\ Camino de Vera, 14. 46071 Valencia. Spain \\ *Corresponding author: jupascu@dca.upv.es
}

\begin{abstract}
In the present work is analysed how frequent feeding and selection programmes could be affecting resources allocation in reproductive rabbit does, and the possible consequences resulted from these changes, as well as the central role of body condition for a suitable female performance considering genetic level, health and welfare. Resources allocation between functions, and consequently body condition, must be genetically driven. Traditional view of body reserves mobilisation in reproductive rabbit does as a response of feed intake must be moved to an animal view, where feed intake must be considered more as an "output" consequence of the resources allocation in the female to ensure current and future litter viability. To a great extent, future reproductive potential of reproductive rabbit females is decided before first partum. There seems to be enough evidence of a possible threshold for the rabbit female birth weight to reach the beginning of reproductive life in a suitable body condition to maximise their future reproductive potential. The moment of first mating could be identified the last 'pure' data of the animal, sign of the animal soma and probably related to their productive potential. The choice of an adequate feeding system during rearing and first pregnancy also seems to be relevant in the reproductive performance of rabbit females in the short and long term. This should allow young females to reach first mating and late pregnancy with a good maturity level, but over-fattening must be avoided to reduce the risk of pregnancy toxaemia and reduced reproduction. The body condition of the females changes during the reproductive cycle and throughout their reproductive life according to their genetically determined level. The problems appear when the animals are forced to differ from this adequate level, increasing susceptibility to disease, other stress factors and eventual failure. The body condition of young rabbit females reaches the peak 10 days before kindling. From this moment to kindling, reproductive rabbit does seem to suffer the highest mobilisation of body reserves, with the body condition showing the lowest level at partum. Negative energy balances detected during lactation do not seem to have the strength of those observed in late
\end{abstract}


pregnancy. Genetic selection in rabbit by litter size at weaning has increased prolificacy but also the ability to obtain resources (more feed intake at the onset of lactation, better energy utilisation during pregnancy), without compromising the survival of rabbit females. However, it could also have increased the sensibility of animals to the environment, addressing more the maternal investment to the future litter respect to the actual under restricted conditions to maximize their selection success "the number". Rabbit does selected for reproductive longevity have a greater soma (body weight and body condition), which enables them to better cope with the possible productive challenges that they may meet in the course of their productive life. There is also evidence that they have greater plasticity in using their soma, making them more robust to overcome demanding situations. In fact, the response to environment restriction of females coming from a line founded for reproductive longevity criteria was flatter than those obtained for females selected for litter size at weaning in all the traits controlled, highlighting their differences on robustness. In addition, it seems to be evidence of a possible improvement of the immune system modulation in robust animals (lower sensitivity to immunological challenges), although further research effort must be done in the future to confirm this matter.

Key words: Rabbit female, rearing management, genetic selection, nutrient partitioning, body condition.

\title{
CONTROLLING THE RABBIT DIGESTIVE ECOSYSTEM TO IMPROVE DIGESTIVE HEALTH AND EFFICACY
}

\author{
Combes S. ${ }^{{ }^{*}}$, Fortun-Lamothe $\mathrm{L}^{\mathbf{1}}$, Cauquil L. ${ }^{1}$, Gidenne T. ${ }^{1}$ \\ ${ }^{1}$ INRA, UMR1289 TANDEM, 24 Ch. Borderouge, CS 52627, 31326 Castanet-Tolosan, France. \\ *Corresponding author: Sylvie.Combes@ toulouse.inra.fr
}

\begin{abstract}
The specific and functional diversity of the rabbit digestive ecosystem is highly diverse. The digestive ecosystem has several physiological roles: hydrolysis and fermentation of nutrients, immune system regulation, angiogenesis, gut development and acting as a barrier against pathogens. Understanding the digestive ecosystem and how to control its functional and specific diversity is a priority, since this could provide new strategies to improve the resistance of the young rabbit to digestive disorders and improve feed efficiency. This review first recalls some facts about the digestive microbiota composition in the main fermentation compartment, and its variability in rabbits and other species with some new insights based on recent molecular approaches. The main functions of the digestive microbiota will then be explained. Finally some possible ways to control rabbit caecal microbiota will be described and a suitable timing for action will be defined.
\end{abstract}

Key words: Microbiota, implantation, digestive efficacy, immune system development, health, rabbit 


\title{
RABBIT PRODUCTION IN LOW-INPUT SYSTEMS IN AFRICA - PROSPECTS, CHALLENGES AND OPPORTUNITIES
}

\author{
Oseni, S.O. \\ Department of Animal Sciences, Obafemi Awolowo University, Ile-Ife, 220005, Osun State, Nigeria \\ *Corresponding author: soseni@oauife.edu.ng
}

\begin{abstract}
High poverty levels continue to plague much of Africa, in spite of several intervention strategies to stem the tide. The role of small livestock like rabbits as a tool in poverty alleviation programmes has been acknowledged for decades and successful national rabbit projects have clearly been demonstrated in Africa. With rising poverty levels across Africa, the need to rejuvenate such national rabbit projects for long-term sustainability becomes apparent. This presentation focuses on the status of rabbit production in Africa, with special attention to smallholder rabbit project development and its connection with poverty alleviation issues in the continent and with an emphasis on the strengths, weaknesses, opportunities and barrriers to the system. A special case is made for the sustainable development of smallholder, low-input rabbit production systems in Africa on account of their popularity, low investment requirements and low economic risks, as well as their contributions to family nutrition, income generation and gender empowerment. Successful rabbit projects in several countries across Africa were identified and the reasons for success, as well as lessons learned, are discussed. In all, several cases standout: the National Rabbit Project of Ghana, the Heifer Project International (HPI) Rabbit Project in Cameroon (HPI-CAM), and CECURI Rabbit Project in Benin Republic. Other fast-paced and moderately developed rabbit industries (e.g., in Egypt, Tunisia and Algeria in particular) are also recognized. Critical constraints to rabbit project developments (political will on the part of the government, non-implementation of sustainable models for low-input and smallholder rabbit units, absence of clientele-focused research and development (R\&D) programmes, etc.) are also discussed. Prospects and opportunities for the development of sustainable smallholder rabbit production models include the following goals: (a) a paradigm shift among researchers to focus on innovative research related to the development of sustainable backyard rabbit production systems; (b) special R\&D focus on the needs of smallholder rabbit units; (c) sustainable breeding programmes to meet the requirements of smallholder rabbit units; (d) documentation and up-scaling of good practices in smallholder rabbit units across regions; (e) development of local value chains in smallholder rabbit development, and (f) establishment of regional and global networks of smallholder family rabbit projects. The actualization of these goals requires a new line involving a sustainability research agenda that focuses more on backyard rabbit farms as the primary beneficiaries. The World Rabbit Science Association could play a key role in the realization of these goals, as enshrined in its constitution. Overall, the need for a poverty focus and a pro-poor research agenda involving owners of backyard rabbits are emphasized.
\end{abstract}

Key words: Rabbits, smallholder units, low-input systems, poverty alleviation, africa. 


\title{
ROLE OF SOLUBLE FIBRE IN DIETS FOR GROWING RABBITS: A REVIEW
}

\author{
Trocino A. ${ }^{1}$, García J. ${ }^{2}$, Carabaño R. ${ }^{2}$, Xiccato G. ${ }^{3}$ \\ ${ }^{1}$ Department of Comparative Biomedicine and Food Science (BCA), University of Padova, Viale \\ dell'Università 16, I-35020, Legnaro, Italy \\ ${ }^{2}$ Departmento de Producción Animal, ETS Ingenieros Agrónomos, Universidad Politécnica de \\ Madrid, E-28040 Madrid, Spain \\ ${ }^{3}$ Department of Agronomy, Food, Natural Resources, Animal and Environment (DAFNAE), University of \\ Padova \\ Viale dell’Università 16, I-35020 Legnaro, Padova, Italy \\ *Corresponding author: angela.trocino@unipd.it
}

\begin{abstract}
In this review, the methods to measure fibre and soluble fibre fractions have been briefly presented; we have referred to soluble fibre as the difference between Total Dietary Fibre (TDF) and Neutral Detergent Fibre (NDF) due to its simplicity to be obtained and the numerous studies that measured it; the effects of soluble fibre on performance, digestive efficiency and physiology, caecal activity and health of growing rabbits have been reviewed by a meta-analysis of studies available in literature, also with the aim of elucidating the relationships with other dietary nutrients. The level of soluble fibre affects the digestive utilizations of soluble and insoluble fibre fractions at ileum and caecum, ileal and caecal microbiota and caecal fermentations by modifying the amount and the type of substrate reaching the caecum. The increase of soluble fibre has a positive effect on the reduction of mortality in growing rabbits affected by epizootic rabbit enteropathy, which could be related to the high fermentability of soluble fibre, the changes exerted in the intestinal microbiota, and an enhanced gut barrier function just after weaning. A minimal supply around $12 \%$ of soluble fibre (as fed) is recommended in diets for post-weaning and growing rabbits containing about $30 \% \mathrm{NDF}$ and $18 \%$ ADF. These conclusions are linked to the use of sugar beet pulp as primary source of soluble fibre and should be confirmed with other soluble fibre sources.
\end{abstract}

Key words: Growing rabbits, soluble fibre, digestibility, caecal fermentation, health.

\section{NEW PERSPECTIVES OF HOUSING REPRODUCTING AND GROWING RABBITS}

\author{
Zsolt Szendr \\ Faculty of Animal Science, Kaposvár University, 40, Guba S. str, Kaposvár, H-7400, Hungary \\ "Corresponding author: szendro.zsolt@ke.hu
}

\begin{abstract}
An increasing proportion of consumers recognize animal welfare aspects, they prefer to buy meat of animals kept in an environment with adequate housing conditions. But the situation is more complicated. Researchers and farmers have to take into consideration
\end{abstract}


consumer demands, animal welfare, production costs, profitability, competitiveness, food safety, traceability, etc. The aim of this review was to compare individual and group-housing system of rabbit does, focusing on the production and welfare aspects. Some information about the benefits and costs of group-living European wild rabbits are also provided. The advantages and disadvantages of different alternative systems of growing rabbits are synthesized as well. The main conclusions of the experiments are summarized. Some of the housing systems (group-housing of does, rearing rabbits on deep litter and in large group) are against the welfare (chronic stress, aggressiveness and injuries, higher risk of diseases and mortality...), reproductive and productive performances are lower, and the cost and the price of rabbit and meat are higher. These housing systems do not respect the demand of animal, they are against the well-being, however consumers are given to believe that these are the best housing conditions, and they pay higher price for the meat originating from these animals. The human idea of the optimal housing conditions of a certain animal may not coincide with those animals' real demands. People do nothavethe rabbits' mind to think. Therefore, it would be very important to give a correct picture, and provide up-to-date information about the real needs of rabbits. Some alternative housing systems (plastic mesh floor, elevated platform, larger cage and footrest for the does, dual-purpose cage, and gnawing stick as environmental enrichment) increase the production cost, but improve the welfare of animals (more comfortable, larger area for activity, less boredom and incidence of behavioral stereotypes). The higher price of rabbit meat originated from these housing systems covers the higher cost of production. At the same time we have to consider the financial opportunities of the poorer who can afford to buy rabbit meat only originated from intensive production system. There are several countries of mostly price-sensitive buyers, whose decisions are primarily determined by the price of products. We should help them to be able to purchase cheaper rabbit meat as well. We had better not forget that the rabbit meat has one of the highest biological values, it is healthy and has some functional aspects, on the other hand, many people cannot buy expensive food. Sevenbillion peoplelivein the world, and one and a halfbillion peopleare starving. The population is increasing, but the field used for agricultural purposes is decreasing. The ecological footprint is a question of not only the future, but present, as today humanity uses the equivalent of 1.5 planets to provide the resources we use and absorb our waste. The increasing needs of human population can be metonlywith intensive production, but at the same time, we have to produce rabbit meat to demanding customers who are able to pay higher price for rabbit meat originating from different alternative systems.

Key words: Rabbit, housing systems, group-housing, alternative methods. 


\title{
UPDATE ON RABBIT ENTERIC DISEASES: DESPITE IMPROVED DIAGNOSTIC CAPACITY, WHERE DOES DISEASE CONTROL AND PREVENTION STAND?
}

\author{
Fabrizio Agnoletti \\ Istituto Zooprofilattico Sperimentale delle Venezie, viale dell'Università 10, 35020 Legnaro (PD), Italy \\ E-mail: fagnoletti@izsvenezie.it
}

\begin{abstract}
Eight years have elapsed since the last World Rabbit Congress on rabbit farming but, since then, there has not been a radical change of knowledge on rabbit enteropathies and still little is known on the etiology of Epizootic Rabbit Enteropathy (ERE). This disease continuous to pose a severe health threat for rabbit meat production farms and it undermines their profitability. Despite improvements in the methodology to experimentally reproduce the disease, and the exclusion of several hypotheses, none of the remaining candidates for ERE etiology have yet been proven. The evolution of ERE under field conditions can be conditioned by the onset of secondary infections, by prophylactic or therapeutic interventions, as well as by management systems. Since there is no laboratory method for ERE diagnosis, as no specific etiological agent is targetable, the diagnosis is complicated further by the absence of specific clinical and anatomopathological findings. ERE outbreaks can have features that are similar to other enteric syndromes, with more or less defined signs that may be easily confused with more traditional conditioned and multifactorial enteric pathologies. Nowadays there is greater knowledge on the causes of enterotoxaemia in rabbits and on the role of C. perfringens, C.difficile and C.spiroforme, whereas no progress has been made on rabbit diseases due to Enterobacteria, especially on rabbit pathogenesis and prevention of E. coli enterities. Technological innovations which include a common use of biomolecular methods (in particular PCR and Real-Time PCR) enable better diagnostic results, thanks to enhanced analytical sensitivity and faster results. A lack of knowledge on the ERE etiological agent and on the pathogenesis of some rabbit enteric diseases has stalled progress to prevent and control the entire group of rabbit enterities. Even the enthusiasm for vaccines against colibacillosis seems to have come to a standstill. Differently from what happened in other animal species, broiler chickens for instance, in rabbit farms the prevention and disease control continue to rely on antimicrobials. Meanwhile the international scenario is changing and, at least in Europe, the widespread resistance to antimicrobials in bacteria is well documented and it is also influencing the policy making process. Reports published in recent years by the European Food Safety Authority (EFSA), the European Centre for Disease Prevention and Control (ECDC) and the European Medicines Agency (EMA) have agreed on the need to use antimicrobials prudently and to reduce their veterinary prescription. The requirement to moderate the use of medications works in hand with a reduction of animal diseases. Currently in Europe, policy-makers are calling on industrial farmers to improve animal welfare which helps to reduce pathologies and consequently the consumption of antimicrobials. Generally there is greater awareness
\end{abstract}


that drugs and medication must be safe and must not pose a risk to the health of European citizens. This is the top priority which ranks above all other productive or commercial interests. Hence, European rabbit industrial farms will have to account for these measures, but this trend will no doubt stretch even beyond European borders. Antimicrobial resistance recognises no border and it is not solely a European problem. Disease prevention can be achieved by ensuring better conditions for farmed animals and more animal-friendly farming practices. Although it is unlikely for rabbit farms to be completely revolutionised in the upcoming years, they will nonetheless have to implement different farming systems, some of which are well known, and on promoting healthier and more hygienic farms and greater biosecurity. Animal density in farms will have to be re-examined since it affects the spreading of pathogenic agents and animal stress. Finally, drug usage will have to be limited, leaving room to alternative products like probiotics, prebiotics, essential oils or acidifiers. The aforementioned proposed actions have to be economically sustainable and must guarantee profit to farmers despite the current international context of rising costs of raw materials and the global economic and financial crisis. The ability to adapt and detect the changes that are taking place is of paramount importance for survival, along with the ability to come up with innovative solutions which are capable of tackling the latest rabbit farming problems.

Key words: Rabbit, enteric diseases, antimicrobial resistance.

\title{
TRENDS IN RABBIT MEAT PROCESSING
}

\author{
Petracci M.*, Cavani C. \\ Dept. of Food Science, Alma Mater Studiorum - University of Bologna, Piazza Goidanich 60, \\ 47521 Cesena (FC), Italy \\ *Corresponding author: m.petracci@unibo.it
}

\begin{abstract}
Further processed products are currently demanded due to their convenience, high food safety and quality standards. However, even if processing industry is pushing more and more towards the introduction of more attractive products for consumers having few time for meal preparation, worldwide most rabbit meat is still sold as whole carcass or cut-up parts. This review will analyses the historical evolution of rabbit meat consumption and main force and weakness factors in relation to the use of rabbit meat to manufacture further processed products. Bearing in mind these considerations, it then describes the more promising technologies to process raw meat materials in order to obtain added-value products by exploiting rabbit meat intrinsic characteristics. Major trends in meat product formulation are also discussed by highlighting strategies to provide healthier meat products meeting current nutritional needs. Finally, main solutions in rabbit meat and meat products packaging are discussed.
\end{abstract}

Key words: Rabbit meat, further processing, technologies, ingredients, packaging. 


\title{
PREDICTING BODY WEIGHT OF RABBIT FROM LINEAR BODY MEASUREMENTS AT VARIOUS AGES BY GENETIC GROUP, PARITY AND SEX
}

\author{
Egena S. S. A. ${ }^{{ }^{*}}$, Akpa G. N. $^{2}$, Aremu A. ${ }^{1}$, Alemede I. C. ${ }^{1}$ \\ ${ }^{1}$ Department of Animal Production, Federal University of Technology P.M.B 65, Minna, \\ Niger state, Nigeria \\ ${ }^{2}$ Department of Animal Science, Ahmadu Bello University Zaria, Kaduna state, Nigeria \\ *Corresponding author's email: achenejesirisky@gmail.com
}

\begin{abstract}
Individual body weight was predicted at various ages by genetic group, parity and sex using two strains of rabbits namely; New Zealand White (NZW), Chinchilla $(\mathrm{CH})$ and their crosses. Data on individual body weight, nose to shoulder length, shoulder to tail length, heart girth, trunk length and length of ear of 130 rabbit kittens were collected on six genetic groups and used to predict body weight at pre-weaning (21 days), weaning (35 days) and post-weaning ages (49 days), respectively. Results revealed that body weight and linear body measurements had mostly significant $(p<0.05$ or $p<0.01)$ association except for $\mathrm{CH}$ breed at 35 days post-partum ( $p>0.05)$. The value of the coefficient of determination ranged from 0.49 to 0.99 being maximal for $\mathrm{CH} \times(\mathrm{CH} \mathrm{x}$ NZW) cross at 21 and 49 days post-partum and minimal for NZW x CH cross at 49 days post-partum. It was concluded that body weight could be predicted accurately based on the value of the coefficient of determination.
\end{abstract}

Key words: Body weight, Linear body measurements, Genetic group, Sex, Parity.

\section{SELECTION INDICES FOR IMPROVING BODY WEIGHT IN NEW ZEALAND WHITE BREED OF RABBIT MAINTAINED AT THE HILLY INDIAN STATE OF MEGHALAYA* \\ Choudhury S. Anjana ${ }^{1}$, ,Goswami $^{2}$, R. N. \\ Department of Animal Genetics and Breeding College of Veterinary Science, Assam Agricultural University, Khanapara, Guwahati - 781 022, India \\ Correspondence author: anjana.ghy@gmail.com \\ * Part of the Ph.D. thesis of first author. 1. Present address- Institute of Veterinary Biologicals, A.H.\& Vety. Dept.,, Govt. of Assam. 2. Dean, Faculty of Veterinary Science, AAU, Khanapara, Guwahati - 781022.}

\begin{abstract}
Selection indices were constructed utilising the body weight records of 1042 male and female New Zealand White rabbits belonging to 76 sire families that were born and maintained at the Rabbit Research Farm, Indian Council of Agricultural Research Complex for North Eastern Hill Region, Umium, Barapani, Meghalaya, distributed
\end{abstract}


over a period of 16 years from 1993 to 2008. Prior to genetic analysis, data were corrected for significant effects of parity, litter size at birth, sex of the animal, season of birth and period of birth by using least squares constants. Estimates of heritability and the genetic and phenotypic correlations were obtained from sire components of variances and covariances. Relative economic weights were estimated based on the feed cost, labour cost, medicine cost and the sale price of meat and hide. A total of eleven selection indices were constructed incorporating body weights at 42 days $\left(\mathrm{X}_{1}\right)$, 90 days $\left(X_{2}\right), 120$ days $\left(X_{3}\right)$ and 180 days $\left(X_{4}\right)$. The expected genetic changes in each of the individual traits $(\mathrm{X})$, the expected changes in aggregate genetic worth $(\mathrm{H})$ and the heritabilities of respective indices were also obtained. On the basis of the relative efficiency $\left(\mathrm{R}_{\mathrm{IH}}\right)$ the four best indices were found to be $\mathrm{I}_{9}=0.8551 \mathrm{X}_{2}+0.7684 \mathrm{X}_{3}$ $\left(\mathrm{R}_{\mathrm{IH}}=0.921\right), \quad \mathrm{I}_{2}=0.1899 \mathrm{X}_{1}+0.9123 \mathrm{X}_{2}+0.7596 \mathrm{X}_{3}\left(\mathrm{R}_{\mathrm{IH}}=0.917\right), \mathrm{I}_{6}=0.2868 \mathrm{X}_{1}+$ $0.7631 \mathrm{X}_{2}\left(\mathrm{R}_{\mathrm{IH}}=0.872\right)$ and $\mathrm{I}_{7}=0.2143 \mathrm{X}_{1}+0.6823 \mathrm{X}_{3}\left(\mathrm{R}_{\mathrm{IH}}=0.853\right)$, respectively. The heritabilities of these four selection indices as noted above were also found to be high, being respectively $0.859,0.844,0.761$ and 0.731 . It is thought that these four indices that were identified as the best viz., $\mathrm{I}_{9}, \mathrm{I}_{2}, \mathrm{I}_{6}$ and $\mathrm{I}_{7}$ could be used effectively both by farmers and breeders for rapid genetic improvement of rabbit in terms of growth performance.

Key words: Selection index, Relative economic weight, New Zealand White rabbits,

\title{
GENETIC DIVERSITY OF RABBIT POPULATIONS IN TUNISIA USING MICROSATELLITES MARKERS
}

\author{
Ben Larbi M. ${ }^{1}$, , San-Cristobal M. ${ }^{2}$, Chantry-Darmon C. ${ }^{3}$, Bolet $\mathrm{G}^{3}{ }^{4}$ \\ ${ }^{1}$ Laboratoire des ressources animales et alimentaires, Institut National Agronomique de Tunisie, 43 \\ Avenue Charles Nicole, 1082 Tunis, Tunisia \\ ${ }^{2}$ INRA UMR 444 Laboratoire de Génétique Cellulaire, chemin de Borde-Rouge 31326 Castanet \\ Tolosan, France \\ ${ }^{3}$ Labogena, INRA, Domaine de Vilvert - 78352 Jouy en Josas, France. \\ ${ }^{4}$ INRA UR 631 Station d'Amélioration Génétique des Animaux, 31326 Castanet Tolosan, France \\ "Manel BEN LARBI: arbi_mana@yahoo.fr
}

\begin{abstract}
This study attempts to provide a comprehensive insight into the prevailing genetic status of Indigenous Tunisian rabbit population using microsatellite markers. Fifteen rabbit populations from villages of Tozeur and Gafsa area were analysed using a panel of 36 microsatellite markers. 294 individuals from these populations were genotyped. In general, high genetic diversity (observed heterozygosity ranging from 0.3 to 0.53 ) and large population differentiation $\left(\mathrm{F}_{\mathrm{ST}}=0.11\right)$ were observed. The current study is the first detailed analysis of the genetic diversity of the Tunisian indigenous rabbit populations. The data generated here provides valuable information about the genetic structure of the 15 rabbit populations and this can be used for designating priorities for their conservation.
\end{abstract}

Key words: Rabbit, Tunisia, local population, genetic diversity, microsatellites. 


\title{
GENETIC PARAMETERS OF LITTER TRAITS IN A LOCAL BALADI BLACK RABBIT IN EGYPT
}

\author{
Abdel-Kafy E.M.*, Hassan N.S., Morsy W.A., Ali Kh.A.A., El-Sawy M.A., \\ Hassanein M.N.F., Sabra Z.A.M \\ Animal Production Research Institute, Agricultural Research Center, Ministry of Agriculture, Dokki, Giza, \\ Egypt. \\ *Corresponding author: sayedabdkaffy@ yahoo.com
}

\begin{abstract}
Some genetic parameters on Baladi Black (BB) litter trait rabbits were evaluated through two years, using Multi-Trait Derivative-Free Restricted Maximum Likelihood (MTDFREML). A total of 111 litters from 49 does, 12 dams and 7 sires were raised to measure some litter traits (litter sizes and weights at birth, 21 days and at weaning). The animal model analysis included parity and month of birth as fixed effects as well as animal and permanent environmental effect as random effects. Heritability's of considered traits were somewhat low being $0.03,0.01,0.01$ and $0.01,0.08$ and 0.09 for litter sizes and weights at the three ages studied respectively. Also, permanent environmental effects were low for both litter sizes and weights at the three ages studied (0.00002, 0.02 and 0.000045 and $0.00042,0.0086$ and 0.0006).
\end{abstract}

Key words: Litter traits, heritability, correlation.

\section{MICROARRAY ANALYSIS OF GENE EXPRESSION PROFILES IN REX RABBIT SKIN}

\author{
Chen Sai-juan ${ }^{1,3}$, Liu Ya-juan ${ }^{1,3}$, Huang Yu-ting ${ }^{1,3}$, Chen Bao-jiang ${ }^{2,3}$, \\ GU Zi-lin $1,2,3$, \\ ${ }^{1}$ Mountain Area Research Institute, Agricultural University of Hebei, No.289, linyusi Street, 071001, \\ Baoding, P.R.China; \\ ${ }^{2}$ College of Animal Science and Technology, Agricultural University of Hebei, No.289, linyusi Street, \\ 071001, Baoding, P.R.China; \\ ${ }^{3}$ Mountain area of Hebei Province Agricultural Engineering Technology Research Center, No.289, linyusi \\ Street, 071001, Baoding, P.R.China. \\ *Corresponding author: shyxq@hebau.edu.cn
}

\begin{abstract}
In order to identify differentially expressed genes in Rex rabbit skin, the expression of all genes in the skin and hair follicle of Rex rabbit were analyzed using cDNA microarray, and then analyzed the differently expressed genes with the Gene Ontology (GO) classification and the pathway analysis. The 2657 differentially expressed genes were identified. Among differentially expressed genes, 1103 genes were functionally known genes, 687 genes were up-regulated and 419 down-regulated. GO analysis indicated that these altered genes were associated with metabolism, signal transduction, cell cycle, cell adhesion, cell proliferation, cell division, apoptosis and other processes. KEGG analysis showed that 95 signal pathways associated with up-regulated genes
\end{abstract}


and 87 signal pathways associated with down-regulated genes had changed significantly $(\mathrm{P}<0.05)$. Some important genes were identified, which might be useful in further study on wool density markers of Rex rabbit.

Key words Rex rabbit, Gene expression, cDNA microarray, GO and KEGG analysis.

\title{
FUNCTIONAL LONGEVITY IN FOUR SPANISH MATERNAL LINES OF RABBITS
}

\author{
EL Nagar A. G. ${ }^{1,3^{*}}$, Sánchez J. P. ${ }^{2}$, Ragab M. ${ }^{1,4}$, Mínguez C. ${ }^{1}$, Baselga M. ${ }^{1}$ \\ ${ }^{1}$ Department of Animal Science, Polytechnic University of Valencia, Camino de Vera S/N, 46022, \\ Valencia, Spain. \\ ${ }^{2}$ Institut de Recerca i TecnologiaAgroalimentàries. Av. AlcaldeRoviraiRoure 191, 25198, Lleida, Spain. \\ ${ }^{3}$ Department of Animal Production, Faculty of Agriculture at Moshtohor, BenhaUniversity, Egypt. \\ ${ }^{4}$ Poultry Production Department, Faculty of Agriculture, Kafr El-Sheikh, Kafr El-Sheikh University, Egypt. \\ *Corresponding author: ayelna@posgrado.upv.es
}

\begin{abstract}
A comparative study among four maternal lines of rabbits (A, V, H and LP) was conducted. Data for this study were collected during the program of selection of these lines from September 1980 to March 2011. The main objective of this work was to compare doe longevity (length of productive life, LPL) in four lines selected for litter size at weaning but founded on different criteria. The analyzed traitwas defined as the time in days between date of the first positive pregnancy diagnosis and date of culling or death. The comparison has been done at their foundation time using the complete pedigree file and the complete data set of the performances from their foundation until March, 2011.The number of does with records was 12693 and the pedigree involved 14805 animals. The second objective of this study was to compare the lines at fixed times, during the last three year-seasons shared by at least three of them. The fixed times of comparison were from March, 1997 to September 1998 (period 1) for A, V and H lines, and from September, 2009 to March, 2011 (period 2) for A, V and LP lines. Survival analyses were carried out with a Cox proportional hazard model. The effective heritability for LPL was 0.16 . The relative risk (RR) for the contrasts Avs V, A vs $\mathrm{H}$ and A vs LP was 3.40, 3.43 and 5.56 at foundation, respectively. RR for the contrasts Avs V and $\mathrm{A}$ vs $\mathrm{H}$ was 1.42 and 1.32, respectively, during the first fixed period of comparison. RR for the contrastsAvs V and A vs LP was 1.41 and 1.71, respectively, during the second fixed period of comparison. The line A had a risk of death or culling greater than the other lines in all comparisons. No significant differences either between $\mathrm{V}$ and LP lines or between $\mathrm{V}$ and $\mathrm{H}$ lines have been founded in any comparison.In general the differences between lines at fixed times were smaller than those at their foundation. Along the generations of selection for litter size, the differences of longevity between lines tend to decrease, due to the action of the natural selection in the lines of lower longevity. The foundation criterion is important to define the initial longevity of the lines.

Key words: Rabbits, Longevity, Maternal lines, Survival analysis, Cox proportional hazard model.
\end{abstract}




\title{
GROWTH TRAITS IN FOUR MATERNAL RABBIT LINES
}

\author{
Mínguez C $^{{ }^{*}}$, , Sánchez J.P. ${ }^{2}$, Ragab M. ${ }^{1,3}$, EL Nagar A.G. ${ }^{1,4}$, Baselga M. ${ }^{1}$ \\ ${ }^{1}$ Dept. of Animal Science, Polytechnic University of Valencia, Camino de Vera S/N, 46022, \\ Valencia, Spain \\ ${ }^{2}$ Institut de Recerca i Tecnologia Agroalimentàries. Av. Alcalde Rovira i Roure 191, 25198, Lleida, Spain \\ ${ }^{3}$ Poultry Production Department, Faculty of Agriculture, Kafr El-Sheikh, Kafr El-Sheikh University, Egypt. \\ ${ }^{4}$ Department of Animal Production, Faculty of Agriculture at Moshtohor, Benha University, Egypt. \\ *Corresponding author: carminba@ posgrado.upv.es
}

\begin{abstract}
This study compares growth traits (weaning weight, slaughter weight and average daily gain) in four maternal lines of rabbits, A, V, H y LP, founded under different criteria, but all of them selected for litter size at weaning at the nucleus of the Polytechnic University of Valencia, until generations $41^{\text {th }}, 37^{\text {th }}, 10^{\text {th }}$ (only until May 2004) and $6^{\text {th }}$ respectively . A Bayesian approach was used for inference. Two types of comparisons were performed. One was carried out at the origin of the lines, using the complete data set (data from June 1980 to November 2010) and a two-trait analysis. Each growth trait was analysed together with litter size at weaning to avoid bias due to selection. The model used for the growth traits was a mixed model that includes as random effects, the additive, the maternal and the litter of birth. The consideration of the complete data set and the inclusion of the additive effects allow the comparison between the lines at their origin and allowed to predict the differences for given periods (expected differences). The other type of comparisons, at fixed periods of time, was done from March 1997 to August 1998 for comparisons between the lines A, V and H (period 1), and from December 2009 to November 2010 for comparisons between the lines A, V and LP (period 2). Each period of comparison corresponded to the last period when all the lines of each set were housed together at the nucleus, having the same management. These analyses used only the data corresponding to each period and one-trait models for the growth traits. These models were the same than the ones referred for the comparisons at the origin, but the additive effects were excluded. These comparisons allow estimating the actual differences between the lines at the given periods (observed differences) and comparing them to the expected differences for the same periods. A similarity between observed and predicted differences can be interpreted as an indication of the suitability of the complete model to explain the traits.

The estimates of the genetic correlations between litter size at weaning and growth traits were positive but low. At the origin, significant differences were observed for growth traits between the different lines. The contrast between H and LP lines was not done because they only shared two years-season. The results showed that at the origin, the $\mathrm{H}$ and LP lines were the heaviest. These differences may be due to different criteria and processes used to establish these lines. In period 1, the results showed that the $\mathrm{H}$ line was the heaviest. In period 2, the results showed that the LP line was the heaviest. In both periods, the observed (computed with the records of each period) and the expected differences (computed with the complete model and data set) were very similar for all traits in the two periods, indicating the suitability of the used models. At each period, the differences between lines for growth traits were smaller than at the
\end{abstract}


origin. This result could be due to a correlated response to the selection for litter size at weaning and to the direct response to a concomitant, non-programmed selection for the growth traits themselves different in intensity between the lines.

Key words: Growth traits, foundation, genetic lines, rabbit.

\title{
THE EFFECT OF DIFFERENT WEANING AGES ON PERFORMANCE IN HYLA RABBITS
}

\author{
Zita L. ${ }^{1}$, Ledvinka Z. ${ }^{1}$, Mach K. ${ }^{2}$, Kočár J. ${ }^{3}$, Klesalová L. ${ }^{1}$, Fučíková A. ${ }^{4}$, \\ Härtlová $\mathbf{H}^{4}{ }^{4}$ \\ ${ }^{1}$ Dept. of Animal Husbandry, Czech University of Life Sciences Prague, Kamýcká 129, 165 21, \\ Prague 6 - Suchdol, Czech Republic \\ ${ }^{2}$ Dept. of Genetics and Breeding, Czech University of Life Sciences Prague, Kamýcká 129, 165 \\ 21, Prague 6 - Suchdol, Czech Republic \\ ${ }^{3}$ Genetic Center HYLA, Ratibořice 11, 675 51, Jaroměřice nad Rokytnou, Czech Republic \\ ${ }^{4}$ Dept. of Veterinary Sciences, Czech University of Life Sciences Prague, Kamýcká 129, 165 21, \\ Prague 6 - Suchdol, Czech Republic \\ *Corresponding author: zita@af.czu.cz
}

\begin{abstract}
The effect of the weaning age of rabbits on growth, feed consumption, mortality and selected slaughter and carcass characteristics was studied in a fattening experiment. One hundred eight HYLA ${ }^{\circledR}$ rabbits from the Genetic Center HYLA Ratiborice were assigned to two groups of 60 and 48 rabbits according to weaning age of 21 and 35 days, respectively. The experimental diet had $171 \mathrm{~g} / \mathrm{kg}$ crude protein and $45 \mathrm{~g} / \mathrm{kg}$ crude fat. Feed and water were available ad libitum. At 35, 42, 49, 56, 63, 70 and 77 days of age, six rabbits of each weaning age were slaughtered. In the experiment, most performance results were not significantly affected by the weaning age. Only the rabbits weaned at 21 days of age had significantly (P 40.05 ) lower live weight at the age of 35 days (1022 and $1098 \mathrm{~g}$, respectively), but at the end of experiment we did not find any differences between the groups. The weaning age did not influence weight gain and feed intake, but mortality was higher in rabbits weaned at 21 days of age. In the majority of slaughter ages, there were a significantly higher live weight, hot carcass weight, chilled carcass weight, liver ratio to carcass chilled weight and insignificantly higher dressing out percentage in rabbits weaned at 21 days of age, while in rabbits weaned at 35 days of age a higher drip loss percentage was recorded.
\end{abstract}

Key words: Rabbit, HYLA, weaning age, slaughter age, growth, feed intake.

\section{RABBIT GENETIC RESOURCES IN THE CZECH REPUBLIC}

\author{
Tůmová, E. ${ }^{{ }^{*}}$, Volek, $Z^{2}$., Chodová, D. ${ }^{1}$, Zita, L. ${ }^{1}$ \\ ${ }^{1}$ Dept. of Animal Husbandry, Czech University of Life Sciences Prague, Czech Republic \\ ${ }^{2}$ Institute of Animal Science Prague, Prague 10 - Uhříněves, Czech Republic \\ *Corresponding author: tumova@af.czu.cz
}




\begin{abstract}
The aim of the study was to describe population size and selected performance characteristics of Czech local breeds, and compare the breeds with a commercial hybrid (Hyplus). In the study, seven Czech original breeds were included, giant breed Moravian Blue (MB), medium breeds Czech White (CW), Czech Spotted (CS), Czech Solver (CSo), Moravian White of Brown Eye (MW) and small breeds Czech Black Guard Hair (CB) and Czech Gold (CG). Population size shows that CSo, MW and CB which are critically endangered. Growth of rabbits was highly significantly ( $\mathrm{P} \unlhd 0.001$ ) affected by genotype and the highest daily weight gain was in MB (42.6 g) and the lowest in CB (26.6 g). All breeds had significantly higher (P \).002) dressing percentage than Hyplus rabbits (57.0\%). The highest nutrient digestibility was in CW with fat and crude fibre showing significantly the highest digestibility (P $₫$ ).001; P $₫ 0.035$ ).
\end{abstract}

Key words: Rabbit, genetic resources, population size, performance

\title{
LITTER TRAITS IN A DIALLEL CROSSING OF THREE RABBIT BREEDS IN NORTHERN GUINEA SAVANNAH ZONE OF NIGERIA
}

\author{
Kabir $M^{1}$., Akpa G.N ${ }^{1}$, Nwagu B.I ${ }^{2}$, Adeyinka I.A ${ }^{2}$ \\ ${ }^{1}$ Genetics and Animal Breeding Unit, Department of Animal Science, Ahmadu Bello University, Zaria. \\ ${ }^{2}$ National Animal Production Research Institute (NAPRI) Shika-Nigeria \\ Corresponding Author: Mohamed Kabir, E-mail:_mkabir@abu.edu.ng; kabirkbs@gmail.com
}

\begin{abstract}
This Study was conducted at the rabbitry unit of Ahmadu Bello University Zaria, with a view to utilize California White (CAW), Chinchilla (CHC) and New Zealand White (NZW) rabbits in a diallel cross to evaluate general and specific combining abilities, as well as maternal and reciprocal effects on litter performance. Data collected from 202 purebred kits born in 34 litters and 528 crossbred kits from 74 litters were used. The crossbred group comprised of 272 'main cross' kits and 256 'reciprocal cross' kits. Results of the study revealed that breed differences in general combining ability (GCA) for litter size indicated that $\mathrm{CHC}$ rabbits had better performance in terms of litter weight, individual kit weight and neonatal/preweaning mortality at birth and weaning than NZW and CAW. Analysis for specific combining ability (SCA) showed that the best combinations for litter size was NZW x CAW (8.5) at birth and (7.0) at weaning. Results of maternal heterotic effects for litter size and weight at birth and weaning showed that higher percentages were obtained from NZW x CAW cross than those from CHC x NZW and CAW x CHC crosses. Similarly, litters from CHC x NZW cross showed better size at birth and at weaning than those from CAW x CHC. Reciprocal effects showed a highly significant effect on litter weight at birth $(31.39 \%)$ for NZW x CHC cross while a significant effect was observed for gestation length and litter size at birth in NZW $\times$ CHC and CHC x CAW. Neonatal and preweaning mortality showed no significant reciprocal effect in NZW x CHC and CHC x CAW
\end{abstract}


crosses. Similarly, reciprocal effect was not important in CAW x NZW cross for all litter traits studied.

Key words: Diallel cross, combining ability, Litter traits.

\title{
THE POLYMORPHISM OF GHR GENE ASSOCIATED WITH THE GROWTH AND CARCASS TRAITS IN THREE RABBIT BREEDS
}

\author{
Wen-Xiu Zhang, Gong-Wei Zhang, Jin Peng, Song-Jia Lai" \\ Institute of Animal Genetics and Breeding, Sichuan Agricultural University, Xinkang Road 46", 625014, \\ Ya'an, Sichuan, China \\ *Corresponding author: Song-Jia Lai, laisj5794@gmail.com
}

\begin{abstract}
Although the growth hormone receptor (GHR) has been widely proposed to affect the carcass traits in livestock, its potential role in domestic rabbits has not been intensively investigated. In the present study, a non-synonymous SNP was identified in exon 3 (c.106 G>C) of GHR gene, which resulted in the amino acid substitution (V36L). This SNP was subsequently genotyped by using PCR-SSCP method among the two hundred and sixty-six individuals from three rabbit breeds (51 Tianfu black rabbits, 104 Ira rabbits, and 111 Champagne rabbits). The allele frequencies across the three breeds were 0.71 for allele $\mathrm{G}$ and 0.29 for allele $\mathrm{C}$, which suggested the moderate polymorphism. The association analyses revealed that the $\mathrm{pH}$ value of longissimus muscle after slaughter 24 $\mathrm{h}(\mathrm{LpH} 24)$ of CC genotype was significantly higher than GC and GG genotypes ( $\mathrm{P}<$ $0.01)$; the 84-day-weight, eviscerated weight, semi-eviscerated weight, eviscerated slaughter rate, and semi-eviscerated slaughter rate of CC genotype was significantly higher than GC genotype $(\mathrm{P}<0.05)$; the eviscerated slaughter rate and $\mathrm{pH}$ of hind leg muscle after slaughter $24 \mathrm{~h}(\mathrm{HpH} 24)$ of $\mathrm{CC}$ genotype was significantly higher than GG genotype $(\mathrm{P}<0.05)$. In contrast, GHR polymorphism had no significant influence on 28 day-weight, 35-day-weight, and 70-day-weight. This SNP of GHR gene could be applied with marker-assistant selection to improve carcass traits.
\end{abstract}

Key words: Rabbit, GHR gene, polymorphism, PCR-SSCP, growth traits, carcass traits

\section{MYOSIN HEAVY CHAIN TYPES AND EXPRESSION LEVELS OF MYOSTATIN AND MYOGENIN GENES IN MUSCLE OF TWO RABBIT BREEDS}

\author{
Kuang L $D^{1}$, Xie X $H^{1 *}$, Lei $M^{1}$, Li C Y $Y^{1}$, Ren Y $J^{1}$, Zhen $\mathbf{J}^{1}$, Zhang X Y $Y^{1}$, Guo Z $\mathbf{Q}^{1}$, \\ Zheng Y C ${ }^{2 *}$ \\ ${ }^{1}$ Sichuan Animal Sciences Academy, Chengdu, 610066, China \\ ${ }^{2}$ College of Life Science and Technology, Southwest University for Nationalities, Chengdu, 610041, China \\ *Corresponding author: kld258@ hotmail.com
}




\begin{abstract}
The aim of the present study was to compare fiber type compositions in terms of Myosin Heavy Chain (MyHC) and expression levels of myostatin (MSTN) and myogenin (MyoG) in longissimus dorsi of two rabbit breeds with different body sizes. Longissimus dorsi samples of Qixin rabbits $(\mathrm{n}=12)$ and German New Zealand of ZIKA rabbits $(\mathrm{n}=12)$ at $84 \mathrm{~d}$ after birth (marketing age) were collected. Quantitative real-time PCR analysis revealed four types of fiber in longissimus dorsi, and MyHC-1 and MyHC-2D were the major types. No significant difference was observed in the proportions of MyHC isoforms in longissimus dorsi between the two breeds. In addition, the two rabbit breeds at $84 \mathrm{~d}$ had showed non-significant mRNA differences in levels of MSTN and MyoG in longissimus dorsi. These results suggest that MyHC types, MSTN and MyoG expression may not directly associated with the different body sizes of the two rabbit breeds studied.
\end{abstract}

Key words: Rabbit, myosin heavy chain, myostatin, myogenin, gene expression.

\title{
MALE CONTRIBUTION TO PROLIFICACY AT EARLY STAGE OF GESTATION
}

\author{
Piles M. ${ }^{1}{ }^{*}$, Mocé ML. ${ }^{2}$, Laborda $\mathrm{P}^{3}$, Santacreu MA. ${ }^{3}$ \\ ${ }^{1}$ IRTA, Torre Marimon s/n, E-08140 Caldes de Montbuí, Barcelona, Spain \\ ${ }^{2}$ Departamento de Producción Animal Sanidad Animal y Ciencia y Tecnología de los Alimentos, \\ Universidad CEU Cardenal Herrera, 46113 Moncada, Valencia, Spain. \\ ${ }^{3}$ Instituto de Ciencia y Tecnología Animal, Universidad Politécnica de Valencia, 46071 Valencia, Spain \\ *Corresponding author: miriam.piles@irta.es
}

\begin{abstract}
The objective of this research was to assess the male contribution to the number of implanted embryos and embryonic survival in a line selected for ovulation rate for 10 generations. In prolific species, these traits could be considered as fertility measurements because they indicate the number and rate of fertilized ova which are able to initiate the embryo development. Selection was based on the phenotypic value of ovulation rate estimated at day 12 of second gestation by laparoscopy. Traits recorded were ovulation rate (OR) estimated as the number of corpora lutea in both ovaries, implanted embryos (IE) estimated as the number of implantation sites and embryonic survival (ES) calculated as IE/OR. A total of 1,477 records from 900 females were used to analyze OR, whereas 1,081 records were used to analyze IE and ES. The number of animals in the pedigree was 1107 . The $\mathrm{h}^{2}$ of the male contribution to IE and ES were low $(0.05[0.01,0.10]$ and $0.07[0.02,0.12])$. The genetic correlations between all the analyzed traits and also between male and female genetic components of EI and ES were estimated with great imprecision and it was not possible to draw any conclusion about them. As expected, the proportion of variation due to the male non-additive genetic plus permanent environmental effects for IE and ES was almost negligible (0.027 [0.001, 0.058] and 0.031 [0.002, 0.068] for EI and ES,
\end{abstract}


respectively), being the repeatability for male contribution to EI and ES around $8 \%$ and $10 \%$, respectively.

Key words: Embryo survival, genetic parameters, implanted embryos, male, rabbit

\title{
GENETIC PARAMETERS FOR AVERAGE DAILY GAIN AND THIGH MUSCLE VOLUME MEASURED BY COMPUTER TOMOGRAPHY IN PANNON TERMINAL LINE RABBITS
}

\author{
Gyovai P. ${ }^{1 *}$, Farkas J. ${ }^{2}$, Radnai I. ${ }^{3}$, Szendr Zs. $^{3}$, Éles V. ${ }^{4}$, Nagy I. ${ }^{4}$ \\ ${ }^{1}$ Health Center Equestrian Academy, Kaposvár University, Guba S. str. 40., 7400, Kaposvár, Hungary \\ ${ }^{2}$ Dept. of Information Technology, Kaposvár University, Guba S. str. 40., 7400, Kaposvár, Hungary \\ ${ }^{3}$ Dept. of Pig and Small Animal Breeding, Kaposvár University, Guba S. str. 40., 7400, Kaposvár, Hungary \\ ${ }^{4}$ Dept. of Agricultural Product Processing and Qualification, Kaposvár University, Guba S. str. 40., 7400, \\ Kaposvár, Hungary \\ *Corresponding author: gyovai.petra@ke.hu
}

\begin{abstract}
In rabbit breeding, Computer Tomography aided selection is exclusively applied worldwide at Kaposvár (Hungary) for the Pannon White rabbit and for the Pannon terminal line rabbit population improving their slaughter performance. The terminal line is created with purpose of increasing the average daily gain $(\mathrm{g} / \mathrm{d})$ and thigh muscle volume $\left(\mathrm{cm}^{3}\right)$ of the progenies. Since 2006 selection has been for average daily gain and thigh muscle volume (applying computer tomography, CT) in a closed population. Objective of the present study was therefore to estimate the efficiency of the CT-aided selection of the Pannon terminal line rabbits for average daily gain and thigh muscle volume. Present analysis was based on data from 22098 Pannon terminal rabbits born between 2006 to 2011 at the rabbit farm of Kaposvár University. The evaluated animals were reared in 3396 litters and the total number of the pedigree file was 27869 . The number of the base animals was 151 . The data on daily gain between the age of 510 weeks and CT-based thigh muscle volume were analyzed using REML and BLUP procedures in order to estimate genetic parameters and breeding values. Estimated heritabilities were moderate for average daily gain $(0.23 \pm 0.02)$ and for thigh muscle volume $(0.25 \pm 0.03)$. Litter effects were low for both traits $(0.16 \pm 0.00 ; 0.09 \pm 0.01$, respectively). Genetic correlation coefficient estimate between average daily gain and thigh muscle volume was low $(0.01 \pm 0.08)$.
\end{abstract}

Key words: Pannon White rabbits, genetic parameters, computer tomography, average daily gain, thigh muscle volume.

\section{EFFECTS OF SELECTION AND INBREEDING ON GROWTH AND CARCASS TRAITS OF PANNON TERMINAL LINE RABBITS}

\footnotetext{
Nagy I. ${ }^{1}$, Gyovai P. ${ }^{2 *}$, Farkas J. ${ }^{3}$, Radnai I. ${ }^{4}$, Éles V. ${ }^{1}$, Szendr Zs. ${ }^{4}$

${ }^{1}$ Dept. of Agricultural Product Processing and Qualification, Kaposvár University, Guba S. str. 40., 7400, Kaposvár, Hungary
} 


\footnotetext{
${ }^{2}$ Health Center Equestrian Academy, Kaposvár University, Guba S. str. 40., 7400, Kaposvár, Hungary ${ }^{3}$ Dept. of Information Technology, Kaposvár University, Guba S. str. 40., 7400, Kaposvár, Hungary ${ }^{4}$ Dept. of Pig and Small Animal Breeding, Kaposvár University, Guba S. str. 40., 7400, Kaposvár, Hungary *Corresponding author: gyovai.petra@ke.hu
}

\begin{abstract}
Effects of selection and inbreeding on average daily gain (between the age of 5-10 weeks) (ADG) and thigh muscle volume (TMV) (measured in vivo with computerized tomography) were estimated in a group of 22098 Pannon terminal line rabbits born between 2006 and 2011 and reared in 3396 litters. The data sets were analyzed with bivariate animal models taking pedigree completeness (complete generation equivalent) into account. By 2011 all rabbits were inbred and their average inbreeding coefficient and complete generation equivalent of the population were $7.69 \%$ and 11.89 , respectively. Significant inbreeding depression (per 10\% inbreeding) was only detected for ADG $(0.57 \mathrm{~g} / \mathrm{d})$. The estimated annual selection response was substantial both for ADG and TMV $\left(1.49 \mathrm{~g} / \mathrm{d}\right.$ and $5.84 \mathrm{~cm}^{3}$, respectively) proving the efficiency of the breeding programme.
\end{abstract}

Key words: Pannon rabbit, genetic trend, inbree ding depression, average daily gain, thigh muscle volume.

\title{
DIVERGENT SELECTION FOR RESIDUAL VARIANCE OF LITTER SIZE
}

\author{
Argente M.J. ${ }^{1 *}$, García M.L. ${ }^{1}$, Muelas R. ${ }^{1}$, Blasco A. ${ }^{2}$ \\ ${ }^{1}$ Departamento de Tecnología Agroalimentaria. Universidad Miguel Hernández de Elche, Ctra de \\ Beniel Km 3.2, 03312 Orihuela, Spain \\ ${ }^{2}$ Instituto de Ciencia y Tecnología Animal. Universitat Politécnica de València, P.O. Box 22012. \\ 46071 Valencia, Spain \\ *Corresponding author: mj.argente@umh.es
}

\begin{abstract}
A divergent selection experiment for residual variance $(\mathrm{Ve})$ of litter size was carried out in rabbits. The selection criterion Ve was the residual variance of litter size, estimated as the phenotypic variance of litter size within female after correcting litter size for the effects of year-season and lactation status (nuliparous, lactating and nonlactating females). Selection pressure on females was approximately $30 \%$ in each line. Males were chosen within sire families in order to avoid inbreeding. Each divergent line had approximately 125 females and 25 males per generation. The traits analyzed were: residual variance of litter size within female with $(\mathrm{Ve})$ and without $(\mathrm{Vr})$ correction for year-season and lactation status effects $(\mathrm{Vr})$ and litter size at birth. Results of five generations of selection were analyzed using Bayesian methods. The high and low lines showed a difference (D) of 0.65 for Ve in the first generation, with a probability of being positive $\mathrm{P}(\mathrm{D}>0)=97 \%$. This difference remained constant for two generations and increased from the fourth generation of selection. The difference for Ve was $1.12(\mathrm{P}(\mathrm{D}>0)=100 \%)$ in the fifth generation. Selection for Ve displayed
\end{abstract}


a high and positive correlated response in Vr. Besides, selection for reducing Ve seemed to increase litter size. In conclusion, there has been response to selection for $\mathrm{Ve}$, and selection for Ve showed a negative correlated response in litter size.

Key words: Canalization, environmental variance, homogeneity, litter size.

\title{
EFFECT OF DIVERGENT SELECTION FOR RESIDUAL VARIANCE OF LITTER SIZE ON HEALTH STATUS AND WELFARE
}

\author{
García M.L. ${ }^{1}$, Argente M.J. ${ }^{1}$, Muelas R. ${ }^{1}$, Birlanga V ${ }^{1}$, Blasco A. ${ }^{2}$ \\ ${ }^{1}$ Departamento de Tecnología Agroalimentaria. Universidad Miguel Hernández de Elche, Ctra de \\ Beniel Km 3.2, 03312 Orihuela, Spain \\ ${ }^{2}$ Instituto de Ciencia y Tecnología Animal. Universitat Politécnica de València, P.O. Box 22012. \\ 46071 Valencia, Spain \\ *Corresponding author: mj.argente@umh.es
}

\begin{abstract}
The objective of this study was to relate does health status and welfare with litter size variability. To assess welfare status, a measure of plasmatic levels of cortisol was taken, since levels of cortisol are related to stress. To assesss health status, reactive protein (CRP), haptoglobin (HP) and amyloid A (SAA) were taken. Does come from a divergent selection experiment for litter size variability were used in the experiment. In order to compare extreme groups of does, dams with the highest litter size variability of the high line and dams with the lowest litter size variability of the low line were used in the experiment. No difference between groups was found for cortisol concentration. However, concentration for CRP and SAA were different with probability of the difference being higher than zero always larger than $95 \%$. No clear conclusions can be drawn for HP. A higher concentration of CRP and SAA suggests that the females with higher litter size variability are more susceptible to pathogens. This susceptibility associated to higher variability of litter size may be under genetic control. If so, selection for reducing litter size variability may lead to does with a higher health status and disease resistance. Serum concentration of CRP and SAA seems to be better markers of health status than HP.
\end{abstract}

Key words: Litter size, homogeneity, cortisol, $\mathrm{C}$ reactive protein (CRP), serum amyloid A (SAA), haptoglobin (Hp), animal welfare.

\section{GENOTYPE AND AGE EFFECTS ON IMMUNITY TRAITS, CORTICOSTERONE AND OXIDATIVE STATUS IN GROWING RABBITS}

\author{
Abdel-Kafy, E.M.*, Hoda Shabaan M.A., El-Sayed A.F.M., Azoz. A.A.A., \\ and Abdel-Latif A. M. \\ Animal Production Research Institute, Agricultural Research Center, Ministry of Agriculture, Giza, Egypt. \\ *Corresponding author: sayedabdkaffy@yahoo.com
}




\begin{abstract}
To investigate the effects of genotype and age on native immunity, corticosterone and oxidative status 60 weaned rabbits were used; 30 Native Middle-Egypt rabbits (NMER) and 30 New Zealand White (NZW). Blood samples were collected and analyzed from each rabbit at 45,60 , and $75 \mathrm{~d}$ of age. Native immunity were included count and differential count of leukocyte, Serum Bactericidal Activity -SBA, Hemolytic complement Assay-HCA, lysozyme). Oxidative status (Reactive Oxygen Substances-ROS and total Antioxidant Capacity of plasma, TAC) were estimated in plasma. Genotype was an important source of variation $(p<0.01)$ for leukocytes where NMER was higher than NZW. Effect of age was not significant in Leukocytes. Genotype and age had significant $(\mathrm{p}<0.05)$ effect in both of Netruphile and Lymphocyte. Netruphile was increased while lymphocyte decreased at $45 \mathrm{~d}$ (after $10 \mathrm{~d}$ from weaning). Corticosterone levels at 45 days were higher than at others ages in both breeds. Breed significantly influenced Lysozyme and SBA in native immunity traits. NMER rabbits were characterized by a higher lysozyme, an increased SBA and complement when compared to NZW rabbits at different age. Lysozyme and HCA trends were higher at $45 \mathrm{~d}$ than at $60 \mathrm{~d}$, whereas the SBA increased with age. Reduced plasma levels of ROS in NMER rabbits at 60 and 75 days of age compared to NZW. TAC and ROS were significantly $(p<0.05)$ affected by age while breed had no significant effect It can be concluded that NMER rabbits were characterized by of native immunity traits (lysozyme, SBA and complement) when compared to NZW rabbits at different ages.
\end{abstract}

Key words: Middle-Egypt rabbits, Genotype, immunity, Corticosterone, Oxidative status, Age.

\title{
GENOTYPE AND AGE AFFECT NATIVE IMMUNITY TRAITS AND OXIDATIVE STATUS DURING SUCKLING PERIOD
}

\author{
Abdel-Kafy, E.M.*, Hoda Shabaan M.A., El-Sayed A.F.M., Azoz. A.A.A., \\ Abdel-Latif A. M. \\ Animal Production Research Institute, Agricultural Research Center, Ministry of Agriculture, \\ Giza, Egypt. \\ *Corresponding author: sayedabdkaffy@yahoo.com
}

\begin{abstract}
To investigate the effects of genotype and age on native immunity and oxidative status during suckling period used 40 rabbit does and 40 kits during suckling period from Native Middle-Egypt rabbits (NMER) and from New Zealand White (NZW). A total of 20 blood samples were collected and analyzed at 15 and $30 \mathrm{~d}$ of post-partum from rabbits does and kits for each genotype. Native immunity were included Serum Bactericidal Activity - SBA, Hemolytic complement Assay - HCA, lysozyme. Oxidative status (Reactive Oxygen Substances - ROS and total Antioxidant Capacity of plasma, TAC) were estimated in plasma. Genotype and interaction between breed
\end{abstract}


and age were source of significantly variation for lysozyme. Interaction between genotype and age had significantly effect in Serum Bactericidal Activity (SBA) $\%$ and Hemolytic complement assay (HCA) CH50. SBA was increased while HCA was decreased at $30 \mathrm{~d}$ compared to $15 \mathrm{~d}$ in does of local breed (NMER). On the contrary in the does of NZW, the SBA was decreased and HCA was increased at $30 \mathrm{~d}$. In rabbit kits age had a strong significantly influenced in lysozyme and HCA levels. Percentage of SBA was significantly affected by age and the interaction between breed and age. Rabbit kits were characterized by a higher HCA and lower SBA at $15 \mathrm{~d}$ compared to at $30 \mathrm{~d}$ in both of breeds. Oxidative status measurements in rabbit does inducted to the interaction between genotype and age had significantly effect in Total Antioxidant capacity (TAC) while Reactive Oxygen Substances (ROS) affected by both of breed and age. TAC values in rabbit kits were affected by breed and the interaction between breed and age. Total Antioxidant capacity (TAC) values in rabbit kits were affected by breed and the interaction between breed and age. In the present trial ROS and TAC values in does of NMER were higher than those in NZW at $30 \mathrm{~d}$ and this same trend observed in kits of NMER with advanced the age. This may be due to NMER rabbits as a local breed being more rustic, are used to move more and may suffer undergoing injuries when the available space is limited. Both of Lysozyme and SBA presented a significantly positive correlation with Antioxidant capacity. A positive correlation was between Lysozyme and SBA in rabbit kits that may be confirming their immune function as early defense barriers. In conclusion, in rabbit's does of local breed (NMER), blood lysozyme concentration and SBA \% increased with advanced of suckling period while complement activity was decreased. An opposite trend was observed for rabbit does of NZW breed. In rabbit kits of both breed (NMER and NZW) increase values observed in serum lysozyme and SBA levels at $30 \mathrm{~d}$ compared to $15 \mathrm{~d}$ post-partum during suckling period that may be indicated an effort to continuously adapt to environmental stress with advanced of age or/and to presence of specific receptors to E. coli on the intestinal epithelium with advanced suckling period in rabbit. Key words: Native immunity, Oxidative status, Genotype, suckling period, rabbit does, rabbit kits

\title{
CONSERVATION PROGRAMME FOR THE NATIVE POLISH BREED OF POPIELNO WHITE RABBITS
}

\author{
Bielański P.*, Kowalska D., Wrzecionowska M. \\ National Research Institute of Animal Production, 32-083 Balice, ul. Krakowska 1, Poland \\ *Corresponding author: pawel.bielanski@izoo.krakow.pl
}

\begin{abstract}
Acting in accordance with the principles of the Convention on Biological Diversity, in 1996 Poland started to implement the FAO's Global Plan of Action for Animal Genetic Resources. A programme for conservation of animal genetic resources was established as part of biodiversity conservation. Among the farm animals conserved in
\end{abstract}


Poland is Popielno White rabbits. In 1999, when the genetic resources conservation programme was launched, the population size of Popielno White rabbits was just 30 females of the foundation stock. By 2011 a herd of 258 does, subjected to performance recording and estimation of breeding value, was kept on 7 farms. In addition, over 200 does are now kept in commercial farms engaged mainly in rural tourism. Breeders acquired them as a result of various training programmes for areas at risk of structural unemployment.

Key words: Popielno White rabbit, genetic resources conservation, rabbit population.

\title{
DIRECT AND CORRELATED RESPONSES OF SELECTION IN DIVERGENT SELECTION FOR INTRAMUSCULAR FAT IN RABBITS
}

\author{
Zomeño C.*, Hernández P., Blasco A. \\ Institute for Animal Science and Technology, Universitat Politècnica de València, Camino de Vera \\ s/n. P.O.Box 22012, 46022, Valencia, Spain. \\ *Corresponding author: crizose@ posgrado.upv.es
}

\begin{abstract}
The objective of this study was to evaluate the genetic response for a divergent selection experiment on intramuscular fat (IMF) content and to estimate the correlated response in carcass and meat quality traits. Data from two generation of selection were used in this study. The base population was composed of 13 males and 83 females. High $(\mathrm{H})$ and Low $(\mathrm{L})$ lines had 8 males and approximately 40 females each one per generation. Selection was based on the average phenotypic IMF value of two full sibs measured in Longissimus muscle (LM). Two rabbits (male and female) of the first parity of each doe were slaughtered at 9 weeks of age. The following traits were recorded: live weight (LW), hot carcass weight, chilled carcass weight, reference carcass weight, scapular fat weight, perirenal fat weight, meat/bone ratio of hind leg, $\mathrm{pH}$ of LM, colour (lightness, $\mathrm{L}^{*}$; redness, $\mathrm{a}^{*}$; yellowness, $\mathrm{b}^{*}$ ) of the carcass and LM. Longissimus muscles were excised from the carcass and the IMF content was measured by near infrared reflectance spectroscopy. Data were analyzed using Bayesian methodology. Response to selection was estimated by the difference between $\mathrm{H}$ and $\mathrm{L}$ lines. The difference between lines for IMF content in the second generation of selection was $0.11 \mathrm{~g} / 100 \mathrm{~g}$, which represents a direct response to selection of $9.8 \%$, of which a $6.8 \%$ was obtained in the first generation and a $3 \%$ in the second. There seems to be a negative correlated response on live weight, carcass and adipose tissues weights, with higher values in $\mathrm{L}$ line. However, the evidence for adipose tissue is rather weak. There is no evidence of changes in carcass and meat colour measurements as well as in meat/bone ratio and muscle $\mathrm{pH}$.
\end{abstract}

Key words: Rabbits, divergent selection, selection response, intramuscular fat, near infrared reflectance, spectroscopy. 


\title{
GENETIC SELECTION FOR LITTER SIZE AND OVULATION RATE IN RABBITS: ESTIMATION OF GENETIC PARAMETERS, DIRECT AND CORRELATED RESPONSES
}

\author{
Ziadi C. ${ }^{{ }^{*}}$, Mocé M.L. ${ }^{2}$, Laborda P. ${ }^{1}$, Blasco A. ${ }^{1}$, Santacreu M.A. ${ }^{1}$ \\ ${ }^{1}$ Institute for Animal Science and Technology, Universitat Politècnica de València, P.O. Box 22012, 46071 \\ Valencia, Spain \\ ${ }^{2}$ Departamento de Producción Animal y Ciencia y Tecnología de los Alimentos, CEU-Cardenal Herrera, \\ Edificio Seminario, 46113 Moncada, Valencia, Spain \\ *Corresponding author: chizia@posgrado.upv.es
}

\begin{abstract}
Our objectives were to estimate direct and correlated responses in survival rates in an experiment of selection for ovulation rate and litter size in rabbits (OR_LS line). The experiment consisted of 2 periods of selection. In period 1, selection was performed for ovulation rate during 6 generations. In period 2, line underwent a two-stage selection for ovulation rate and litter size during 7 generations. Two-stage selection was based on the phenotypic value of ovulation rate and the average litter size over the first two parities. Total selection pressure was about $30 \%$. The line had approximately 17 males and 75 females per generation. Traits recorded were: ovulation rate estimated as the number of corpora lutea in both ovaries (OR); number of implanted embryos (IE); litter size (LS), estimated as total number of rabbits born recorded at each parity; embryo survival (ES) estimated as IE/OR, fetal survival (FS) estimated as LS/IE, and prenatal survival (PS) estimated as LS/OR. Data were analyzed using Bayesian methodology. The estimated heritabilities of LS, OR, ES, FS and PS were 0.07, 0.21, 0.07, 0.12 and 0.16 respectively. In the first period of selection, OR increased 1.4 ova in 6 generations, but no correlated response was observed in LS due to decreased fetal survival. After 7 generations of two-stage selection for ovulation rate and litter size, OR increased 1.0 ova and correlated response on LS was high ( 0.9 kits). Correlated responses for embryo, fetal, and prenatal survival in the second selection period were $0.02,0.02$, and 0.07 respectively. Two-stage selection for ovulation rate and litter size could be a promising procedure to improve litter size in rabbits.
\end{abstract}

Key words: Litter size, ovulation rate, survival rates, genetic responses, two-stage selection.

\section{SELECTION FOR OVULATION RATE IN RABBITS: OOCYTE CONCENTRATIONS OF GLUTATHIONE AND ATP}

\footnotetext{
Laborda, P. ${ }^{1,2}$, Santacreu, M. A. ${ }^{1}$, Blasco, A. ${ }^{1}$, Mocé, M. L. ${ }^{1,3}$

${ }^{1}$ Instituto de Ciencia y Tecnología Animal, UniversitatPolitècnica de València, 46071 Valencia. Spain.

${ }^{3}$ Departamento de Producción Animal y Ciencia y Tecnología de los Alimentos. Universidad Cardenal Herrera-CEU. Edificio Seminario. 46113 Moncada, Valencia. Spain.

${ }^{2}$ Correspondingauthor: patlavi@dca.upv.es
} 


\begin{abstract}
The present study was designed to determine the concentrations of glutathione (GSH)and ATP in rabbit oocytes in a line of rabbits selected for ovulation rate (line $\mathrm{OR}$ ) for ten generations, its unselected control line and a line selected for ovulation rate and litter size (line OR_LS) for ten generations. The relationship of GSH and ATP concentrations with ovulation rate was studied. GSH and ATP concentrations were used to assess oocyte quality. Atotal of 50does of the line OR, 41 does of the control line and 45 does of the line OR_LS were used. Ovulation was inducedby an intramuscular injection of $1 \mathrm{mg}$ of buserelin acetate and animals were slaughtered 16 hours thereafter. Oocytes were collected by flushing the oviducts.GSH concentration was determined by HPLC, while ATP concentration was determined by bioluminiscency. Ovulation rate was classified into three levels: low (10-13 corpora haemorragica), medium (14-18corpora haemorragica) and high (19-24 corpora haemorragica). Oocyte glutathione concentration was significantly lower in oocytes from females with high $(9.1 \pm 0.3 \mathrm{pmol})$ and medium $(9.6 \pm 0.1 \mathrm{pmol})$ ovulation rates than in oocytes from females with low ovulation rates $(10.2 \pm 0.3 \mathrm{pmol})$. No significant differences were found for ATP concentration. No differences in the concentrations of GSH and ATP between the line selected for ovulation rate and the control line were found, but the line OR_LS had a higher concentration of GSH (around 0.7 pmol/oocyte more). It seems that high ovulation rates could be associated with poorer oocyte quality in comparison with low ovulation rates.
\end{abstract}

Key words: Rabbits, selection, ovulation rate, ATP, glutathione, oocyte quality.

\title{
DETECTING SINGLE NUCLEOTIDE POLYMORPHISMS (SNPS) IN TOLL-LIKE RECEPTOR TWO GENES IN THE RABBIT
}

\author{
Zhang X.Y., Huang D.P., Zhang C.X., Xie L., Yang C., Li J.L., Deng X.D., Lei M., \\ Xie X.H. \\ Research Institute of Rabbit, Sichuan Animal Science Academy, No. 7, Niusha Rd., 610066, \\ Chengdu, China \\ *Corresponding author: Xie Xiao-hong. Zhangxiangyu757@163.com
}

\begin{abstract}
Toll-like receptors (TLRs) recognize pathogen-associated molecular patterns (PAMPs), which are derived from pathogen, and participate in activation of the immune responses as well. TLR2 gene can recognize PAMPs specific to bacterial disease such as pneumonia. In the present study, we sequenced the coding regions of the TLR2 gene in 15 rabbits from five breeds, including New Zealand White, Californian, Flemish Giant, Chinchilla and Fu Jian Yellow. In total, we discovered 11 single nucleotide polymorphism (SNPs), including four nonsynonymous SNPs located within the predicted TLR domains. Three replacements that change the amino acid characteristics were detected at bases 259, 319 and 997 in the TLR2 gene. The SNPs in
\end{abstract}


the TLR2 gene may increase the probability of adaptation to variability of PAMPs due to the rapid evolution of pathogens and the possibility of survival in rabbit populations. These novel SNPs will be useful in future studies to investigate the association between the TLR2 gene and disease resistance.

Key words: Rabbit, toll-like receptors gene, single nucleotide polymorphism (SNP), Innate immunity.

\title{
A COLLABORATIVE EUROPEAN NETWORK ON RABBIT GENOME BIOLOGY: RGB-NET
}

\author{
Garreau H. ${ }^{1}$, Bosze Z. ${ }^{2}$, Curik I. ${ }^{3}$, Piles M. ${ }^{4}$, Rogel-Gaillard C. ${ }^{5}$, Thulin C.-G. ${ }^{6}$, \\ Fontanesi L. ${ }^{7}$, RGB-Net consortium \\ ${ }^{1}$ INRA, UR631 SAGA, F-31326, Castanet-Tolosan, France \\ ${ }^{2}$ Agricultural Biotechnology Center, 4. Szentgyörgyi A. Gödöll „,Hungary \\ ${ }^{3}$ University of Zagreb, Faculty of Agriculture, Department of Animal Science, Svetosimunska 25,10.000 \\ Zagreb, Croatia \\ ${ }^{4}$ IRTA, Torre Marimon s/n, E-08140 Caldes de Montbuí, Spain \\ ${ }^{5}$ INRA, UMR1313 Laboratory of Animal Genetics and Integrative Biology, 78352 Jouy en Josas Cedex, France \\ ${ }^{6}$ Swedish University of Agricultural Sciences, SE-901 83 Umeå, Sweden \\ ${ }^{7}$ University of Bologna, Dept. of Agro-Food Science and Technology, Viale Fanin 48, 40127 Bologna, Italy \\ Corresponding author: garreau@toulouse.inra.fr
}

\begin{abstract}
COST Action TD1101 "Rabbit Genome Biology-Net" is an action granted by COST in the domain of Biomedicine and Molecular Biosciences. Chaired by the University of Bologna and INRA, it will last for 4 years from November 2011, and gather 94 experts from 20 European countries and from USA, China, Japan, Taiwan and South Africa. Rabbit Genome Biology-Net (RGB-Net) aims at building an open international network of research organizations, associations and companies in all rabbit research areas and in other complementary research fields (breeders, geneticists, bioinformaticians, physiologists, evolutionists, embryologists, immunologists, physicians, industry experts, etc.) in order to facilitate the transfer of rabbit genomic information from experimental data into usable benefits and applications. Four Working Groups are focused on i) the refinement of the European rabbit genome resources and the development of genome-based platforms, ii) genetic aspects in meat, fur and pet rabbits and biodiversity resources, iii) the rabbit as a model in basic biology and human diseases and as a tool for biotechnology applications, and iv) genetic and comparative genomic aspects for the study, exploitation and management of wild lagomorphs. The outcome is a coordination of rabbit research activities and a transfer of knowledge, that will produce a strong European added value across a broad spectrum of biology research fields.
\end{abstract}

Key words: European rabbit, lagomorphs, genome biology, translational research, networking expertise. 


\title{
DIVERGENT SELECTION FOR DIGESTIVE DISORDERS IN TWO COMMERCIAL RABBIT LINES: RESPONSE OF CROSSBRED YOUNG RABBITS TO AN EXPERIMENTAL INOCULATION OF Echerichia coli 0103.
}

\author{
Garreau H. ${ }^{1}$, Brard S. ${ }^{1}$, Hurtaud J. ${ }^{2}$, Guitton E. ${ }^{3}$, Cauquil L. ${ }^{4}$, Licois D. ${ }^{3}$, \\ Schwartz B. ${ }^{3}$, Combes S. ${ }^{4}$, Gidenne T. ${ }^{4}$ \\ ${ }^{1}$ INRA, UR 631 SAGA Chemin de Borde Rouge, BP 52627, 31326, Castanet Tolosan, France \\ ${ }^{2}$ Grimaud Frères, La Corbière, 49450 Roussay, France \\ ${ }^{3}$ INRA, Plateforme Expérimentale d'Infectiologie, \\ ${ }^{4}$ INRA, UMR 1289 TANDEM Chemin de Borde Rouge, BP 52627, 31326, Castanet Tolosan, France \\ * Corresponding author: garreau@toulouse.inra.fr
}

\begin{abstract}
A divergent selection for digestive disorders, $\mathrm{R}$ for resistance and $\mathrm{S}$ for sensitivity, based on routine observational data of signs of enteropathy, was carried out in AGP39 and AGP59 commercial lines of the Hypharm breeding company. Two successive batches (B1 and B2) of 178 crossbred animals, $89 \mathrm{R}$ and $89 \mathrm{~S}$, were produced by mating AGP39 well evaluated bucks with AGP59 well evaluated does and AGP39 bad evaluated bucks with AGP59 bad evaluated does, respectively. In each batch, 27 R animals (RC) and 27 animals (SC) were chosen to constitute the control group while $62 \mathrm{R}$ animals (RI) and $62 \mathrm{~S}$ animals (SI) were chosen for inoculation. Individual EBV of animals of the RI group and of the SI group was calculated as the mean of their sire and dam's EBV. In each batch, 31 animals with the lowest EBV in the RI group and 31 animals with the highest EBV in the SI group were sorted to constitute the group RRI and the group SSI, respectively.Young rabbits were carried from Hypharm to the INRA Experimental Platform for Infectious Disease (PFIE) just after weaning at 30 days of age. Inoculated rabbits received $10^{5}$ bacteria of the strain LY265, E. Coli O103:H2:K-, rhamnose negative (Licois et al., 1992), by oral administration, at 37 days of age. All animals were weighed and checked for clinical symptoms just before the inoculation, 2 days, 6 days, 9 days and 13 days after the inoculation. Average daily weight gain was calculated for each interval. Individual mortality was recorded daily. 13 days after inoculation, 9 rabbits of each sub-group were sacrificed to measure $\mathrm{pH}$ of the caecal digesta and for caecum and caecum appendix weighing. The impact of the E. coli challenge was significant for growth and for the caecum relative weight. Although mortality tended to be higher in sensitive animals than in resistant animals in batch $1(\mathrm{p}=0.12)$ there was no significant difference between RI and SI groups for cumulative mortality, daily weight gain and caecum measurements. Mortality was significantly lower $(\mathrm{p}=0.04)$ in RRI group than in SSI group at day 11 , day 12 and day $13(31.8 \%, 34,8 \%$ and $36.6 \%$ vs. $50 \%, 5.1 \%$ and $54.7 \%$ respectively). This difference corresponded to 11 animals for each of the 3 periods.
\end{abstract}

Key words: Rabbit, disease resistance, digestive disorders, divergent selection. 


\title{
IS SEXUAL RECEPTIVITY OF THE DOES A HERITABLE TRAIT? PRELIMINARY RESULTS IN DIVERGENT SELECTION SCHEME
}

\author{
Brun J.M. ${ }^{1}$, Monniaux D. ${ }^{2}$, Tircazes A. ${ }^{1}$, Balmisse E. ${ }^{3}$, Bodin L. ${ }^{1}$, Theau-Clément M. ${ }^{1}$ \\ (1) INRA, UR631 SAGA, F-31326 Castanet-Tolosan, France \\ ${ }^{(2)}$ INRA, UMR 6175 PRC, F-37380 Nouzilly, France \\ ${ }^{(3)}$ INRA, UE PECTOUL, F-31326 Castanet-Tolosan, France \\ *Corresponding author: jean-michel.brun@toulouse.inra.fr
}

\begin{abstract}
Sexual receptivity of the does at insemination greatly influences fertility and is generally induced by hormones or by technical devices called "bio-stimulations". In the research context of more sustainable farming systems, an original alternative would be to exploit the genetic pathway to increase the receptivity level of the does at insemination. The purpose of the present experiment was to estimate the heritability of rabbit does receptivity and to test a divergent selection scheme on sexual receptivity. The experiment spanned two generations, the founder generation (G0) made of 140 rabbit does and the G1 generation comprising two divergently selected lines with 70 does each. The selection rate of the G0 females to form the G1 lines was 24/140. The selection tests consisted in 18 successive receptivity tests at the rate of three per week. A total of 4695 tests from 273 females were analyzed. The average receptivity was $56.5 \%$. The heritability of Ri, the elementary performance (the $0 / 1$ result of a single test) was estimated at $0.01 \pm 0.02$ from an animal model and at 0.02 from the sire and dam variance components. The heritability of the average receptivity of a doe was $0.05 \pm 0.02$ with an animal model and 0.08 from the sire and dam variance components. In agreement with the low estimated heritability, the realized heritability was not different from zero. The occurrence of pseudo-pregnancy during the tests as a consequence of uncontrolled ovulations could have interfered with receptivity and the tests results. Our prospect is to model Ri by analyzing the sequences of tests results as chronological series. Moreover, trying to establish a typology of the sequences, taking pseudo-pregnancy into account, would improve the modelling and hence, the estimation of heritability.
\end{abstract}

Key words: Rabbit, selection experiment, sexual receptivity, heritability.

\section{GENOTYPE BY IN FARM TEMPERATURE INTERACTION ON DOE REPRODUCTIVE PERFORMANCE AND LENGTH OF PRODUCTIVE LIFE}

\section{Sánchez J.P., Piles M.}

Institut de Recerca i Tecnologia Agroalimentàries, Torre Marimon s/n, 08140, Caldes de Montbui, Spain

*Corresponding author: juanpablo.sanchez@irta.es 


\begin{abstract}
The aim of this study was to assess the magnitude of the interaction between in farm temperature and additive genetic effects for prolificacy, weaning weight and longevity. Data came from Caldes line, which has been selected for post-weaning growth since 1983. A total of $18,491,16,868$ and 6,743 records for total born (TB), number of weaned kits (NW) and average weaning weight (avg-WW), and longevity (Long) were considered. For TB, NW and avg-WW different Bayesian Hierarchical models were employed while Long was studied using a semiparametric Bayesian proportional hazard model. The estimated magnitude of the interaction between additive genetic effects and temperature descriptors was nearly null for TB and Long, while for NW and avg-WW it shown a relevant magnitude. For these two traits the most likely form for this interaction was that in which genetic variation exist for both the temperature onset in which the animals experiment a linear change in their performances and for the change itself. Checking the estimated values of the heritabilities for the two definitions of heat stress for NW and avg-WW it can be concluded that the variation on the onset of heat stress is that showing the stronger genetic determination, but between each other a positive and high genetic correlation exist (around 0.74); however it must be noted that the genetic correlation between both definitions of heat stress and the performance of the trait is negative, around -0.7. Thus, although there is room for selective breeding to increase tolerance to heat stress on avg-WW, restrictions should be imposed to avoid average performances of the traits being reduced.
\end{abstract}

Key words: Genetic parameters, heat stress, prolificacy, weaning weight, longevity.

\title{
CROSSBREEDING EFFECTS ON LITTER SIZE COMPONENTS IN RABBITS
}

\author{
Ragab M. ${ }^{1,3^{*}}$, Sánchez J. P. ${ }^{2}$, EL Nagar A. G. ${ }^{1,4}$, Mínguez C. ${ }^{1}$, Desantes J ${ }^{1}$, Baselga M. ${ }^{1}$ \\ ${ }^{1}$ Dept. of Animal Science, Polytechnic Uni. of Valencia, Camino de Vera S/N, 46022, Valencia, Spain. \\ ${ }^{2}$ Institut de Recerca i Tecnologia Agroalimentàries. Av. Alcalde Rovira i Roure 191, 25198, Lleida, Spain. \\ ${ }^{3}$ Poultry Production Department, Fac. of Agriculture, Kafr El-Sheikh University, Egypt. \\ ${ }^{4}$ Department of Animal Production, Faculty of Agriculture at Moshtohor, Benha University, Egypt. \\ *Corresponding author: moramo@upvnet.upv.es
}

\begin{abstract}
A crossbreeding experiment between four maternal lines of rabbits was carried out to estimate the crossbreeding effects on litter size components. The experiment was designed as a complete diallel crossing involving A, V, H and LP lines, all of these lines have been selected for litter size at weaning. A total of 2025 does, from the sixteen genetic types were subjected to laparoscopy. The sixteen genetic groups were distributed in four Spanish farms but only one group was presented in all farms to connect the data (line V). The recorded traits were ovulation rate (OR), number of implanted embryos (IE), total born (TB), number born alive (NBA), embryo survival (ES), fetal survival (FS) and prenatal survival (PS). An animal model was used to estimate components of variance using a REML procedure. Contrasts to show the
\end{abstract}


differences between direct genetic effects of lines, differences between maternal genetic effects of lines and individual heterosis were estimated according to Dickerson model after solving the appropriate animal model conditioned on the REML variance components. In general, relevant but no always significant differences between lines in direct genetic effects were found. Line LP presented higher direct genetic effects than the other lines, significantly different from line A. All contrasts of maternal effects were not significant except between the LP and V lines. High positive values of heterosis contrasts were found between lines A and H. The cross between lines LP and $\mathrm{V}$ had negative heterosis for all traits with considerable negative effects on TB and NBA (16\% and $11 \%$ of the mean, respectively).

Key words: Rabbits, Maternal lines, Crossbreeding components, Ovulation rate, Litter size, Laparoscopy.

\title{
PHYLOGENETIC RELATIONSHIP AMONG FOUR EGYPTIAN AND ONE SPANISH RABBIT POPULATIONS BASED ON MICROSATELLITE MARKERS
}

\author{
Grimal A. ${ }^{1}$, Safaa H.M. ${ }^{2}$, Saenz-de-Juano M.D. ${ }^{1}$, Viudes-de-Castro M.P. ${ }^{3}$, \\ Mehaisen G.M.K. ${ }^{2}$, Elsayed D.A.A. ${ }^{2}$, Lavara R. ${ }^{1}$, Marco-Jiménez F. ${ }^{1}$, Vicente J.S. ${ }^{1,}$ \\ ${ }^{1}$ Instituto de Ciencia y Tecnología Animal, Universidad Politécnica de Valencia, Spain \\ ${ }^{2}$ Animal Production Department, Faculty of Agriculture, Cairo University, Egypt \\ ${ }^{3}$ Centro de Investigación y Tecnología Animal, IVIA, Spain \\ *Corresponding author: jvicent@dca.upv.es
}

\begin{abstract}
Seventeen microsatellite loci were used to identify the phylogenetic relationship among four Egyptian breeds and one Spanish line of rabbits. A total of 114 bucks rabbits belonging to four Egyptian breeds -Black Baladi (EBB), Gabali (EG), Red Baladi (ERB) and White Giza (EWG)- and Spanish White New Zealand line from Universidad Politécnica de Valencia (NZW) were studied. All microsatellite loci typed were polymorphic. The average number of alleles per locus was 5.41, ranging from 2 to 12 . A total of 16 private alleles were found in 7 out of 17 microsatellite loci used. Mean observed heterozygosity was 0.527 , ranging from 0.477 in the NZW breed to 0.581 in the EWG. Lower values for Ho were found for all populations. The inbreeding coefficient of individuals relative to the total population $\left(\mathrm{F}_{\mathrm{IT}}\right)$ was 0.279 . The overall within-population heterozygote deficit $\left(\mathrm{F}_{\mathrm{IS}}\right)$ was 0.165 , ranging from 0.045 in NZW breed to 0.266 in EBB breed. The overall variation between population $\left(\mathrm{F}_{\mathrm{ST}}\right)$ was 0.137 , where the NZW breed showed the most differentiated population $\left(\mathrm{F}_{\mathrm{ST}}=0.194\right)$. The Neighbour-Joining tree of the Reynolds genetic distances $\left(D_{R}\right)$ among populations shows a clear separation of the Spanish population (NZW) from the Egyptians breeds and there is a population mixture in the Egyptian populations. Only the ERB may to cluster in one independent population.
\end{abstract}

Key words: Rabbit populations, microsatellite markers, heterozygosity, heterozygote deficit, genetic distances. 


\title{
ESTIMATION OF GENETIC PARAMETERS AND TRENDS FOR BIRTH WEIGHT CRITERIA IN HYCOLE D LINE
}

\author{
Lenoir G.1, Garreau H.2, Banville M. \\ ${ }^{1}$ SARL HYCOLE, Route de Villers-Plouich, 59159 Marcoing, France. \\ ${ }^{2}$ INRA, SAGA Chemin de Borde Rouge, BP 52627, 31326 Castanet Tolosan, France. \\ *Corresponding author: hycole.guillaume@nordnet.fr
}

\begin{abstract}
This study aims to estimate the genetic variability of different rabbit weight criteria at birth in the Hycole D line. There were 2108 litters measured in the data set, realized from December 2009 to September 2010. Heritabilities estimated for birth weight mean, total litter birth weight, minimal birth weight, maximal birth weight, range between maximal and minimal birth weight and total born alive rabbits were 0.15 , $0.13,0.07,0.12,0.11$ and 0.10 , respectively. Genetic correlations of the minimal birth weight with the other birth weights and within-litter variation of birth weight were favourable. The genetic variability of minimal birth weight and favourable genetic correlations with other criteria allow an efficient selection of this criterion in a breeding scheme. This criterion was added to the breeding objective in September 2010. A second data set consists of 7219 measurements recorded from December 2009 to January 2012 was used to estimate the genetic progress achieved. The gain on the criterion weight of the lightest rabbit is $+0.9 \mathrm{~g}$ for animals born in 2011 compared to those born in 2010.
\end{abstract}

Key words: Rabbits, genetic parameters, genetic trends, birth weight; litter traits.

\section{SELECTION FOR WEANING WEIGHT IN HYLA BREED: GENETIC PARAMETERS AND TRENDS}

\author{
Loussouarn V.1, Robert R.1, Garreau H.2 \\ ${ }^{1}$ EUROLAP, Le Germillan BP 21, 35140, GOSNE \\ ${ }^{2}$ INRA, UR 631 SAGA Chemin de Borde Rouge, 31326, CASTANET TOLOSAN \\ Corresponding author: prodeurolap@orange.fr
}

\begin{abstract}
Maternal ability is a key factor in rabbit farming. Improvement of maternal ability for the young rabbit growth is one of the selection aims of the Hyla D line. This trait is evaluated by the individual weight at weaning (35 days). Direct and maternal genetic values are estimated using the BLUP methodology applied to an animal model. Since the second quarter of 2007, the genetic gain was estimated at 115 grams for direct effects and 53 grams for maternal effects. Estimates of heritability are 0,20 and 0,06 for direct effects and maternal effects, respectively. Selection for weaning weight was
\end{abstract}


efficient. Weights of the two genetic values in the breeding objectives are discussed in order to favor improvement of maternal effects on weaning weight.

Key words: Rabbits, Maternal abilities, Breeding values, BLUP, heritability, weaning weight.

\title{
GENETIC PARAMETERS AND TRENDS FOR LITTER AND GROWTH TRAITS IN A SYNTHETIC LINE OF RABBITS CREATED IN ALGERIA
}

\author{
Bolet $\mathbf{G}^{\mathbf{*}}$. Zerrouki $\mathbf{N}^{1}$., Gacem $\mathbf{M}^{\mathbf{1}}$., Brun J.M ${ }^{\mathbf{1}}$., Lebas $\mathbf{F}^{\mathbf{1}}$. \\ ${ }^{1}$ INRA, UR631, Station d'Amélioration Génétique des Animaux, BP52627,31326 Castanet Tolosan Cedex \\ France \\ ${ }^{2}$ Faculty of Biological and Agronomic Science. University Mouloud Mammeri, Tizi-Ouzou, Algeria. \\ ${ }^{4}$ Cuniculture, 87A Chemin de Lasserre, 31450 Corronsac, France \\ *Corresponding author: Gerard.bolet@ toulouse.inra.fr
}

\begin{abstract}
A synthetic strain (called ITELV2006) has been created to improve the genetic stock for rabbit meat production in Algeria, obtained by a crossing between the local population and the INRA2666 strain. This paper gives estimations of heritabilities and genetic progress for some reproductive and productive traits, after 4 generations of homogenization (F1 to F4) followed by 4 generations of selection for litter size at birth and 75 days weight (G0 to G3). Heritabilities of litter size are in a range of 0.08 to 0.11 ; doe environment components are similar to heritabilities. For young individual weight at weaning, at 75 days and growth rate, heritabilities are low (0.12 to 0.16$)$ and common litter component are high (0.45 to 0.62$)$. The very high values of common litter effect can be explained by strong environmental effects. A high heritability of 0.43 was observed for doe weight at parturition. There was a genetic progress on all traits (except mean kit weight at birth), ranging from 0.3 to 0.6 units of standard error of genetic value. As a genetic progress has been obtained on selected and correlated traits, the superiority of this strain on local populations, observed in F4, is confirmed and amplified. The selection nucleus keeps on breeding in the ITELV experimental farm at Baba Ali. In January 2012, animals have been sent in some farms to confirm the value of this strain in different environmental conditions before distributing it to other farms to improve reproductive and productive performances of rabbits used in Algeria for meat production.
\end{abstract}

Key words : Algeria, rabbit, synthetic strain, selection, genetic parameters. 


\title{
PRE-WEANING GROWTH OF KITS BASED ON MOTHER'S COAT COLOR AND KINDLING SEASON IN ALGERIAN RABBITS POPULATION
}

\author{
Abdelli-Larbi O. ${ }^{1}$, Berchiche M. ${ }^{2}$, Bolet G. ${ }^{3}$, Lebas F. $^{4}$ \\ ${ }^{1}$ Laboratoire de Biochimie Analytique et de Biotechnologie, Université Mouloud Mammeri, Tizi-Ouzou,, \\ Algeria \\ ${ }^{2}$ Département des Sciences Agronomiques, Université Mouloud Mammeri, Tizi-Ouzou, Algérie. \\ ${ }^{3}$ INRA Station d'Amélioration Génétique des Animaux, BP 27, 31326 Castanet Tolosan Cedex, France \\ ${ }^{4}$ Cuniculture, $87 \mathrm{~A}$ Chemin de Lasserre, 31450 Corronsac, France \\ *Corresponding author: abdelli_ouiza200@yahoo.fr
}

\begin{abstract}
In order to study the growth of suckling kits of a local Algerian rabbit population, weights of 590 litters (3965 kits) were measured at birth, 7, 14, 21 and 28 days. Rabbits were reared in wire mesh cages placed in a building with natural lighting and absence of temperature regulation. This population is characterized by an average individual birth weight of $54 \mathrm{~g}$ and the weight at 30 days is $404 \mathrm{~g}$. Kits grew with a regular average growth rate of $10.24 \mathrm{~g} / \mathrm{d}$ between birth and 24 days and of $19.02 \mathrm{~g} / \mathrm{d}$ between 24 and 30 days. The influence of mother's phenotype (albino or colored coat) and of the kindling season (3 seasons in a year : Feb-May, June-Sept and Oct-Jan), on the evolution of litter size and weight of the suckling rabbits was established. The colored females were more prolific than the albino ones : 5.76 vs 5.33 weaned/litter $(\mathrm{P}=0.013)$. The young rabbits born from albino females tended to have the larger individual weight at weaning: 379 vs $357 \mathrm{~g}(\mathrm{P}<0.064)$. The birth season influenced mainly $(\mathrm{P}<0.001)$ litter size from birth until weaning in favor of the spring season : 5.94 weaned/litter vs 5.42 during the hot season (Jun-Sept) and 4.85 after summer. At birth, the litter weight was larger for the Feb-May season $(\mathrm{P}=0.013)$ and the advantage becomes highly significant $(\mathrm{P}<0.001)$ till weaning. The weakest litter weight was observed during Oct-Jan season. Season has no significant effect on kits individual weight at weaning.
\end{abstract}

Key words: Young rabbit, weight, coat color, season, local Algerian population.

\section{CANONICAL CORRELATION ANALYSIS OF BODY MEASUREMENTS AND CARCASS TRAITS OF CROSS BRED RABBIT POPULATION}

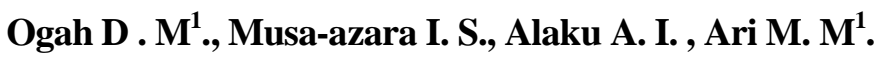 \\ Animal Science Department, Nasarawa State University Keffi,Shabu-Lafia Campus, Nigeria. \\ College of Agriculture pmb 33 Lafia Nasarawa State,Nigeria. \\ Corresponding author: mosesdogah@yahoo.com
}




\begin{abstract}
In this study, canonical correlation analysis was applied to estimate the relationship between body measurements and carcass traits of 28 male cross bred rabbits of about 12 weeks of age, reared under semi intensive system. Four body measurements, preslaughter weight (PSW), body length (BL), chest circumference (CC), and ear length (EL) as predictor variable while dressing percentage (DP), hot carcass weight (HCW) and cold carcass weight $(\mathrm{CCW})$ as criterion variables. Preslaughter weight and body length had significant $(\mathrm{P}<0.001)$ simple correlation coefficients with the carcass traits except for dressing percentage. The three canonical variate pairs ranged between .99 to .42 and only the first pair was significant $(\mathrm{P}<0.001)$. From the analysis preslaughter weight and body length can be regarded as the main factors as live measurement traits, while dressing percentage did not have pronounced effect on the emerged criterion variables.
\end{abstract}

Key words : Mixed bred rabbit, carcass, body measurements, canonical correlation.

\title{
DEVELOPMENT REGULARITY OF WOOL FIBER AND EXPRESSION CHARACTERISTICS OF KERATIN ASSOCIATED PROTEINS GENE IN THREE RABBIT BREEDS
}

\author{
Li Ting ${ }^{1}$, Wu Tian-Wen ${ }^{1}$, Wan Xiao-Ying ${ }^{1}$, Sun Lu-Lu ${ }^{1}$, Shi Fu-Yue ${ }^{1}$, Pan Yu- \\ Lai $^{2}$, Wu Xin-Sheng ${ }^{1}$ * \\ ${ }^{1}$ Animal Science and Technology College, Yangzhou University, 225009, Yangzhou, China \\ ${ }^{2}$ Jinling Rabbit Farm of Jiangsu Province, 211103, Nanjing, China \\ "Corresponding author: xswu@yzu.edu.cn
}

\begin{abstract}
This study measured the length of wool fiber of three rabbit breeds (including Fujian Yellow rabbit, German Angora rabbit and American Rex) in different growth periods respectively. We got four data sets of different positions, which were neck, back, buttock and abdomin. Real-time fluorescence quantitative PCR method was used to analyse the expression characteristic of KAP 3.1 gene in back and buttock at the same time. The result of wool staple length indicated that the growth speed of wool fiber in Fujian Yellow rabbit and American Rex rabbit was higher than German Angora rabbit before two weeks old, but the wool length of American Rex rabbit was longer than the other two breeds after four weeks old. Results of RT-PCR showed that the expression of KAP3.1 gene had a high level in all breeds when it was new-born, and expression in Fujian Yellow rabbit and American Rex rabbit was higher than Angora rabbit. The expressions increased slowly in general, and the characteristics were similar between different sexes and positions. The expression of KAP3.1 gene in Fujian Yellow rabbit and American Rex rabbit reduced when it was four weeks and 12 weeks old, moreover, the reduction of back in American Rex rabbit was higher than Fujian Yellow rabbit. We might predict that the development of wool fiber length was associated with KAP3.1 gene.
\end{abstract}

Key words: Rabbit; skin; wool fiber; KAP gene; RT-PCR; expression characteristics. 


\title{
GENETIC DETERMINISM OF FEED EFFICIENCY IN RABBIT. ANALYSIS OF A SELECTION EXPERIMENT FOR TWO CRITERIA OF FEED EFFICIENCY
}

\author{
Drouilhet L. ${ }^{1 *}$, H. Garreau ${ }^{1}$, F. Tudela ${ }^{2}$, J. Ruesche ${ }^{1}$, F. Benitez ${ }^{2}$, C. Baillot ${ }^{2}$, T. \\ Gidenne $^{3}$, C. Larzul ${ }^{4}$ \\ 1INRA, UR 631 SAGA Chemin de Borde Rouge, 31326, CASTANET TOLOSAN \\ 2INRA, UE 1322 Pectoul PEA Cunicole Toulousain, 31326, CASTANET TOLOSAN \\ 3INRA, UMR 1289 TANDEM Chemin de Borde Rouge, 31326, CASTANET TOLOSAN \\ 4INRA, UMR 1313 GABI, Domaine de Vilvert, 78352, JOUY-EN-JOSAS \\ *Corresponding author: laurence.drouilhet@toulouse.inra.fr
}

\begin{abstract}
Genetic parameters of feed efficiency and growth traits were estimated in two selected rabbit lines after 6 generations of selection. The ConsR line was selected for residual feed intake (RFI) under ad libitum feeding. The AlimR line was selected for average daily gain (ADG from 30 to 63 days) under restricted feeding corresponding to $80 \%$ of ad libitum feed intake of control animals. Estimates of heritability of ADG and FCR (feed conversion ratio) were higher in the AlimR line than in the ConsR line, while estimates of heritability of weight at 30 and 63 days-old were similar between lines. Heritability of ADG $(0.25)$, the selection criterion of the AlimR line, was higher than RFI (0.15), the selection criterion of the ConsR line. Estimates of heritability and genetic correlations between weaning weight, weight at 63 days, ADG and FCR are also presented for each line.
\end{abstract}

Key words : Rabbit, genetic selection, feed efficiency, feed conversion ratio, growth rate.

\section{MORPHOLOGICAL AND QUALITATIVE CHARACTERISTICS OF A COMPOSITE RABBIT POPULATION IN BACKYARD SYSTEMS IN SOUTHWESTERN NIGERIA}

\author{
Oseni* S.O., Oke O.O. \\ Department of Animal Sciences, Obafemi Awolowo University, Ile-Ife, Nigeria \\ "Corresponding author: soseni@oauife.edu.ng
}

\begin{abstract}
Limited reports exist on the phenotypic and genetic characterization of heterogeneous rabbit populations raised in traditional backyard systems prevalent in Nigeria and other countries in sub-Saharan Africa. Such information will facilitate the design of sustainable breeding programmes that would have direct benefits to limited-resource farmers as well as promote conservation through utilization. It would also enhance the inclusion of these stocks into animal genetic resources data bases, as well as the full understanding of this population of rabbits that is raised principally under backyard systems. The objectives of
\end{abstract}


this study were to conduct an on farm characterisation of composite rabbit population based on morphological and qualitative traits and to evaluate the extent of phenotypic variability in a heterogeneous rabbit population. The study was conducted in farms across four locations (Ile-Ife, Oshogbo, Ogbomoso and Ibadan) in south-western Nigeria. Variables recorded included qualitative and morphological traits and include the following: ear dimension and orientation, coat texture, colour and fur density, face and nose profiles, temperament, body type, eye colour, teat number (breeding does) and pad size. Morphological measurements included body length, chest and thigh circumference. Results showed three-quarters of the animals had long and broad ear dimensions, while ear orientation was predominantly erect $(98.5 \%)$. Coat colour patterns were non-uniform $(56.2 \%)$ and uniform (43.8\%). The distribution of animals for temperament showed that docile, moderately docile and wild were $44.8 \%, 52.5 \%$ and $2.7 \%$ respectively. Eye colour classes were $60.5 \%, 14 \%, 15 \%$ and $0.5 \%$ for black, red, blue and yellow eyes respectively. For breeding does, functional teat number were $94.9 \%, 3.7 \%$ and $1.4 \%$ for 8,10 and 6 teats respectively. Analysis of morphological traits of heterogeneous rabbits across locations in south-western showed that there were no marked differences in chest circumference, body length and thigh circumference $(\mathrm{P}>0.05)$. In summary, heterogeneous rabbits display diversity in qualitative traits that could be further investigated for inclusion in a structured breeding programme under a clientele-based system, with resource-limited farmers and householders as beneficiaries.

Key words: Rabbit, Nigerian populations, phenotypic characterization, morphological traits, backyard systems, sustainable breeding programmes.

\title{
MORPHOLOGICAL CHARACTERISATION AND PRINCIPAL COMPONENT ANALYSIS OF BODY DIMENSIONS IN NIGERIAN POPULATION OF ADULT RABBITS
}

\author{
Ajayi B. A. , Oseni" S.O. \\ Department of Animal Sciences, Faculty of Agriculture. Obafemi Awolowo University, Ile-Ife. Nigeria \\ "Corresponding author: soseni@ oauife.edu.ng
}

\begin{abstract}
Body weight and linear body measurements were taken on 139 adult rabbits belonging to a composite population in south-western Nigeria. The objectives of this study were to define the body dimensions of adult heterogeneous rabbits and investigate the morphological variables that contribute to body conformation by the use of principal component analysis. Variables measured included body length, heart girth, ear length, ear width, tail length, face length, fore-arm length and shoulder length, thigh length and thigh circumference. Data were subjected to multivariate analysis using PAST ${ }^{\circledR}$. Mean body weight of all animals was $1880 \mathrm{~g}$ with a range of 1500 to $2800 \mathrm{~g}$ indicating wide variability. In all, four principal components accounted for $86.85 \%$ of total variation in morphological traits for this rabbit population. Variables that make up the first principal component (PC1) which accounted
\end{abstract}


for $55 \%$ of the total variance are heart girth, hind-leg length and thigh length. The second PC (PC2) accounted for $13.74 \%$ of total variance included hearth girth, fore-arm length and hind-leg length, while PC3 included body length, fore-arm length and the thigh length and accounted for $10.70 \%$. Finally, this rabbit population showed no sexual dimorphism between the two sexes.

Key words: Rabbits, Nigerian population, Morphological body conformation \& Principal component analysis.

\title{
GENETIC GROUPS COMPARISONS FOR LITTER AND LACTATIONAL TRAITS AND FEEDING PARAMETERS IN PROGRAM OF SYTHESIZING NEW LINES OF RABBITS
}

\author{
Khalil, M.H. ${ }^{1}$, Al-Saef, A M. ${ }^{2}$ \\ ${ }^{1}$ Faculty of Agriculture, Benha University, Moshtohor, 13736, Qalubia, Egypt \\ ${ }^{2}$ College of Agriculture \& Veterinary Medicine, Qassim University, Buriedah 51452 P.O.Box 6622, Saudi \\ Arabia. \\ ${ }^{1}$ Corresponding author: maherhkhalil@yahoo.com
}

\begin{abstract}
Five-years crossing scheme involving the Spanish V-line (V) and Saudi Gabali (S) rabbits was practiced to produce 14 genetic groups: $\mathrm{V}, \mathrm{S}, 1 / 2 \mathrm{~V}^{1 / 2} \mathrm{~S}, 1 / 2 \mathrm{~S}^{1} / 2 \mathrm{~V}, 3 / 4 \mathrm{~V}^{1} / 4 \mathrm{~S}, 3 / 4 \mathrm{~S}^{1 / 4} \mathrm{~V}$, $\left(1 / 2 \mathrm{~V}^{1 / 2} \mathrm{~S}\right)^{2},\left(1 / 2 \mathrm{~S} \mathrm{~S}^{1} / 2 \mathrm{~V}\right)^{2},\left(3 / 4 \mathrm{~V}^{1} / 4 \mathrm{~S}\right)^{2},\left(3 / 4 \mathrm{~S}^{1} / 4 \mathrm{~V}\right)^{2},\left(\left(3 / 4 \mathrm{~V}^{1} / 4 \mathrm{~S}\right)^{2}\right)^{2},\left(\left(3 / 4 \mathrm{~S}^{1 / 4} \mathrm{~V}\right)^{2}\right)^{2}$, Saudi 2 and Saudi 3. A total of 3496 litters of 1022 does mothered by 419 dams and fathered by 151 sires were used to evaluate litter size at birth (LSB) and weaning (LSW), litter weight at birth (LWB) and weaning (LWW), litter survival (PLS), milk yield at lactation intervals of 0-7 days (MY07), 0-21 days (MY021), 0-28 days (total, TMY), milk conversion ratio (MCR), milk components (fat, protein, lactose, ash and total solids), total (TFC) and daily (DFC) feed consumption per doe per litter, feed to litter gain conversion ratios (FCRLG), and feed to milk conversion ratios (FCRM) in different doe genetic groups obtained. The solutions of the mixed model equations for the genetic group effects were used to identify the possibilities of using Saudi 2 and $\mathrm{S} 3$ as synthetic lines in hot climate areas.

S2 line was significantly superior to S by 1.12 kit, 1.45 kit, $54 \mathrm{~g}, 558 \mathrm{~g}, 72 \%, 111 \mathrm{~g}, 170 \mathrm{~g}$, $180 \mathrm{~g}$, and $753 \mathrm{~g}$ in LSB, LSW, LWB, LWW, PLS, MY7, MY21, MY28, and TMY, respectively $(\mathrm{P}<0.05$ or $\mathrm{p}<0.01)$. For $\mathrm{S} 3$ line, the corresponding superiorities were 0.99 kit, 1.54 kit, 40 g, 578 g, 9.1\%, 118 g, 195 g, 208 g, and 929 g, respectively $(\mathrm{P}<0.05$ or $\mathrm{p}<0.01)$. For S2 and S3 vs V line, the contrasts for litter traits were mostly non-significant. The highest contrasts in fat, lactose and protein and total solids were in favour of $S 2$ relative to $S$ line by $1.7,0.8,0.35$ and $3.0 \%$ and by $2.0,0.9,0.36$ and $3.5 \%$ for $\mathrm{S} 3$ line $(\mathrm{P}<0.05$ or $\mathrm{p}<0.01)$. The best genetic group in conversion ratio of milk to litter-gain was $0.20 \mathrm{~kg} / \mathrm{kg}$ for $\mathrm{S} 2$ doe group and $0.18 \mathrm{~kg} / \mathrm{kg}$ for $\mathrm{S} 3$ doe group relative to $\mathrm{S}$ and $\mathrm{V}$ lines. Rates of feed consumption per litter in synthetic S2 and S3 does compared to S and V does were moderately favourable by 0.555 and $0.883 \mathrm{~kg}$ in TFC and 20 and $32 \mathrm{~g}$ in DFC, respectively. Feed conversion ratios increased slightly by 0.32 in does of S2 and 0.16 in
\end{abstract}


does of S3. Does of S2 and S3 recorded relatively higher feed consumption but with favourable conversion ratios of feed to litter gain compared to $\mathrm{S}$ and $\mathrm{V}$ doe groups.

Key words: Crossbreeding, synthetic lines, litter traits, lactation, feeding parameters.

\title{
GENETIC GROUPS COMPARISONS FOR GROWTH, CARCASS, MEAT QUALITY AND BLOOD PARAMETERS IN PROGRAM OF SYTHESIZING NEW LINES OF RABBITS
}

\author{
Khalil, M.H. ${ }^{1}$, El-Zarie, M.F. ${ }^{2}$ \\ ${ }^{1}$ Faculty of Agriculture, Benha University, Moshtohor, 13736, Qalubia, Egypt \\ ${ }^{2}$ College of Agriculture \& Veterinary Medicine, Qassim University, Buriedah 51452 P.O.Box6622, Saudi Arabia. \\ ${ }^{1}$ Corresponding author: maherhkhalil@yahoo.com
}

\begin{abstract}
An evaluation for five-year crossbreeding project was performed for growth, carcass performance, meat quality and blood parameters. This crossing project involving a Spanish maternal line called V-line (V) and a Saudi Gabali (S) rabbits and 14 genetic groups of V, $\mathrm{S}, \quad 1 / 2 \mathrm{~V}^{1 / 2 \mathrm{~S}}, \quad 1 / 2 \mathrm{~S} 1 / 2 \mathrm{~V}, \quad 3 / 4 \mathrm{~V}^{1} / 4 \mathrm{~S}, \quad 3 / 4 \mathrm{~S}^{1 / 4 \mathrm{~V}}, \quad\left(1 / 2 \mathrm{~V}^{1 / 2} \mathrm{~S}\right)^{2}, \quad\left(1 / 2 \mathrm{~S}^{1} / 2 \mathrm{~V}\right)^{2}, \quad\left(3 / 4 \mathrm{~V}^{1 / 4} \mathrm{~S}\right)^{2}, \quad\left(3 / 4 \mathrm{~S}^{1 / 4} \mathrm{~V}\right)^{2}$, $\left(\left(3 / 4 \mathrm{~V}^{1} / 4 \mathrm{~S}\right)^{2}\right)^{2},\left(\left(3 / 4 \mathrm{~S}^{1} / 4 \mathrm{~V}\right)^{2}\right)^{2}$, Saudi 2 (S2), and Saudi $3(\mathrm{~S} 3)$ were produced. A total number of 10178 rabbits fathered by 106 sires and mothered by 621 dams were weaned and 2770 rabbits fathered by 91 sires and mothered by 402 dams were slaughtered. The solutions of the mixed model equations for the genetic group effects were used to evaluate genetic groups of this project in terms of body weights, preslaughter weight (PSW), hot carcass weight $(\mathrm{HCW})$,dressing percentages (DP), offal weight (OW), weights of meat, fat and bone in the carcass, dry matter (DM), crude protein (CP), ether extract (EE) and ash in the lean. Blood parameters including total proteins (TP), albumin (ALB), globulin (GLOB), albumin: globulin ratio (AGR), total lipids (TL), cholesterol concentration (CH), and cholesterol index (CI) were also evaluated. S2 was significantly superior in body weights by $36,165,193,222$ and $157 \mathrm{~g}$ at 4, 6, 8, 10 and 12 weeks of age relative to $S$ rabbits, while the corresponding superiorities were 31, 148, 188, 230 and $129 \mathrm{~g}$ for S3 line. S2 and S3 were significantly superior in the majority of carcass and meat quality traits relative to line $\mathrm{V}$ or $\mathrm{S}$. Tissues composition in the carcass were mostly in favour of $\mathrm{S} 2$ and $\mathrm{S} 3$ by 92.9 , 12.0 and $13.8 \mathrm{~g}$ for weights of meat, bone and fat, respectively, while the respective superiorities were 110, 10.5 and $14.9 \mathrm{~g}$ for S3 line relative to the founder breeds. Carcasses were significantly in favour of S2 and S3 relative to V line rabbits for some traits (PSW, $\mathrm{HCW}$ and $\mathrm{OW}$ ). DM, CP, EE and ash contents in the lean were mostly in favour of the synthetic lines relative to the founder breeds where the estimates for S2 relative to $\mathrm{S}$ were greatly deviated by values of 5.0, 6.6, -3.3 and $2.6 \%$ in DM, CP, EE and ash and by 5.1, $6.1,-3.9$ and $2.1 \%$ in $\mathrm{S} 3$ rabbits, respectively $(\mathrm{P}<0.05$ or $\mathrm{P}<0.01)$. Blood concentrations in terms of TP, ALB, GLOB and AGR in S2 and S3 were lower than those in the founder S and $\mathrm{V}$, while $\mathrm{CH}$ and $\mathrm{TL}$ were decreased and $\mathrm{CI}$ was improved in blood of the synthetic lines. Rabbits of $\mathrm{S} 2$ showed heavier body weights than $\mathrm{S} 3$ rabbits by 27, 68, 54, 53 and 57 $\mathrm{g}$ at $4,6,8,10$ and 12 weeks of age, while carcass, meat quality and blood parameters were nearly similar in both lines.
\end{abstract}

Key words: Rabbits, synthetic lines, growth, carcass, meat quality, blood parameters. 


\title{
EFFECT OF DIETARY ASCORBIC ACID AND BETAINE SUPPLEMENTATION ON SEMEN CHARACTERISTICS OF RABBIT BUCKS UNDER HIGH AMBIENT TEMPERATURE
}

\author{
Hassan R.A. , Morsy W.A., Abd El-Lateif A. I. \\ Animal Production Research Institute, Agricultural Research Center, Ministry of Agriculture, Dokki, \\ Cairo, Egypt. \\ *Corresponding author: redaalihasan@yahoo.com
}

\begin{abstract}
The objective of this study was to evaluate the effects of dietary ascorbic acid and betaine supplementation on semen characteristics and some blood constituents of APRI line rabbit bucks under high ambient temperature. A total of 24 APRI line rabbit bucks were randomly divided into four experimental treatments ( 6 each). Animals were fed ad libitum the basal diet supplemented without (control), with $250 \mathrm{mg}$ ascorbic acid $/ \mathrm{kg}$ diet or betaine at 0.5 and $1 \mathrm{~g} / \mathrm{kg}$ diet. Animals were provided with water freely. The average daily temperature and relative humidity inside the rabbitry were $32.5 \pm 4.5{ }^{\circ} \mathrm{C}$ and $75.5 \pm 3.5 \%$, respectively. Under heat stress conditions, dietary ascorbic acid and betaine supplementation caused an increase $(\mathrm{P}<0.05)$ in ejaculation volume, where $1 \mathrm{~g}$ of betaine was more effective $(\mathrm{P}<0.05)$ than $0.5 \mathrm{~g}$ of betaine. Sperm concentration ranged from $180.7 \times 10^{6} \mathrm{cell} / \mathrm{ml}$ to $214.8 \times 10^{6} \mathrm{cell} / \mathrm{ml}$. Supplementing ascorbic acid and different levels of betaine in diets increased $(\mathrm{P}<0.001)$ sperm concentration, without differences $(\mathrm{P}>0.05)$ between ascorbic acid and $0.5 \mathrm{~g}$ betaine. Sperm motility was improved $(\mathrm{P}<0.01)$ with supplementing ascorbic acid and both doses of betaine in diets. The highest motility rate was recorded with rabbit bucks fed $1 \mathrm{~g}$ betaine $/ \mathrm{kg}$ diet as $49.67 \%$ and the lowest motility was detected in those fed control diet as $37.83 \%$. Ascorbic acid and different levels of betaine decreased $(\mathrm{P}<0.001)$ dead sperm, without differences between ascorbic acid and both doses of betaine. Fertility rate was increased with supplementing dietary ascorbic acid or betaine without any significance except for $1 \mathrm{~g}$ betaine, which recorded the highest value. With respect to the blood serum constituents in rabbit bucks serum total protein, albumin, globulin and total lipids significantly increased when ascorbic acid or betaine were supplemented. Betaine and ascorbic acid supplementation significantly decreased serum glucose concentration. Liver functions as judged by liver enzymes (e.g., GOT and GPT) were significantly decreased by dietary ascorbic acid or betaine supplementation. In this study, $1 \mathrm{~g}$ betaine supplementation in rabbit bucks diet significantly improves semen quality and modify some blood constituents under high ambient temperature during summer in Egypt. If the results are confirmed on a larger scale, it could be therefore concluded that $1 \mathrm{~g}$ betaine supplementation in the diet, could be advisable in hot climates.
\end{abstract}

Key words: Rabbit, Ascorbic acid, Betaine, Heat stress, Semen characteristics. 


\title{
EFFECT OF DIETARY ASCORBIC ACID AND BETAINE SUPPLEMENTATION ON PRODUCTIVITY OF RABBIT DOES UNDER HIGH AMBIENT TEMPERATURE
}

\author{
Morsy W.A., Hassan R.A., Abd El-Lateif A.I. \\ Animal Production Research Institute, Agricultural Research Center, Ministry of Agriculture, Dokki, Cairo, \\ Egypt. \\ *Corresponding author: wawad74@yahoo.com
}

\begin{abstract}
The objective of this study was to evaluate the effects of dietary ascorbic acid and betaine supplementation on productivity and milk production of APRI line rabbit does under high ambient temperature. A total of 24 APRI line rabbit does, 8-9 months old, were divided into four experimental treatments (6 each). Rabbit does were fed ad libitum the basal diet supplemented without (control), with $250 \mathrm{mg}$ ascorbic acid/kg diet or betaine at 0.5 and $1 \mathrm{~g} / \mathrm{kg}$ diet. Animals were provided with water freely. The average daily temperature and relative humidity inside the rabbitry were $32.5 \pm 4.5{ }^{\circ} \mathrm{C}$ and $75.5 \pm 3.5 \%$, respectively. In another trial, twenty lactating rabbit does (five per diet) were used to measure milk production. Under heat stress conditions, pregnant rabbit does given diet containing $1 \mathrm{~g}$ betaine $/ \mathrm{kg}$ diet showed the highest $(\mathrm{P}<0.01)$ weight gain than those fed other experimental diets during the pregnancy period. During the lactation period, the rabbit does irrespective of the experimental diets lost weight ranging from 93 to $113 \mathrm{~g}$, which was about $3.60 \%$ of their initial live body weight with low losses for rabbit does fed diet containing $1 \mathrm{~g}$ betaine $/ \mathrm{kg}$ diet. The rabbit does fed diets containing ascorbic acid or betaine weaned more rabbits than those fed control diet (5.73 vs. 3.71; $\mathrm{P}<0.001$, as average). Rabbit does fed $1 \mathrm{~g}$ betaine $/ \mathrm{kg}$ diet recorded the highest values of litters weights, during the first three weeks. The pre-weaning mortality rate was higher in the control diet compared to diets with $250 \mathrm{mg}$ ascorbic acid $/ \mathrm{kg}$ diet or 0.5 and $1 \mathrm{~g}$ betaine $/ \mathrm{kg}$ diet $(36.16 \%$ vs. 20.21 , 20.39 and $13.81 \% ; \mathrm{P}<0.001$, respectively). Fertility rate was increased by supplementing $1 \mathrm{~g}$ betaine $/ \mathrm{kg}$ diet. On the other hand, daily feed intake of pregnant and lactating rabbit does increased $(\mathrm{P}<0.01)$ with supplementing $1 \mathrm{~g}$ betaine $/ \mathrm{kg}$ diet. Supplementing dietary ascorbic acid and betaine increased $(\mathrm{P}<0.001)$ feed intake of pups in the last 9 days of the lactation period, where pups fed diet containing $1 \mathrm{~g}$ betaine $/ \mathrm{kg}$ diet recorded the highest value. Rabbit does given diets with ascorbic acid or betaine showed a better $(\mathrm{P}<0.01)$ milk index. Moreover, feed conversion ratio was significantly improved $(\mathrm{P}<0.001)$ by supplementing ascorbic acid or betaine in diets during the first three weeks of the lactation period, where rabbit does fed $1 \mathrm{~g}$ betaine $/ \mathrm{kg}$ diet recorded the best value. Also, the feed conversion ratio was better $(\mathrm{P}<0.001)$ for diets supplemented with ascorbic acid or betaine during the last 9 days of lactating period. Betaine at a level of $1 \mathrm{~g} / \mathrm{kg}$ caused an increase $(\mathrm{P}<0.05)$ in milk production whereas milk yield increased $(\mathrm{P}<0.05)$ by 26.2 and $42.8 \%$ in rabbit does fed 0.5 and 1 $\mathrm{g}$ betaine $/ \mathrm{kg}$ diet, respectively. The same trend was observed for milk production in relation to week of lactation, which was increased only with $1 \mathrm{~g} / \mathrm{kg}$ betaine level
\end{abstract}


throughout the lactation period. In this study, $1 \mathrm{~g}$ betaine supplementation in rabbit does diet significantly improves productivity and milk production under high ambient temperature during summer in Egypt. If the results are confirmed on a larger scale, it could be therefore concluded that $1 \mathrm{~g}$ betaine supplementation in the diet, could be advisable in hot climates.

Key words: Rabbit, Ascorbic acid, Betaine, Heat stress, Reproductive performance

\title{
VIABILITY AND FERTILIZING ABILITY OF EXTENDED RABBIT SEMEN STORED AT $5^{0} \mathrm{C}$
}

\author{
El-Kelawy H.M., M. I. Tawfeek, M. N. El-Gaafary , H. Ibrahim \\ Dept. of Animal Production, Inst. of Efficient Productivity, Zagazig University, \\ Zagazig, Egypt. \\ *Corresponding author's email: drhassan_2105@yahoo.com
}

\begin{abstract}
A total number of six bucks and sixty five doe rabbits were used in this study to evaluate viability and fertilizing ability of diluted rabbit spermatozoa stored at $5^{\circ} \mathrm{C}$. Rabbits were used for semen collection using an artificial vagina. Ejaculates of good initial motility (> 70\% motile spermatozoa) were pooled and diluted. Heterospermic pools were divided into three aliquots to study the extender effect on semen motility. In the $1^{\text {st }}$ aliquot semen was diluted in saline solution $(0.9 \% \mathrm{NaCL})$. The $2^{\text {nd }}$ and $3^{\text {rd }}$ aliquots semen were diluted either with glucose-yolk citrate or fructose-yolk Tris. The dilution rate was 1 semen: 5 diluent v/v. The diluted semen was then cooled to $5^{0} \mathrm{C}$ over 1.5- 2 hours and stored for 2 days. In the fertility trial, sixty five Baladi Black rabbit does were randomly allotted into two groups. Rabbit does of the $1^{\text {st }}$ group were inseminated artificially by fresh semen while those of the $2^{\text {nd }}$ group, were artificially inseminated with cooled semen stored for $24 \mathrm{~h}$. All of them were artificially inseminated using a dose of $1 \mathrm{~mL}$ containing $50 \times 10^{6}$ motile sperm cell. To induce ovulation, each doe was intramuscularly injected with $0.2 \mathrm{ml} \mathrm{Receptal} / \mathrm{doe}$.

The effect of the type of extender on the percentage of motile spermatozoa was significant $(\mathrm{P}<0.05)$. The highest values of the percentage of motile spermatozoa were recorded with fructose-yolk Tris and glucose-yolk citrate and the lowest with saline solution. The duration of storage time at $5^{0} \mathrm{C}$ up to 48 hours significantly decreased $(\mathrm{P}<0.01)$ the percentage of motile spermatozoa and sperm viability, irrespective of the extender used. Interactions between the type of extender and storage time on percentage of motile and dead spermatozoa were insignificant. Rabbit doe artificially inseminated with fresh and cooled semen showed similar results. Compared with glucose-yolk citrate, Fructose-yolk-Tris buffer is more effective for dilution and rabbit semen preservation at $5^{\circ} \mathrm{C}$, and for maintaining fertilizing ability.
\end{abstract}

Key words: Rabbit, Semen preservation, Extenders, Productivity, insemination. 


\title{
SEXUAL RECEPTIVITY AND CONCEPTION RATE OF RABBIT DOES FED SELECTED PERENNIAL FORAGES IN ILE-IFE, NIGERIA
}

\author{
Ola S.I.*, Williams O.S., Obamojure I.A., Okunlola A.M. \\ Dept. of Animal Sciences, Faculty of Agriculture, Obafemi Awolowo University, 220005, Ile-Ife, \\ Nigeria \\ "Corresponding author: idowuola@ymail.com
}

\begin{abstract}
Moringa oleifera, Tephrosia candida and Cajanus cajan are perennial shrubs that can provide fresh forages to rabbits in a forage based production system of small holder operations, especially during the dry season. This study compared the sexual receptivity parameters (vulva colour, mating duration and, copulation rate), conception rate, litter performance and productivity of rabbit does fed these forages to those fed the conventional Centrosema pubescence or sole concentrate diets. Fifty heterogenous does were allotted equally to the five treatments (four forage based diets and the control diet). The forages were offered ad libitum plus a supplementation of concentrate at $2 \%$ of body weight. After 2 weeks of flushing the does were randomly mated to one of the 10 bucks. Does were mated again one week after weaning of kits (at 5 weeks). During both reproduction cycles the sexual receptivity parameters were observed while the conception rate was determined at palpation and parturition. Litter size and weight were also recorded at parturition and the productivity index calculated as the product of conception rate and litter size. Purple was the most exhibited vulva colour in all the does fed the different forages as well as the control group fed only the concentrate diet, while reddish vulva was the least observed. Mating duration was faster for does fed Moringa and concentrate diets. The preliminary data of the fertility were lower in the Cajanus fed does with only $60 \%$ compared to over $70 \%$ in Moringa, Centrosema, Tephrosia and Concentrate groups. Litter size was the highest in Concentrate fed does (5.8 born alive). Among the forages grougs Moringa and Tephrosia gave a higher litter size than Cajanus and Centrosema (4.8 and 4.9 vs 4.2 and 4.0 born alive, respectively). Overall productivity was significantly higher for the control group (4.8 born alive/mating), intermediate for does fed Moringa or Tephrosia (3.7 and 3.4 born alive/mating, respectively) and lower with the Cajanus or Centrosema diet (2.5 and 2.9, respectively). Thus for dry season, feeding of rabbit under the Ile-Ife conditions, Moringa or Tephrosia forages supplemented with concentrate diet seems to be an interesting option. However, the results have to be confirmed using a larger number of does.
\end{abstract}

Key words: Rabbit, perennial forage, sexual receptivity, conception rate, litter size. 


\title{
EFFECT OF ECG DOSE AND VITRIFICATION METHOD ON In Vitro SURVIVAL RATE OF RABBIT EMBRYOS
}

\author{
Samia Z. Meshreky ${ }^{1}$, Abdel-Aal E.S. ${ }^{1}$, Fahim H.N. ${ }^{1}$, Neama A. Ashmawy ${ }^{2}$ \\ ${ }^{1}$ Animal Production Research Institutes, Agriculture Research center, Dokki, Giza, Egypt. \\ ${ }^{2}$ Faculty of Agriculture, Cairo University, Giza, Egypt. \\ *Corresponding author: samia_meshreky2010@ hotmail.com
}

\begin{abstract}
Forty one New Zealand White multiparous rabbit does with an average live body weight of $3.78 \pm 0.15 \mathrm{~kg}$ were used as embryo donors in two experiments. In the $1^{\text {st }}$ experiment, twenty donors were intramuscularly administered with 20 or 40 IU eCG/kg live weight, $68 \mathrm{~h}$ before artificial insemination (AI). Immediately prior to insemination, the does were intravenously injected with hCG at $40 \mathrm{IU} / \mathrm{kg}$ live weight. In a $2^{\text {nd }}$ experiment, 21 does were injected with $20 \mu \mathrm{g} \mathrm{GnRh}$ intramuscularly and inseminated. The embryos were collected from slaughtered does $48-50 \mathrm{~h}$ post AI, vitrified using one of the two vitrification methods. In the $1^{\text {st }}$ method, the cryoprotective solution was a 1:1:2 solution $(\mathrm{v} / \mathrm{v} / \mathrm{v})$ of $3.5 \mathrm{M}$ DMSO, $4.4 \mathrm{M}$ EG in DPBS $+0.132 \mathrm{~g} \mathrm{CaCl}_{2} / \mathrm{L}+0.2$ (w/v) BSA/L. Vitrification was carried out in two steps. In the $2^{\text {nd }}$ procedure, an one-step loading process in the vitrification solution containing $40 \%$ EG, $18 \%$ Ficoll 70+0.3 M/l sucrose. Irrespective of the vitrification method, the percentage of morphologically normal embryos recovered from does injected with 40 IU eCG was lower compared to $20 \mathrm{IU}$, nevertheless, the difference was not significant. In contrast, the embryo diameter was significantly smaller when the eCG dose increases. In $40 \mathrm{IU}$ eCG treated does, only $42 / 147$ embryo vitrified-thawed reached hatching blastocysts stage (28.6\%) vs. 95/186 (51.1\%) in 20 IU group. Irrespective of the hormonal treatments in the $1^{\text {st }}$ and $2^{\text {nd }}$ experiments, one-step vitrification procedure with EG+Ficoll+sucrose improved insignificantly post-thaw morphologically normal embryos and development to hatching blastocysts stage compared to two-step vitrification procedure with EG+DMSO. It could be concluded that treating rabbit does with $40 \mathrm{IU}$ eCG/kg live weight delays embryo development and reduced quality scores and embryo diameters compared to $20 \mathrm{IU}$. One-step vitrification method (EG+Ficoll+sucrose) appears to be appropriate for cryopreservation of rabbit embryos Key words: eCG dose, Vitrification methods, Rabbit Embryos.
\end{abstract}

\section{EFFECT OF VITRIFICATION AND CRYOSTORAGE LENGTH ON VIABILITY OF RABBIT EMBRYOS AFTER THAWING}

\author{
Samia Z. Meshreky*, Fahim H.N., Abdel-Aal E.S., Samya E. Ibrahim \\ Animal Production Research Institutes, Agriculture Research center, Dokki, Giza, Egypt. \\ *Corresponding author: samia_meshreky2010@ hotmail.com
}




\begin{abstract}
The effects of vitrification and cryostorage length in liquid nitrogen (LN2) on in vitro survival of rabbit embryos were examined. A total of 374 morphological normal embryos collected from 20 superovulated multiparous New Zealand White rabbit were divided into two groups. The first group ( $\mathrm{n}=94)$ was non-vitrified used as a fresh control group and the second group $(n=280)$ was vitrified and storage in liquid nitrogen at three different times ( 2 days, 6 months or one year). Regardless the cryostorage length in LN2, post thawing morphological normal appearance rates of cryopreserved rabbit embryos were significantly affected by vitrification procedure. Only 62.1-67.4\% from embryo vitrified-thawed appears undamaged. Blastocyst and hatching rates were decreased $(\mathrm{P}<0.05)$ in vitrified group compared to the control group, whilst no difference was observed among different storage time in liquid nitrogen. Blastocyst and hatching rates ranged between 51.7-58.9 and 39.8-47.4\% in vitrified-thawed embryos groups compared to 94.7 and $90.4 \%$ in control group. Significance difference was observed in embryo diameter between vitrified groups and control group (123-124 vs. $129 \mathrm{~m}$ ). Blastocyst and hatching rates did not vary according to the cryostorage length from 2 days until 1 year in LN2. In a same way, no significant differences were found in diameter of warmed embryos when the cryostorage increases. Our results indicate that compared to the control group, the vitrification process decreases the in vitro embryo development. In contrast, the cryostorage length in liquid nitrogen did not affect the in vitro development of rabbit embryos ( $\geq 16$-cells stage).
\end{abstract}

Key words: Vitrification, Storage time, Rabbit embryos.

\title{
FEEDING REGIMEN DURING REARING IN FEMALE RABBITS UNDER EGYPTIAN ENVIRONMENTAL CONDITIONS: EFFECT ON OVARIAN ACTIVITY AND EMBRYO QUALITY PRODUCTION
}

\author{
Samia Z. Meshreky ${ }^{1 *}$, Neama A. Ashmawy ${ }^{2}$, Ali Kh. A.A. ${ }^{1}$, Mervat M. Arafa ${ }^{1}$ \\ ${ }^{1}$ Animal Production Research Institute, Agricultural Research Centre, Giza, Egypt. \\ ${ }^{2}$ Faculty of Agriculture, Cairo University, Geza, Egypt. \\ *Corresponding author: samia_meshreky2010@hotmail.com
}

\begin{abstract}
Forty New Zealand White rabbit does, ten weeks old with an average live body weight of $1605 \pm 10 \mathrm{~g}$, were divided into four homogenous groups. The $1^{\text {st }}$ group was fed ad libitum (control, C) and the $2^{\text {nd }}$ group was fed ad libitum but fasted one day per week (F). The $3^{\text {rd }}$ group was restricted fed (80\% of ad libitum, R-1) while the last group was also restricted fed but they received their diet in two meals/day (at 8-9 am and 5-6 pm, R-2). All treatment groups were fed according to the treatment procedure until one week prior to the first insemination (22 weeks of age) to stimulate receptivity (flushing), afterwards they were all fed ad libitum the standard diet. At the end of the flushing period, does were intramuscularly injected with $20 \mathrm{~g} \mathrm{GnRH}$ and were
\end{abstract}


inseminated with fresh semen. All does were slaughtered at $72-76 \mathrm{hr}$ post AI. Daily weight gain was significantly $(\mathrm{P}<0.001)$ reduced in restricted and one day/week fasted groups. Compared to the control group, ovulation rate and number of CL on ovaries significantly $(\mathrm{P}<0.05)$ increased with restrictive diets. Fertilization rate was higher in $\mathrm{R}-2$ group, followed by R-1 than in $\mathrm{F}$ and $\mathrm{C}$ groups, respectively, but differences were not significant. Relative weights of ovaries, oviducts and uterus were increased $(\mathrm{P}<0.05)$ under feeding regime. From the histological point of view, oviducts and uterus development were more pronounced with fed restriction groups, followed by $\mathrm{F}$ than $\mathrm{C}$ groups. Restricted fed does had an increased number of embryos recovered and significantly $(\mathrm{P}<0.05)$ higher percentages of embryo developed to early blastocyst stage with an excellent or good quality. It can be concluded that restricted regime given in two or one meal/day, with one week flushing period before the $1^{\text {st }}$ insemination, enhances ovarian efficiency, genital organs development, and improves preimplantation embryo development.

Key words: Rabbits, feeding regimen, ovarian efficiency, embryo survival.

\title{
REPRODUCTIVE PERFORMANCE OF BUCKS WITH VARIOUS BEHAVIORAL TYPES IN NEW ZEALAND WHITE AND TERMOND WHITE RABBITS
}

\author{
Gacek L. ${ }^{1}$, Brzozowski M. ${ }^{2 *}$, Głogowski R. ${ }^{2}$ \\ ${ }^{1}$ National Research Institute of Animal Production, Experimental Station Chorzelów, Poland \\ ${ }^{2}$ Warsaw University of Life Sciences, Faculty of Animal Sciences, Poland \\ *Corresponding author: marian_brzozowski@sggw.pl
}

\begin{abstract}
The aim of the study was to compare the reproductive performance of Termond White (TW) and New Zealand White (NZ) bucks with various behavioral types. The empathic and novel-object tests were implemented to determine the patterns in rabbit reactions: -Aggressive, -Tame and -Timid. The comparison of bucks' behavior with mating duration and fertility rate did not evidence significant relations. Further studies will be necessary before integrating behavior tests in rabbit bucks breeding programs.

Key words: Termond White rabbit; New Zealand White rabbit; behavioral test; reproductive performance.
\end{abstract}

\section{EFFECT OF DIFFERENT LIGHTING SCHEDULES (16L:8D OR 12L:6D) ON REPRODUCTIVE PERFORMANCE OF RABBIT DOES}

Matics Zs.*, Gerencsér Zs., Radnai I., Mikó A., Nagy I., Szendr Zs. Kaposvár University, Faculty of Animal Science, H-7400, Kaposvár, Guba S. str. 40. (Hungary) 


\begin{abstract}
The objective of the experiment was to compare the reproductive performance of rabbit does in a routine (16L:8D) and in proportionally shorter (18 hours) 12L:6D lighting regime. The experiment was conducted at the experimental rabbit farm of the Kaposvár University. Crossbred rabbit does were randomly housed in two identical rooms. Drinking water (from nipple drinkers) and commercial pellet were available ad libitum. The temperature varied between $14-28{ }^{\circ} \mathrm{C}$, depending on the season. The two rooms only differed in the lighting regime: $24 \mathrm{~h}$ group $=16$ hours light and 8 hours dark $(\mathrm{n}=54$ does); $18 \mathrm{~h}$ group $=12$ hours light and 6 hours dark ( $\mathrm{n}=54$ does). Rabbit does were first inseminated at 16.5 weeks of age. AI was applied $11 \mathrm{~d}$ post partum $(42 \mathrm{~d}$ reproductive rhythm, single batch system). Cross-fostering was applied within groups with max. 8 kits/litter at first kindling and max. 10 kits/litter at subsequent parities. Rabbit does could nurse their kits freely. Data of the first 5 consecutive reproductive cycles were evaluated. Body weight of the does at kindling, kindling rate, litter size at birth, at day 21 and 35 showed no significant differences among the groups. Mortality of the kits for the periods of 0-21 and 0-35 days were independent of the lighting schedule. Litter weight at day 21 and 35 was $4 \%$ lower in $18 \mathrm{~h}$ group compared to the $24 \mathrm{~h}$ group $(\mathrm{P}<0.05)$. Calculating the productivity index, the number of kits born alive and number of kits at day 35, per $100 \mathrm{AI}$, were $7.5 \%$ (813 vs. 757 kits) and 5.2\% (714 vs. 679) higher in the $18 \mathrm{~h}$ group compared to the $24 \mathrm{~h}$ group. Considering the opposite tendencies of the kits' body weight, the two groups did not differ for the total weight of the weaned rabbits per $100 \mathrm{AI}$ (18h: $630 \mathrm{~kg}$; 24h: $632 \mathrm{~kg}$ ). Does survival did not differ significantly during the experimental period $(83 \%$ and $81 \%$ in groups $18 \mathrm{~h}$ and $24 \mathrm{~h}$, respectively, $\mathrm{P}=0.735)$. Reproductive performance of rabbit does housed in a routine $(16 \mathrm{~L}: 8 \mathrm{D}=24$ hours $)$ or proportionally shorter $(12 \mathrm{~L}: 6 \mathrm{D}=18$ hours $)$ lighting regime was similar.
\end{abstract}

Key words: Rabbit does, lighting schedule, reproductive performance.

\title{
EFFECT OF DIFFERENT FREEZING EXTENDERS ON SEMEN QUALITY, FERTILITY AND PROLIFICACY IN TWO SELECTED LINES OF RABBIT BUCKS
}

\author{
Safaa H.M. ${ }^{1^{*} \text {, Lavara R. }}{ }^{2}$, Viudes-de-Castro M.P. ${ }^{3}$, \\ Elsayed D.A.A. ${ }^{1}$, Mehaisen G.M.K. ${ }^{1}$, Marco-Jiménez F. ${ }^{2}$, Vicente J.S. ${ }^{2}$ \\ ${ }^{1}$ Cairo University, Faculty of Agriculture, Animal Production Department, 12613, Giza, Egypt \\ ${ }^{2}$ Instituto de Ciencia y Tecnologia Animal, Universidad Politécnica de Valencia, Departamento de Ciencia \\ Animal: Laboratorio de Biotecnologia de la Reproduccion, 46071, Valencia, Spain \\ ${ }^{3}$ Centro de Tecnologia Animal-Instituto Valenciano de Investigaciones Agrarias Agrarias (CITA-IVIA), \\ Poligono La Esperanza, no. 100, 12400, Segorbe, Castellon, Spain \\ *Corresponding author: hosam.safaa@gmail.com
}

\section{ABSTRACT}

The aim of this study was to evaluate the cryoprotective effect of different freezing extenders against cryopreservation injuries on rabbit sperms of 2 lines selected for 
hyper-prolificacy $(\mathrm{H})$ and longevity $(\mathrm{L})$. Ejaculates were collected and pooled from ten sexually mature rabbit bucks per each line. A total number of 196 pooled semen ejaculates per line were used to evaluate post-thawing semen by 252 artificial inseminations using White New Zealand rabbit does. Semen was equally divided into 3 volumes and diluted (1:1) with different TRIS citric acid based extenders (A, B and C). In extender $\mathrm{A}, 3 \mathrm{M}$ dimethyl sulfoxide and $0.1 \mathrm{M}$ sucrose were added as cryoprotectants. For extender B, the sucrose in extender A was replaced by $20 \%$ eggyolk, and for extender C, the TRIS-based extender was supplemented with $2 \mathrm{M}$ acetamide and $20 \%$ egg-yolk. No interaction effect was detected between rabbit line and semen extender on studied traits. Moreover, no significant differences were detected between $\mathrm{H}$ - and L-lines for all traits except for prolificacy that was higher in L- line (6.04 vs. 4.37 young born at birth, respectively). However, freezing semen with extender A and B showed better post-thawing semen quality characteristics, fertility and prolificacy than frozen semen with extender $\mathrm{C}$. It could be concluded that extenders $\mathrm{A}$ and $\mathrm{B}$ are preferable for freezing semen of $\mathrm{H}$ - and L-rabbit lines than extender $\mathrm{C}$ to obtain higher fertility and prolificacy. A moderate and interesting relationship was found between acrosomal integrity of frozen semen and fertility rate. $(\mathrm{r}=0.17 ; \mathrm{P}=0.04)$.

Key words: Rabbit, semen freezing extender, semen quality, fertility, prolificacy.

\title{
EFFECT OF MELATONIN ON IN VITRO DEVELOPMENT OF MORULA RABBIT EMBRYOS
}

\author{
Mehaisen G.M.K. ${ }^{{ }^{*}}$, Saeed A.M. ${ }^{2}$ \\ ${ }^{1}$ Animal Production Department, Faculty of Agriculture, Cairo University, 7 Gamaa Street, 12613, Giza, Egypt \\ ${ }^{2}$ Animal Biotechnology Department, Animal Production Research Institute, Dokki, Giza, Egypt \\ *Corresponding author: gamoka7@gmail.com
}

\begin{abstract}
This study aimed to investigate the effect of melatonin supplementation at different levels, in culture medium, on rabbit embryo development. Embryos were recovered from nulliparous Red Baladi rabbit does by laparotomy technique 72 hours postinsemination. Normal morulae were cultured till the stage of hatched blastocysts in the following four culture media; (i) control (TCM-199 + 20\% fetal bovine serum), (ii) control $+10^{-9} \mathrm{M}$ melatonin, (iii) control $+10^{-6} \mathrm{M}$ melatonin and (iv) control $+10^{-3} \mathrm{M}$ melatonin. The high level of melatonin at $10^{-3} \mathrm{M}$ significantly increased the in vitro development of embryos (92\% for $10^{-3} \mathrm{M}$ vs. $84 \%$ for $10^{-6} \mathrm{M}$ and $76 \%$ for $10^{-9} \mathrm{M}$ and control, $\mathrm{P}<0.05)$. However, the addition of melatonin with different levels did not improve the hatchability rate of these embryos (16-30\% vs. 52\% for melatonin groups vs. control, $\mathrm{P}<0.05$ ). Results show that adding melatonin at $10^{-3} \mathrm{M}$ to morula rabbit embryos enhances their development, while $10^{-6} \mathrm{M}$ melatonin slightly increased blastocyst rate and $10^{-9} \mathrm{M}$ had no effect on embryo development. This effect strongly suggests a physiological role of melatonin in embryo protection.
\end{abstract}

Key words: Melatonin, In vitro development, Embryos, Rabbits. 


\title{
EFFECT OF BIRTH SEASON ON ONSET OF PUBERTY AND SEMEN CHARACTERISTICS IN MALE RABBIT OF ALGERIAN POPULATION (Oryctolagus cuniculus)
}

\author{
Boulbina I. ${ }^{1,2}$, AinBaziz H. ${ }^{1}$, Ilès I. ${ }^{1}$, Zenia $S .{ }^{1}$, Belabbas R. ${ }^{1}$, Temim $S^{1}$. \\ ${ }^{1}$ Laboratoire de Recherche «Santé et Production Animales», Ecole Nationale Supérieure Vétérinaire \\ d'Alger, BP 161, 16200 El Harrach - Alger, Algérie. \\ ${ }^{2}$ Institut National de la Recherche Agronomique d'Algérie, BP 37 Mehdi Boualem, Baraki - Alger, \\ Algérie. \\ *Corresponding author: ibtissemb@yahoo.fr
}

\begin{abstract}
The objective of this work was to determine the effect of birth season on the puberty age of male rabbit from local Algerian population (Oryctolagus cuniculus). Another objective was to study the quantitative and qualitative characteristics of semen during the same period. The mounting behaviour was controlled in 25 young males (14 were born in summer and 11 were born in winter) from the $11^{\text {th }}$ week of age until the appearance of a positive mounting which resulted in the first ejaculate into the artificial vagina i.e. onset of puberty. Sperm collection started from the first ejaculate until $100 \%$ of the rabbits reached puberty. Since the onset of puberty, bucks were solicited one day per week two times separated by an interval of 10 to 20 minutes. Thus, 108 ejaculates were collected from the group of rabbits born in summer (S) and 82 ejaculates from those born in winter $(\mathrm{W})$.

The onset of puberty was found to be between weeks 15 and 19 of age for rabbits born in winter and taking longer, between weeks 17 and 23 for young rabbits born in summer. The study of sexual activity and sperm production during the period of onset of puberty as a function of birth season showed that the libido was better in rabbits born in winter (14 s vs $22 \mathrm{~s}$ ), nevertheless this difference was not statistically significant $(\mathrm{P}>0.05)$. The same group of rabbits showed a significantly higher $\mathrm{pH}$ as well as the total and gel-free volume (7.46 vs $7.01 ; 0.74 \mathrm{ml}$ vs $0.37 \mathrm{ml}$ and $0.52 \mathrm{ml}$ vs $0.32 \mathrm{ml}$ respectively; $\mathrm{P}<0.001)$. However, statistical analysis did not indicate any significant difference in color, sperm production, mass and individual motility, or the percentage of live spermatozoa between the two groups of rabbits considered in this study. Numerous anomalies of spermatozoa were observed in rabbits born in winter (32.6\%) compared to rabbits born in summer $(27.6 \%$; $\mathrm{P}<0.01)$. This study underlined the important effect of birth season on puberty age and semen characteristics.
\end{abstract}

Key words: Local male rabbit, puberty, semen, spermatozoa, summer, winter. 


\title{
EFFECTS OF FASTING DURING PREGNANCY IN RABBIT DOES
}

\author{
Brecchia G. ${ }^{1}$, Menchetti L. ${ }^{2}$, Cardinali R. ${ }^{3}$, Polisca A. ${ }^{2}$, Troisi A. ${ }^{2}$, Maranesi M. ${ }^{1}$, \\ Boiti C. ${ }^{1}$ \\ ${ }^{1}$ Department of Biopathological Science, Hygiene of Animal and Food Productions, University of Perugia, Italy \\ ${ }^{2}$ Department of Pathology, Diagnostic and Clinic, University of Perugia, Italy \\ ${ }^{3}$ Department of Applied Biology, University of Perugia, Italy \\ Correspondence should be addressed to Gabriele Brecchia, Via San Costanzo, 4 Perugia, Italy, \\ gabriele.brecchia@unipg.it
}

\begin{abstract}
This study sought to examine the effects of the food restriction performed in different stages of pregnancy on maternal leptin plasma concentrations and on the productive performance of both the rabbit does and their litters. A total of 40 primiparous non lactating New White Zealand females were randomly assigned into four groups according to their nutritional treatments during the pregnancy. Control group (C) was provided with $130 \mathrm{~g} / \mathrm{d}$ of commercial food. The other three groups were fed with a restricted amount of food (30\% restriction, $90 \mathrm{~g} / \mathrm{d}$ ) from day 0 to 10 day (R1), from day 9 to $18(\mathrm{R} 2)$ and from day 19 to 28 of pregnancy (R3). At the end of the restriction period, the does returned to standard ration. Productive performance of R1 and control groups were comparable. The rabbits of R1 group showed a rapid increase in weight after the re-feeding and the lower values of leptin $(\mathrm{P}<0.001)$. This compensatory growth was not evident in other experimental groups. $\mathrm{R} 2$ recorded lower litter weight at weaning $(\mathrm{P}<0.05)$ and higher pre-weaning mortality than control group (26.98 vs. $16.85 \%)$. $\mathrm{R} 3$ showed lower litter size $(\mathrm{P}<0.01)$, born alive $(\mathrm{P}<0.01)$, weight at kindling $(\mathrm{P}<0.05)$, litter weight at weaning $(\mathrm{P}<0.05)$ and higher perinatal $(16.13 \mathrm{vs}$. $7.94 \%$ ) and pre-weaning mortality ( 26.67 vs. $16.85 \%$ ) compared to control group. Milk production of the $\mathrm{R} 3$ was lower than in control $(\mathrm{P}<0.05)$. The effects of restricted feeding on pregnancy depend on the stage of privation during the pregnancy period: while a food restriction in early pregnancy did not seem to determine significant differences in productivity, a restriction in the last third of pregnancy, a critical period for energy homeostasis, resulted in the reduction of performance and impaired milk production. Food restriction reduced plasma leptin concentrations, in particular during the first period of pregnancy. However, the trend of leptin in pregnancy period and its relationship with body weight and fat reserves requires further study.
\end{abstract}

Key words: Rabbits, pregnancy, food restriction, reproductive performance, leptin.

\section{INFLUENCE OF ENVIRONMENTAL TEMPERATURE AND RELATIVE HUMIDITY ON SEMEN CHARACTERISTICS IN MALE RABBIT (ORYCTOLAGUS CUNICULUS) OF LOCAL ALGERIAN POPULATION}

\author{
Ainbaziz H. ${ }^{{ }^{*},}$, Boulbina I. ${ }^{2}$, Ilès I. ${ }^{1}$, Belabbas R. ${ }^{1}$, Zenia S. ${ }^{\mathbf{1}}$, Temim $\mathbf{S}^{\mathbf{1}}$. \\ ${ }^{1}$ Laboratoire de Recherche "Santé et Production Animales", Ecole Nationale Supérieure Vétérinaire,
}


El-Harrach PB 161, 16200, Alger, Algérie

${ }^{2}$ Institut National de la Recherche Agronomique, BP 37 Mehdi Boualem, Baraki - Alger, Algérie.

*Corresponding author: ainbaziz@yahoo.fr

\begin{abstract}
The aim of the present study was to evaluate the effect of the season (summer and spring) on sexual activity and quantitative and qualitative semen characteristics of local male rabbit. Two groups of eleven male rabbits each (11 months-old) were exposed to summer (THI index mean value: 29.6) and to spring (THI index mean value: 20.2) conditions. Initial live weights were simila: $3234 \pm 242 \mathrm{~g}$ and $3152 \pm 210 \mathrm{~g}(\mathrm{P}>0.05)$ respectively for rabbits reared in summer and spring. During 9 weeks for each season, 188 and 166 ejaculates were collected respectively in summer and spring groups. In the summer season, the daily feed intake of rabbit was significantly lower (96.8 g/d vs. $114.8 \mathrm{~g} / \mathrm{d} ; \mathrm{P}<0.001)$. In contrast, rabbit live weight gain measured between the first week and the 9th week was not affected by the season (201.8 g vs. $179.6 \mathrm{~g} ; \mathrm{P}>0.05)$.Besides, both of rates of ejaculates obtained, useful ejaculates, ejaculates without gel and urine were lower in rabbits reared in summer than those collected in spring, but the values were not significantly different $(\mathrm{P}>0.05)$ between the 2 groups. Except the $\mathrm{pH}$, all parameters performed by rabbits reared in spring and summer conditions were different. In summer, the male rabbit libido (time until ejaculation) was significantly altered (14.8 vs. 7.2 seconds, $\mathrm{P}<0.001)$. Sperm volume without gel, spermatozoa mobility, viability and concentration by ejaculate decreased significantly respectively by $22 \%(\mathrm{P}<0.001), 25 \%(\mathrm{P}<0.05), 26.7 \%(\mathrm{P}<0.001)$ and $29 \%$ $(\mathrm{P}<0.001)$. The rate of total anomalies of sperm cells was significantly increased in summer period (18.8\%, $\mathrm{P}<0.001)$.In conclusion, sexual activity and semen quality were significantly altered in local rabbits exposed to the Algerian summer conditions.
\end{abstract}

Key words: Libido, Rabbit, Season, Semen characteristics.

\title{
EFFECT OF THE AVERAGE KITS BIRTH WEIGHT AND OF THE NUMBER OF BORN ALIVE PER LITTER ON THE MILK PRODUCTION OF ALGERIAN WHITE POPULATION RABBIT DOES
}

\author{
Zerrouki N. ${ }^{1 *}$, Chibah K. ${ }^{1}$, Amroun T. ${ }^{1}$, Lebas F. ${ }^{2}$ \\ ${ }^{1}$ Faculty of Biological and Agronomic Science. University Mouloud Mammeri of Tizi-Ouzou, Algeria.. \\ 2 Cuniculture, 87A, chemin de Lasserre, 31450. Corronsac. France. \\ * Corresponding author e-mail : ice-yacine@hotmail.fr
}

\begin{abstract}
In order to determine the influence of litter size at birth and of the average birth weight of kits on the milk production of does, 153 litters from rabbit does of Algerian White population, were studied during the lactation period (3 weeks following parturition). Milk production of does was estimated by weighing each doe before and after the single daily suckling (3-5mn between the 2 weighing operations). The factors studied were the effect of the number of born alive (5 levels: from 4 to 8 kits) and the effects of the average weight of kits at birth (4 levels: from 30-50g to more than 70g). The rabbit does of White
\end{abstract}


population produced on average $2264 \pm 733 \mathrm{~g}$ in 21 days, that is $108 . \pm 5.8 \mathrm{~g}$ of milk/day or $18.7 \mathrm{~g} / \mathrm{kit}$ and per day. When the number of born alive increased from 4 to 8 kits per litter, the doe's milk production was significantly increased : $475,664,668 \mathrm{~g}$ and $1787 \mathrm{~g}$ vs $663,908,983 \mathrm{~g}$ and $2527 \mathrm{~g}$, respectively during weeks $1,2,3$ and during the whole period for litters of 4 vs 8 kits at kindling $(\mathrm{P}<0.001)$. Simultaneously the individual kits milk intake in 21 days was reduced by $22 \%$. The average weight of kits at birth affected also significantly the average milk production during the two first weeks or during the whole period. During the first and the second week, milk yield was $28 \%$ and $18 \%$ larger for females giving birth to heavy kits than for those giving birth to light kits. For the 21 days period the increase was of $18.2 \%$ ( $\mathrm{P}=0.011)$. For the heaviest kits at birth ( $70 \mathrm{~g} \&$ more) the milk intake during the first week was 37\% larger than that for the lightest ones (30 to $50 \mathrm{~g}$ ) but the difference became not significant during the third week of lactation.

Key words: Milk production, birth weight, litter size, Algerian White population rabbits.

\title{
CONCENTRATION OF GLUTATHIONE AND ATP AS A MEASURE OF OOCYTE MATURATION IN RABBIT FEMALES
}

\author{
Laborda, P. $^{1,3}$, Santacreu, M. A. ${ }^{1}$, Moya, V. J. ${ }^{1}$, Mocé, M. L. ${ }^{1,2}$ \\ ${ }^{1}$ Instituto de Ciencia y Tecnología Animal, Universitat Politècnica de València. \\ Camino de Vera s/n. 46071 Valencia. Spain. \\ ${ }^{2}$ Departamento de Producción Animal y Ciencia y Tecnología de los Alimentos. Universidad Cardenal \\ Herrera-CEU. Edificio Seminario. 46113 Moncada, Valencia. Spain. \\ ${ }^{3}$ Corresponding author: patlavi@dca.upv.es
}

\begin{abstract}
The present study was designed to determine the concentrations of ATP and glutathione (GSH) in ovulated and not-ovulated rabbit oocytes in a line of rabbits selected for ovulation rate. ATP and GSH concentrations were used to assess oocyte quality. A total of 58 does belonging to the $9^{\text {th }}$ generation of a line selected for ovulation rate were used to assess ATP concentrations. A total of 10 does belonging to the $10^{\text {th }}$ generation of the same line were used to assess GSH concentrations. Ovulation was induced by an intramuscular injection of $1 \mathrm{mg}$ of buserelin acetate and animals were slaughtered 16 hours thereafter. Ovulated oocytes were collected by flushing the oviducts. Not-ovulated oocytes were aspirated from preovulatory follicles with a $1 \mathrm{ml}$ syringe and a $25 \mathrm{G}$ needle. Oocytes were processed. ATP concentration was determined by bioluminiscency. ATP concentration ranged from 0.6 to $2.4 \mathrm{pmol} /$ oocyte in not-ovulated oocytes and from 0.8 to $5.0 \mathrm{pmol} /$ oocyte in ovulated oocytes. GSH concentration was determined by HPLC. Glutathione concentration ranged from 0.5 to $2.2 \mathrm{pmol} /$ oocyte in not-ovulated oocytes and from 5.2 to $10.2 \mathrm{pmol} /$ oocyte in ovulated oocytes. These differences in ATP and GSH concentrations between not-ovulated and ovulated rabbit oocytes might indicate that ATP and GSH are synthesized during oocyte maturation.

Key words: ATP, glutathione, ovulated oocyte, not-ovulated oocyte.
\end{abstract}




\title{
INFLUENCE OF PARITY ORDER ON AVAILABLE UTERINE SPACE PER FETUS, PLACENTAL AND FETAL DEVELOPMENT IN RABBITS
}

\author{
Belabbas R..$^{*}$, Ilès I. ${ }^{2}$, Ainbaziz H. ${ }^{2}$, Boumahdi Z. ${ }^{1}$, Boulbina I. ${ }^{2}$, Benali N. ${ }^{2}$, \\ Temim S. ${ }^{2}$ \\ ${ }^{1}$ University of Saad Dahleb Blida, Biotechnology Laboratory of Animal Production, Blida, Algeria \\ ${ }^{2}$ Laboratory of research "Health and Animal Production", National Veterinary School, Algeria \\ *Corresponding author: rafikbelabbas@yahoo.fr
}

\begin{abstract}
Our objective was to study, in the rabbit of local population, the effect of parity, on fetal and placental development and available uterine space per fetus. Twenty rabbit does (10 nulliparous and 10 primiparous) were mated and sacrificed at $24^{\text {th }}$ of pregnancy. The uterine horns were examined to estimate the vascularization of implantation sites, the intra-uterine position (oviductal, middle and cervical), available uterine space. The fetuses in oviduct position presented maternal placenta weight significantly different from those in middle $(+12 \%)$ and cervical position $(+8.6 \%)$. The vascularization influenced the weight, the crown-rump length and available uterine space. The fetuses receiving 25 blood vessels presented the best performances $(p<0.05)$. The number of fetus per horn affects significantly the weight and available uterine space. At $24^{\text {th }}$ of pregnancy, the vascularization influenced the fetal development and available uterine space but; the position influenced only the weight of maternal placenta.
\end{abstract}

Key words: Rabbits, parity order, placenta, fetus, available uterine space.

\section{RELATIONSHIPS BETWEEN OVULATION RATE, LITTER SIZE AND PRENATAL SURVIVAL COMPONENTS IN RABBIT DOES}

\author{
Ragab M. ${ }^{1,2}$, Vicente J. S. ${ }^{1}$, Lavara R. ${ }^{1}$, Desantes, J. ${ }^{1}$, Baselga, M. ${ }^{1}$ \\ ${ }^{1}$ Instituto de Ciencia y Tecnología Animal, Universidad Politécnica de Valencia, \\ Camino de Vera S/N, 46022, Valencia, Spain. \\ ${ }^{2}$ Poultry Production Department, Fac. of Agriculture, Kafr El-Sheikh University, Egypt. \\ *Corresponding author: moramo@upvnet.upv.es
}

\section{ABSTRACT}

The aim of this study was to evaluate the relationships between ovulation rate (OR), implanted embryos (IE), total born (TB), number born alive (NBA) and embryo (ES), fetal (FS) and prenatal survival (PS) in females of high reproductive performance, resulting from a complete diallelic cross between four Spanish maternal lines of rabbits. Sixteen genetic types were studied (the four lines, and their twelve simple crosses). A total of 2025 does in their third, fourth or fifth gestations were subjected to a laparoscopy 11-12 days after mating. The previous traits were analysed with a model 
that included for all the traits, the genetic group-farm-year-season combination (GFYS), the parity order and the lactation state. For all the traits, excepted OR, the linear and quadratic effects of a covariate were considered. The covariate OR was included for the analysis of the other traits; IE for TB, NBA and FS; and NBA for TB for NBA. The general means obtained for the traits were: 15.2 ova for OR, 13.4 embryos for IE, 11.1 rabbits for TB, 10.2 rabbits for NBA, 87.9\% for ES, 84.9\% for FS and $74.0 \%$ for PS. None effects of parity order and lactation stages were observed, but the GFYS effect was significant. It is remarkable that survival rates obtained were high, with prenatal survival higher than $70 \%$ and proportional distribution of losses before and after $12^{\text {th }}$ day of gestation. A negative curvilinear and significant relationship was found between ovulation rate and litter size components, affecting in the same sense the survival rates, but only the coefficients of regression of the quadratic term were significant for ES and PS. Moreover, the relationship of the covariate implanted embryos with TB, NBA and FS, and also the covariate TB with NBA were also significant and negative. This could be considered as a primary expression of the uterine capacity limits. The significant regression coefficients of the linear term ranged between 1.20 and 1.36, and the corresponding coefficients of the quadratic term, between -0.03 and -0.02 for IE, TB and TBA. In spite of significance of the quadratic coefficients, they might be not relevant because it closed to zero. No effects of parity order and lactation status were observed. A negative curvilinear and significant relationship was found between ovulation rate and the rest of litter size components, affecting in the same sense the survival rates.

Key words: Rabbits, laparoscopy, litter size components, prenatal survival, quadratic regression.

\title{
EFFECT OF LACTATION STAGE ON LITTER SIZE COMPONENTS IN RABBITS
}

\author{
Ragab M. ${ }^{1,2}$, Lavara R. ${ }^{1}$, Vicente J. S. ${ }^{1}$, Mínguez C. ${ }^{1}$, Baselga, M. ${ }^{1}$ \\ ${ }^{1}$ Dept. of Animal Science, Polytechnic University of Valencia, Camino de Vera S/N, 46022, \\ Valencia, Spain. \\ ${ }^{2}$ Poultry Production Department, Faculty of Agriculture, Kafr El-Sheikh University, Egypt. \\ *Corresponding author: moramo@upvnet.upv.es
}

\begin{abstract}
The aim of this study was to evaluate the possible effect of lactation stage on ovulation rate (corpora lutea number, OR), implanted embryos (IE), total born (TB), and embryo (ES), fetal (FS) and prenatal survival (PS) in multiparous does, pertaining to a complete diallel cross between four Spanish maternal lines of rabbits. Sixteen genetic types were studied (four maternal lines: A, V, H and LP, currently belonging respectively, to generation 41,37, 20 and 7, selected for litter size at weaning), and their twelve simple crosses). A total of 1592 does in their third, fourth or fifth gestations were subjected to a laparoscopy 11-12 days after mating. To estimate the lactation stage effect, in relation to the number of days between kindling and insemination, 4 classes were considered: $\langle 11,11-12,13-15$ and $>15$ days of lactation.
\end{abstract}


The means of all traits reflected the high reproductive capacities: 15.43 ova, 13.17 embryos, 10.97 total born, $86.67 \%, 83.05 \%$ and $71.98 \%$ for OR, IE, TB, ES, FS and PS, respectively. Regarding parity order, no differences between the third, fourth and fifth gestations were observed for all analyzed traits. A positive, significant and relevant relationship was found between OR and IE, and also between OR and LS, due to their physiological sense.

On multiparous and receptive rabbit does, the number of corpora lutea increases with the interval between birth and mating or $\mathrm{AI}(\mathrm{P}=0.05)$, but lactation stage did not significantly influences the IE, TB, ES, FS and PS. In multiparous lactating rabbit does, the ovulation rate, implanted embryos and litter size could increase when the interval between kindling and mating (or insemination) increases.

Key words: Rabbits, laparoscopy, litter size components, prenatal survival, lactation stage effect.

\title{
OESTRUS INDUCTION IN PRIMIPAROUS LACTATING RABBITS BY A 48 HOURS MOTHER-LITTER SEPARATION: ENDOCRINE AND BEHAVIOURAL RESPONSES
}

\author{
Ilès I. ${ }^{*}{ }^{*}$, Benazzoug Y. ${ }^{2}$, Messili A. ${ }^{2}$, Boukhari S. ${ }^{1}$, Boiti C. ${ }^{3}$ \\ ${ }^{1}$ Laboratory of Animal Health and Production, National Veterinary School of Algiers, BP 161, Algeria. \\ ${ }^{2}$ University of Science and Technology, Faculty of Biological Sciences, BP 32, Bab-Ezzouar, 16111, Algeria. \\ ${ }^{3}$ Dipartimento di Scienze Biopatologiche ed Igiene delle Produzioni Animali e Alimentari, \\ Sezione di Fisiologia, Università di Perugia, Via S. Costanzo 4, 1-06100 Perugia, Italia. \\ *Corresponding author: iles_imene@yahoo.fr
}

\begin{abstract}
Primiparous does express low mating acceptance during lactation and different oestrus induction methods are employed to improve sexual receptivity. The aim of this work was to study the effect of a biostimulation, a 48 hours doe-litter separation (DLS), in primiparous lactating rabbits on: 1) mating acceptance at day 11 and days 12-14 postpartum ; 2) external characteristics of the vulva; 3 ) plasma concentration of estradiol (E2), testosterone $(\mathrm{T})$, progesterone (P4) and cortisol (CT). Seventy primiparous does from local population were divided at day 1 after kindling, in two equal groups: control $(\mathrm{C}$, $\mathrm{n}=35)$ and DLS $(\mathrm{n}=35)$. Litter size was equalised to 6-7 kits. The does had free access to the nest-box, except from day 9 to day 11 postpartum (PP) for the DLS group. For doe-litter separation, the nest-box entry was closed. Blood samples were obtained from 10 does per group at days 9 and $11 \mathrm{PP}$, before mating. The results showed that the DLS treatment improved the mating acceptance at day $11 \mathrm{PP}(88.5$ vs. $54.2 \%, \mathrm{P}<0.005)$ and the frequency of red or pink and turgid vulva (54.3 vs. $20 \%, \mathrm{P}<0.005)$. DLS does had the lowest percentage of white vulva ( 20 vs. $48.6 \%, \mathrm{P}<0.05$ ). The sexual receptivity of DLS does depended on the time for which the female was presented to the male: $60 \%$ refused mating before opening the nest-box, while $80.9 \%$ of them accepted the male after the nursing
\end{abstract}


episode. From day 12 to day $14 \mathrm{PP}$, the sexual receptivity was higher in DLS group than in the control group ( 75 vs. $43.7 \%$ ), the difference was however not significant $(\mathrm{P}>0.05)$. Estradiol, Testosterone and Progesterone plasma levels in DLS group rose significantly from day 9 to day $11 \mathrm{PP}(+44.4 \%,+59.2 \%$ and $+82 \%$, respectively, $\mathrm{P}<0.01)$ compared to control group $(+6.7 \%,-3.9 \%$ and $+33.4 \%$, respectively, $\mathrm{P}>0.05)$. In contrast, cortisol plasma levels were not affected by the DLS treatment $(-12.4 \%$ for control, $\mathrm{P}>0.05$, and $14.4 \%$ for DLS group, $\mathrm{P}>0.05$ ). The percentage of "high progesterone syndrome" (P4>1ng/ml) was not different between groups (30 vs. $40 \%$, for DLS and C respectively, $\mathrm{P}>0.05$ ). The $48 \mathrm{~h}$ doe-litter separation acted as an efficacy oestrus inductor in primiparous lactating rabbits. This biostimulation method induced modifications to the steroidogenic activity of the ovary, particularly by enhancing the secretion of estrogens and testosterone, and consequently, by influencing positively the sexual behaviour of the does.

Key words: Reproduction, biostimulation, rabbit does, sexual receptivity, steroid hormone.

\title{
FEED INTAKE OF REPRODUCTIVE RABBIT DOES OF TWO POPULATIONS RAISED IN ALGERIAN CONDITIONS
}

\author{
Cherfaoui $\mathrm{Dj}^{\mathbf{1}^{*}}$, Berchiche $\mathrm{M}^{2}$ \\ ${ }^{1}$ Département des Sciences Biologiques, Faculté des Sciences Biologiques et Agronomiques, \\ Université Mouloud Mammeri, Tizi-Ouzou, Algérie. \\ ${ }^{2}$ Département des Sciences Agronomiques, Faculté des Sciences Biologiques et Agronomiques, \\ Université Mouloud Mammeri, Tizi-Ouzou, Algérie. \\ *Corresponding author: yadj_65@yahoo.fr
}

\begin{abstract}
The objective of this study was to evaluate feed intake of rabbit does from two populations raised in Algeria (local population does and white population does). Sixty nulliparous rabbit females, 30 of each population, submitted to a semi-intensive reproductive rhythm were controlled over 3 reproductive cycles, at the experimental farm of the University of Tizi-ouzou (Algeria). Feed intake (g/d), digestible energy intake (DE kcal/d), and live weight were measured in pregnant, lactating and pregnantlactating females. The feed intake and digestible energy intake were significantly higher in white does than in local ones both in pregnant, pregnant-lactating females $(+18,+10 \%$ respectively, $\mathrm{P}<0.001)$ and lactating does $(+9 \% ; \mathrm{P}=0.0011)$. The reproductive cycle had not a significant effect on feed intake but had influenced does live weight at mating. The feed intake sharply decreased for both females during the last week of pregnancy.The live weight was significantly higher for white does than for local ones, whatever the stage of the reproductive cycle $(\mathrm{P}<0.001)$.
\end{abstract}

Key words: Rabbit does, local, population, feed intake. 


\title{
OVULATION INDUCTION IN RABBIT DOES SUBMITTED \\ TO ARTIFICIAL INSEMINATION BY ADDING LECIRELIN \\ TO THE SEMINAL DOSE. PRELIMINARY RESULTS
}

\author{
Dal Bosco A. ${ }^{1}$, Cardinali R. ${ }^{1 *}$, Rebollar P.G. ${ }^{2}$, Millán P. ${ }^{2}$, Brecchia G. ${ }^{3}$, \\ Castellini C. ${ }^{1}$ \\ ${ }^{1}$ Dept. of Applied Biology, University of Perugia, Borgo XX Giugno 74, 06121 Perugia, Italy \\ ${ }^{2}$ Dept. of Animal Production. Universidad Politécnica de Madrid. Ciudad Universitaria s/n. \\ 28040 \\ Madrid. Spain \\ ${ }^{3}$ Department of Biopathological Science, Hygiene of Animal and Food Productions, University of \\ Perugia, Italy \\ *Corresponding author: rcardinali@inwind.it
}

\begin{abstract}
The aim of this study was to analyze the effect of intravaginal administration of lecirelin on ovulation induction in rabbit does. Eighty pluriparous does (Martini genetic strain) were submitted to AI using a seminal dose of $0.5 \mathrm{ml}$ containing about 10 million sperms. To stimulate ovulation, 4 homogeneous groups were submitted to different treatments: Control Group: $0.2 \mathrm{ml}$ intramuscular administration of lecirelin (Dalmarelin, Fatro ${ }^{\circledR}$ ); 0.2 Group: $0.2 \mathrm{ml}$ intravaginal administration of lecirelin; 0.6 Group: $0.6 \mathrm{ml}$ intravaginal administration of lecirelin; 2.0 Group: $2 \mathrm{ml}$ intravaginal administration of lecirelin. In groups receiving an intra-vaginal administration, 25 $\mathrm{g} / \mathrm{ml}$ Dalmarelin was diluted in the seminal dose using benzilic alcohol $(20 \mathrm{mg} / \mathrm{ml})$ as excipient. Blood samples were collected from all females, to determine $\mathrm{LH}$ prior (60, -30 and 0 minutes) and (30,60, 90, 120 and 180 minutes) after AI, and progesterone once a week for 4 weeks. After 7 days from AI, 10 does per group were euthanized in order to analyze the ovarian status. The does of control group showed a high LH peak after 30 minutes from AI; whereas intra-vaginal administration of 0.2 and $0.6 \mathrm{ml}$ determined a lower increase of LH blood concentration after 2 hours. The highest dose did not produce any LH or progesterone increase. The ovary status showed a higher number of corpora lutea in Control group $(\mathrm{P}<0.05)$, followed by 0.2 and 0.6 ones, whereas embryos were recorded only in Control and 0.2 groups. The unsuccessful of the other experimental groups could be ascribed to the negative effect of benzilic alcohol on seminal characteristic. Only $30 \%$ of 0.2 group does were pregnant and the prolificacy was $8 \mathrm{kits} / \mathrm{doe}$. Compared to the control group, the progesterone concentration in pregnant does showed lower value in 0.2 group. In conclusion, in spite of the obtained results, it will be necessary to test different Dalmarelin formulations (lower volume, different excipient) to recommend the minimal dose to inject intravaginally for inducing ovulation.
\end{abstract}

Key words: Rabbit doe, ovulation induction, Lecirelin. 


\title{
MAJOR PROTEINS OF THE SEMINAL PLASMA OF NEW ZEALAND WHITE RABBITS AND ASSOCIATION WITH SEMEN CRITERIA
}

\author{
Arruda-Alencar, J.M. ${ }^{1}{ }^{*}$, Viana-Neto, A.M. ${ }^{1}$, Souza, C.E.A. ${ }^{1}$, Martins, J. A. M. ${ }^{1}$, \\ Moreno, F. B. ${ }^{2}$, Moreira, A. C. O. ${ }^{2}$, Guerreiro, M. E. F. ${ }^{1}$, Moura, A. A. ${ }^{1}$ \\ ${ }^{1}$ Dept. of Animal Science, Federal University of Ceará, Av. Mister Hull, s/n., Campus do Pici, 60 \\ 021-960, Fortaleza-CE, Brazil. \\ ${ }^{2}$ School of Pharmacy in University Fortaleza, Av. Washington Soares, 1321, Edson Queiroz, 60 \\ 811-905, Fortaleza-CE, Brazil. \\ *Corresponding author: josyarruda@gmail.com
}

\begin{abstract}
In rabbits, there are only few studies relating rabbit seminal plasma (SP) proteins and semen criteria and all those have been conducted in temperate regions. Therefore, information on the proteome of rabbit seminal plasma is crucial for the understanding on how these proteins regulate sperm attributes. The objective of this research was to describe the identities of the major rabbit seminal plasma proteins and associations between protein spots and semen criteria. Semen samples from 12 mature New Zealand White rabbit bucks were collected and evaluated, and SP was subjected to 2Delectrophoresis. Major protein spots were identified by mass spectrometry. Correlation coefficients were calculated to estimate associations between spot intensities and semen traits. Rabbit bucks ejaculated an average of $363.5 \pm 69.7$ million sperms, with $82.0 \pm 6.3 \%$ motile cells, vigor of $3.8 \pm 0.2$ and $67.8 \pm 4.1 \%$ of morphologically normal cells. Most spermatozoa $(56.5 \pm 4.2 \%)$ had both intact acrosome and functional membrane. On average, each seminal plasma protein map had $244.3 \pm 47.2$ spots, with 63 consistently present on all gels, representing $62.7 \pm 7.1 \%$ of the combined intensity of all spots. The seven major spots of the gels, representing $37.8 \pm 4.1 \%$ of all spot intensities were identified as Annexin 5, while a single spot matched a zeta globin-like protein. Annexin 5 spot intensities were positively associated with semen criteria, including sperm vigor, concentration, and morphology, and negatively related to the percentage of sperm with head abnormalities. Zeta globin-like spot, in turn, was correlated with the percentage of cells with both membrane and acrosome damaged. Associations among protein spots and semen traits suggest that, in rabbits, seminal proteins are involved in the regulation of important aspects of sperm function.
\end{abstract}

Key words: Rabbits, seminal plasma, protein profile, semen.

\section{PRODUCTIVITY AND BODY COMPOSITION OF RABBIT DOES SUBMITTED TO THREE BREEDING SYSTEMS}

\author{
Theau-Clément M. ${ }^{1 *}$, Weissman . $^{2}$, Davoust C. $^{2}$, Galliot P. ${ }^{3}$, Souchet $C_{.}{ }^{3}$, \\ Bignon L. ${ }^{3}$, Fortun-Lamothe $\mathrm{L}$ \\ ${ }^{1}$ INRA, UR631 SAGA, F-31326 Castanet-Tolosan, France
}


${ }^{2}$ INZO, Rue de l'Eglise, BP 50019, 02407 Chierry Cedex, France

${ }^{3}$ ITAVI, 28, rue du Rocher 75008, Paris, France

${ }^{1}$ INRA, UMR1289 TANDEM, F-31326 Castanet-Tolosan, France

*Corresponding author: Michele.Theau-Clement@toulouse.inra.fr

\begin{abstract}
The aim of this study was to compare 3 rabbit breeding systems on the performance of 332 females during 4 consecutive cycles. An intensive system (group 35; reproduction rhythm: $\mathrm{RR}=35$ days, first insemination $\mathrm{AI}_{1}=20.6$ weeks, weaning age: $\mathrm{WA}=32$ days) was compared to a semi-intensive system (group $42 ; \mathrm{RR}=42$ days, $\mathrm{AI}_{1}=19.6$ weeks, $\mathrm{WA}=35$ days) and an extensive one (group 49; $\mathrm{RR}=49$ days, $\mathrm{AI}_{1}=16.6$ weeks, WA=30 days). The productivity measured at 28 days $(3.5,4.2$ and $4.6 \mathrm{~kg} / \mathrm{AI}$, respectively for groups 35, 42 and 49), at 63 days post partum (30,38 and $42 \mathrm{~kg} /$ female for 4 cycles) and the total body energy were significantly increased $(45.4,46.8$ and $49.5 \mathrm{MJ}$, for groups 35 , 42 and 49 , respectively) when the reproductive rhythm decreased ( $\mathrm{P}<0.001)$. It must be underlined that kits mortality before and after weaning decreased when the reproduction rhythm decreased (11.4, 7.3, and 1.9\% and 18.3, 15.3 and 10.6\%, for groups 35, 42 and 49 , respectively, $\mathrm{P}<0.05)$. The yearly productivity by doe was 79,83 and $78 \mathrm{~kg}$ respectively. But only an analysis of economical, environmental and social performance will allow comparing the sustainability of these 3 production systems.
\end{abstract}

Key words: Rabbit, Breeding system, Productivity, Body composition, Growth.

\title{
EFFECTS OF A MODULATION OF THREE RABBIT BREEDING SYSTEMS ON REPRODUCTIVE PERFORMANCE AND YOUNG GROWTH
}

\author{
Theau-Clément M. ${ }^{1 *}$, Galliot . $^{2}$ Souchet $\mathrm{C}^{2}{ }^{2}$, Bignon L. ${ }^{2}$, Fortun-Lamothe $\mathrm{L}^{3}$ \\ ${ }^{1}$ INRA, UR631 SAGA, F-31326 Castanet-Tolosan, France \\ ${ }^{2}$ ITAVI, 28, rue du Rocher 75008, Paris, France \\ ${ }^{3}$ INRA, UMR1289 TANDEM, F-31326 Castanet-Tolosan, France \\ *Corresponding author: Michele.Theau-Clement@toulouse.inra.fr
}

\begin{abstract}
The aim of this study was to test on 292 rabbit does during 2 reproductive cycles $\left(5^{\text {th }}\right.$ and $6^{\text {th }}$ insemination), the consequences of a modulation of breeding practices. Three rabbit breeding systems were defined $(35,42$ and 49) varying in reproductive rhythm (35, 42 or 49 days, respectively), age at weaning (32, 35 or 30 days, respectively) and age at slaughter $(63,70$ or 70 days, respectively). Females were allocated to four groups in which the system changed (from the $1^{\text {st }}$ to the $4^{\text {th }} \mathrm{AI}=$ initial system) to another (from the $5^{\text {th }}$ to the $6^{\text {th }} \mathrm{AI}=$ modulation), before returning to the initial system $\left(7^{\text {th }} \mathrm{AI}\right)$. Does of group 35-42-35 were inseminated from $\mathrm{AI}_{1}$ to $\mathrm{AI}_{4}$ every 35 days and for 2 following cycles every 42 days, before returning to a 35 system before the $7^{\text {th }} \mathrm{AI}$. Does of group 42-35-42 were inseminated from $\mathrm{AI}_{1}$ to $\mathrm{AI}_{4}$ every 42 days and for the 2 following cycles every 35 days, before returning to a 42 system before the $7^{\text {th }}$ AI. Does of group 42-49-42 were inseminated from $\mathrm{AI}_{1}$ to $\mathrm{AI}_{4}$ every 42 days and for the 2
\end{abstract}


following cycles every 49 days, before returning to a 42 system before the $7^{\text {th }}$ AI. Does of group 49-42-49 were inseminated from $\mathrm{AI}_{1}$ to $\mathrm{AI}_{4}$ every 49 days and for the 2 following cycles every 42 days, before returning to a 49 system before the $7^{\text {th }}$ AI. Because of poor reproductive performance in the 35 system (despite a high growth of kits before weaning due to a more energetic diet of does), a sudden change from a 35 system to a 42 one significantly increased productivity at 63 days from 4.23 to 6.92 $\mathrm{kg} / \mathrm{AI}$. Conversely, the 42 system was not very sensitive to an intensification (group 42-35-42) or an extensification (42-49-42) of one week. Similarly, an intensification of one week of the 49 system (group 49-42-49) did not influence the productivity of rabbits. The consequences of a return to the initial system were weak but deserve to be tested over a longer period.

Key words: Rabbit, breeding system, flexibility, reproductive performance, growth.

\title{
EFFECTS OF THREE DIFFERENT CRYOPROTECTANTS ON OXIDATIVE STRESS OF RABBIT SEMEN DURING CRYOPRESERVATION
}

\author{
Yinghe Qin*, Cao J. \\ College of Animal Science and Technology, China Agricultural University \\ NO.2 Yuanmingyuan West Road, Haidian District, Beijing, 100193 \\ *Corresponding author: qinyinghe@ cau.edu.cn
}

\begin{abstract}
Glycerol, DMSO and acetamide are three cryoprotectants commonly used in the process of cryopreservation of rabbit semen. In this study, these three cryoprotectants with concentration of $4 \%$ were tested for their effect on oxidative stress of rabbit sperm. After thawing, the oxidative stress was evaluated by five indicators: level of carbonyl groups and malondialdehyde, activity of superoxide dismutase (SOD), glutathione reductase (GR) and glutathione peroxidase (GSHPX). The results showed that glycerol provided the lowest protection to GR $(\mathrm{P}<0.05)$ and SOD $(\mathrm{P}<0.01)$ activity. While acetamide provided lowest protection to $\mathrm{GR}(\mathrm{P}<0.01)$, the performance of DMSO was between those of glycerol and acetamide. None of the three cryoprotectants could provide enough protection to protein oxidation and glutathione peroxidase.
\end{abstract}

Key words: Rabbit, sperm cryopreservation, oxidative stress, carbonyl groups, superoxide dismutase (SOD).

\section{REPRODUCTIVE PERFORMANCE OF RABBIT DOES BY ADDING LEUPRORELIN IN SEMEN TO INDUCE OVULATION}

\author{
Zhang Y.Q., Yinghe Qin* \\ College of Animal Science and Technology, China Agricultural University, \\ NO.2 Yuanmingyuan West Road, Haidian District, Beijing, 100193, P.R.China \\ *Corresponding author: qinyinghe@ cau.edu.cn
}




\begin{abstract}
This trial aimed to evaluate the reproductive performance of rabbit does by adding leuprorelin, a GnRH analogue, in semen to induce ovulation as an alternative method of intramuscular injection. A total of 529 healthy does of line HYLA, including 228 nulliparous strain $\mathrm{C}$ does and 301 multiparous strain $\mathrm{D}$ does, were divided into five groups randomly and equally as following: (1) L5: adding $5 \mathrm{~g} /$ doe leuprorelin to the seminal dose. (2) L10: adding $10 \mathrm{~g} /$ doe leuprorelin to the seminal dose. (3) L15: adding $15 \mathrm{~g}$ /doe leuprorelin to the seminal dose. (4) PC: intramuscularly injecting with $1 \mathrm{~g}$ /doe buserelin. (5) NC: control group not performed ovulate induction. We collected blood samples from 12 rabbit does each group (6 Strain C, 6 Strain D), respectively, at the time of 0,1 and 2 hour relative to AI, for determination of the changes of FSH and LH concentrations. Fertility of L10 and L15 were significantly higher than that of NC group (L10: 57.69\%; L15: 64.55\%; NC: 30.48\%), and comparable to PC (PC: 63.46\%); while fertility of L5 (49.06\%) was significantly lower than that of L15 and PC. Prolificacy parameters were not significantly influenced by the ovulation induction treatments between five groups $(\mathrm{P}>0.05)$. Due to the induction treatment, significant change of plasma FSH concentration with time both in L15 and $\mathrm{PC}$ groups was found $(\mathrm{P}<0.05)$. Similarly, there were significant changes of plasma LH concentration with time in L5, L15 and PC groups $(\mathrm{P}<0.05)$. Though the trend of increase of LH concentration with time in L10 group was found, it was not significant $(\mathrm{P}>0.05)$. These changes, both in FSH and LH levels could explain the better reproductive performances obtained in the L15 and PC groups. Taking together, our study confirmed that adding leuprorelin into the semen could be used to obtain the fertility comparable to those with the general intramuscular injection of buserelin for the ovulation induction in rabbit does. Nevertheless, the injected dose of leuprorelin must be more than $10 \mathrm{~g} / \mathrm{doe}$.
\end{abstract}

Key words: Leuprorelin; Semen; Rabbit; Artificial insemination; Ovulation induction

\title{
INFLUENCE OF COAT COLOUR, SEASON AND PHYSIOLOGICAL STATUS ON REPRODUCTION OF RABBIT DOES OF AN ALGERIAN LOCAL POPULATION.
}

\author{
Mazouzi-Hadid F. ${ }^{1}$, Lebas F. ${ }^{2}$, Berchiche M. $^{3}$, Bolet G. $^{4}$ \\ ${ }^{1}$ University of Tizi-Ouzou, Department of Biology, Faculty of Sciences of Biology and Agronomy (FSBA) \\ 15000 Tizi-Ouzou, Algeria \\ ${ }^{2}$ Cuniculture, 87A Chemin de Lasserre, 31450 Corronsac, France \\ ${ }^{3}$ University of TIZI-OUZOU, Department of Agronomy, Faculty of Sciences of Biology and Agronomy \\ (FSBA) \\ 15000 TIZI-OUZOU, Algeria \\ ${ }^{4}$ INRA, UR631 SAGA, F-31326 Castanet-Tolosan, France \\ Corresponding author: mazouzi_hadid@yahoo.fr
}

\begin{abstract}
In Algeria, rabbit meat production is low. It is mainly obtained in small farms with rabbits from local populations whose productivity and growth are rather low, but which
\end{abstract}


are well adapted to local environment. Among them, farmers use to prefer white animals, with the albino or himalayan alleles of gene C. The objective of this experiment was to verify the validity of this preference for white rabbit does during a large enough period to check also the effect of season. From September 2006 to June 2010, reproduction data from 209 females (138 white and 71 coloured) mated by 51 males (35 white and 16 coloured) were recorded. There was no effect of sire colour and no interactions between coat colour, season and physiological status of does. There was a significant relationship between coat colour (white vs. coloured) on most reproductive traits, except receptivity and fertility (and subsequently interval between kindling), in favour of coloured females. Litter size was higher by 0.63 kits born $(\mathrm{P}=0.045), 1.25$ born alive $(\mathrm{P}<0.001)$ and 1 weaned $(\mathrm{P}=0.003)$. There was a highly significant effect of season on all measured traits. Receptivity, fertility and prolificacy were significantly higher before the hot period; in summer, reproductive performances were depressed, but no more than during the following period, which confirms the good adaptation of this local population to hot conditions. We can also conclude that there is in this population an unfavourable genetic association between reproduction and albino and himalayan alleles of $\mathrm{C}$ gene which has to be confirmed and explored more in details.

Key words: Algeria, Rabbit, Reproduction, Coat colour, Season.

\title{
FIELD TEST OF THE EFFECTIVENESS OF RABBIT SEMEN EXTENDER MRA-bit ${ }^{\circledR}$ INCORPORATING GnRH ANALOGUE.
}

\author{
Quintela L.A ${ }^{1}$, Barrio M. ${ }^{1}$, Prieto C. ${ }^{2}$, Gullón $\mathbf{J}^{2 *}$, Vega $\mathrm{MD}^{1}$, Sánchez M. ${ }^{2}$, García \\ $\mathbf{N}^{2}$ Becerra J.J. ${ }^{1}$,Peña A.I. ${ }^{2}$, Herradón P.G. ${ }^{2}$, Hernandez-Gil R. ${ }^{3}$ \\ ${ }^{1}$ Reproduction and Obstetrics. University of Santiago de Compostela, Lugo, Spain. \\ ${ }^{2}$ COGAL, S. Coop. Gallega 36530 Rodeiro. PONTEVEDRA \\ ${ }^{3}$ Kubus, S.A. P.I. Európolis. Calle Varsovia, 20. 28232 Las Rozas de Madrid. \\ "Corresponding author: cogalvet@cogal.net
}

\begin{abstract}
The aim of this work was to evaluate the efficacy of MRA-bit ${ }^{\circledR}$ rabbit semen extender based on reproductive performance of high number of lactating rabbit does inseminated under farm conditions. 2307 commercial hybrid multiparous lactating does (Hyplus strain PS19) belonging to four industrial rabbit farms (farm 1: 574 does; farm 2: 624 does; farm 3: 519 does and farm 4: 590 does) located in Galicia, Spain, were used. All the does were treated hormonally to synchronise the oestrus. The

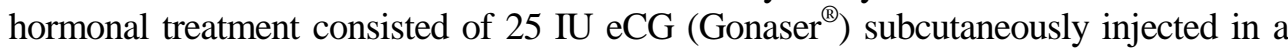
volume of $1 \mathrm{ml}, 48 \mathrm{~h}$ before AI. The 2307 does were randomly divided in 2 equal groups in each farm. All the does were inseminated during 3 successive cycles, at 42 days intervals. At the moment of AI, the 2 groups inseminated with the same heterospermic pool between treatments in different farms, received different hormonal treatments for ovulation induction: 1) control group: $0.2 \mathrm{ml}$ of Lecirelina (Dalmarelin ${ }^{\circledR}$ ) were intramuscularly injected immediately after AI; 2) experimental group: $0.5 \mathrm{ml}$ of
\end{abstract}


semen diluted with MRAbit ${ }^{\circledR}$ was inseminated. Despite different results between farms, neither kindling rate nor prolificacy was influenced by the ovulation method. In conclusion, on multiparous lactating rabbit does prepared for AI (light stimulation + eCG injection), MRA-bit ${ }^{\circledR}$ allows eliminating GnRH injection without affecting reproductive performance.

Key words: Rabbit, artificial insemination, ovulation induction.

\title{
SECRETION OF 17B-ESTRADIOL AT MATING TIME IN RABBIT DOES ACCORDING TO THE SEASON, THE RECEPTIVITY, THE PHENOTYPE AND THE LITTER SIZE
}

\author{
Mazouzi-Hadid F. ${ }^{1}$, Berchiche M. ${ }^{2}$, Theau-Clément M. ${ }^{3}$ \\ ${ }^{1}$ University of Tizi-Ouzou, Department of Biology, Faculty of Sciences of Biology and Agronomy (FSBA) \\ 15000 Tizi-Ouzou, Algeria \\ ${ }^{2}$ University of Tizi-Ouzou, Department of Agronomy, Faculty of Sciences of Biology and Agronomy (FSBA) \\ 15000 Tizi-Ouzou, Algeria \\ ${ }^{3}$ INRA, UR631 SAGA, F-31326 Castanet-Tolosan, France \\ Corresponding author: mazouzi_hadid@yahoo.fr
}

\begin{abstract}
This study was carried on Algerian local population rabbit does, white dress with red eyes (albino) and colored dress with black eyes, raised in natural conditions, natural mating and semi-intensive rhythm. The aim of this study was to determine under these conditions, the plasmatic rates of $17 \beta$-estradiol (E2) and seasonal variations in rabbit does which accept or refuse mating. At each season, blood samples were taken from 24 does, just after the presentation to the buck, half accepting mating and half refusing it. The further litter size at birth was registered from females witch accept mating. Our results over one year, show that the colored does which accept mating have an estradiol rate significantly higher than those which refuse it $(21.83 \mathrm{vs} 14.84 \mathrm{pg} / \mathrm{ml}$ respectively, $\mathrm{P}<0,001)$. The season significantly influences estradiol secretions with a maximal rate in winter and minimal in autumn $(22.89 \mathrm{vs} 15.90 \mathrm{pg} / \mathrm{ml}$ respectively, $\mathrm{P}<0.05)$. Colored does have higher variations of plasmatic estradiol. These results evidence the relationship between the estradiol rate, sexual receptivity and the phenotype of does; they show too the influence of environmental conditions, particularly the season, on the rate of plasmatic estradiol and consequently on the rabbit does sexual receptivity. It doesn't appear any significant correlation between rate of E2 at the moment of mating and the further litter size at birth.
\end{abstract}

Key words: $17 \beta$-estradiol, rabbit does, phenotype, season, litter size.

\section{PERFORMANCE OF RABBIT DOES IN CAGES WITH OR WITHOUT ELEVATED PLATFORM OR PLASTIC FOOTREST}

\author{
Mikó A. ${ }^{1}{ }^{*}$, Szendr Zs. ${ }^{1}$, Gerencsér Zs. ${ }^{1}$, Radnai I. ${ }^{1}$, Odermatt M. ${ }^{2}$, Nagy I. ${ }^{1}$, \\ Matics Zs.
}


${ }^{1}$ Kaposvár University, Faculty of Animal Science, 7401 Kaposvár, POBox 16, Hungary

${ }^{2}$ Olivia Ltd, 6050 Lajosmizse, Mizse 94, Hungary

*Corresponding author: miko.annamaria@ke.hu

\begin{abstract}
The aim of the study was to compare the production of does housed in conventional flat-deck cages (with or without footrest) or in two types of enlarged cages equipped with platform (wire-mesh or plastic-mesh platform). Altogether 108 crossbred female rabbits were randomly sorted to four groups of different cage types: $\mathrm{CN}$ : common wire-mesh flat-deck cage $(86 \times 38 \times 30 \mathrm{~cm})(\mathrm{n}=30)$; $\mathrm{CF}$ : cage similar to the $\mathrm{CN}$ cage but with footrest $(\mathrm{n}=30)$; ECPF: enlarged cage $(102.5 \times 38 \times 61 \mathrm{~cm})$ with wire-mesh platform, the cage floor was wire-mesh with a plastic footrest and the size of platform was $28.5 \times 38 \mathrm{~cm}(\mathrm{n}=24)$. EECP: extra enlarged cage $(102.5 \times 52.5 \times 97 \mathrm{~cm})$ with plastic-mesh platform, the cage floor was wire-mesh and the size of platform was 41.5 x $52.5 \mathrm{~cm}(\mathrm{n}=24)$. The results of five subsequent productive cycles were evaluated. Sore hock on the hind legs was examined at each insemination. Pregnancy rates and the litter size (total, alive, at 21 and 35 days of age) of the groups were not different. The weight of does at kindling was the highest in CF group and the lowest in the $\mathrm{CN}$ cage $(\mathrm{P}<0.001)$. Significant differences in litter- and individual weights were observed. In the enlarged cages the litter weight at 21 days was significantly higher than that of $\mathrm{CN}$ group (3576 and 3516g vs $3291 \mathrm{~g}$, resp., $\mathrm{P}<0.001$ ). For the litter weight at day 35 significant differences were only recorded between the EECP and $\mathrm{CN}$ does $(\mathrm{P}<0.05)$. Individual body weights at 21 and 35 days were also higher in enlarged cages than that in the small cages $(\mathrm{P}<0.001)$. The does with severe sore hock had lower kindling rate. Both plastic platform and footrest had positive effect on the prevention of footpad injuries. The incidence and severity of sore hock were the lowest in EECP group and the highest in $\mathrm{CN}$ cages. Based on the larger individual and litter weight and lower incidence of sore hock, housing of rabbit does in enlarged cages with platform seems advantageous. The presence of a footrest to standard cages had only a positive effect on the incidence and severity of sore hocks.
\end{abstract}

Key words: Rabbit does, housing, platform, footrest, reproductive performance.

\title{
DESCRIPTIVE ANALYSIS OF RABBIT SEXUAL RECEPTIVITY AND ITS SOURCES OF VARIATION
}

\author{
Theau-Clément M. ${ }^{1}$, Monniaux D. ${ }^{2}$, Tircazes A. ${ }^{1}$, Balmisse E. ${ }^{3}$, Bodin L. ${ }^{1}$, Brun \\ J.M. ${ }^{1}$ \\ (1) INRA, UR631 SAGA, F-31326 Castanet-Tolosan, France \\ ${ }^{(2)}$ INRA, UMR 6175 PRC, F-37380 Nouzilly, France \\ ${ }^{(3)}$ INRA, UE PECTOUL, F-31326 Castanet-Tolosan, France \\ *Corresponding author: Michele.theau-clement@toulouse.inra.fr
}




\begin{abstract}
This study aimed at evaluating on a large scale, the variability between rabbit does of estrus behavior, and at identifying factors influencing this behavior in the context of a selection experiment. The experiment spanned two generations (G0 and G1) with 2 batches at each generation (B1 and $\mathrm{B} 2)$. The founder generation $(\mathrm{F}=\mathrm{G} 0)$ was made of 140 rabbit does and the G1 generation was made of 2 lines with 70 does each: a low (L) and a high $(\mathrm{H})$ receptivity line. Rabbit does were tested for expression of lordosis behavior in the presence of a buck during 18 successive tests ( 3 tests/week). On the basis of 4716 receptivity tests from 275 females, the average receptivity was $56.6 \%$ and $18.2 \%$ of does expressed a low receptivity $(<34 \%), 50.7 \%$ a medium one and $33.1 \%$ a high one $(>66 \%)$. This result confirms the high variability of sexual receptivity of non-lactating rabbit does maintained without any biostimulation or hormonal treatment. The contribution of females to the total variance was $20.0 \%$ whereas only $1.2 \%$ for bucks. The percentage of receptive does was not significantly different between generations ( 57.5 vs $56.5 \%$ respectively for G0 and G1) and the line within generation $(\mathrm{F}(\mathrm{G} 0)$ : $57.5, \mathrm{~L}(\mathrm{G} 1)$ : $57.7, \mathrm{H}(\mathrm{G} 1)$ : $55.4 \%)$. This result indicates the lack of response to selection. In contrast, the average receptivity was significantly higher in B1 than in B2 (61.5 vs 52.5\%). Two hypotheses (season effect or buck tiredness) were discussed. Differences between lines in the pattern of change in receptivity could have a genetic origin. An effect of the test operator was evidenced. The occurrence of pseudo-pregnancy during the tests as a consequence of uncontrolled ovulations could have interfered with receptivity and the tests results. Further studies would be necessary to verify that sexual behavior is not sensitive to a residual effect of previous tests.
\end{abstract}

Key words: Rabbit, sexual receptivity, estrus behavior, divergent selection. 


\title{
DRIED CHICORY PULP AS FIBRE SOURCE IN FATTENING RABBIT DIETS
}

\author{
Guermah H. ${ }^{1 *}$, Maertens L. ${ }^{2}$ \\ ${ }^{1}$ Department of Agronomic Science, University M.Mammeri of Tizi-ouzou, BP 17, RP 15000, Algeria \\ ${ }^{2}$ Institute for Agricultural and Fisheries Research, Animal Sciences Unit, Scheldeweg 68, \\ B-9090 Melle, Belgium \\ *Corresponding author guermahocine@yahoo.fr
}

\begin{abstract}
One-hundred-ninety-two hybrid weanlings of 32 days were fed one of 4 iso-energetic $(9.65 \mathrm{MJ} / \mathrm{kg})$ and iso-nitrogeneous $(16.4 \% \mathrm{CP})$ diets: a low dietary digestible fibre content (Control diet), a high digestible fibre diet (Beet pulp diet) and 2 diets with chicory pulp (CP). Chicory pulp was introduced (10 and 20\%) in the fattening diet mainly at the expense of beet pulp, as an alternative source of soluble fibre. Each dietary treatment consisted of 12 replicates of 4 rabbits. Weight gain was high (average of $54 \mathrm{~g} /$ day) and comparable for the CP diets, control and the beet pulp diet. However, feed conversion ratio was improved with the diet containing $20 \%$ chicory pulp compared to the control diet. Mortality was low and not influenced by the dietary treatment. It is concluded that chicory pulp is a good alternative digestible fibre source in balanced diets for rabbits and can be used at least till $20 \%$.
\end{abstract}

Key words: Rabbit, chicory pulp, digestible fiber, dietary inclusion.

\section{EFFECT OF DIETARY STARCH LEVELS ON PERFORMANCE AND DIGESTIBILITY OF GROWING RABBITS}

\author{
El-Tahan H.M. ${ }^{1 *}$, Amber Kh. ${ }^{2}$, Morsy W.A. ${ }^{1}$ \\ ${ }^{1}$ Animal Production Research Institute, Agricultural Research Center, Ministry of Agriculture, Dokki, \\ Gizza, Egypt \\ ${ }^{2}$ Department of Poultry Productions, Faculty of Agriculture, Kafrelsheikh University, Egypt \\ *Corresponding author: Tahan_Hossam@yahoo.com
}

\begin{abstract}
The aim of this study was to evaluate the effects of different levels of starch in diets of growing rabbit on the growth performance and digestibility coefficients. Sixty NZW rabbits were divided randomly into three experimental groups of 20 rabbits each (10 males +10 females) of 5 weeks of age with an average live body weight of $(637.5 \pm$ $6.5 \mathrm{~g}$ ), were used in this study. Rabbits were equal with respect to body weight and sex. The following 3 diets were obtained: control (17.30\% starch and 3.23\% EE), High Starch $(22.11 \%$ starch and $1.37 \%$ EE) and Low Starch (12.30\% starch and 5.13\% EE). All diets were nearly iso-nitrogenous, iso-caloric and contained similar levels of crude
\end{abstract}


fiber and micro elements. Results indicated that rabbits fed diets containing high starch level had significantly highest body weight, while those fed diet with low starch level had the lowest body weight. But no differences were observed with the control diet. Rabbits fed high starch and control diet recorded a higher daily weight gain $(28.7 \mathrm{~g})$ than those fed low starch diet $(23.8 \mathrm{~g} / \mathrm{d}, \mathrm{P}<0.001)$. Rabbits fed high starch diet had the best feed conversion ratio (FCR) (3.37), while the worst FCR was observed with those fed low starch diet $(3.63 ; \mathrm{P}<0.01)$. The apparent digestibility of DM, OM, CP and GE significantly increased (about $8 \%$ for DM, OM and GE, and 4\% CP) with the starch level, whereas digestibility coefficients of EE and NFE significantly decreased (about $10 \%, \mathrm{P}<0.001$ ) by increasing the levels of starch in experimental diets. While, no significant differences could be observed in CF digestibility coefficient.

Growth performance and nutrient digestibility coefficients were significantly reduced except digestibility coefficients of EE and NFE in rabbits fed low starch diet, as compared with other starch levels in iso-caloric and iso-fibrous diets .Thus it could be concluded that feeding high starch diet (up to 22.11\%) permitted to obtain the best growth performance and digestibility coefficients in growing rabbits.

Key words: Growing rabbits, starch, growth performance, digestibility.

\title{
NUTRITIVE VALUE OF FRESH SULLA (Hedysarum flexuosum) AS A SOLE FEED FOR GROWING RABBITS
}

\author{
Kadi S.A. ${ }^{1}$, Belaidi-Gater N. ${ }^{2}$, Oudai H. ${ }^{2}$, Bannelier C. ${ }^{3,4,5}$, Berchiche M. ${ }^{1}$, \\ Gidenne T. ${ }^{3,4,5}$ \\ ${ }^{1}$ Faculté des Sciences Biologiques et Sciences Agronomiques, Université M. MAMMERI, Tizi-Ouzou, Algérie \\ ${ }^{2}$ CFPA de Mechtras, 15440 Tizi-Ouzou, Algérie \\ ${ }^{3}$ INRA, UMR1289 Tissus Animaux Nutrition Digestion Ecosystème et Métabolisme, F-31326 Castanet-Tolosan, \\ France \\ ${ }^{4}$ Université de Toulouse, INPT ENSAT, UMR1289 Tissus Animaux Nutrition Digestion Ecosystème et \\ Métabolisme, \\ F-31326 Castanet-Tolosan, France \\ ${ }^{5}$ ENVT, UMR1289 Tissus Animaux Nutrition Digestion Ecosystème et Métabolisme, F-31076 Toulouse, France \\ *Corresponding author: kadisiammar@yahoo.fr
}

\begin{abstract}
For determining the nutritive value of Sulla (Hedysarum flexuosum), containing organic matter (OM) 84.3; crude protein (CP) 22.5; neutral detergent fibre (NDF) 49.0; acid detergent fibre (ADF) 34.3; acid detergent lignin (ADL) $10.8 \%$ on DM basis, sixteen rabbits of Algerian white local population (individually caged) weaned at $35 \mathrm{~d}$ old (mean body weight: $541 \pm 29 \mathrm{~g}$ ) were fed ad libitum fresh green Sulla as a sole feed during five weeks. The faecal digestibility of the Sulla was measured between 49 and 53 days of age on 12 rabbits. The digestibility of DM, OM, CP, NDF and ADF was $52.3 ; 52 ; 64.4 ; 35.5$ and $28 \%$, respectively. The average DM intake reached $114.2 \mathrm{~g} / \mathrm{d}$ $\left(125.6 \mathrm{~g} / \mathrm{kg} \mathrm{LW}^{0.75}\right)$, while the digestible CP intake was $17.7 \mathrm{~g} / \mathrm{d}\left(19.5 \mathrm{~g} / \mathrm{kg} \mathrm{LW}^{0.75} \mathrm{~d}\right)$ and that of digestible energy (DE) was $1.05 \mathrm{MJ} / \mathrm{d}\left(1.15 \mathrm{MJ} / \mathrm{kg} \mathrm{LW}^{0.75}\right)$. These
\end{abstract}


digestible nutrients intake allowed to meet not only the maintenance requirement, but also to support a growth rate of $18.9 \mathrm{~g} / \mathrm{d}$. The digestible energy concentration of the fresh Sulla was $9.2 \pm 0.15 \mathrm{MJ} / \mathrm{kg} \mathrm{DM}$, while the digestible crude protein concentration was $145 \pm 1.8 \mathrm{~g} / \mathrm{kg}$ DM. Harvested at young stage of growth, Sulla could be considered as a good and balanced fibre source for the growing rabbit and comparable to other good quality forages such as alfalfa and ryegrass.

Key words: Growing rabbit, digestibility, fresh Sulla (Hedysarum flexuosum), growth performance, nutritive value.

\title{
NUTRITIVE VALUE OF COMMON REED (Phragmites australis) LEAVES FOR RABBITS
}

\author{
Kadi S.A. , Ouendi M. ${ }^{1}$, Slimani M. ${ }^{2}$, Selmani K. ${ }^{2}$, Bannelier C. ${ }^{3,4,5}$,Berchiche \\ M. ${ }^{1}$, Gidenne T. ${ }^{3,4,5}$ \\ ${ }^{1}$ Faculté des Sciences Biologiques et Sciences Agronomiques, Université M. MAMMERI, Tizi-Ouzou, Algérie \\ ${ }^{2}$ CFPA de Mechtras, 15440 Tizi-Ouzou, Algérie \\ ${ }^{3}$ INRA, UMR1289 Tissus Animaux Nutrition Digestion Ecosystème et Métabolisme, F-31326 Castanet, \\ Tolosan, France \\ ${ }^{4}$ Université de Toulouse, INPT ENSAT, UMR1289 Tissus Animaux Nutrition Digestion Ecosystème et \\ Métabolisme, F-31326 Castanet-Tolosan, France \\ ${ }^{5}$ ENVT, UMR1289 Tissus Animaux Nutrition Digestion Ecosystème et Métabolisme, F-31076 Toulouse, France \\ *Corresponding author: kadisiammar@yahoo.fr
}

\begin{abstract}
The nutritive value and potential use of sun-dried common reed (Phragmites australis) leaves "CRL", for the growing rabbit was studied by comparing 3 diets (regression method) containing an increasing incorporation of CRL: 0\% (control, CRL0), $15 \%$ (CRL15) and 30\% (CRL30) in substitution to the control diet (356 g NDF and $197 \mathrm{~g}$ $\mathrm{CP} / \mathrm{kg}$ ). Three groups of 37 rabbits (individually caged) were fed ad libitum the three diets from weaning ( $35 \mathrm{~d}$, mean weight: $722 \pm 142 \mathrm{~g}$ ) to $77 \mathrm{~d}$ of age. The faecal digestibility of the diets was measured between 42 and 46 days of age on 10 rabbits per group. Common reed leaves can be considered as a roughage since it contained $64 \%$ of NDF (38\% of ADF) and $10.2 \%$ of crude protein. The digestible energy (DE) content of CRL calculated by regression was null $(-1.8 \pm 0.29 \mathrm{MJ} / \mathrm{kg}$ as fed) that classed this roughage as a source of ballast, probably active for transit stimulation. The digestibility of crude protein reached $28.5 \%$, corresponding to a digestible crude protein concentration of $29.0 \pm 5.6 \mathrm{~g} / \mathrm{kg}$ as fed basis. Health status was not affected by the CRL incorporation rate. However, incorporation of CRL in feeds impaired the growth less than $10 \%$ (34.2 for CRL0 vs $31.4 \mathrm{~g} / \mathrm{d}$ for CRL15 and CRL30, from 35 to $77 \mathrm{~d}$ old) and feed conversion $16 \%$.
\end{abstract}

Key words: Growing rabbit, digestion, Reed leaves (Phragmites australis), growth performance, nutritive value. 


\title{
IMPACT OF A DIETARY FIBER DEFICIENCY ON THE CAECAL ECOSYSTEM OF THE YOUNG RABBIT. MODULATION BY YEAST PROBIOTICS.
}

\author{
Kimsé M. ${ }^{\text {*⿻弋 }}$, Combes S., Cauquil L., Fortun-Lamothe L., Bayourthe C., Gidenne T. \\ INRA, UMR1289 Tissus Animaux Nutrition Digestion Ecosystème et Métabolisme, F-31326 Castanet- \\ Tolosan, France \\ Université de Toulouse, INPT ENSAT, UMR1289 Tissus Animaux Nutrition Digestion Ecosystème et \\ Métabolisme, F-31326 Castanet-Tolosan, France \\ ENVT, UMR1289 Tissus Animaux Nutrition Digestion Ecosystème et Métabolisme, F-31076 Toulouse, \\ France \\ ${ }^{1}$ Université Abobo-Adjamé, UFR des Sciences de la Nature, Laboratoire de Biologie et de Cytologie \\ Animale, 02 BP 801 Abidjan 02, Côte d'Ivoire \\ * Corresponding author: Tel: +33 (0)5 612851 00; Fax : +33 (0)5 612853 19, kimsey_m@yahoo.fr
}

\begin{abstract}
The effect of a fiber deficiency combined with a live yeast dietary supplementation (Saccharomyces cerevisiae) was analyzed on the young rabbit cæcal ecosystem from 28 (weaning) to 58 days of age. A bifactorial experimental design (2x2) was used: fiber concentration in diet (fiber deficient "FD" = 9\% ADF vs 19\% ADF for control diet), and yeast supplementation $\left(10 \mathrm{~g} / \mathrm{kg}\right.$ Actisaf® yeast, i.e $\left.10^{7} \mathrm{CFU} / \mathrm{gDM}\right)$ or not. At 36 days of age, the cæcal $\mathrm{pH}$ was higher in FD groups (+0.3 units) than control. Ammonia $\left(\mathrm{NH}_{3}\right)$ level in cæcum at 58 days increased from 6.3 for control to $14.8 \mathrm{mmol} / \mathrm{l}$ for FD groups. Cæcal redox potential $\left(\mathrm{E}_{\mathrm{h}}\right)$, diversity and structure of bacterial communities (fingerprint method) were not affected by the dietary fiber level. The yeast supplementation had no significant effect on biotope $\left(\mathrm{pH}, \mathrm{E}_{\mathrm{h}}, \mathrm{NH}_{3}\right)$ and cæcal bacterial biocenosis (structure, diversity). However, the yeast supplementation tended to increase the bacterial biodiversity by $9 \%(\mathrm{P}=0.06)$ compared to the control.
\end{abstract}

Key words: Probiotics, yeast, rabbit, biotope, biocenosis, ecosystem.

\section{IMPACT OF USING PEA VINES AS NON- CONVENTIONAL FEEDSTUFF ON GROWTH PERFORMANCE OF RABBITS}

\author{
Fawzia A. Hassan ${ }^{1 *}$; G. H. Zaza ${ }^{1}$;. R. M. Ibrahim ${ }^{2}$, M. A. Ali $^{2}$ \\ ${ }^{1}$ Animal Production Research Institute, Agricultural Research Center, 12618. El- Dokki, Giza, Cairo, Egypt \\ ${ }^{2}$ Department of Animal Production, Faculty of Agriculture, Cairo University, Giza, Egypt \\ "Corresponding author: fawzia_amer@yahoo.com
}

\begin{abstract}
The aim of this work was to study the effect of partial and total substitution of clover hay by pea vines (PV) in rabbit diets and their effects on growth performance and fecal
\end{abstract}


digestibility of New Zealand White rabbit. Forty five rabbit, six weeks old with an average body weight $728.2 \mathrm{~g}$ were randomly divided into five groups. Each group consisted of three replicates (of three rabbits each). Results of growth trail revealed that $50 \%$ PV fed group achieved significantly $(\mathrm{P}<0.05)$ better LBW by $11.5 \%$, ADG by $18 \%$ and FCR by $4.1 \%$ compared with control group. Regarding to fecal digestibility's, the recorded values for control and 50\% PV diets were $64.99 \%$ vs. $69.25 \%$ for DM; $67.09 \%$ vs. $71.36 \%$ for OM.; 65.08 vs. $72.36 \%$ for CP.; 44.49 vs. $51.40 \%$ for $\mathrm{CF}$ and 73.28 vs. $75.31 \%$ for NFE, respectively. The same trend for fecal digestibility were significant found $(\mathrm{P}<0.05)$ between $75 \%$ compared with control group, being $64.99 \%$ vs. $67.59 \%$ for DM and $65.08 \%$ vs. $68.56 \%$ for CP, respectively. Rabbit group fed $50 \%$ PV recorded the highest values of DCP, TDN and DE in comparison with other experimental groups. It could be concluded that incorporation pea vines as non traditional fiber source in rabbit diets at 25, 50, 75 and 100\% has no negative effect on growth performance and digestibility of most of nutrients and nutritive values of tested diets.

Key words: Pea vines, rabbits, digestibility, growth.

\title{
PERFORMANCE OF GROWING RABBITS FED DIETS SUPPLEMENTED WITH SANGROVIT ${ }^{\circledR}$ IN INTERACTION WITH THE FEEDING PLAN
}

\author{
Teillet B. ${ }^{1}{ }^{*}$, Colin M. ${ }^{1}$, Lebas F. ${ }^{2}$, Alvensleben S.v. ${ }^{3}$, Bezille H. ${ }^{3}$, Prigent A.Y. ${ }^{4}$ \\ ${ }^{1}$ COPRI, Coat Izella, 29830 Ploudalmézeau, France \\ ${ }^{2}$ Association Cuniculture, 87A Chemin de Laserre, 31450 Corronsac, France \\ ${ }^{3}$ Phytobiotics Feed Additives, Wallufer Strasse 10a, 65343 Eltville, Germany \\ ${ }^{4}$ EARL 3L, Coat Izella, 29830 Ploudalmézeau, France \\ *Corresponding author: copri@wanadoo.fr
}

\begin{abstract}
Fattening rabbit mortality during the $50-60 \mathrm{~d}$ period is generally in relation with digestive troubles like diarrheas and enterocolitis. Out of the antibiotics, one of the solutions used to control this mortality is the feed restriction, which significantly decreases mortality, but simultaneously reduces growth rate. The feed additive Sangrovit $^{\circledR}$, is a natural product extracted from Macleaya cordata, plants belonging to the Papaveraceae family, which contains quarternary benzophenanthridine and protopine alkaloids (QBA PA) of which sanguinarine has the highest content. The QBA PA alkaloids as sanguinarine are phytoalexine substances produced by the plants to inhibit further growth of bacteria, fungi and viruses. The aim of the present study was to determine the effect of Sangrovit ${ }^{\circledR}$ on viability, growth and slaughter performance of fattening rabbit between weaning and slaughter time. A trial was carried out with an experimental design $3 \times 2$ with the dosage of Sangrovit ${ }^{\circledR}(0,40$ and $80 \mathrm{ppm}$ ) as the first factor and the feeding plan as the second factor (restricted feeding versus ad libitum feeding). Rabbits (1573) were distributed in 6 homogenous groups composed of 53 cages of 5 rabbits each, where they were fed from weaning to slaughtering. This work confirms that, without the additive, the feed restriction reduced
\end{abstract}


mortality (11.0 vs $17.7 \%$; $\mathrm{P}<0.05)$ and the feed conversion ratio (3.84 vs 4.06$)$ but also reduced growth rate (39.6 vs $43.1 \mathrm{~g} / \mathrm{d} ; \mathrm{P}<0.01)$. The addition of $40 \mathrm{ppm}$ of Sangrovit ${ }^{\circ}$ induced a significant reduction of mortality $(\mathrm{P}<0.05)$ but an unexplained late mortality erased the benefit. At the opposite, the dosage of $80 \mathrm{ppm}$ of Sangrovit ${ }^{\circledR}$ decreased significantly $(\mathrm{P}<0.05)$ the mortality in ad libitum conditions $(9.4 \%$ vs $17.7 \%)$. Whatever the dosage, Sangrovit ${ }^{\circledR}$ has no average effect on growth rate, feed efficiency or slaughter rate, but the lower mortality reduced the economical feed conversion ratio. This publication shows that the dosage of an additive is different according to the feeding plan. In conditions of feed restriction, the recommended dosage is $40 \mathrm{ppm}$. In ad libitum conditions, $80 \mathrm{ppm}$ of Sangrovit ${ }^{\circledR}$ has the same effects on mortality than the restriction feeding, keeping the positive effects on the growth of feeding ad libitum. Consequently, the profit of rabbits fed ad libitum with $80 \mathrm{ppm}$ of Sangrovit ${ }^{\circledR}$ is higher than the one of rabbits feed restricted without Sangrovit ${ }^{\circledR}$.

Key words: Fattening rabbits, Sangrovit ${ }^{\circledR}$, digestive troubles, feed restriction.

\title{
EFFECTS OF DIETARY ENERGY CONTENT ON REPRODUCTIVE PERFORMANCE OF LOCAL RABBIT DOES
}

\author{
Saidj D.*, Salhi O., Ain Baziz H., Temim S. \\ Research Laboratory "Animal Health and Breeding”, High National Veterinary School, El-Harrach \\ PB 161, 16200, Algiers, Algeria \\ *Corresponding author: dyhiasdj1@ @yahoo.fr
}

\begin{abstract}
Thirteen rabbit does of local population were used to study the effect of dietary energy content during reproduction on reproductive performance at the second parturition. Three experimental groups were constituted by ten does that received different diets $(T$, A and B) during reproduction (first and second gestation and lactation). Diets differed in their digestible energy (DE) content $(2300,2450$ and $2600 \mathrm{kcal} \mathrm{DE}$ for diets T, A and $\mathrm{B}$, respectively) were supplied ad libitum between parturition and weaning.

The use of high energy diets shows positive effects in does weight at $3^{\text {rd }}$ week post partum and at weaning (3221g for does in group B vs. $2859 \mathrm{~g}$ for does in group T at weaning) with weight gain mating-weaning does higher in group B (199.5g for does in group B vs 56.1g for does in group A vs $-94.4 \mathrm{~g}$ for does in group T). Feed intake a day is lower in group B (234.9g for does in group B vs. $245.4 \mathrm{~g}$ for does in group A vs.262.5g for does in group T). There is less mortality at birth for litters in group B. (4.9\% for does in group B vs. 16.6 for does in group A vs. 25.3\% for does in group $\mathrm{T})$ and there is more birth weaning-mortality for litters in group T.
\end{abstract}

Key words: Rabbit doe, Diet, Energy, Reproductive performance 


\title{
REARING-DIET STRATEGY AND PRODUCTIVE LONGEVITY OF CROSSBREED RABBIT DOES
}

\author{
Savietto D., Martinez-Paredes E., Ródenas L., Baselga M., Cervera C., Blas E., \\ Pascual J.J. \\ Instituto de Ciencia y Tecnología Animal. Universitat Politècnica de València. Camino de Vera \\ s/n. 7G. Valencia, 46022 \\ *Corresponding author: dasavi@upv.es
}

\begin{abstract}
A total of 619 crossbreed rabbit does were controlled from 63 days old to the time of death, culling or censored record (7\% of censored records with a minimum age of $647 \mathrm{~d}$ ) to evaluate how rearing-diet strategy can affects the productive their life span. During the rearing period (from 63 days old to $1^{\text {st }}$ parturition), the animals were divided in two groups, according to the diet received. A total of 308 females received a control diet $(\mathrm{C}$; $18.4 \%$ crude protein and $19.5 \%$ acid detergent fibre) and 311 females received a fibrous diet (F; $13.4 \%$ crude protein and $23.4 \%$ acid detergent fibre). The diet received during this period affected rearing development, reproductive performance and lifespan of rabbit does. The use of the diet $\mathrm{F}$ seems to avoid the possible overconditioning of young females fed diet $\mathrm{C}$ at first insemination ( $-238 \mathrm{~g}$ of live weight and $-0.35 \mathrm{~mm}$ of perirenal fat thickness; $\mathrm{P}<0.05$ ), and it did not affect their long term reproductive performance (49.5 and 51.0 kits born alive per female for diets $\mathrm{C}$ and F, respectively). Young females reared with diet $\mathrm{F}$ lived on average 46.4 days longer than those receiving $\operatorname{diet} \mathrm{C}(\mathrm{P}<0.05)$, which also occurred at early reproductive life $\left(+4.0\right.$ and $+5.0 \%$ at $2^{\text {nd }}$ partum and weaning time, respectively). This longer life lead to a higher total production of kits per female reared $(+7.4$ kits born alive per female; $\mathrm{P}<0.05)$.
\end{abstract}

Key words: Rabbit, rearing-diet, crossbreed-does, longevity and reproduction.

\section{DIETARY SUPPLEMENTATION WITH MANNANOLIGOSACCHARIDES AND $\beta$-GLUCANS IN GROWING RABBITS. 1. GROWTH PERFORMANCE, HEALTH STATUS AND CARCASS TRAITS}

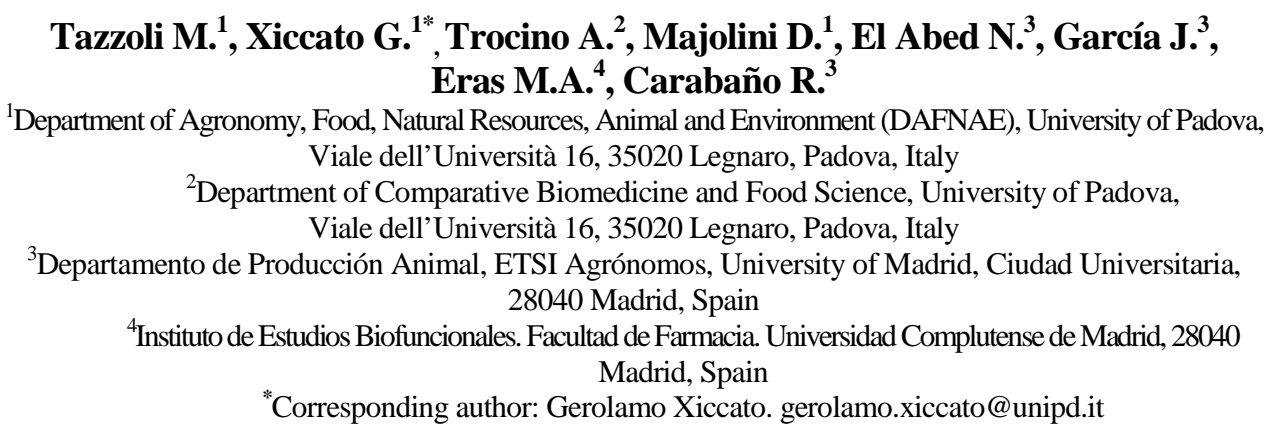




\begin{abstract}
A total of 384 rabbits weaned at $32 \mathrm{~d}$ of age were assigned to six experimental groups of 64 rabbits each, homogeneous in live weight (average and variability) and housed in individual cages. Animals fed ad libitum until slaughter (75 d) six diets which differed for the type and level of the supplemented additive: diet $\mathrm{C}$ without additives; diets G1 and G2 supplemented with two levels of $\beta$-glucans from Saccharomices cerevisiae (100 and $200 \mathrm{mg} / \mathrm{kg}$, respectively); diets M1 and M2 supplemented with mannanoligosaccharides (Actigen, Alltech; 400 and $800 \mathrm{mg} / \mathrm{kg}$, respectively); and diet GM (100 mg $\beta$-glucans $+400 \mathrm{mg}$ mannanoligosaccharides $/ \mathrm{kg}$ ). Health status of animals was good (average mortality $3.5 \%$ ) and both caecal fermentation traits and nutrient apparent digestibility were not affected by the inclusion level and type of additive. Growth performance of rabbits was not affected by the treatments, but daily weight gain (55.6 vs. $55.2 \mathrm{~g} / \mathrm{d} ; \mathrm{P}=0.07$ ) and live weight (2131 vs. $2100 \mathrm{~g} ; \mathrm{P}=0.07$ ) values of rabbits at the end of the first period after weaning ( $55 \mathrm{~d}$ of age) were slightly higher in rabbits fed $\beta$-glucans diets compared with those fed mannanoligosaccharides diets. The slaughter traits were similar among the experimental groups. In conclusion, under the rearing conditions of the present trial and in absence of epizootic rabbit enteropathy, the dietary supplementation with mannanoligosaccharides and/or $\beta$-glucans did not produce any appreciable advantage in growth performances and carcass quality of meat rabbits.
\end{abstract}

Key words: Mannanoligosaccharides, $\beta$-glucans, performance, health status, growing rabbits.

\title{
WATER NUTRITIONAL SUPPLEMENTATION FOR FATTENING RABBITS: \\ EFFECT ON FEED AND WATER INTAKE, GROWTH PERFORMANCE AND VIABILITY OF FATTENING RABBITS DURING THE SUMMER PERIOD IN THE WEST OF FRANCE.
}

\author{
Salaün J.M.*, Bourdillon A., Picot A., Renouf B. \\ Sanders, Centre d'affaires Odyssée, ZAC Cicé Blossac, 35170 Bruz, France \\ *Corresponding author: jean-marc.salaun@ sanders.fr
}

\begin{abstract}
Performances and viability of 1728 growing rabbits divided in 3 groups with different water nutritional supplementation were analysed. This study was realised in a closed farm in western France during summer 2011. The first group (FG) received during all the fattening period (35 days to 71 days) a nutritional supplementation in the water (called Fortizen). The second group (TG) received the supplementation only when the temperature in the farm was over $24^{\circ} \mathrm{C}$. The control group (CG) did not receive any supplementation. Fortizen is composed of dextrose, vitamin $\mathrm{C}$, grape polyphenol, betaine and electrolytes (Na-K-Cl). Viability rate for FG group was better than for TG group (96.0 \% vs 91.5) and for CG group $(92.6 \%, \mathrm{p}<0.006)$. During the first week
\end{abstract}


after weaning FG and TG groups viabilities equalled to $100 \%$ whereas a slight decrease in group CG viability was observed. There was no significant difference between the 3 groups for live weight, weight gain, feed intake and feed conversion for the periods considered. During the whole fattening period, the maximal daily temperature exceeded $24^{\circ} \mathrm{C}$ on 18 days only. The average of maximum temperature was $24.5^{\circ} \mathrm{C}$. Those mild conditions turned out to be not favourable to test the beneficial role of a nutritional complement in the prevention of heat stress but the supplementation improved the viability of growing rabbits.

Key words: Heat stress, weaning stress, growth, viability, rabbit

\title{
ALTERNATIVE FEED INGREDIENTS AND THEIR EFFECT ON THE PRODUCTION OF GROWING RABBITS
}

\author{
Eiben Cs. ${ }^{1}$ *, Gódor-Surmann K. ${ }^{1}$, Kustos K. ${ }^{2}$, Maró A., ${ }^{3}$, Vörös G ${ }^{4}$, Gippert T ${ }^{5}$ \\ ${ }^{1}$ Institute for Small Animal Research and Co-ordination Centre for Gene Conservation, Isaszegi út 200., H-2100, \\ Gödöll , Hungary \\ ${ }^{2}$ Lab-Nyúl Ltd., Malomtó u. 8., H-2100, Gödöll , Hungary \\ ${ }^{3}$ UB Merchants Ltd., F út 130., H-2085, Pilisvörösvár, Hungary \\ ${ }^{4}$ PO-RA-VET Ltd., Méhészet 6., H-2100, Gödöll , Hungary \\ ${ }^{5}$ GBT PRESS Ltd., Sportföld u. 21/F, H-2112, Veresegyház, Hungary \\ *Corresponding author: eiben@katki.hu
}

\begin{abstract}
In order to develop new, more efficient diets for growing rabbits, the use of food processing by-products (apple pulp, brewer's yeast), less used vegetal materials (barley, carob pulp) and feed protein products (soya concentrate, milk-powder replacer) was tested with formulation of eight isonutritive diets and assessing their effect on the production. The 35day-old Pannon white rabbits were weaned and caged singly ( $n=36 /$ treatment) or in groups of three ( $n=54 /$ treatment). Dietary ratio of raw materials used in the control diet (C) was reduced and substituted with 7.5\% apple pulp (diet A), 2\% brewer's yeast (diet Y), 5\% barley (diet B), 4\% carob pulp (diet CP), 2\% hydrolized soya-protein concentrate (diet HS) and $2 \%$ or $4 \%$ milk-powder replacer (diet U2 or U4). The rabbits fed these diets until 63 days of age and a single finishing diet up to 77 days old. The 49-63 day growth rate of the $\mathrm{C}, \mathrm{A}, \mathrm{CP}$ and $\mathrm{U} 4$ rabbits was good and similar (41-44 g/day) and that of the A rabbits was $12-20 \%$ higher $(\mathrm{P}=0.010)$ than the $\mathrm{Y}, \mathrm{B}, \mathrm{HS}$ and $\mathrm{U} 2$ rabbits (44 vs 37-39 g/day). The $63-$ day body weight of rabbits fed C, A, CP, U2 and U4 diets did not differ (2036 g as average) and it was $3.8 \%$ higher $(\mathrm{P}<0.05)$ than the rabbits fed Y, B and HS diets $(1961 \mathrm{~g}$, as average). The 35-77 day growth rate, feed intake and the 77-day final weight were similar but the U2 rabbits had poorer 35-77 day feed conversion (3.4 vs 3.2 in the other rabbits, $\mathrm{P}=0.022)$. The $35-77$ day mortality was lower $(\mathrm{P}=0.05)$ for rabbits fed $\mathrm{A}$ diet ( 15 $\%$ ) moderate in the CP, C, HS and U4 rabbits (from 21 to 29\%) and higher in the U2, B and Y rabbits (from 31 to 35\%). Both apple pulp and carob pulp are recommended as feed ingredient in weaning diets primarily because they promoted rabbits health.
\end{abstract}

Key words: Food processing by-product, Less used plant constituent, Feed protein product 


\title{
INTEGRATION BETWEEN SUPPLEMENTAL VITAMIN E AND ENDOGENOUS ANTIOXIDANT ENZYMES OF DIFFERENT RABBIT GENETIC RESOURCES: 1- EFFECT ON PERFORMANCE DURING SUMMER SEASON
}

\author{
El-Medany Sh.A. ${ }^{1}$, Abdel-Khalek A.M. ${ }^{2 *}$, Gad Alla S.A. ${ }^{2}$, Gihan Shaaban F. ${ }^{3}$, Abo- \\ Warda M. A. ${ }^{2}$, Arafa Mervat M. ${ }^{2}$, Azoz A.A., Meshreky Samia Z. ${ }^{2}$ \\ ${ }^{1}$ Regional Centre for Food and Feed, ARC, Dokki, Giza, 588, Egypt. \\ ${ }^{2}$ Animal Production Research Institute, ARC, Dokki, Giza, 12618, Egypt. \\ ${ }^{3}$ Department of Poultry Science, Faculty of Agriculture, Fayoum University, Fayoum, 63514, Egypt. \\ *Corresponding author: aabdelkhalek_apri@yahoo.com
}

\begin{abstract}
Supplemental antioxidants, in association with the action of endogenous antioxidants' enzymes could bring back the rabbit performance as high as possible during stress episode. The current study was initiated to explore the effect of the relationship between rabbit breed (exotic; V-line vs. native; Gabali) and dietary vitamin E level; 40 (control), 80, or $120 \mathrm{mg} / \mathrm{kg}$ diet, and their respective effect on growth performance, carcass traits, and blood plasma levels of $\alpha$-tocopherol and endogenous antioxidants' enzymes glutathione peroxidase (GSH-Px), superoxide dismutase (SOD), and catalase (CAT). One hundred-fifty-six week old rabbits of both genotypes (25 rabbit allocated for each vitamin $\mathrm{E}$ level), were distributed among the 6 experimental treatments. Results indicate that breed had no effect on growth performance and plasma antioxidants' enzymes activities. However, V-line rabbits had significantly higher hot carcass and total edible carcass quarters, but lower plasma $\alpha$-tocopherol level compared to Gabali rabbits. Rabbits fed the highest dietary vitamin E level (120 $\mathrm{mg} / \mathrm{kg}$ ) significantly showed the highest live weight gain, best feed conversion ratio, highest plasma $\alpha$-tocopherol level, and lowest GSH-Px activity compared to 40 or 80 $\mathrm{mg} / \mathrm{kg}$ diet level. The interaction between rabbit breed and dietary vitamin E level significantly affected total weight gain and plasma $\alpha$-tocopherol level. Other studied traits (feed conversion ratio, carcass traits' percentages, or plasma antioxidants' enzymes or $\alpha$-tocopherol levels) were not significantly affected by the interaction.

It could be recommended adding a high level of vitamin $\mathrm{E}(120 \mathrm{mg} / \mathrm{kg}$ diet $)$ to alleviate some of the impact of heat stress on rabbits, irrespective the breed used, and without expected contribution of the endogenous antioxidant enzymes activities.
\end{abstract}

Key words: Growing rabbit, vitamin E, rabbit genotype, antioxidant enzymes, heat stress.

\section{GROWTH PERFORMANCE AND BEHAVIOR OF GROWING RABBITS SUBJECTED TO FEED RESTRICTION}

\author{
Pinheiro V., ${ }^{1,2}$, Torres S. ${ }^{1}$, Monteiro D., ${ }^{1,2}$, Silva S. ${ }^{1,2}$, Mourão J.L. ${ }^{1,2}$ \\ ${ }^{1-} \mathrm{UTAD}^{2}{ }^{2}$ - CECAV - Department of Animal Science, University of Trás-os-Montes e Alto Douro, P. O. \\ Box 1013, 5000-911 Vila Real, Portugal \\ *Corresponding author: vpinheir@utad.pt
}




\begin{abstract}
The aim of this work was to study the behavior and productive performance of fattening rabbits, subjected to feed restriction during the first 4 weeks of growing period. A total of 180 hybrid rabbits (NZ x C) of both sexes 35 days old, were divided into four groups of 45 animals each, logged in 9 cages (5 rabbits/cage). The four treatments were the control diet ad libitum (C) and three different levels of restriction according to the time of feed access: 5h/d (D5); 10h/d (D10) and access every other day, or skip a day (D24). In the last week, animals had permanent access to feed. The access to feed begins at 9:30 pm. Individual weight and feed intake per cage were controlled weekly. At the end of the first, third and fourth weeks, in order to evaluate the behavior of animals, they were filmed during one minute at different periods of the day (9:30, 12:00 and 19:30h). Data was analyzed and determined the percentage occurrence of each behavior. The access restriction to feed for D5 and D24 resulted, respectively, in decreases of $8 \%$ and $11 \%$ in the final live weight, $16 \%$ and $20 \%$ in weight gain and $19 \%$ and $27 \%$ in feed intake, but the feed efficiency increased $6 \%$ and $16 \%$, compared to the control group. For the group D10, only significant differences were found in feed efficiency, which has an overall improvement of $16 \%$ compared with the control group. No significant effect was observed in health status of animals. In the behavioral ethogram, these restrictions caused a decrease in the occurrence of normal and an increase of abnormal behaviors. Access to feed $10 \mathrm{~h}$ per day seemed to be beneficial to rabbits because it does not impair growth and improve feed efficiency, but some behaviors were affected.
\end{abstract}

Key words: Rabbit, feed restriction, growth, behavior.

\title{
VALUE OF WHEAT STRAW AND ALFALFA HAY AS FIBER SOURCE FOR FATTENING RABBITS IN ALGERIA
}

\author{
Lebas F. ${ }^{1 *}$, Gacem M. ${ }^{2}$, Adaouri M. ${ }^{2}$, Bouguira A. ${ }^{3}$, Zerrouki N. ${ }^{4}$, Boudina H. ${ }^{2}$, \\ Tazka H. ${ }^{3}$ \\ ${ }^{1}$ Cuniculture Association, 87A Chemin de Lasserre, 31450 Corronsac, France \\ ${ }^{2}$ Institut Technique des Elevages, ITELV, Baba Ali, BP03/A, Birtouta-Alger, Algeria \\ ${ }^{3}$. Institut National de la Recherche Agronomique, INRAA - Alger, Algeria \\ ${ }^{4}$ Université Mouloud Mammeri, Tizi-Ouzou, Algeria \\ *Corresponding author: lebas@ cuniculture.info
}

\begin{abstract}
The objective of the present experiment was to determine if the poor growth (24-26 $\mathrm{g} / \mathrm{d})$ of the rabbit synthetic strain selected in Algeria, when fed with commercial diets, could be improved with the utilization of better balanced diets. Two experimental balanced diets (16\% crude protein, $28.5 \% \mathrm{NDF})$ were formulated with alfalfa hay $(32 \%)$ or wheat straw $(22 \%)$ as main fibre source. The other raw materials were respectively barley ( 25 or $24 \%$ ), soybean meal $(6.5 \%$ or $14 \%)$, wheat bran (35 or $36 \%)$, oil $(0$ or $1 \%)$, minerals and vitamins $(1.5$ or $4 \%)$. The growth performances of 227 rabbits of the synthetic strain (31 days old) fed with one of theses 2 diets or with a
\end{abstract}


commercial diet used as Control diet were studied until slaughter age (79 days). Average daily gain (ADG) with the Control diet was $26.8 \mathrm{~g} / \mathrm{d}$, within the range of previous measures. With alfalfa and straw diets, growth rate was improved by about $20 \%$ (ADG 31.5 and $33.0 \mathrm{~g} / \mathrm{d}$ respectively for the 2 fibre sources; $\mathrm{P}<0.001$ ). With the 2 experimental diets, in the same order, carcass yield was also significantly improved $(\mathrm{P}<0.001)$ : 65.4 and $66.4 \%$ vs $63.5 \%$ with the Control diet, without significant modification of carcass adiposity. The first conclusion of the authors is that growth rate of rabbits of the new synthetic line could be easily improved with the use of a better balanced diet than the classical commercial ones. The second conclusion is that if alfalfa (dehydrated or hay) is not available or at an excessive price, wheat straw could be used without problem as main fibre source in rabbit diet's formulation.

Key words: Growing rabbit, wheat straw, alfalfa.

\title{
CHEMICAL COMPOSITION OF SOME RAW MATERIALS AVAILABLE FOR RABBIT FEEDING IN BENIN
}

\author{
Lebas F. ${ }^{1}$, Bannelier C. ${ }^{2}$, Adoukonou J. ${ }^{3}$, Djago A.Y. ${ }^{4}$ \\ ${ }^{1}$ Cuniculture, 87A Chemin de Lasserre, 31450 Corronsac, France \\ ${ }^{2}$ INRA Unité de recherche Tandem, Centre Inra de Toulouse, 31320 Castanet Tolosan, France \\ ${ }^{3}$ Coopérative UGAM, Miniki, BP 266 Savalou, Benin \\ ${ }^{4}$ CECURI, Campus Universitaire d'Abomey-Calavi, BP2009 Cotonou, Benin \\ *Corresponding author: lebas@cuniculture.info
}

\begin{abstract}
During the past ten years various chemical analyses of 25 raw materials used in Benin for rabbit feeding were performed. The aim of the present paper is to make this information available for a maximum of potential users. The studied products were 9 sun dried forages (Albizia chevalierii foliage, Bidens pilosa whole plant, Cajanus cajan foliage, Desmodium scorpiurus vines, Leucaena leucocephala foliage, Manihot esculenta foliage, Puerearia phaseolides whole plant, Samanea saman foliage, Sida acuta foliage), 7 energy sources (cashew industry by-product, maize germ, maize grain (white), cassava peels, cassava root chips, wheat bran and maize bran), 3 industrial fiber sources (cassava distillery by-product, rice hulls and teak wood sawdust) and 6 protein sources (local fish meal, local toasted soybean seeds, local cottonseed meal, local palm kernel meal, imported soybean meal and local brewers grain). The nutrients analyzed were dry mater (DM), ash, crude protein (CP), ash, crude fiber, ether extract, neutral detergent fiber (NDF), acid detergent fiber (ADF), lignin (ADL) and gross energy. In addition for 8 forages and 5 other raw materials mineral composition was determined for calcium, phosphorus, magnesium, sodium and potassium. All were expressed as percentage of DM. It should be noticed that, if as expected the studied forages could be interesting fiber sources for rabbit feeding ( $\mathrm{ADF}=21$ to $39 \% \mathrm{DM}$, $\mathrm{ADL}=6.5$ to $24.6 \% \mathrm{DM})$ ), their $\mathrm{CP}$ content is also high enough (15 to $29 \% \mathrm{DM}$ ) to provide a noticeable proportion of rabbits total protein requirement. Nevertheless their high level of potassium (1.4 to 3.9\% DM) may limit their incorporation level in rabbit
\end{abstract}


feeds. Determination of residual trypsin inhibitor activity indicated that traditional soybean seeds toasting was efficient since the residual activity was only $5.8 \mathrm{TUI} / \mathrm{mg}$. Then with their high protein level (44.2\% DM), local toasted soybean seeds should be considered as an interesting source of protein for rabbits.

Key words : Rabbit feeding, raw material, analytical composition.

\title{
EFFECT OF DIETS CONTAINING WHOLE WHITE LUPIN SEEDS ON MILK COMPOSITION AND YIELD OF RABBIT DOES AND PERFORMANCE AND HEALTH OF THEIR LITTERS
}

\author{
Volek Z.*, Marounek M., Volková L., Kudrnová E. \\ Institute of Animal Science, Přátelství 815, Prague, CZ-104 00, Czech Republic \\ *Corresponding author: volek.zdenek@vuzv.cz
}

\begin{abstract}
The aim of this study was the evaluate the effect of lactation and weaning diets based on whole white lupin seeds (Lupinus albus cv. Amiga) on milk composition and yield of the non-pregnant rabbit does, as well as on performance and health of their litters. The lactation diet SL contained both soybean and sunflower meals as the main protein source, whereas the lactation diet LL was based on whole white lupin seeds. The weaning diet SW had soybean meal as the main protein source, whereas the weaning diet LW was based on whole white lupin seeds. A total of 32 (16 per treatment) Hyplus PS 19 rabbit does (all does at the $2^{\text {nd }}$ parturition) were allocated to two groups and fed one of the two experimental lactation diets for 30 days. The litters were standardised to 9 kits on the day of birth, and were fed one of the two weaning diets from 17 to $72 \mathrm{~d}$ of age. At the weaning ( $30 \mathrm{~d}$ of age), 6 rabbits per litter were used for the growth performance and health risk index evaluation. There was a better feed conversion ratio $(\mathrm{P}=0.003)$ between 1 and 21 day of the lactation in the does fed the LL diet than in those fed the SL diet. There was a higher milk yield between 22 and 30 day of the lactation $(\mathrm{P}=0.044)$, as well as for the entire lactation $(\mathrm{P}=0.094)$, in the rabbit does fed the LL diet. At 21 days of lactation, there was a significantly lower dry matter and protein content in milk from the does fed the LL diet. However, protein output per kg live weight was not significantly affected by dietary treatment. Milk fat content was non-significantly higher and fat output per kg live weight turned out significantly higher in the does fed the LL diet. Milk of the does fed the LL diet contained more oleic, $\alpha$-linolenic and EPA acid and less linoleic acid and short-chain fatty acids. There was a better milk conversion in litters of the rabbit does which were fed the LL diet (1.96 vs. $2.04, \mathrm{P}=0.048)$. There was no mortality of kits before weaning. After weaning, weight gain, feed intake, feed conversion ratio or live weight at the end of the experiment was not affected by dietary treatment. However, health risk index (sum of mortality and morbidity) was significantly lower in rabbits fed the LW diet than in those fed the SW diet (3.0\% vs $16.7 \%, \mathrm{P}=0.016)$. It can be concluded that whole white
\end{abstract}


lupin seeds is a suitable protein source for lactating rabbit does. The diet based on whole white lupin led to higher milk yield, milk fat output per kg live weight, $\mathrm{C} 18: 3 \mathrm{n}$ 3 and $\mathrm{C} 20: 5 n-3$ content in milk.

Key words: Rabbit, Diet, White lupin, Milk, Health status

\title{
EFFECT OF A LESS CONCENTRATED WEANING DIET AND AN EXTENSIVE REPRODUCTIVEMANAGEMENT ON THE LONG TERM RABBIT DOE PERFORMANCE AT PARTURITION
}

\author{
Martínez-Vallespín B., Martínez-Paredes E., Ródenas L., Cervera C., Pascual \\ J.J., Blas E.* \\ Instituto de Ciencia y Tecnología Animal, Universidad Politécnica de Valencia, Camino de Vera 14, 46071 \\ Valencia, Spain \\ *Corresponding author: eblas@dca.upv.es
}

\begin{abstract}
The effects of using a less concentrated weaning diet and of delaying the insemination and the weaning on the performance of rabbit does at parturition were studied in successive cycles, from $2^{\text {nd }}$ to $6^{\text {th }}$ parturition. A total of 188 primiparous females were involved in the experiment; they were distributed in 4 groups in a factorial design, with 2 feeding systems (FS) and 2 reproductive managements (RM). Groups C28 and C42 were kept on a conventional FS, receiving a commercial reproduction diet (diet R) during the whole experiment; groups E28 and E42 were kept on an experimental FS, receiving a less concentrated weaning diet (diet E) from $18^{\text {th }}$ day post-partum (dpp) until weaning. Groups C28 and E28 were managed in a semi-intensive RM: insemination at $11^{\text {th }} \mathrm{dpp}$ and weaning at $28^{\text {th }} \mathrm{dpp}$; groups $\mathrm{C} 42$ and $\mathrm{E} 42$ were managed in an extensive RM: insemination at $25^{\text {th }} \mathrm{dpp}$ and weaning at $42^{\text {nd }} \mathrm{dpp}$. The number of kits born alive was lower in $\mathrm{E} 42$ than in $\mathrm{C} 42(-1.2 \pm 0.4, \mathrm{P}=0.004)$, although the difference in litter weight did not reach the significance level $(-32 \pm 18 \mathrm{~g}, \mathrm{P}=0.088)$ because of compensatory effect of higher individual weight of kits in $\mathrm{E} 42$ than in $\mathrm{C} 42(+3.5 \pm 1.5 \mathrm{~g}$, $\mathrm{P}=0.022)$. At $2^{\text {nd }}-3^{\text {rd }}$ parturitions, litter size was higher in the extensive than in the semiintensive $\mathrm{RM}(+1.3 \pm 0.4, \mathrm{P}<0.001)$, although the difference in litter weight did not reach the significance level $(+32 \pm 17 \mathrm{~g}, \mathrm{P}=0.063)$ because of lower individual weight of kits in the extensive than in the semi-intensive RM $(-5.0 \pm 1.4 \mathrm{~g}, \mathrm{P}<0.001)$. On the contrary, performance at $4^{\text {th }}-6^{\text {th }}$ parturitions decreased in the extensive RM, with lower litter size $(-0.8 \pm 0.4 \mathrm{~g}, \mathrm{P}=0.026)$, similar individual weight of kits $(-1.0 \pm 1.3 \mathrm{~g}, \mathrm{P}>0.1)$ and lower litter weight $(-58 \pm 16 \mathrm{~g}, \mathrm{P}<0.001)$ than in the semi-intensive RM.
\end{abstract}

Key words: Rabbit does, parturition, weaning diet, reproductive management. 


\title{
INTAKE LIMITATION STRATEGY AND DIETARY PROTEIN CONCENTRATION: EFFECT ON RABBIT GROWTH PERFORMANCE AND HEALTH, FROM A LARGE-SCALE STUDY IN A FRENCH NETWORK OF EXPERIMENTAL UNITS (GEC)
}

\author{
Gidenne T. ${ }^{1 *}$, Combes S. ${ }^{1}$, Briens C. $^{2}$, Duperray J. ${ }^{3}$, Mevel L. ${ }^{4}$, Rebours G. ${ }^{4}$, \\ Salaun J.M. ${ }^{5}$, Weissman D. ${ }^{6}$, Combe Y. ${ }^{1,7}$, Travel A. ${ }^{7}$ \\ ${ }^{1}$ INRA, UMR1289 TANDEM, Ch. Borderouge, BP 52627, 31326 Castanet-Tolosan, France. ${ }^{2}$ CCPA, ZA \\ du Bois de Teillay, 35150 Janzé, France. ${ }^{3}$ Evialis, Talhouet BP 234, 56006 Vannes, France. ${ }^{4}$ TECHNA, \\ BP 10, rte de St Etienne de Montluc, 44220 Coueron, France. ${ }^{5}$ CYBELIA, Centre d'affaires l'Odyssée, \\ ZAC Cicé Blossac, 35170 Bruz, France. ${ }^{6}$ INZO, Rue de l'église, BP 50019, 02407 Chierry, France. ${ }^{7}$ \\ ITAVI, INRA, UMT BIRD, Unité Rech. Avicoles, BP 1, 37380 Nouzilly, France. \\ *Corresponding author: thierry.gidenne@toulouse.inra.fr
}

\begin{abstract}
The performance and the digestive health status of growing rabbits were analysed in five experimental sites, according to a $2 \times 2$ design: increasing the dietary crude protein $(\mathrm{CP})$ concentration $(\mathrm{C}$ vs. HP diet $=+20 \% \mathrm{CP}$ ), and free intake or a $25 \%$ limitation (100 vs. 75) for four weeks after weaning (35d), corresponding to four groups of 541 rabbits (C100, HP100, C75, HP75) bred in collective cages from 35 to 70d. No significant interactions were found between these two factors. From 35 to 70d, a higher dietary $\mathrm{CP}$ did not promote the growth or the intake, and even impair slightly the feed conversion $(\mathrm{P}=0.02)$. Reversely, a $25 \%$ intake limitation improved the feed conversion by 0.4 units $(\mathrm{P}<0.001)$ while the growth was reduced by $14 \%(\mathrm{P}<0.001)$, during the restriction period (35-63d). When restricted rabbits were fed freely (63-70d) a high compensatory growth was recorded for previously restricted rabbits, and was higher for C75 (+21\% vs. C100) than for HP75 (+14\% vs. HP100). Over the whole fattening period (35-70d), after a 4 weeks intake reduction $(-25 \%)$ and one week with a free intake, the growth and final weight were reduced by $10 \%$ and $5.6 \%$, respectively $(\mathrm{P}<0.001)$, whereas the feed conversion was improved by 0.3 units $(\mathrm{P}<0.001)$.

The crude protein level did not affect the digestive health of the growing rabbit. In return, our restriction strategy resulted in a $70 \%$ less mortality rate $(2.4$ vs. $7.0 \%$, $\mathrm{P}<0.001)$ and a $30 \%$ reduction of the morbidity rate $(6.2$ vs. $8.9 \%, \mathrm{P}=0.02)$ by digestive disorders during the restriction period; accordingly the health risk index was half reduced for restricted rabbits. From weaning to slaughter, the mortality rate decreased from $8.2 \%$ for ad-libitum fed to $3.3 \%$ for restricted rabbits.
\end{abstract}

Key words: Feed restriction, dietary protein, growth, health, rabbit. 


\title{
GROWTH PERFORMANCE OF RABBITS UNDER DIETARY MANIPULATIONAT DIFFERENT POST WEANING AGESFOR HEAVIER BODY WEIGHTS
}

\author{
Orheruata, A. M., Bello-Onaghise, G., Omoyakhi, J. M. \\ Department of Animal Science, University of Benin, P. M. B. 1154, Benin City, Nigeria. \\ Email-maorheruata@yahoo.co.uk or micorhe@uniben.edu
}

\begin{abstract}
This study was conducted to determine the effect of dietary manipulation of growth in rabbits at different post-weaning ages on body weight (BW) at sexual maturity. A diet of $12 \% \mathrm{CP}$ and $3238 \mathrm{kcal} \mathrm{ME} / \mathrm{kg}$ was formulated as the control diet while another diet of $16 \% \mathrm{CP}$ and $2906 \mathrm{kcal} \mathrm{ME} / \mathrm{kg}$ was formulated as the experimentaldiet. Dietary treatments were as follows: Treatment 1: 16\% CPdiet given between weaning (4 weeks) and8 weeks of age, Treatment 2:16\% CP diet given between8and 12 weeks of age,Treatment 3: 16\% CP diet given between 12and 16 weeks of age, and Treatment 4:control diet of $12 \% \mathrm{CP}$ which was fed from weaning to 24 weeks of age. Besides, forage was also supplied.The BW records from 40 animals (10 per treatment) were collected from weaning to 24 weeks of age. Results showed significant differences in BW of the rabbits from 12 weeks of age onwards, with those in Treatment 2 and Treatment 1 having the highestand the lowest BW, respectively.Results of the study therefore revealed that the adoption of the management practice of manipulating growth through feeding between 8 and 12 weeks of age will result in the production of table size rabbits of $1.464 \mathrm{~kg}$ and $1.655 \mathrm{~kg}$ at 16 and 20 weeks of age, respectively.
\end{abstract}

Key words: Rabbit, post-weaning growth, Diet.

\section{EFFECTS OF A ONE WEEK INTENSIVE FEED RESTRICTION IN THE GROWING RABBIT: Part 1 - PERFORMANCE AND BLOOD BIOCHEMICAL PARAMETERS}

\author{
Ebeid T..$^{*}$, Tůmová E. ${ }^{2}$, Volek, $Z^{3}{ }^{3}$ \\ ${ }^{1}$ Dept. of Poultry Production, Faculty of Agriculture, Kafrelsheikh University, 33516, Kafr El-Sheikh, Egypt \\ ${ }^{2}$ Dept. of Animal Husbandry, Czech University of Life Sciences, Prague, Czech Republic \\ ${ }^{3}$ Research Institute of Animal Production, Prátelství 815, Prague 10-Uhrínìves, CZ-104 01, Czech Republic \\ *Corresponding author: tarkamin@yahoo.com
}

\begin{abstract}
A total of 192 Hyplus rabbits (male and female ratio 1:1) of weaning age $35 \mathrm{~d}$ were randomly divided into three experimental groups ( $\mathrm{n}=64$ each), group 1 was fed ad libitum (control), group 2 (R50) was restricted from 42 to $49 \mathrm{~d}$ of age $(50 \mathrm{~g} / \mathrm{d} / \mathrm{rabbit})$, and group 3 (R65) was restricted from 42 to $49 \mathrm{~d}$ of age $(65 \mathrm{~g} / \mathrm{d} / \mathrm{rabbit})$. After the
\end{abstract}


restriction time, all the groups were back to ad libitum feeding till the end of the experiment (70 d of age). Growth was recorded weekly. After restriction period, haematological and biochemical parameters were measured in a week interval. During the restricted period, the values of daily weight gain in restricted rabbits were lower than in full-fed rabbits, but after restriction, when animals were again fed ad libitum, a compensatory growth was found. Final body weight (at $70 \mathrm{~d}$ of age) tended to be lower in restricted groups $(-9 \%, \mathrm{P}=0.08)$. Blood plasma glucose, total protein and urea concentrations were not significantly affected by feed restriction in growing rabbits. However, feed restriction reduced blood plasma triacylglycerols (-23\% in R50 and $16 \%$ in R65 vs control, $\mathrm{P}<0.05$ ), and non-esterified fatty acids (NEFA, $19 \%$ in R50 and $23 \%$ in R65) while increased cholesterol ( $+27 \%$ in R50 and $+29 \%$ in R65 vs control, $\mathrm{P}<0.01$ ). Feed restriction reduced the erythrocyte number by 6 and $7 \%$ in R50 and 3 resp. $(\mathrm{P}<0.05)$ and haemoglobin concentration by 7 and 5\% in R50 and R65, resp. $(\mathrm{P}<0.01)$, meanwhile mean cell volume (MCV) was increased by 1.5 and $2.7 \%$ in $\mathrm{R} 50$ and R65, resp. $(\mathrm{P}<0.05)$. Feed restriction had no significant effect on leukocyte number and haematocrit value. It could be concluded that short-term limitation of the feed intake improved feed conversion ratio, had a limited negative effect on final body weight, reduced blood plasma TAG and NEFA, and seemed to produce normal blood picture in fattening rabbits.

Key words: Feed restriction, growth, biochemical constituents, blood picture.

\title{
COMPARATIVE STUDY ON CAECAL FERMENTATION PATTERN IN ADULT DOMESTIC RABBITS AND WILD HARES
}

\author{
Marounek M. ${ }^{1,3, *}$, D. Mista ${ }^{2}$, Z. Volek $^{3}$ \\ ${ }^{1}$ Institute of Animal Physiology and Genetics, Academy of Science of the Czech Republic, 14220 Prague, \\ Czech Republic \\ ${ }^{2}$ Wroclaw University of Environmental and Life Sciences, Faculty of Veterinary Medicine, 50375 \\ Wroclaw, Poland \\ ${ }^{3}$ Institute of Animal Science, 10400 Prague, Czech Republic \\ *Corresponding author: marounek@iapg.cas.cz
}

\begin{abstract}
Domestic rabbits and wild hares, despite their morphological resemblance and similar type of digestion, would differ in profile of caecal fermentation end-products. Without controlling the intake pattern of the two species, the caecal concentrations of total volatile fatty acids were higher and ammonia concentrations lower in rabbits than in hares (99 and $21 \mathrm{mmol} / \mathrm{l}$ vs. 47 and $33 \mathrm{mmol} / \mathrm{l}$, resp.). Caecal microorganisms of rabbits produced more acetate $(66 \mathrm{mmol} / \mathrm{l})$ and butyrate $(19 \mathrm{mmol} / \mathrm{l})$ than propionate $(10 \mathrm{mmol} / \mathrm{l})$. Corresponding acetate, butyrate and propionate concentrations in hares were 28,5 and $9 \mathrm{mmol} / \mathrm{l}$, resp. This was confirmed with in vitro experiment. In rabbit caecal cultures fermentation was accompanied with a significant methane release (15.3 $\pm 2.2 \mathrm{mmol} / \mathrm{l})$. In hares only traces of methane were produced $(0.1 \mathrm{mmol} / \mathrm{l})$.
\end{abstract}


Calculations of metabolic hydrogen recovery suggested that reductive acetogenesis exists in caeca of both animal species.

Key words: Rabbit, hare, caecum, fermentation, methane.

\title{
EFFECT OF DIETARY LYSINE ON PRODUCTION PERFORMANCE, INSULIN LIKE GROWTH FACTOR-I (IGF-I) MRNA EXPRESSION IN GROWING RABBITS
}

\author{
Jing W. Q. ${ }^{1,2}$, Li F. C. ${ }^{1^{*}}$ \\ ${ }^{1}$ College of Animal Science and Technology, Shandong Agricultural University, Taian, 271018, P. R. \\ China \\ ${ }^{2}$ College of Life Science, Shandong Linyi University, Linyi, 276005, P. R. China \\ *Corresponding author: chlf@ sdau.edu.cn
}

\begin{abstract}
An experiment was conducted to study the effects of different amounts of dietary lysine on production performance, serum growth hormone $(\mathrm{GH})$, insulin-like growth factor-I (IGF-I) concentration and IGF-I mRNA expression of growing rabbits. One hundred weaned New Zealand rabbits were allocated to individual cages and randomly divided into five groups. Five diets, containing 5.5 (L1), 6.5 (L2), 7.5 (L3), 8.5 (L4) and $9.5 \mathrm{~g} / \mathrm{kg}$ (L5) lysine per kg diet, respectively. Average daily gain (ADG) of L3, L4 and L5 were 21.70, 34.37, 23.46 and 13.27, 24.93, 14.79\% high than those of L1 and L2 $(\mathrm{P}<0.05)$, respectively. The feed gain ratio $(\mathrm{F} / \mathrm{G})$ of $\mathrm{L} 4$ and $\mathrm{L} 5$ were $22.73,15.45$ and 17.27, 9.49\% low than those of L1 and L2 $(\mathrm{P}<0.05)$, respectively. Lysine did not affect serum GH concentrations $(\mathrm{P}>0.05)$. Serum IGF-I concentration tended to have a quadratic increase from L1 to L5 ( $\mathrm{P}=0.07)$. Hepatic and muscular IGF-I mRNA relative abundance tended to increase when dietary lysine level increased $(\mathrm{P}=0.053$, $\mathrm{P}=0.082$, respectively). Providing a diet mainly consisted of corn, wheat bran and peanut vine, the most appropriate dietary lysine level for weaner to 70-day-old growing meat rabbits was $8.5 \mathrm{~g} / \mathrm{kg}$ diet. IGF-I may be an important factor controlling body growth of growing rabbits.
\end{abstract}

Key Words: New Zealand rabbit, lysine, production performance, IGF-I, mRNA expression

\section{EFFECTS OF A ONE WEEK FEED RESTRICTION IN THE GROWING RABBIT : Part 2: DEVELOPMENT OF THE DIGESTIVE SYSTEM}

\footnotetext{
Tůmová E..$^{*}$, Volek, Z. ${ }^{2}$, Makovický, P. ${ }^{3}$, Chodová, D. ${ }^{1}$

${ }^{1}$ Dept. of Animal Husbandry, Czech University of Life Sciences Prague, Czech Republic

${ }^{2}$ Institute of Animal Science Prague, Prague 10 -Uhříněves, Czech Republic

${ }^{3}$ Dept. of Veterinary Science, Czech University of Life Sciences Prague, Czech Republic

*Corresponding author: tumova@af.czu.cz
} 


\begin{abstract}
The objective of the study was to evaluate changes in growth and morphology of intestines and liver depending on feeding regime and age of growing rabbits. Hyplus rabbits (192 rabbits weaned at 35 days) were divided into 3 groups of 64. Group 1 was fed ad libitum, group 2 (R50) was restricted from 42 to 49 days of age (50 g per day per rabbit), and group 3 (R65) was restricted from 42 to 49 days of age (65 g). Rabbits were fed ad libitum from 35 to 41 days of age and from 50 days till the end of the experiment at 70 days of age. From the age 49 days, 8 rabbits from a group were slaughtered in a week interval for intestine and liver characteristic determination. Length of intestines increased from 49 to $70 \mathrm{~d}$ old, in small intestine from 275 to $340 \mathrm{~cm}$, large intestine from 98 to $139 \mathrm{~cm}$ and in caecum from 34 to $39 \mathrm{~cm}$. Liver weight was at the age of 42 days 62 $\mathrm{g}$ and at $70 \mathrm{~d} 116 \mathrm{~g}$. Feed restriction (P $\$$ ).01) affected length of small intestine with the highest values in the group R65 (difference between ADL and R65 group was $21 \mathrm{~cm}$ ). Highly significant interactions of feeding regime and age were determined in villi height, (the lowest values in the group R65, $448 \mu \mathrm{m}$ at the age of $49 \mathrm{~d}$ and the highest in the same group but at the age of $56 \mathrm{~d}, 630 \mu \mathrm{m}$ ), crypts depth (P $₫) .001$; the highest and lowest depth of crypts were in the group R65 at $56 \mathrm{~d} 150 \mu \mathrm{m}$ and 63 days of age 108 $\mu \mathrm{m})$. Significant interactions of age and feeding regime (P $₫$ ).001) in hepatocytes diameter revealed the smallest diameter in the ADL group and in the group R50 g, 19.2 $\mu \mathrm{m}$ at the age of $49 \mathrm{~d}$ and the largest in the R50 at the age of $70 \mathrm{~d} 25.2 \mu \mathrm{m}$.
\end{abstract}

Key words: Rabbit; feed restriction; intestine and liver morphology

\title{
EFFECTS OF A ONE WEEK INTENSIVE FEED RESTRICTION IN THE GROWING RABBIT. Part 3: MUSCLE FIBRE DEVELOPMENT
}

\author{
Chodová D. ${ }^{1}$, Tůmová E. ${ }^{1}$, Volek Z. ${ }^{2}$ \\ ${ }^{1}$ Department of Animal Husbandry, Czech University of Live Sciences, Kamýcká 129, 165 21, \\ Prague 6 - Suchdol, Czech Republic \\ ${ }^{2}$ Institute of Animal Science, Přátelství 815, 104 00, Prague 10 - Uhř́něves, Czech Republic \\ *Corresponding author: chodova@af.czu.cz
}

\begin{abstract}
The effect of a one week intensive feed restriction was studied on the muscle fibre development of the growing rabbit. Rabbits were divided into 3 groups. Group 1 (ADL) was fed ad libitum, group 2 (R50) was restricted on $50 \mathrm{~g}$ per rabbit per day and group 3 (R65) was restricted on 65 g per rabbit per day. Restriction was applied from 42 to 49 days of age. Before and following restriction, rabbits were fed ad libitum. Samples of musculus longissimus dorsi (MLD) were taken from slaughtered rabbit for determination of histochemical parameters (number of muscle fibres, cross sectional area, diameter and fibre type distribution) in a week interval from 49 to 70 days. Rabbits were selected according to similar live weight, so loin weight and proportion of loin were not influenced by feed restriction. The lowest (P $₫$.001) number of $\alpha \mathrm{R}$
\end{abstract}


fibres in MLD was in R50 group at 70 days of age (25 fibres per $1 \mathrm{~mm}^{2}$ ), it means decrease by $-48 \%$ compare to control group. There were no differences between ad libitum fed and restricted group in fibre cross-sectional area (1057 - 1429, 1156 - 1321 and $2398-2692 \mathrm{~m}^{2}$ for $\beta \mathrm{R}, \alpha \mathrm{R}$ and $\alpha \mathrm{W}$ at 70 days of age, respectively). Restricted rabbits had the $(\mathrm{P}=0.010)$ smallest percentage of $\alpha \mathrm{R}$ muscle fibres $(-15 \%$ for $\mathrm{R} 50$ or $22 \%$ for R65 compare to ad libitum). The lowest percentage of muscle fibres type $\alpha \mathrm{R}$ was found for R50 group at 70 days of age $(9.0 \%$ vs $13 \%$ in ad libitum fed rabbits). Restricted group $\mathrm{R} 65$ had $(\mathrm{P}=0.009)$ a higher contribution of $\alpha \mathrm{W}$ muscle fibres $(85 \%)$ than the ad libitum group (82\%).

Key words: Rabbit, feed restriction, loin, muscle fibre.

\title{
MANNANOLIGOSACCHARIDES CAN MODIFY CAECAL MICROBIAL FERMENTATIONS OF RABBITS IN THE POST WEANING
}

\author{
Iannaccone F., Bovera F.*, Di Meo C., Piccolo G., Nizza A. \\ Dept. of Animal Science and Food Control, University of Napoli Federico II, via F. Delpino, 1, \\ 80137 Napoli, Italy \\ *Corresponding author: bovera@unina.it
}

\begin{abstract}
From 2007 to 2011 a total of 1152 growing rabbits were used in 8 different trials two trials per year were conducted, the first in the winter (January-February), the second in the summer (July-August). For each trial, 144 rabbits were equally divided into three groups (48 rabbits/group) fed the same basal diet and, from weaning (35 days) up to 62 days of age, submitted to the following dietary treatments: a control group (CONT), without additives; a MOS group fed mannanoligosaccharides (Bio-Mos®; Alltech Biotechnology, Lexington, KY, USA) at $1 \mathrm{~g} / \mathrm{kg}$ of feed; an antibiotic group (ANT) fed the basal diet supplemented with antibiotics (colistin sulphate, $144 \mathrm{mg} / \mathrm{kg}$; tylosin, 100 $\mathrm{mg} / \mathrm{kg}$; and oxytetracyclin, $1000 \mathrm{mg} / \mathrm{kg}$ ). Feed intake, mortality rate and caecal fermentation characteristics were studied by treatment, season (summer and winter) and their interaction. The mortality rate was significantly $(\mathrm{P}<0.05)$ lower in rabbits fed MOS (13.6\%) than the control (21.4\%) and the ANT group (19.7\%). In summer the mortality rate $(24.6 \%)$ was higher than in the winter $(11.9 \%)$. Rabbits fed antibiotics showed a higher $(\mathrm{P}<0.05)$ feed intake than the CONT group $(133$ vs $118 \mathrm{~g} / \mathrm{d})$, while no significant differences were recorded for the MOS in comparison to the other groups. MOS group had a higher total volatile fatty acid (tVFA) production than the other two groups(+ 17 and $+35 \%$, than CONT and ANT groups, respectively, $\mathrm{P}<0.01)$, due in particular to a higher production of acetate, propionate and valerianic acids. Ammonia production was the highest $(\mathrm{P}<0.01)$ in caecal content from CONT group $(6.35$ vs. 4.23 and $3.98 \mathrm{Mmol} / \mathrm{l}$, respectively for CONT, ANT and MOS group). During summer feed intake, tVFA and acetate production were significantly reduced (- 10, - 18 and $21 \%$, respectively) respect to winter. During winter, CONT and ANT groups showed a higher (from 10 to $16 \%$ ) production of VFAs (excluding isovaleric acid). On the contrary, rabbits fed MOS had, during winter a lower (from 9 to $13 \%$ )production of
\end{abstract}


VFAs. Mannanolisaccharides seemed able to modify caecal fermentations of growing rabbits, particularly when the climatic conditions do not fall in the optimal range of rabbit, when the temperature increases and induces a lower feed intake and a higher mortality rate .

Key words: Mannanoligosaccharides, antibiotics, rabbit, caecal fermentation, post weaning period.

\title{
IMPACT OF PROBIOTICS ON INTESTINAL MICROBIAL COMMUNITY DIVERSITY OF GROWING REX RABBITS
}

\author{
Wang Chunyang ${ }^{1}$, Li Fuchang ${ }^{1}$, Zhu Yanli ${ }^{1}$, Wang Xuepeng ${ }^{1}$, Sun Liangzhan ${ }^{1}$ \\ College of Animal Science and Technology, Shandong Agricultural University, No 61, Daizong Street, \\ 271018 Taian, China \\ *Corresponding author: wcy@sdau.edu.cn
}

\begin{abstract}
An experiment was conducted to determine the effects of Lactobacillus on growth performance, serum metabolite, the number of mast cells and microbial community diversity of growing Rex Rabbits. A total of 120 rabbits weaned at age of 30 days were randomly divided into four groups. The control group was fed on basal diet only. The group I was fed on basal diet with antibiotics (Zinc Bacitracin), and group II and III were fed on basal diet adding Lactobacillus zeae (LB1) and Lactobacillus rhamnosus (L3) respectively. The results obtained were as follows: feed to gain ratio $(\mathrm{F} / \mathrm{G})$ of the rabbits fed with Lactobacillus isolates was significantly lower than that of control group $(\mathrm{P}<0.05)$. The concentration of alanine aminotransferase (ALT) was significantly lower $(\mathrm{P}<0.05)$ when rabbits were fed with Lactobacillus isolates LB1 and L3. Meanwhile, the concentration of IgG and IgM increased significantly $(\mathrm{P}<0.05)$. Lactobacillus isolates had no influence on the number of mast cells in jejunum and duodenum $(\mathrm{P}>0.05)$ but increased the number of mast cells in caecum significantly $(\mathrm{P}<0.05)$. The analysis of Enterobacterial Repetitive Intergenic Consensus PCR (ERIC-PCR) indicated that Lactobacillus isolates can adjust the intestinal microbial community diversity of growing rabbits. In conclusion, the application of Lactobacillus isolates LB1 and L3 all can increase the growth performance, enhance the immunologic function and adjust the intestinal microecosystem of growing Rex Rabbits.

Key words: Rex Rabbit, Lactobacillus, microbial community diversity, intestine
\end{abstract}

\section{EFFECTS OF DIFFERENT PROTEIN, FIBRE AND ENERGY LEVELS ON GROWTH PERFORMANCE AND THE DEVELOPMENT OF DIGESTIVE ORGANS IN GROWING MEAT RABBIT}

\author{
Wang Xuepeng $^{1 *}$, Ma Mingwen ${ }^{2}$, Sun Liangzhan ${ }^{1}$, Wang Chunyang ${ }^{1}$, Zhu Yanli ${ }^{1}$, \\ Li Fuchang ${ }^{1}$
}




\begin{abstract}
Six groups of 40 New Zealand White rabbits, each were reared from 30 days of age on diets containing different protein, fibre and energy were used to study influences on productive performance, the development of digestive organs, biochemical and hormonal parameters of rabbits. Six groups were fed on diet A (control group), diet B (higher protein group), diet $\mathrm{C}$ (higher energy group), diet $\mathrm{D}$ (higher energy and lower fibre group), diet $\mathrm{E}$ (higher protein and energy group) and diet $\mathrm{F}$ (higher protein and energy with lower fibre group), respectively. The results showed that the average daily gain of rabbits fed on diet A, B, C, D, E and F was 22.8, 26.9, 24.7, 21.5, 28.1 and $24.5 \mathrm{~g}$, respectively, while the feed/gain rate was 3.6, 3.0, 3.2, 3.5, 2.7 and 3.1, respectively. This might suggested that higher protein, energy and fibre diet could increase the average daily gain and decrease the feed/gain rate. Rabbits fed on diet $F$ had the highest relative weight of stomach, followed by diet B, A, C, E, and D, were 71.4, 67.1, 64.9, 53.8, 52.5, $52.3 \mathrm{~g} / \mathrm{kg}$, respectively. Rabbits fed on diet A had the highest relative weight of small intestinal contents, followed by diet C, E, F, B and D, were 58.0, 56.0, 52.8, 47.3, 46.3, 44.5 g/kg, respectively. Rabbits fed on diet A had the highest relative weight of caecum, followed by diet D, F, E, C and B, were 107.3, 98.6, $96.4,88.4,79.5,76.2 \mathrm{~g} / \mathrm{kg}$, respectively. These suggested that the relative weights of stomach, small intestinal contents and caecum were significant affected by different protein, fibre and energy levels ( $p<0.01$ or 0.05 ). However, there were no significant changes in the relative weights of stomach contents, small intestine and caecum contents ( $p>0.05$ ). The activities of small intestine trypsin of rabbits fed on diet $\mathrm{C}$ were higher than those of other diets followed by diet A, D, F, E and B ( $<<0.05)$. However, no significant changes in the activities of small intestine amylase and lipase were observed ( $p>0.05$ ). The values of plasma total protein, albumin, Albumin/Globulin ratio, glucose, total cholesterol and urea nitrogen revealed non-significant changes among all groups that received different dietary treatment $(\mathrm{P}>0.5)$.
\end{abstract}

Key words: Protein, fibre, energy.

\title{
EFFECT OF DIETARY LIGNIN/STARCH RATIO ON THE NUMBER OF M CELL IN APPENDIX OF GROWING RABBITS
}

\author{
Zhu Y., Wang C., Wang X., Li F., Sun L., Li B. \\ College of Animal Science and Technology, Shandong Agricultural University No.61, Daizong Street, \\ 271018, Tai'an, China. \\ *Corresponding author: zyl0539@163.com
}




\begin{abstract}
This study aimed to analyse the effect of dietary lignin /starch ratio on the number of $\mathrm{M}$ cell in appendix of growing rabbits. Two hundred weanling rabbits of both sexes (half/treatment), of $35 \mathrm{~d}$ old, were blocked by fifty healthy rabbits per group after a 7-d adaptation period and assigned to the 4 experimental diets by average live weight. Four different lignin to starch ratio diets I (0.34), II (0.28), III (0.22), IV (0.14) were formulated. Five rabbits per group were killed to require samples, every 10 days from52 to 82 days old. Vimentin immunoreactivity was determined the M cell number in the follicle-associated epithelium (FAE) of appendix. Significant interactions between age and diets were found. Rabbits fed the high lignin / low-starch diet (diet I) had a higher number of $\mathrm{M}$ cell in appendix than other diets at 52 days of age $(\mathrm{P}<0.001)$. A similar effect was observed at 62 days of age. In contrast, when dietary lignin/starch ratio decreased to 0.14 , a significant decrease of the $M$ cell number in appendix was observed at 52 days of age $(\mathrm{P}<0.001)$. With age, except diet I, the $\mathrm{M}$ cell number were similar between other diets $(\mathrm{P}>0.05)$ at 62 days of age. At 72 and 82 days of age, there was no difference in $\mathrm{M}$ cell number among four diets $(\mathrm{P}>0.05)$. Thus, a high lignin/low-starch diet would induce a $\mathrm{M}$ cell number increase at early stage of the experiment. With age, the intestinal environment would gradually adapt to the dietary components change, and the local mucous immunity seemed not affected by diet.
\end{abstract}

Key words: Rabbit, Dietary lignin/starch ratio, M cells, sacculus rotundus, Appendix.

\title{
ENZYME OUTPUT CAPACITY OF THE PANCREAS IN ADULT RABBIT ACCORDING TO DIET COMPOSITION
}

\author{
Dojana N. ${ }^{{ }^{*},}$ Codreanu I. ${ }^{1}$, Orasanu A. ${ }^{2}$ \\ 1. Faculty of Veterinary Medicine, University of Agronomical Sciences and Veterinary Medicine, \\ Independentei 105, 050097, Bucharest 5, Romania; \\ 2. Institute of Diagnosis and Animal Health, Staicovici 63, 050557, Bucharest 5, Romania \\ * Corresponding author: dojana2001@yahoo.com
}

\begin{abstract}
Three groups of adult rabbits were fed for 35 days with high starch diet (high starch group, HSG), high protein diet (high protein group, HPG), or high fat diet (high fat group, HFG) compared with a control group (CG) fed with a specific diet. Then pancreatic juice was collected and measured in acute experiments, in two variants of secretion: basal and stimulated by secretin. Pancreatic juice samples were analysed for protein content and amylase, trypsin and lipase activities. Basal values of juice flow (in $\mu \mathrm{L} / 10 \mathrm{~min} / \mathrm{Kg}$ b.w.) showed no significant differences between any experimental fed groups (overall mean: 33) vs. CG (mean: 27). Secretin stimulated juice flows were increased in all the groups from 3.5 in HFG to 4.8 folds in CG, but the increase was higher only in HSG (180) vs. CG (130) $(\mathrm{P}<0.05)$. Basal protein flows (in $\mu \mathrm{g} / 10$ $\mathrm{min} / \mathrm{Kg}$ b.w.) of experimental fed groups (overall mean: 29 ) did not differ significantly vs. CG (mean: 32). In contrast, the stimulated protein output was $39 \%$ higher in HSG vs. CG $(\mathrm{P}<0.05)$. Amylase activities were higher in $\mathrm{HSG}$ vs. $\mathrm{CG}$, both in basal
\end{abstract}


$\left(144 \times 10^{3}\right.$ and, $52 \times 10^{3}$ amylase units $\left.(\mathrm{AU}), \mathrm{P}<0.001\right)$ and in the stimulated pancreatic juice $\left(422 \times 10^{3}\right.$ and $\left.162 \times 10^{3} \mathrm{AU}, \mathrm{P}<0.001\right)$. Moreover, the activities of trypsin and lipase in HSG did not differ significantly vs. CG, nor for basal neither for stimulated juice. Trypsin activity (in nmols benzoyl-argynil-ethyl-ester decomposed / $10 \mathrm{~min} / \mathrm{kg}$ bw) was higher for HPG vs. CG, both in basal (62.5 vs. $22.2, \mathrm{P}<0.01)$ and in stimulated juices (166.0 vs. $31.5, \mathrm{P}<0.001)$. Basal lipase activity (in mequivalents of liberated oleic acid per mg protein per $\left.\mathrm{h}, 37^{\circ} \mathrm{C}\right)$ was higher in HFG vs. CG (122.4 and 86.5, respectively). In the stimulated juice, lipase activity increased to 246.0 in HFG and 184.1 in CG, but no significant differences were found in HFG vs. CG nor for lipase neither for amylase and trypsin.

Key words: Pancreatic juice, nutrition, rabbit.

\title{
DIETARY SUPPLEMENTATION OF SPIRULINA (Arthrospira platensis) AND THYME (Thymus vulgaris L.). PART 1: EFFECT ON PRODUCTIVE PERFORMANCE OF GROWING RABBITS
}

\author{
Gerencsér Zs. ${ }^{1}$, Szendr Zs. ${ }^{1}$, Matics Zs. ${ }^{1}$, Radnai I. ${ }^{1}$, Kovács M. ${ }^{1}$, Nagy I. ${ }^{1}$, \\ Dal Bosco A. ${ }^{2}$, Dalle Zotte A. ${ }^{3}$ \\ ${ }^{1}$ Faculty of Animal Science, Kaposvár University, Guba S. str. 40, H-7400, Kaposvár, Hungary \\ ${ }^{2}$ Department of Applied Biology, Animal Science Section, University of Perugia, Borgo XX \\ Giugno 74,06100 Perugia, Italy \\ ${ }^{3}$ Department of Animal Medicine, Production and Health, University of Padova, Agripolis, Viale \\ dell'Università 16, 35020 Legnaro (PD), Italy \\ *Corresponding author: gerencser.zsolt@ke.hu
}

\begin{abstract}
The objective of this study was to evaluate the effect of a dietary supplementation between the ages of 5-11 or between only 8 to 11 weeks, with Spirulina or/and Thyme on the growing rabbits' performances. At weaning (5 weeks) the rabbits were randomly allotted to 7 groups (42 rabbits/group, 3 rabbits/cage). Rabbits of the control group (C) received a control pelleted feed throughout the experiment (5-11 weeks of age) without any supplementation. In the other groups, the diet was completed by $5 \%$ Spirulina (S), or 3\% Thyme (T) or by both (ST) for the whole (5-11 wk; groups: S-S, T-T, ST-ST), or for part of the growing period (8-11 wk; groups: C-S, C-T, C-ST). Supplementing the diet with Spirulina or/and Thyme had no effect on the rabbits' weight gain, body weight, feed consumption, morbidity and mortality. Significant differences were only found for feed conversion ratio that was lower for the C-T group (3.39) than for the $\mathrm{C}-\mathrm{C}$ groups $(3.54, \mathrm{P}<0.05)$. Based on the results, the feed supplements applied separately or jointly had no substantial effect on the growing rabbits' production and health status.
\end{abstract}

Key words: Spirulina, thyme, growing rabbits, productive performance 


\title{
TIME FEED RESTRICTION REDUCES DIGESTIVE DISORDERS WITHOUT DECREASING GROWTH PERFORMANCES OF GROWING RABBITS IN ERE CONDITIONS.
}

\author{
Duperray J. ${ }^{1 *}$, Laurent J.M. ${ }^{1}$, Adelis R. ${ }^{1}$, Haberkorn F. ${ }^{1}$, Guyonvarch A. ${ }^{1}$ \\ ${ }^{1}$ In Vivo NSA, Talhouët, BP 235, 56006 Vannes Cedex, France \\ *Corresponding author: jduperray@evialis.net
}

\begin{abstract}
The aim of this study was to test the effects of feed restriction on health status of rabbits in Epizootic Rabbit Enteropathy (ERE) conditions. A control group (AL) fed ad libitum was compared to three other groups. The FR group was feed restricted (about 15\%). Access to feed of AL12 and AL14 groups was time restricted: 12 or 14 hours per day respectively. The available quantity of feed in feeders was more than ad libitum intake. Rabbits were housed in collective cages (8 rabbits per cage). Live weight and feed intake were recorded at 34, 43, 50, 57 and 69 days. Mortality was checked every day and morbidity was controlled when rabbits were weighted. Rabbits of AL group showed a non significantly higher mortality rate compared to restricted groups, while morbidity was significantly higher at 50 days of age (12.5\% vs.57.5\%). Feed restriction gave a non significant decrease in average daily gain (ADG) of $5 \%$ and a non significant decrease of $63 \mathrm{~g}$ in live weight at slaughtering. Feed restriction by limiting the access to feed leaded to similar health status results as the FR group: reduction of the mortality $(6.3 \%$ and $8.8 \%$ vs $15.0 \%$ in the control group) and significantly lowered morbidity. Respect to the control group, the feed intake was higher in AL14 group (145g/j vs. $137 \mathrm{~g} / \mathrm{j}, \mathrm{P}<0.05)$, but was similar in AL12 group $(138 \mathrm{~g} / \mathrm{j})$. Average daily gain was improved in both AL12 and AL14 groups (+7 to 10\%, P<0.05). In addition, AL12 and AL14 leaded to an increase of $10 \%$ in the number of slaughtered rabbits, an increase in average live weight at slaughtering of 5.4\% and a better economic feed conversion ratio. Although AL12 and AL14 had the same feed intake as the control group during the first week of the fattening period, AL12 and AL14 showed far less health problems during the second week and later. This indicates that the improvement of the health status was due not only to feed restriction, but also to the fasting period during the day. AL14 group feeding strategy seemed to be a better one than a classical feed restriction program since it combines a positive effect on health status and it guarantees good growing performances.
\end{abstract}

Key words: Feed restriction, time access, ERE. 


\title{
DIETARY SUPPLEMENTATION OF SPIRULINA (Arthrospira platensis) AND THYME (Thymus vulgaris L.). PART 3: EFFECT ON CAECAL BACTERIAL COMMUNITY IN GROWING RABBITS
}

\author{
Vántus V. ${ }^{1}$, Dalle Zotte, A. ${ }^{2}$, Kovács, M. ${ }^{1}$, Dal Bosco A. ${ }^{3}$, Szendr , Zs. ${ }^{1}$, \\ Zsolnai, A. ${ }^{1 *}$ \\ ${ }^{1}$ Faculty of Animal Science, Kaposvár University, 40, Guba S. str., H-7400, Kaposvár, Hungary \\ ${ }^{2}$ Department of Animal Medicine, Production and Health, University of Padova, Agripolis, Viale \\ dell'Università 16, 35020 Legnaro (PD), Italy \\ ${ }^{3}$ Department of Applied Biology, University of Perugia, Borgo XX Giugno 74, 06121 Perugia, Italy \\ *Corresponding author: attila.zsolnai@gmail.com
}

\begin{abstract}
ABSCTRACT
Two groups of 42 rabbits were fed either a diet supplemented or not with Spirulina Duration, from weaned (35d old) to 11 weeks of age. Samples of caecal content were collected at the $14^{\text {th }}, 28^{\text {th }}$ and $48^{\text {th }}$ day of the supplementation, to evaluate the effect on the bacterial diversity of microbiota using molecular tools. After bacterial DNA extraction, the quantity of bacteria, belonging to phylum Firmicutes and Bacteroidetes were determined by qPCR reactions. The copy number of the two phyla did not significantly evolved from 49 to $83 \mathrm{~d}$ of age, and ranged between 87000 and 118000 . The amount of Bacteroidetes and Clostridium group (Clostridium leptum and Clostridium coccoides), belonging to the Firmicutes phylum, were not significant modified by Spirulina dietary supplementation.
\end{abstract}

Key words: Spirulina, caecal microbiota, rabbit, qPCR.

\section{DIETARY SUPPLEMENTATION WITH MANNANOLIGOSACCHARIDES AND $\beta$ GLUCANS IN GROWING RABBITS. 2 GUT BARRIER AND INTESTINAL MICROBIOTA AFTER WEANING}

\author{
El Abed N. ${ }^{1}$, Menoyo D. ${ }^{1}$, García J. ${ }^{1}$, Carabaño R. ${ }^{1 *}$, Pérez de Rozas A. ${ }^{2}$, Badiola \\ $I^{2}$., Eras M.A. ${ }^{3}$ Tazzoli M. ${ }^{4}$, Trocino A. ${ }^{5}$, Majolini D. ${ }^{4}$, Xiccato G. ${ }^{4}$ \\ ${ }^{1}$ Departamento de Producción Animal, ETSI Agrónomos, University of Madrid, Ciudad Universitaria, \\ 28040 Madrid, Spain \\ ${ }^{2} \mathrm{CReSa}$ (UAB-IRTA), Bellaterra, 08193 Barcelona, Spain \\ ${ }^{3}$ Instituto de Estudios Biofuncionales. Facultad de Farmacia. Universidad Complutense de Madrid, 28040 \\ Madrid, Spain \\ ${ }^{4}$ Department of Agronomy, Food, Natural Resources, Animal and Environment (DAFNAE), University of \\ Padova, Viale dell'Università 16, 35020 Legnaro, Padova, Italy \\ ${ }^{5}$ Department of Comparative Biomedicine and Food Science, University of Padova, Viale \\ dell'Università 16, 35020 Legnaro, Padova, Italy \\ *Corresponding author: Rosa Carabaño.rosa.carabano@upm.es
}




\begin{abstract}
The aim of this work was to determine the effect of yeast mannanoligosaccharides (MOS; Actigen, Alltech) and yeast $\beta$-glucans on gut barrier and intestinal microbiota in rabbits. A control diet (C) was formulated to meet rabbit growth requirements. G1 and G2 diets were obtained by supplementing $C$ diet with $\beta$-glucans from Saccharomyces cerevisiae (100 and $200 \mathrm{mg} / \mathrm{kg}$ respectively), M1 and M2 diets were supplemented with mannanoligosaccharides (Actigen, Alltech) $(400$ and $800 \mathrm{mg} / \mathrm{kg}$ respectively), and GM diet was supplemented with $100 \mathrm{mg} / \mathrm{kg}$ of $\beta$-glucans $+400 \mathrm{mg} / \mathrm{kg}$ of MOS. Ninety six rabbits weaned at 32 days of age were randomly assigned to the six experimental diets and slaughtered 15 days after weaning. The type of diet did not affect villus length and goblet cell counts, but crypt depth was reduced at the highest levels of MOS and $\beta$-glucans supplementation. Both MOS and $\beta$-glucans increased specific sucrose activity $(\mathrm{P}=0.001)$ and soluble protein concentration $(\mathrm{P}<0.05)$ in jejunal mucosa; they also modified ileal and caecal microbiota and modulated the immune response. Compared with the control diet, the supplementation with 200 $\mathrm{mg} / \mathrm{kg}$ of $\beta$-glucans (G2) and $800 \mathrm{mg} / \mathrm{kg}$ of MOS (M2) reduced the expression of iNOS in ileum. Rabbits fed the M2 diet showed also the lowest mRNA abundance of IL6. In appendix, rabbits fed G2 showed increased IL6 expression and those fed the M2 reduced the expression of INF $\gamma$. In conclusion, MOS and $\beta$-glucans changed intestinal microbiota and modulated the immune response by reducing the expression of some pro-inflammatory cytokines in ileum and caecum of weaned rabbits.
\end{abstract}

Key words: Yeast mannanoligosaccharides, yeast $\beta$-glucans, weaning rabbit, immunity, microbiota, jejunum morphology.

\title{
HAEMATOLOGICAL AND SERUM BIOCHEMICAL RESPONSE OF GROWING RABBITS FED GRADED LEVELS OF Moringa oleifera LEAF MEAL
}

\author{
Ewuola E.O., Jimoh O.A., Atuma O.V., Soipe O.D. \\ Animal Physiology Laboratory, Department of Animal Science, \\ University of Ibadan, Ibadan, Nigeria. \\ *Corresponding author: bisi_ewuola@yahoo.co.uk; GSM:+234(8)060862361
}

\begin{abstract}
An experiment was conducted with 36 crossbred rabbits (7-9weeks) to assess their haematological and serum biochemical response when fed a graded level of Moringa oleifera leaf meal (MOLM) to replace soybean meal. The experimental diets had inclusion levels of $0 \%, 5 \%, 10 \%, 15 \%$ MOLM in treatments 1 (control), 2, 3 and 4 respectively, with nine rabbits per treatment and for a nine week feeding trial. After the feeding trial, blood samples were collected from each rabbit through ear vein using a sterilized disposable syringe. Packed Cell Volume, Red Blood Cell, Haemoglobin, White Blood Cell, Mean Cell Volume, Mean Cell Haemoglobin, Mean Cell Haemoglobin Concentration, platelets and leukocyte differential counts were similar among the four
\end{abstract}


diets, except neutrophils which were significantly higher in control rabbits than others. The serum Total protein, albumin and globulin concentration of animals fed MOLMbased diets were not significantly different from those fed the control diet. The Aspartate Amino Transferase, Alanine Amino Transferase and Alkaline Phosphatase activities examined in rabbits fed 5, 10 and 15\% MOLM were not significantly different from those rabbits fed the control diet. However, the values obtained from this study were within the normal range of healthy rabbits. The average daily weight gain were $6.8 \mathrm{~g}$, $5.4 \mathrm{~g}, 6.49 \mathrm{~g}$ and $3.8 \mathrm{~g}$ for rabbits fed treatments $1,2,3$ and 4 respectively. The daily dry matter intake of animals on treatments 1, 2, 3 and 4 were 98g, 98g 100g and 94g resp. This suggested that feeding MOLM up to $15 \%$ inclusion in rabbit diet will not have adverse effect on the biochemical response of the growing rabbits.

Key words: Moringa leaf meal, Haematology, serum biochemistry, rabbits

\title{
EFFECT OF THE RATIO LIGNIN TO CELLULOSE (ADF- ADL) ON CAECAL FERMENTATION, GUT MORPHOLOGY AND PERFORMANCE OF RABBITS AROUND WEANING
}

\author{
Krieg. R. ${ }^{1.2^{*}}$, Martienssen.M. ${ }^{3}$, Zentek. J. ${ }^{4}$ \\ 1 Small Animal Breeding and Research, Merseburger Str. 3, 06255 Mücheln. Germany \\ 2 Dept. Crop and Animal Sciences, Faculty of Agriculture and Horticulture, Humboldt- \\ Universität zu Berlin, Phillipstr. 13, 10115 Berlin, Germany \\ 3 Dept. Environmental Sciences and Process Engineering, Brandenburg University of \\ Technology, Siemens- Halske- Ring 8, 03046 Cottbus, Germany \\ 4 Inst. of Animal Nutrition, Dept. of Veterinary Medicine, Freie Univerität Berlin, Königin- \\ Luise-Str. 49, 14195 Berlin, Germany \\ *Corresponding author: ronald.krieg@t-online.de
}

\begin{abstract}
The effect of the lignin:cellulose ratio (LCR) on intestinal morphology and microbial activity should be described. A pelleted feed was given ad libitum (CF 17.0\%; CP 15.4\%; CL 3.4\% DM). Supplementation of $\operatorname{Arbocel}^{\circledR}$ (23.2\% ADL and $71.1 \%$ ADF in DM) and Vitacel $^{\circledR}(0.1 \%$ ADL and $80.5 \%$ ADF in DM; Rettenmaier GmbH. Germany) in alternating parts (0-2-4-6-8\% each) was practiced. Therefore the amount of ADF increased slightly in the 5 feeds, while the lignin level (as a result of Arbocel ${ }^{\circledR}$ addition) increased from 3.5 to $5.7 \%$ in DM, and the LCR increased (0.26/ 0.30/ 0.32/ 0.34/ 0.40 ). Fifty females were divided in five feeding groups with 10 mothers and 8.1 suckling animals per doe. After the 28 day suckling period 200 weaned rabbits were divided into five groups, following the feeding group of their mothers. At day 12 after weaning caecum samples from 20 healthy animals of each group were taken and histological parameters resp. volatile fatty acids (VFA) were analyzed.

Neither mortality or morbidity measured from 29 to $40 \mathrm{~d}$ old differed among the five groups, while the feed intake and growth was reduced. When the LCR increased the
\end{abstract}


total concentration of VFA in caecum linearly decreased, while the VFA molar proportions were slightly modified. For an increased LCR we detected a decreased in caecal crypt depth $(222 / 236 / 192 / 150 / 142 \mu \mathrm{m})$. To describe the physiological potential in a complete feed the lignin and cellulose content seemed not sufficient. If the lignin content was 5\% (DM) in feed and LCR over 0.4 the microbial activity would decreased and the caecal mucosa would be reduced.

Key words: Rabbit, weaning, lignin, lignocellulose, caecum, volatile fatty acids, morbidity.

\title{
TOTAL AND ILEAL DIGESTIBILITY AND CAECAL BACTERIAL FIBROLYTIC ACTIVITY IN ADULT RABBIT FED WITH RESISTANT STARCH
}

\author{
Pinheiro V. ${ }^{1}$, Falcon E., Cunha L. ${ }^{2}$, Mourao J. L. ${ }^{1}$, Gidenne T. ${ }^{3 *}$ \\ 1 - UTAD, CECAV - Department of Animal Science, University of Trás-os-Montes e Alto Douro, P. O. \\ Box 1013, 5000-911 Vila Real, Portugal \\ 2 - Department of Animal Science, University Técnica of Lisboa, Instituto Superior of Agronomia, Tapada \\ da Ajuda, 1000 Lisboa, Portugal \\ 3 - INRA INPT ENSAT ENVT, UMR1289 Tissus Animaux Nutrition Digestion Ecosystème et \\ Métabolisme, F-31326 Castanet-Tolosan, France \\ * Corresponding author: thierry.gidenne@ toulouse.inra.fr
}

\begin{abstract}
The effect of intake of resistant starch on the digestive response of the rabbit was analysed by comparing a low, medium, or a high intake of resistant starch obtained by replacing wheat starch (WS) by raw potato starch (PS) in diets. Three diets, with 0,7 or $14 \%$ of PS (resp. WS, PS7 and PS14) and having a high and similar concentration of starch $(20 \%)$, were given to adult rabbits. The ileal, caecal and total digestibility, and the bacterial enzymatic activity (cellulase, xylanase and pectinase) have been measured in ileo-cannulated animals. In adult rabbit the ileal digestibility of starch was over $95 \%$, while that of protein averaged $69 \%$. Only the ileal starch digestibility was slightly reduced ( 98.3 for $96.7 \% ; \mathrm{P}=0.001$ ) when $14 \%$ of potato starch replaced wheat starch. The bacterial fibrolytic activity in the caecal content was not significantly affected by level of resistant starch. Consequently, we assume that even for a high intake of resistant starch, the ileal starch concentrations and flow remained low, and should not be a risk factor for the microbial activity and balance in the caecum.
\end{abstract}

Key words: Adult rabbits, potato starch, digestibility, caecal activity.

\section{EFFECT OF MASH FEED ON THE PERFORMANCE OF GROWING RABBITS.}

\author{
Montessuy S..$^{{ }^{*}}$, Guerin P. ${ }^{1}$, Rebours G. ${ }^{1}$, Reys S. ${ }^{1}$ \\ ${ }^{1}$ Techna, BP10, 44220 Couëron, France \\ *severine_montessuy@techna.fr
}




\begin{abstract}
This trial shows the effect of an increasing proportion of "mash" (crude raw materials) on growth performance of rabbits between 32 and 70 days old. Four diets were compared, including an increasing proportion of mash $(0,15,20$ and $25 \%)$. Nutritional composition of diets was similar. Feed intake was restricted between 32 to 56 days and thereafter animals were fed ad libitum. During the restricted period (32-56 d), weight gain and feed conversion ratio were impaired significantly as the proportion of mash increased (e.g. for weight gain: 48.1, 46.0, 45.1 and $43.9 \mathrm{~g}$ per day for the diets with 0 , 15, 20 and 25\% of mash, respectively). During the ad libitum period (56-70 d), a compensatory growth took place for the 3 "mash" diets, but it was not enough to compensate the lower growth during the restricted period. On the whole period, the diets with mash impaired significantly the feed conversion ratio from 2.75 (control) to 2.96 (25\% mash).
\end{abstract}

Key words: Rabbit, feed presentation, mash, performance, growing.

\title{
EUROPEAN RING-TEST ON THE CHEMICAL ANALYSES OF TOTAL DIETARY FIBRE AND SOLUBLE FIBRE OF COMPOUND DIETS AND RAW MATERIALS FOR RABBITS
}

\author{
Xiccato G. ${ }^{1}$, Trocino A. ${ }^{2}$, Tazzoli M. ${ }^{1}$, Majolini D. ${ }^{1}$, Carabaño R ${ }^{3}$, Villamide \\ M.J., García J. ${ }^{3}$, Nicodemus N. ${ }^{3}$, Abad R. ${ }^{3}$, Blas E. ${ }^{4}$, Cervera C. ${ }^{4}$, Ródenas L. ${ }^{4}$, \\ Martínez E. ${ }^{4}$, Falcao-E-Cunha L. ${ }^{5}$, Bengala Freire J.P. ${ }^{5}$, Maertens L. ${ }^{6}$, Bannelier \\ $\mathrm{C}^{7}$, , Segura M. ${ }^{7}$, Gidenne T. ${ }^{7}$ \\ ${ }^{1}$ Department of. Agronomy, Food, Natural Resources, Animal and Environment (DAFNAE), University of Padova \\ Viale dell'Università 16 - I-35020 Legnaro, Padova, Italy \\ ${ }^{2}$ Department of Comparative Veterinary Biomedicine and Food Science (BCA), University of Padova, \\ Viale dell'Università 16, I-35020 Legnaro, Padova, Italy \\ ${ }^{3}$ Departamento de Producción Animal, ETSI Agrónomos, University of Madrid, Ciudad Universitaria, 28040 Madrid, \\ Spain \\ ${ }^{4}$ Instituto de Ciencia y Tecnología Animal, Universidad Politécnica de Valencia, Camino de Vera s/n, 46022 Valencia, \\ Spain \\ ${ }^{5}$ Instituto Superior de Agronomia, Universidade Técnica de Lisboa, Tapada de Ajuda, 1399 Lisboa, Portuga \\ ${ }^{6}$ Institute of Agricultural and Fisheries Research, Scheldeweg 68, 9090 Melle, Belgium \\ ${ }^{7}$ INRA, UMR 1289, Tissus Animaux, Nutrition, Digestion, Ecosystème et Métabolisme (TANDEM), BP 52627, F-31326 \\ Castanet-Tolosan Cedex, France \\ *Corresponding author: gerolamo.xiccato@unipd.it
}

\begin{abstract}
Due to the role of soluble fibre (SF) on the digestive physiology and gut health of postweaning rabbits and to the lack of reference methods for SF determination, in the framework of the harmonization activity on rabbit science methodologies carried out by EGRAN (European Group on Rabbit Nutrition), a collaborative study was achieved on the determination of total dietary fibre (TDF), aNDF corrected for protein and ash (aNDFcorr) and SF calculated as the difference between TDF and aNDFcorr. Five EGRAN laboratories analysed nine samples: four compound diets and five raw
\end{abstract}


materials (alfalfa meal, wheat bran, grape marc, sunflower meal, sugarbeet pulp) with different levels of fibre fractions and SF. Each sample was analysed 3 runs for TDF and aNDFcorr. TDF was analysed according to the AOAC Method 991.43 using the kit and the procedure of Megazyme ${ }^{\circledR}$.

TDF averaged $48.2 \% \mathrm{DM}$, with one laboratory having higher values (49.3\% vs $47.9 \%$; $\mathrm{P}<0.001)$. The TDF values varied among samples $(\mathrm{P}<0.001)$, from about $40 \% \mathrm{DM}$ for diets to $60 \% \mathrm{DM}$ for grape marc and sugarbeet pulp. Repeatability $\left(\mathrm{S}_{\mathrm{R}}=0.95 \% \mathrm{DM}\right)$ and reproducibility of TDF $\left(\mathrm{S}_{\mathrm{L}}=1.68 \% \mathrm{DM}\right)$ were good with a low coefficient of variation among laboratory: $\mathrm{CV}_{\mathrm{L}}=3.9 \%$. The aNDFcorr (mean $37.1 \% \mathrm{DM}$ ) significantly differed from laboratories that used Ankom system $(36.4 \% \mathrm{DM})$ to laboratories that used Fibertech equipment (38.3\% DM). The differences among laboratories due to the equipment and to the corrections for ash and protein explained the poorer repeatability and reproducibility of aNDFcorr determination, with $\mathrm{CV}_{\mathrm{L}}=6.6 \%$. SF values differed $(\mathrm{P}<0.001)$ among laboratories (from $9.6 \%$ to $12.0 \%$ $\mathrm{DM}$ ) and samples (from $4.0 \% \mathrm{DM}$ of wheat bran to $8-11 \% \mathrm{DM}$ of diets and alfalfa meal to $24.3 \% \mathrm{DM}$ of sugarbeet pulp). The among-laboratory variability of SF was higher $\left(\mathrm{S}_{\mathrm{L}}=2.97 \% \mathrm{DM} ; \mathrm{CV}_{\mathrm{L}}=26.8 \%\right)$, due to the variability of both TDF and aNDFcorr analyses.

In conclusion, TDF analysis was characterized by good repeatability and reproducibility, but it was less reproducible in case of raw materials with high SF levels. The among laboratory variation increased with aNDFcorr, because of the differences in analytical equipment and the procedure for protein and ash corrections. Finally SF reproducibility appeared rather good for complete diets and raw materials with low or medium concentration (SF 4-10\% DM), but it was affected by the analytical errors of both TDF and aNDFcorr and needs a better harmonization.

Key words: Total dietary fibre, soluble fibre, collaborative study, feed composition, EGRAN.

\title{
DIETARY SUPPLEMENTATION OF SPIRULINA (Arthrospira platensis) AND THYME (Thymus vulgaris). PART 2: EFFECT ON GASTROINTESTINAL GROWTH, CAECAL MICROBIOTA AND FERMENTATION IN RABBITS
}

\author{
Bónai A., ${ }^{1}$, Dalle Zotte A. ${ }^{2}$, Kametler L. ${ }^{1}$, Vántus V. ${ }^{1}$, Morsy W. A. ${ }^{3}$, Matics, Zs. ${ }^{1}$, \\ Dal Bosco A. ${ }^{4}$, Szendr Zs. ${ }^{1}$, Kovács M. ${ }^{1}$ \\ ${ }^{1}$ Faculty of Animal Science, Kaposvár University, 40. Guba S. str., H-7400, Kaposvár, Hungary \\ ${ }^{2}$ Department of Animal Medicine, Production and Health, University of Padova, Agripolis, \\ Viale dell'Università 16, 35020 Legnaro (PD), Italy \\ ${ }^{3}$ Animal Production Research Institute, Agricultural Research Center, Ministry of Agriculture, \\ Dokki, Cairo, Egypt \\ ${ }^{4}$ Department of Applied Biology, Animal Science Section, University of Perugia, Borgo XX \\ Giugno 74, 06121, Perugia, Italy \\ *Corresponding author: bonai.andras@ mail.ke.hu
}




\begin{abstract}
The objective of this study was to evaluate the effect of a dietary supplementation with Spirulina or/and Thyme on the rabbit gastrointestinal tract development (from 5 to 11 weeks old), the composition of the microbiota and production of volatile fatty acids. Four groups of 21 rabbits weaned at 35 days of age and then fed ad libitum, either a control diet or the same diet supplemented with 5\% Spirulina or 3\% Thyme, or both. Six healthy animals from each group were randomly selected and sacrificed at 35, 56 and 77 days of age. No significant differences were detected in body weight (bw) between the groups. Relative weight of kidneys, stomach, small intestine, caecum decreased with age from $0.8,1.5,3.0,1.5 \%$ bw to $0.6,1.1,2.5,1.4 \%$ bw resp. No diet effect on $\mathrm{pH}$ of the small intestine and the caecal content was detected, while gastric $\mathrm{pH}$ increased with age from 1.5 to 2.0. Number of E. coli, total anaerobic and strictly anaerobic bacteria decreased with age (from $\log _{10} 3.9$ to $3.2,8.8$ to 8.4 and 8.1 to 7.8 resp.). No effect of the diet could be demonstrated. Supplementation with Thyme has no significant effect on caecal VFA profile. In conclusion, Spirulina and/or Thyme supplementation of diet after weaning had no substantial effect on the growth of the gastrointestinal tract, the composition of the caecal microbiota and VFA production.

Key words: Spirulina, Thyme, Gastrointestinal growth, Caecal fermentation, caecal microbiota, Rabbit.
\end{abstract}

\title{
HAEMATOLOGICAL INDICES OF RABBITS FED GRADED LEVELS OF TWO FIBRE SOURCES
}

\author{
Atansuyi, A.J. ${ }^{1 *}$, Akinyemi, M.B. ${ }^{2}$, Omo-Akeju, M.O. ${ }^{3}$, Chineke C.A. ${ }^{4}$, Aletor \\ V.A. ${ }^{5}$ \\ Department of Animal Production and Health, \\ Federal University of Technology, P. M. B. 704, Akure, Ondo State, Nigeria \\ E-mail: atansuyiwale@yahoo.com
}

\begin{abstract}
The study was conducted to establish the relationship between packed cell volume (PCV) and other blood parameters of rabbits fed graded levels of fibre sources. A total of twenty-five weaner rabbits used for the study were randomly assigned into five dietary groups of five replicates. The study lasted for twelve weeks. The two dietary fibre sources used were Wheat Offal (W/O) and Brewery Dried Grain (BDG). Treatment A without fibre source was the control while treatments $\mathrm{B}$ and $\mathrm{C}$ contained W/O, treatments D and E contained BDG as fibre sources each at 30\% and 60\% levels of inclusion respectively.Two rabbits were randomly selected per treatment for slaughtering and blood collection at the end of the study. The blood parameters studied were: packed cell volume (PCV), erythrocyte sedimentation rate (ESR), red blood cells (RBC), white blood cell (WBC), haemoglobin concentration (HBC), lymphocytes (LYMN), neutrophils (NEUT), monocytes (MONO), eosinophils (EOS) and basophils $(\mathrm{BASOPH})$. The blood parameters were subjected to correlation and regression
\end{abstract}


analysis. The analysis revealed that correlation coefficient between PCV-HBC was perfect and highly significant $(\mathrm{P}<0.01)$. It was also significant for PCV-ESR and $\mathrm{PCV}-\mathrm{RBC}(\mathrm{P}<0.05)$ while the other parameters were not significantly different $(\mathrm{P}>$ $0.05)$. However, the study also showed that negative correlation existed between PCVLYMPH, PCV-MONO and PCV-ESO. The three functions used for prediction in the study were linear, exponential and quadratic. Accuracy of prediction was best with quadratic function except for WBC where the accuracy of prediction was best with linear function. The result showed that the level of PCV was directly proportional to the level of haemoglobin and an increament in ESR, BASOPH and RBC led to corresponding increase in PCV of the animals. However, the level of WBC, NEUT, LYMN, MONO and EOS did not affect the level of PCV. This means that the level of these parameters in the blood were determined by the presence of foreign materials but not the level of PCV. The study therefore recommended that rabbits fed graded levels of fibre sources could be reared intensively as meat animals on commercial scale using W/O and BDG as fibre sources with no or minimal haematological disorders.

Key words: Relationship, Rabbit, fibre, haematology and parameter 


\title{
GROWTH PERFORMANCE OF RABBITS MANIPULATED AT EARLY POST WEANING AGE FOR HEAVIER BODY WEIGHTS
}

\author{
Orheruata, A. M., Bello-Onaghise, G. , Omoyakhi, J. M. \\ Department of Animal Science, University of Benin, P. M. B. 1154, Benin City, Nigeria. \\ Email- maorheruata@yahoo.co.uk or micorhe@ uniben.edu
}

\begin{abstract}
This study was conducted to determine the effect of manipulation of growth in rabbits at post-weaning ages on body weight (BW) at sexual maturity. A diet of $12 \% \mathrm{CP}$ was formulated as the control diet and a $16 \% \mathrm{CP}$ diet was used to manipulate growth at weaning ( $28 \mathrm{~d}$ ) to 8 weeks, 8 to 12 weeks, and 12 to 16 weeks for a total of four diets treatments. The $\mathrm{BW}$ records from weaning to 20 weeks post-weaning age were collected and arranged in a completely randomized design and subjected to statistical analyses. Results of analyses showed significant differences in BW of the rabbits at every phase of manipulation with those in Treatment 2 (fed between $8-12$ weeks of age) having higher $\mathrm{BW}$ values. The difference in $\mathrm{BW}$ of rabbits that received Treatment 2 was consistently higher than those of other diet treatments from weaning to 20 weeks of age. Correlation coefficient values among BW of rabbits at postweaning ages ranged from 0.375 to 0.966 . The highest correlation coefficient value $(0.966 ; \mathrm{P}<0.001)$ was obtained between BW at 16 and 20 weeks, while the lowest (0.375) was between 4 and 16 weeks of age. Results of the study therefore revealed that the adoption of the management practice of manipulating growth through feeding between 8 and 12 weeks of age will result in the production of table size rabbits of $1.464 \mathrm{~kg}$ and $1.655 \mathrm{~kg}$ at 16 and 20 weeks of age, respectively.
\end{abstract}

Key words: Rabbit, Post-weaning growth, Diet

\section{SOCIAL ACCEPTANCE OF RABBIT MEAT PRODUCTION IN EKITI STATE OF SOUTHWESTERN NIGERIA}

\author{
Dairo, F. A. S. ${ }^{1}$, Abi, H. M. ${ }^{1}$, Oluwatusin, F. M. ${ }^{2}$ \\ ${ }^{1}$ Dept. of Animal Production \& Health Sciences, Ekiti State University, P.M. B. 5363, 234/030, \\ Ado-Ekiti, Nigeria. \\ ${ }^{2}$ Dept. of Agricultural Economics \& Extension, Ekiti State University, P.M. B. 5363, 234/030, Ado-Ekiti, \\ Nigeria. \\ *Corresponding author: fasdairo@yahoo.com
}

\begin{abstract}
This study examined the socio-economic characteristics of rabbit farmers and rabbit meat consumers that influenced the awareness and acceptability levels in Ekiti State,
\end{abstract}


Nigeria. The experimental procedures were field surveys, personal interviews, and administration of structured questionnaires to farmers involving the characteristics of the people in 8 out of 16 local government areas of Ekiti State that were randomly selected for the study. Results showed a fairly high level of awareness of rabbit production $(60 \%)$ with low levels of rabbit producers $(0.70 \%)$ and rabbit meat consumers $(17.0 \%)$. The producers which cut across the family status were largely in the age group of $51-60$ years $(26.0 \%)$ and $>60$ years $(26.0 \%)$. Forty-seven percent of the producers were married and $7.0 \%$ divorced. About $66.7 \%$ raised rabbits with intention of sales for educational purpose (teaching and research), while $33.3 \%$ strictly raised rabbits for meat consumption. Fifty-nine percent of the respondents seldom consume rabbit meat, while $8.0 \%$ consume it on a daily basis. Rabbit consumption cuts across the social stratum but was more evident in the farmers group (32.0\%), followed by civil servants and traders (29.0\% each). Consumers preferred smoked meat $(72.0 \%)$ to frozen or roasted. Production of the rabbit is at its infancy in Ekiti State, but with about $9.72 \%$ growth, which is encouraging. Kitchen wastes only were used to feed rabbits by $22.0 \%$ of the rabbit producers, $37.0 \%$ fed forages alone, $33.0 \%$ kitchen wastes/forages and $8.0 \%$ pellets/forages. Most of the respondents $(66.0 \%)$ used bamboo/wood hutches, while $1 \%$ kept their rabbits in welded iron cages. The family accounted for the major source of labour (96.30\%) with no credit facility. Overall, production challenges identified were lack of good foundation stock, disease/pest infestation (notably mange), inability to purchase good quality feed, and lack of government support.

Key words: Rabbits, Social acceptability, meat consumption, Ekiti State, Nigeria

\title{
CHARACTERIZATION OF REPRODUCTIVE PERFORMANCE OF THE APRI LINE OF RABBITS
}

\author{
Abou Khadiga G. ${ }^{1}$, , Youssef Y. M. K. ${ }^{2}$, Baselga M. ${ }^{3}$ \\ ${ }^{1}$ Faculty of Desert and Environmental Agriculture, Fuka, Matrouh, Alexandria University, Egypt. \\ ${ }^{2}$ Animal Production Research Institute, Nadi El-Sead Str., Doki, Giza, Egypt \\ ${ }^{3}$ Departamento de Ciencia Animal, Universidad Politécnica de Valencia, Camino de Vera, 14. 46071 \\ Valencia, Spain \\ *Corresponding author:abokhadiga@yahoo.com
}

\begin{abstract}
An attempt to characterize the reproductive performance of a new synthetic maternal line of rabbits (APRI) recently formed in Egypt has been carried out. The formation of the line, a general description, main features of its reproductive performance are presented here. Selection program, genetic improvement and primary results are included, as well. Data of six generations after the line formation were considered for litter, reproductive and milk traits. Most of the results are in the range of those that have been reviewed for the specialized lines in the Mediterranean area. The reproductive performance of the APRI line could be an indicator to an acceptable line that performs well under Egyptian conditions. Continuation of the current selection
\end{abstract}


program and using this line in three-way crossbreeding schemes in Egypt to produce the higher performing does is recommended.

Key words: Rabbits, Maternal line, Litter traits, Reproductive performance.

\title{
TRADE BALANCE OF HUNGARIAN RABBIT MEAT
}

\author{
Szendr K.*, Szendr Zs. \\ Kaposvár University, 7400 Kaposvár, P. O. Box 16, Hungary \\ "Corresponding author: szendro.katalin@ke.hu
}

\begin{abstract}
In 2009, Hungary was at the $14^{\text {th }}$ place ranking among rabbit meat producing countries (5,400 tons). However, since domestic rabbit meat consumption was low (3-4\%), and $96-97 \%$ of the slaughtered rabbits were sold to international markets, it claimed the $4^{\text {th }}$ place when only the rabbit meat trade was concerned. No data are available about selfconsumption levels. According to the database of FAOSTAT, the main present challengers are China, France, and Belgium. Hungarian rabbit meat was exported mainly to Italy (46.3\%), Germany (20.3\%) and Switzerland (18.8\%), while the Russian Federation and the Netherlands significantly increased their import demands. Although Italy increased its imports in total, the share of Hungarian rabbit meat declined (from 75.7 to $55.4 \%$ between 2005 and 2009). In contrast, Germany demands far less foreign rabbit meat, but the imports from Hungary have steadily increased (17.8\%). The Swiss imports were also shrinking, but the share of Hungarian rabbit meat remains at approximately $50 \%$. Besides stimulating national consumption, Hungarian rabbit meat production and trade could be facilitated by retaining the position in existing markets, also by expanding the exports to those countries where further potential can be exploited due to increased demand. Small-scale rabbit production almost ceased in Hungary and was only $1-2 \%$ of the total purchased quantity. The contribution or share of Hycole, Pannon White, Debreceni White, Hyla and Zika were 60.9, 30.5, 4.5, 2.8 and $1.3 \%$, respectively. According to the demands of foreign markets, rabbit cages with platforms were established in large numbers, where the kits can be reared at their place of birth. In conclusion, although the promotion of high quality Hungarian rabbit meat is no longer enough to captivate new target markets; innovative approaches are needed in marketing, while reliability and better satisfaction of consumers' demands should be also emphasized.
\end{abstract}

Key words: Rabbit meat, Hungary, production, trade balance, export, import.

\section{TRAITS OF MEAT QUALITY IN RABBITS IN AN INTEGRATED ORGANIC FARMING SYSTEM}

\footnotetext{
Cossu M. E. ${ }^{1 *}$, Cervini M. L. ${ }^{1}$, Lamanna M. L. ${ }^{1}$, Giardina E. ${ }^{2}$

1. Dto. Producción Animal Facultad de Agronomía. Univ. de Buenos Aires. Av. San Martín 4453, Bs. As. Argentina.

2. Dto. Producción Vegetal. Facultad de Agronomía. Univ. de Buenos Aires. Av.San Martín 4453, Bs. As.A rgentina.

*Corresponding author: mcossu@agro.uba.ar
} 


\begin{abstract}
The aim of the trial was to characterize the carcass and meat quality of New Zealand White $\mathrm{x}$ Californian (NZWxC) rabbits obtained from an organic farming system, associated with vegetable production. Twenty-five rabbits of both sexes and 35 days of age were bred during Autumn in 5 plots located in the Organic Vegetable Garden of the Faculty of Agronomy. The rabbits were fed with vegetables, fresh and dried alfalfa forage and cereals from the organic vegetable garden. At slaughter (107 days; $2,4 \mathrm{~kg}$ live weight), dressing percentages and qualitative trait measures of the carcass and nutritive values of the meat were recorded. The average of both sexes for carcass yield was $56 \%$ with a meat/bone ratio of 4.5. Despite the slaughter age, the levels of fat in the carcass $(2.06 \%$ of carcass weight) and WB shear force values (1.82 and 1.52 for the loin and the hind leg, respectively) were low, corresponding to a lean carcass and very tender meat. The n6/n3 ratio was 4.4 (loin) and 3.7 (hind leg) and the PUFA/SFA measure was 0.88 (loin) and 0.80 (hind leg) which, according to the limits recommended for human consumption (n6/n3 <4 and PUFA/SFA >0.45), were lower and higher, respectively. The production of $\mathrm{NZWxC}$ rabbits reared on floor, integrated with the organic vegetable garden production, reached the slaughter weight required by the Argentine market ( 2.3 to $2.5 \mathrm{~kg}$ ) after 107 days. Rabbit meat produced from the organic farming system as associated with horticultural production resulted in high nutritional values, according to the dietary recommendations for the care of human health.
\end{abstract}

Key words: Rabbit, vegetable garden, organic production, meat nutritional value.

\title{
THE INTERNATIONAL COMPETITIVENESS OF CHINA'S RABBIT MEAT INDUSTRY
}

\author{
Laping Wu, Rui Gu, Xuanfu Li \\ College of Economics \& Management, China Agricultural University. \\ No.17, Qinghua East Road, Haidian District Beijing, 100083, P.R. China \\ E-mail: wulp@cau.edu.cn
}

\begin{abstract}
Based on the introduction and development of the Chinese rabbit meat sector, which is based on both production and trade perspectives, this study developed a Revealed Comparative Advantage (RCA) index to analyze the competitiveness of Chinese rabbit sector in the world market. Cost and price comparisons among major rabbit producing countries were made to further explore the reasons for specific advantages and level of competitiveness. The results show that China has enjoyed a higher comparative advantage in rabbit production every year since 2003, though it did face a rapid decline before 2003. The Chinese rabbit meat sector has bright future in both production and trade, especially in the present view of the tight grain supply in China. Raising rabbits will continue to be an important choice for both saving feed grain while providing enough meat.
\end{abstract}

Key words: Rabbit, meat, international competitiveness, RCA, China 


\title{
TRANSFORMING THE BACKYARD FARMING UNIT TO THE INDUSTRIAL PRODUCTION UNIT: THE 'KANGDA MODEL'
}

\author{
Yan Y.K.", Li S.D., Zhang P. \\ Qingdao Kangda Foodstuff Co., LTD, No. 317 Binhai Avenue Jiaonan 266400, Qingdao, China \\ *Corresponding author: yanyk@ vip.sina.com
}

\begin{abstract}
China is the largest rabbit raising country in the world. Rabbit production account for $42 \%$ of that of the world. Most production is represented by small-scale backyard farms. Compared with the European industrial farming pattern (all-in, all-out), its production efficiency and economic benefits are $27.4 \%$ to $45.5 \%$ lower. In rural China, the raising of rabbits has become a major activity for many farmers. Under this circumstance, the raising patterns or model should be changed. The industrial farming system is the best choice for farmers to improve their production efficiency and economic benefits. But it is difficult for farmers to realize the benefits of industrialscale farming. The best avenue is for farmers to form or constitute cooperatives, and contractually cooperate with large rabbit meat processing companies. Qingdao Kangda Foodstuffs Co., Ltd., is the largest rabbit meat processing company in China. It has several large breeding farms, feed factories, and rabbit production farms. However, production from Kangda's own farms is not enough, and we need more rabbits from small-scale rabbit farms. Qingdao Kangda offers a protective price to cooperative farmer groups and resupplies breeding stock, supplies the feed, the artificial insemination service, technology training, etc. Farmers supply the market meat rabbits to the processing company through a cooperative structure. This is a win-win position. This kind of approach or solution is called the 'Kangda Model'. Furthermore, this model helps farmers to adopt the industrial farming, all-in, all-out system. Farmers can also sell back their infertility breeders through the cooperative unit to reduce production costs. The Kangda model - a corporation involving rabbit meat processing companies and rabbit grower cooperatives - could change the profit pattern of China's rabbit meat industry in the near future.
\end{abstract}

Key words: Industrial farming, Rabbit farming, Cooperative, Kangda model.

\section{ANNUAL PRODUCTIVITY INDEX: A SYNTHETIC INDEX OF RABBIT GENETIC VALUES FOR IMPROVING FARM EFFICIENCY}

\author{
Finzi A. ${ }^{1}$, Crosta M. ${ }^{1}$, González-Redondo P. ${ }^{2 *}$ \\ ${ }^{1}$ Rabbit Unconventional Keeping Experimental Centre, Consorzio Coniglio Verde Leprino di Viterbo, 01030 \\ Vasanello (Viterbo), Italy \\ ${ }^{2}$ Departamento de Ciencias Agroforestales, Escuela Técnica Superior de Ingeniería Agronómica, Universidad \\ de Sevilla, 41013 Sevilla, Spain \\ *Corresponding author: pedro@us.es
}




\begin{abstract}
To face the problem of selecting for increased production, or at least to maintain an acceptable level of reproduction rate, in backyard or small rabbit keeping units, a simple total selection index was developed in the mid 1980's. This index, named Annual Productivity Index (IPa, according to the Italian language), was based on the estimation of the annual, cumulative number of kits weaned per doe. The practical application of the IPa has worked well for many years, allowing for the selection of does in a simple manner and while maintaining an acceptable level of production on a farm by identifying and culling animals with a lower reproductive performance index. In order to test the predictive value of this index (for the selection of better does that weaned more kits versus culling of the worst does), an analysis was performed utilising the carefully recorded doe cards of an industrial farm located in the Viterbo province (Italy). The mean $\mathrm{IPa}$ value of the farm was 48.5 weaned rabbits per doe per year. Index values rose sharply from the first weaning, but increased more slowly from the third to the $14^{\text {th }}$ weanings (parity), while remaining at high values for does weaning 50 rabbits per year. A randomly selected sample consisting of a third of the breeding stock was necessary to validate estimates of IPa values for the entire breeding herd that involved all weaning records between the $1^{\text {st }}$ and the $14^{\text {th }}$ weanings. Present index values could be reliably predicted $(\mathrm{P}<0.001)$ based on the IPa value of a certain weaning order as a function of the value of another previous weaning beyond the $3^{\text {rd }}$ weaning. Therefore, the IPa index has been confirmed as a useful tool for selecting does and as a tool to easily measure the overall productivity level of a farm.
\end{abstract}

Key words: Rabbit, Management, Annual Productivity Index, Culling, Selection.

\title{
EVALUATION OF FEATHER MEAL IN THE DIET OF GROWING RABBITS
}

\author{
Trigo M. ${ }^{1}$, Borrás M. ${ }^{1}$, Muro M. ${ }^{1}$, Lamanna L. ${ }^{3}$, Antonini A. ${ }^{1,2}$, Cossu M. \\ ${ }^{1}$ Curso de Introducción a la Producción Animal, Facultad de Ciencias Agrarias y Forestales, \\ Universidad Nacional de La Plata, 60 y 119, B1904AAO, La Plata, Argentina \\ ${ }^{2}$ Instituto de Genética Veterinaria, Facultad de Ciencias Veterinarias, Universidad Nacional de La \\ Plata, 60 y 118, B1904AAO, La Plata, Argentina \\ ${ }^{3}$ Departamento de Producción Animal, Facultad de Agronomía, Universidad de Buenos Aires, Av. \\ San Martín 4453, C1417DSE, Buenos Aires, Argentina \\ *corresponding author: mstrigo@agro.unlp.edu.ar
}

ABSTRACT

The aim of this study was to evaluate the effect of an alternative protein source $(\mathrm{MM}=$ meat meal and $\mathrm{FM}=$ feather meal) and level (17 and 14\% CP) on performance and carcass traits in rabbits. For the experiment, 128 New Zealand $\mathrm{x}$ Californian rabbits were used, being weaned at 28 days of age. The experimental design was a $2 \times 2$ factorial arrangement of two sources of animal protein: MM (meat meal as the control diet) and FM (hydrolyzed feather meal) and two levels of crude protein (CP: 17\% and $14 \%$ as a control (being an alternative, lower protein requirement in the finishing period)). The digestibility of diets was evaluated based on 10 animals per treatment (between 49 and 56 days of age), using cages provided with individual faeces collectors. Performance traits recorded were daily weight gain, feed conversion ratio, 
dry matter digestibility, feed cost per rabbit and feed cost per $\mathrm{kg}$ of meat produced. Forty animals (10 for each treatment) were slaughtered at 75 days of age, following standard procedures of slaughter. Data were analyzed by ANOVA. The protein level of diet significantly influenced feed intake, DM digestibility, weights at 55 days and at slaughter, rate of feed conversion, percentage of gastro-intestinal tract, weight of the stomach (full and empty), weight of the full caecum, hot carcass weight, and carcass yield. The source of protein significantly influenced actual and dry matter intake levels and feed cost per rabbit. Although the inclusion of FM did not generally affect performance traits, it did affect performance on the protein-restricted diets.

Key words: Rabbits, Diet, Protein level, Protein source, Feather meal.

\title{
DEVELOPING SUSTAINABLE DIETS FOR RABBITS: EFFECT OF SWEET POTATO FORAGE ON GROWTH AND FEEDING TRAITS
}

\author{
Garza M.T. ${ }^{1}$, Lukefahr S.D. ${ }^{1 *}$, Schuster G.L. ${ }^{2}$, Mc-Cuistion K.C. ${ }^{1}$ \\ ${ }^{1}$ Dept. of Animal, Rangeland and Wildlife Sciences and ${ }^{2}$ Dept. of Agriculture, Agribusiness, and \\ Environmental Sciences, MSC 228, Texas A\&M University, Kingsville, TX 78363, USA \\ *Corresponding author: s-lukefahr@tamuk.edu
}

\begin{abstract}
The objective of this two-year investigation was to develop a sustainable feeding system involving diets for growing rabbits based on sweet potato (SP) forage (leaves with vines) with limited commercial feed or energy supplements that could potentially benefit smallholder families. Diets evaluated in 2010 consisted of: 1) commercial pellets, 2) 24-hr wilted SP forage plus half of the commercial pellets consumed by control animals on the previous day, and 3) 24-hr wilted SP forage with crimped oats. In 2011, diets were: 1) commercial pellets, 2) 24-hr wilted SP forage with crimped oats, and 3) SP hay made by exposing harvested forage in a drying room or in open sunlight for approx. $4 \mathrm{~d}$ with crimped oats. Forage was offered to rabbits on an ad libitum basis. Diets were evaluated based rabbit performance. The duration of the 2010 and 2011 studies were 35 and $28 \mathrm{~d}$. Breed types were crossbred and New Zealand White (NZW). The 2010 study involved 54 NZW and crossbred rabbits from 15 litters with initial age ranging from 51 to $57 \mathrm{~d}$. The 2011 study involved 45 NZW and crossbred rabbits from 12 litters with initial age ranging from 54 to $56 \mathrm{~d}$. All pens contained three rabbits of the same breed type but different litters. A mixed-model was used to analyze growth and feeding traits that included the source of litter as random blocks. Chemical analyses revealed that DM varied for commercial pellets, SP wilted and hay as forage, and crimped oats at 92.9, 14.5, 48.0, and 92.8\%, respectively. Leaves from SP had numerically higher CP (32.5 vs. $17.7 \%)$ but lower gross energy (3.45 vs. $4.34 \mathrm{mcal} / \mathrm{kg}$ ) than commercial pellets. Also, the NDF value was lower for SP leaves than pellets (16.0 vs. $38.3 \%$ ), but $\mathrm{ADF}$ and $\mathrm{ADL}$ values were numerically similar. The Ash content of SP leaves was higher than for pellets (15.5 vs. 9.6\%). In both years, initial BW means were similar $(\mathrm{P}>0.05)$ across diets. Mean ADG was more
\end{abstract}


rapid and final $\mathrm{BW}$ was heavier for controls than for forage fed groups $(\mathrm{P}<0.0001)$. For pen traits in 2010, controls consumed an average of $96.9 \mathrm{~g} / \mathrm{d}$ of pellets, while the wilted SP with $50 \%$ pellets group consumed an average of $48.2 \mathrm{~g} / \mathrm{d}$ of pellets $(\mathrm{P}<0.05)$. The average rabbit DM intake of wilted SP forage with $50 \%$ pellets and without pellets was 17.5 and $26.5 \mathrm{~g} / \mathrm{d}$, respectively $(\mathrm{P}<0.05)$. In 2011 , average rabbit $\mathrm{DM}$ intake was highest $(\mathrm{P}<0.05)$ for pellets and lowest for wilted SP and intermediate for SP hay. In 2010 , no differences were detected $(\mathrm{P}>0.05)$ among diets for gross feed efficiency. However, for the 2011study, gross feed efficiency was significantly different among all three diets. In conclusion, despite superior growth performance of controls fed commercial pellets, the cost of SP forage was considerably lower (economic analyses not reported in this paper) and growth performance was satisfactory, which warrants further investigation.

Key words: Rabbits, forages, growth, sweet potato, sustainability.

\title{
RABBIT REARING AND AIR QUALITY: STATE-OF-THE- ART AND KEY UNKNOWNS
}

\author{
Calvet S., Cambra-López M., Adell E., Torres A.G., Estellés F.* \\ Institute of Animal Science and Technology, Universitat Politècnica de València, Camino de Vera \\ 14, 46022, Valencia, Spain \\ *Corresponding author: feresbar@upv.es
}

\begin{abstract}
Animal production is a potential source of atmospheric pollution in regards to ammonia, greenhouse gases, and airborne particulate matter. Ammonia can cause respiratory problems to human and animals and cause environmental eutrophication and acidification. Methane and nitrous oxide are greenhouse gases with high global warming potential. High concentrations of particulate matter (PM) can cause detrimental effects on health and welfare of humans and animals and can threaten the environment, as well. These pollutants have been quantified in most livestock production systems. However, information about these emissions from rabbit farming is scarce. For this reason, emission values cannot be extrapolated from other species, and therefore research in regards to the quantification of airborne pollutant concentration and emissions from rabbit houses is still necessary. The main objective of this work was to describe recent advances on the research line developed by the "Livestock and Environment" research group of the Institute of Animal Science and Technology of the Universitat Politècnica de Valencia (Spain), regarding the quantification of airborne pollutant concentration and emissions from rabbit houses: ammonia, greenhouse gases, and particulate matter. This paper will also address research gaps and future research directions in this area. Gas concentrations and emissions were monitored in three rabbit farms in Eastern Spain during four seasons, while particulate matter concentrations and emissions were monitored in two rabbit units during autumn. Fattening rabbits and does were studied in both cases. Concentrations of ammonia and carbon dioxide remained below the thresholds
\end{abstract}


recommended for animal and human health, while nitrous oxide concentrations were found to be low. Regarding emissions, significant differences were obtained among different observation periods, both for does and fattening rabbits. Ammonia and nitrous oxide emission factors for rabbit production were found to be higher than those reported for other animal categories. Airborne PM concentrations in both rabbit farms were below occupational thresholds according to human health, and below maximum exposure recommendations for livestock. Particulate matter concentrations were significantly influenced by type of human farm activity performed in the building rather than by animal activity. Average PM emission rates $(\mathrm{g} / \mathrm{h})$ were slightly higher in fattening rabbits compared to reproducing does. Emission rates expressed per animal unit were lower compared to poultry, pigs or cattle. According to our current knowledge, future research should examine the relationship among air pollutants on the farm, environmental impacts, and farm productivity. The effect of increased concentrations of air pollutants, especially NH3 and PM, on rabbit health should be further analysed. To improve the quality of national air pollutant emission inventories, representative emission factors for different regions and management systems would be required.

Key words: Ammonia, Methane, Nitrous oxide, Particulate matter, Emissions.

\title{
EVALUATION OF CLIMATE CONTROL STRATEGIES IN RABBIT HOUSES
}

\author{
Estellés F.*, Bustamante E., Torres A.G., Calvet, S. \\ Institute of Animal Science and Technology, Universitat Politècnica de València, Camino de Vera \\ 14, 46022, Valencia, Spain \\ *Corresponding author: feresbar@upv.es
}

\begin{abstract}
Productive and health traits, animal welfare, and environmental pollution factors are strongly affected by environmental conditions. Therefore, achieving optimal conditions for animals in terms of environmental conditions is crucial. In order to achieve the highest level of well-being for rabbits, the main factors that must be controlled are: temperature, relative humidity, air velocity, and gas concentrations (mainly ammonia and carbon dioxide). Among all tools available to control, the key factor is ventilation rate. The main aim of this paper is to provide a clear methodology to determine ventilation rates in rabbit buildings to achieve optimal environmental conditions. In addition, different ventilation designs will be evaluated in terms of air velocity and distribution profiles. To this aim, ventilation rate requirements were calculated following four criteria (controlling temperature, relative humidity, carbon dioxide, and ammonia concentrations) for a whole year in a given location (Castellón, Spain) for both fattening rabbits and reproducing does. Air velocity patterns and velocities were studied in four structures considered as being representative of typical rabbit buildings using computational fluid dynamics. One of them was naturally ventilated while the other three were considered as mechanically ventilated buildings. For the given
\end{abstract}


conditions, the maximum ventilation rate requirements occurred at the end of autumn, while there was other peak during summer. In general, the control of humidity is the most restrictive criteria, followed by ammonia concentration control. Regarding the air velocity patterns in buildings, naturally ventilated buildings, as well as cross-flow and chimney mechanically ventilated buildings, presented a more homogeneous distribution. The position of sidewall inlets had a strong effect on the air velocity profiles at animals' level, being a potential tool to reduce heat stress in warm climates.

Key words: Rabbits, Ventilation rate, Climate control, Air velocity, Air distribution.

\title{
BIOLOGICAL UTILIZATION OF VISCERA SLAUGHTER WASTE FROM RABBITS AS COMPOST
}

\author{
Cossu M.E ${ }^{1}{ }^{*}$, Cumini M.L ${ }^{1}$, Lamanna M.L ${ }^{1}$, Gambetti $P^{1}$., Iglesias M. F., ${ }^{1}$ \\ Robbiolo M. ${ }^{1}$, Lienneman T. ${ }^{1}$, Vela E. ${ }^{2}$ \\ ${ }^{1}$ Departamento de Producción Animal. Facultad Agronomía. Univ. de Buenos Aires. Av. San Martín \\ 4453.Argentina. \\ ${ }^{2}$. Laboratorio de Suelos. Facultad Agronomía. Univ. de Buenos Aires. Av. San Martín \\ 4453.Argentina \\ *Corresponding author: mcossu@agro.uba.ar
}

\begin{abstract}
The aim of the trial was to study composting as a bioconversion technique for the treatment and processing of rabbit viscera, considered as a slaughter waste. Nine compost cribs ( $0.60 \mathrm{~m} \times 1 \mathrm{~m} \times 0.40 \mathrm{~m}$ high) were made and contained one of the following mixtures (3 cribs /treatment): Control - $60 \%$ wood chips and $40 \%$ rabbit faeces; Viscera - 60\% wood chips and 40\% viscera, and VF - $60 \%$ wood chips, $20 \%$ faeces and $20 \%$ rabbit viscera. The cribs were located on the grounds of a penitentiary located in Entre Ríos, Argentina, that included a rabbit production unit, a rabbit slaughter house, a vegetable garden, and a carpentry unit. Prior to turning the compost, temperature and $\mathrm{pH}$ readings were determined weekly and samples were sent to the laboratory for soils of the Faculty of Agronomy (Univ. Buenos Aires) to determine humidity, electrical conductivity, and nutrient content. Treatment data were tested using statistical analyses procedures for time repeated measures. The $\mathrm{pH}$ of the 3 treatments complied with standard values set for organic fertilizers ( $\mathrm{pH} 4-9)$ with no differences $(\mathrm{P}>0.05)$ among treatments. Viscera and Control treatments showed a moisture content level close to the recommended value $(<20 \%)$. All treatments produced compost with values below the threshold for ash $(<60 \%$ set by the EPA). The contents of $\mathrm{K}$ and $\mathrm{P}$ were acceptable for all treatments, being higher in Control and Viscera groups compared to the VF treatment. The organic carbon content was lower than the recommended level (> $15 \%$ set by the EPA) after 15 days of composting, although treatments Viscera and Control had higher values than VF, being close to recommended levels. In conclusion, the composting process offers a technically relevant solution to the negative environmental impact caused by the improper handling of the viscera of rabbits. The physical and chemical data results from the three treatments suggest the
\end{abstract}


recommendation of using composting mixtures from the sawdust-faeces and sawdust-viscera.

Key words: Composting, rabbit viscera, faeces, penitentiary unit.

\title{
ANALYSIS OF MANAGEMENT TECHNIQUES ON PRODUCTIVITY INDICATORS USING THE bdcuni SPANISH DATABASE
}

\author{
Serrano P. ${ }^{1}$, Pascual M. ${ }^{1}$, Lavara R. ${ }^{2 *}$, Gómez E.A. ${ }^{1}$ \\ ${ }^{1}$ IVIA - Centro de Investigación y Tecnología Animal, P.O. Box 187, Segorbe, 12400 Castellón, Spain. \\ ${ }^{2}$ Instituto de Ciencia y Tecnología Animal, Universidad Politécnica de Valencia, Camino de Vera s/n, \\ 46022 Valencia, Spain. \\ *Corresponding author: rlavara@dca.upv.es
}

\begin{abstract}
The objective of this work was to study the effect of the size of the farm $(<600$ does, 600-1,000 does and >1,000 does), the geographic area (north, central, and Mediterranean area), the batch management (one or more batches), and the season (hot and mild season) on technical trait production results of rabbitries, using data from the Spanish rabbit database "bdcuni". Technical data from a total of 46 farms were used with 947 batches recorded. Size of the farm had an effect $(\mathrm{P}<0.05)$ only on the amount of $\mathrm{kg}$ produced per kindling, being higher on farms with 600 to 1,000 does than on farms with less than 600 does. Batch management was only related with the market liveweight, being the heaviest on farms managed using one batch. No effects of season $(\mathrm{P}>0.05)$ were observed on real fertility, number of kindlings per female and year, and mortality rates. Effects of season of insemination on liveweight for sale, number of kits born alive, number of kits weaned, number of kits produced, and amount of kg produced per female and year, per insemination, and per kindling were found $(\mathrm{P}<0.05)$ with higher values for inseminations in hot compared to the season. Geographic area had an effect $(\mathrm{P}<0.05)$ on several production traits, mostly with differences between the north compared to central and Mediterranean areas.
\end{abstract}

Key words: Production, rabbits, technical management.

\section{ECONOMIC EVALUATION OF RABBIT GENOTYPES DIFFERING IN GROWTH RATE AND CARCASS CHARACTERISTICS}

\author{
Szendr K. ${ }^{1 *}$, Odermatt M. ${ }^{2}$, Matics Zs. ${ }^{1}$, Széles Gy. ${ }^{1}$, Horn P. ${ }^{1}$, Szendr Z Zs. ${ }^{1}$ \\ ${ }^{1}$ Kaposvár University, 7400 Kaposvár, P. O. Box 16, Hungary \\ ${ }^{2}$ Olivia Ltd., 6050 Lajosmizse, Mizse 94., Hungary \\ "Corresponding author: szendro.katalin@ke.hu
}




\begin{abstract}
The aim of the study was to carry out an economic evaluation of different genotypes based on the most important cost factors of feed and the revenue from processed products. Pannon White (PW) and maternal line (M) does were inseminated with the sperm of 3 genotypes: M, PW, or a large body line (LB), each selected on different criteria (M: litter size, PW: weight gain and carcass traits, LB: weight gain and carcass traits). Progeny of 7 genotypes of different crossing combinations $(n=224)$ were evaluated: MM, MPW, MLB, PWPW, PWM, PWLB, LBLB. Rabbits were weaned at the age of $5 \mathrm{wk}$. Body weight was measured at 5 and $11 \mathrm{wk}$ and the feed intake fortnightly. The weight of whole carcass, head, heart and lung, liver, kidneys, fore part, loin fillet, mid part's bone, thigh meat, and thigh bone were quantified. The revenue from whole carcass and carcass parts were based on the Italian market price. Gross profit was calculated on the level of production chain (including farm and slaughterhouse) based on the actual weight at slaughtering and of $2.5 \mathrm{~kg}$. Cost to revenue and gross profit to cost ratio, also the efficiency were determined on equal weight in all genotypes. MM performed the lowest values in terms of cost of weaned and slaughter rabbits, production cost and total expenses, followed by PWPW, while LBLB was the most expensive. LBLB realized the highest total revenue from carcass parts $(9.31 € / \mathrm{kg})$ and the highest gross profit (5.58 €/rabbit), based on the actual slaughter weight, followed by PWLB (8.94 and $5.54 €$, respectively). While calculating on equal slaughter weight of $2.5 \mathrm{~kg}$, the highest gross profit was found in PWPW (4.65 $€)$, followed by PWLB (4.57 €). The best cost to revenue ratios (42.66 and 43.12\%) and gross profit to cost ratios (134 and 132\%) were found in the case of PWLB and PWPW, respectively. Despite the general negative correlation between adult weight and carcass traits, on average, the performance of progenies of PW does and the progenies of LB males were superior. Comparing the pure genotypes, Pannon White rabbits reached the best results, followed by the large body line and the maternal line. In general, long-term CT-based selection on carcass traits leads to the development of more valuable genotypes in terms of cost to revenue, gross profit to cost ratios and efficiency.
\end{abstract}

Key words: Rabbit, Genotypes, Meat value, Cost to revenue, Gross profit, Efficiency.

\title{
ESTABLISHMENT AND OPERATION OF CHINA'S RABBIT PRODUCTION COOPERATIVES
}

\author{
Yinghe Qin \\ College of Animal Science and Technology, China Agricultural University \\ NO.2 Yuanmingyuan West Road, Haidian District, Beijing, 100193 P.R. China \\ E-mail: qinyinghe@ cau.edu.cn
}

\begin{abstract}
China is now the world's largest rabbit farming country. The percentage of its rabbit meat production in total meat production has increased year by year. In addition, rabbit farming regions are widely spread across the country with vast numbers of both microor small-scale backyard rabbit breeders. The main problem of the small-scale rabbit
\end{abstract}


farming system is the lack of marketing ability and the difficulty of applying new technologies. The key solution to address this problem is to develop reasonable and effective organization of large numbers of small-scale farmers so that they can collectively deal with market demand and also achieve technical progress by forming rabbit farming cooperatives. There are three major types of rabbit farming cooperatives in China, each with different structure and marketing modes (according to the composition and management areas) cooperative members that can most effectively meet the growing market demand. Along with the development of China's rabbit farming industry, rabbit farming cooperatives will likely exist for many years, but will continue to adjust in accordance with the development of the domestic and global market and economy.

Key words: Rabbits, Production, Farming cooperatives, China.

\title{
A PARTICIPATORY APPROACH TO DEFINE OBJECTIVES, CRITERIA AND INDICATORS FOR VALUATING THE SUSTAINABILITY OF RABBIT REARING UNITS
}

\author{
Fortun-Lamothe L. ${ }^{1}$, Litt J. ${ }^{2}$, Coutelet G. ${ }^{3}$, Gidenne, T. ${ }^{1}$ \\ ${ }^{1}$ INRA, UMR1289 Tissus Animaux Nutrition Digestion Ecosystème et Métabolisme, F-31326 \\ Castanet-Tolosan, France \\ ${ }^{2}$ ITAVI Sud Ouest, Maison de l'Agriculture, Cité Galliane, BP 279, 40005 Mont-de-Marsan Cedex \\ ${ }^{3}$ ITAVI, 4 rue de la Bienfaisance - 75008 Paris \\ *Corresponding author: lamothe@toulouse.inra.fr
}

\begin{abstract}
This work describes four steps involved in the construction of a method for evaluating the sustainability of rabbit farms: 1) determining the boundaries of the system evaluated; 2) defining and weighting sustainability objectives and criteria; 3 ) choosing sustainability indicators; 4) converting the indicator measurement into a score to facilitate interpretation of the results. The work was developed collaboratively as part of a participatory approach based on building consensus between experts, rabbit industry actors (producers, breeders, slaughterers...), citizens, and consumers. The outcome was a survey containing 110 questions related to economic, environmental, and social goals that can be used to evaluate sustainability of the rabbit breeding unit. The method was validated by in-field application in a national network of 82 reference farms. Analysis of the data gathered from this network enabled us to produce national data on sustainability performance and economic, social, and environmental efficiency. Key words: Sustainability assessment, Methodology, Rabbit, Indicator.
\end{abstract}




\title{
SUSTAINABILITY OF FRENCH RABBIT BREEDING SYSTEMS
}

\author{
Fortun-Lamothe L. ${ }^{1 *}$,G. Coutelet ${ }^{2}$,J. Litt ${ }^{3}$, S. Combes ${ }^{1}$, \\ T. Gidenne ${ }^{1}$, S. DeJean ${ }^{4}$ \\ ${ }^{1}$ INRA, UMR1289 TANDEM, Chemin de Borde Rouge, BP 52627, F-31326 Castanet Tolosan, \\ France \\ ${ }^{2}$ ITAVI, 4 rue de la Bienfaisance - 75008 Paris, France \\ ${ }^{3}$ ITAVI Sud Ouest, Maison de l'Agriculture, Cité Galliane, BP 279, 40005 Mont de Marsan Cedex, \\ France \\ ${ }^{4}$ Institut de Mathématiques, Université Paul Sabatier, 31062 Toulouse cedex 9, France \\ *Corresponding author: lamothe@toulouse.inra.fr
}

\begin{abstract}
This work aimed at evaluating the sustainability of performance of French rabbit breeding systems using the DIAMOND method. Seventy-six rabbit farms in 12 French regions, chosen to be representative of French production units, were surveyed to obtain 111 measured indicators as related to economic, environmental, and social issues. The farms were specialised (level of economic specialisation $=76 \%)$ and were of variable size $(210$ 2,100 females). The responses obtained were transformed into scores (or sustainability units) and then pooled by objectives or sustainability goals. Analysis of the data showed that economic, environmental, and social performances were highly variable among farms (means: 45,44 , and 37 points on a scale of $0-100$, and CV: 27,14 and $16 \%$, respectively). In conclusion, results revealed that technical choices or structural characteristics of the farm influence the sustainability scores and categorises rabbit farms according to their sustainability profile.
\end{abstract}

Key words: Sustainability, Economy, Environment, Social, Rabbit.

\section{PRESENT STATUS OF THE WRSA-SUPPORTED RABBIT DEVELOPMENT PROJECT IN HAITI}

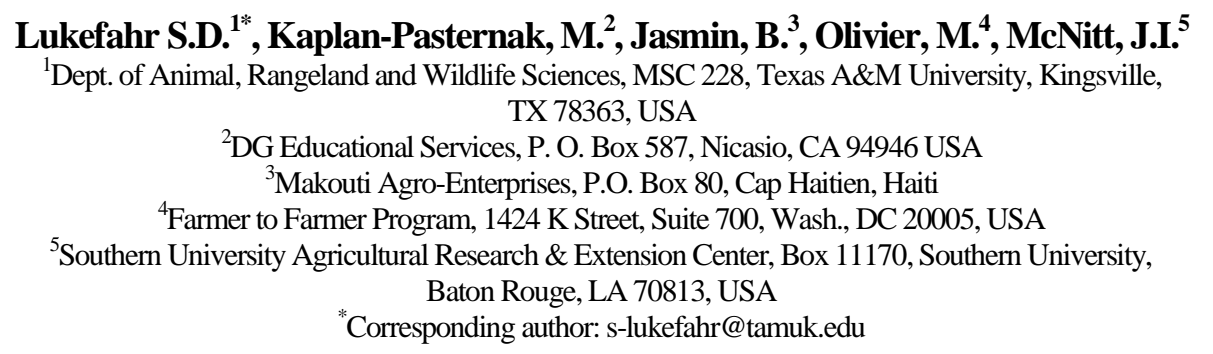

\begin{abstract}
Haiti is the poorest country in the Western Hemisphere. Formal efforts to expand smallscale rabbit production in Haiti with the aim of alleviating poverty have been made since 1996 through the Farmer to Farmer (FTF) program that is coordinated by Partners of the Americas and funded by the U.S. Agency for International Development. The modus
\end{abstract}


operandi of this program is to send out American volunteers with specialty skills (e.g., rabbit health, reproduction, project development, forage production, and food safety) for 2 to 3 weeks to train mostly farmers, but also students and professionals, at key project locations. Following the more recent devastating earthquake in Haiti in January of 2010, this and other humanitarian efforts have been intensified to further expand rabbit farming enterprises to over 1,000 resettled rural families. In general, farmer enthusiasm towards rabbit project success has been high. Survey data reveal that the people are most willing to raise rabbits and consume the meat on a regular basis. In terms of housing, sheds constructed using a simple pole-barn with aluminum roof design and cages assembled as a quonset-hut style design have been more recently promoted by the host organization, Makouti Agro-Enterprise. Typical of many projects in the LDCs, local diets are foragebased. However, many farmers have struggled in offering a quality diet even though feed ingredients as supplements exist locally. In addition, common health-related problems include low body condition, infertility, and slow growth, which appear to be largely associated with poor quality diets. Common diseases include ear and skin mange and coccidiosis. Hence, retraining efforts continue to focus on feeding and health, as well as on general management, and good progress is being achieved. In 2010, the ongoing rabbit program was aided with monies donated by the World Rabbit Science Association (WRSA). The WRSA gift was used to improve the technical knowledge on rabbit production through farmer training and the purchase of breeding stock and equipment. Since receiving WRSA funding assistance, 3,075 farmers have received rabbit training by FTF volunteers and Makouti staff in 123 separate training sessions. In addition, Makouti staff locally manages the project. They have been working closely with several rabbit experts for many years now and have acquired much knowledge and useful experience, which has not only been applied to advance this project, but to ensure eventual selfsufficiency status. To date, 1,718 rabbit producers maintain 1,246 production units (consisting of 32,642 total breeding rabbits) have been established in four regions, which have directly benefited 6,931 participants. Over the past 2-1/2 years there has been a $142 \%$ increase in the number of breeding rabbits. The average increase in monthly income from rabbit sales is 19.55 USD per family (some families are earning over 200 USD per month), which relates to 403,043 USD over the past three years. A positive sign is that most rabbits are sold for breeding rather than for meat because of the growing popularity of rabbit farming. In conclusion, despite major challenges, much progress has been realized towards strengthening the foundation of the rapidly expanding meat rabbit industry in Haiti. The monetary gift by the WRSA is greatly appreciated, which will ensure that the project will continue to improve many people's lives in Haiti for years to come.

Key words: Rabbits, poverty alleviation, project development, sustainability, Haiti.

\title{
EVALUATION OF PERFORMANCE AND HEALTH STATUS OF DWARF RABBITS FROM WEANING TO MATURITY
}

\author{
Dalle Zotte A.*, Sartori A. \\ ${ }^{1}$ Dept. of Animal Medicine, Production and Health, University of Padova, Agripolis, Viale dell'Università, 16, \\ 35020, Legnaro (PD), Italy \\ *Corresponding author: antonella.dallezotte@unipd.it
}




\begin{abstract}
This study was carried out to follow the body development of dwarf rabbits from weaning to adult age, according to their gender. One hundred and forty five "coloured dwarf" rabbits of six wk of age weighing $514 \pm 27 \mathrm{~g}$ were used. The animals were housed in individual cages and were fed ad libitum with a commercial pelleted diet. Individual body weight and feed consumption were measured twice a week to determine weight gains, feed intake, and feed conversion index. Health status was monitored daily in order to identify animals that were losing weight, diarrhoea events, or with teeth problems. At 20 and 45 wk of age, the animals' fatness was evaluated by measuring their skin fold width. From 19 wk of age onwards, the live weight of females $(\mathrm{F})$ was significantly heavier than that of males (M) $(\mathrm{P}<0.05)$. Up to $20 \mathrm{wk}$ of age, the feed intake levels were higher and weight gains more rapid in $\mathrm{F}$ than $\mathrm{M}$, whereas from $40 \mathrm{wk}$ of age onwards, the situation was reversed. At 45 wk of age, the skin fold width was significantly thicker in $M$ than in $F(4.28$ vs $3.56 \mathrm{~mm}$, respectively; $\mathrm{P}<0.001$ ). During the first $20 \mathrm{wk}$ of age, 9 rabbits died for digestive problems, whereas 13 were excluded for sickness and 5 for overgrowth of teeth. The teeth problems were also observed in 42 other rabbits at the end of the trial, but it did not lead to animal's culling. These results showed a clear sexual dimorphism in live performances, resulting in heavier live weights in $\mathrm{F}$ than $\mathrm{M}$ at adult age. For this reason, feed companies should consider diversified diets according to the gender. The live weight at $45 \mathrm{wk}$ of age exceeded the standard values of the reference dwarf breed.
\end{abstract}

Key words: Dwarf rabbit, Maturity, Growth, Health status

\title{
MORPHOMETRIC CHARACTERISTICS OF DWARF RABBITS: EFFECTS OF AGE AND GENDER
}

\author{
Dalle Zotte A. ${ }^{1}{ }^{*}$, Paci G. ${ }^{2}$, Sartori A. ${ }^{1}$ \\ ${ }^{1}$ Department of Animal Medicine, Production and Health, University of Padova, Agripolis, Viale dell'Università \\ 16, 35020, Legnaro (PD), Italy \\ ${ }^{2}$ Department of Animal Pathology, Prophylaxis and Food Hygiene, University of Pisa, Viale delle Piagge 2, \\ 56124 Pisa, Italy \\ *Corresponding author: antonella.dallezotte@unipd.it
}

\begin{abstract}
The aim of the study was to provide information on the morphometric development of dwarf rabbits from growing until adult age, according to their gender. A total of 136 "coloured dwarf" rabbits (74 males and 62 females) were used. At 20 and 45 weeks of age, the rabbits were weighed and body measurements were taken on each rabbit at predefined anatomical points using a digital Caliper $(\mathrm{mm})$ or a measuring tape $(\mathrm{cm})$. The measurements included: three distance measurements (in $\mathrm{cm}$ ): body length, BL; ear length, EL; head length, HL; height measurement (in $\mathrm{cm}$ ): head height, $\mathrm{HH}$; seven width measurements (in mm): shoulder width, SW; rump width, RW; tibia width, TW; ear width, EW; forehead width, FHW; head width, HW, skin fold width, FW; two circumferences (in $\mathrm{cm}$ ): thoracic circumference, TC; and abdominal circumference, AC. Using these body measurements, a total of 3 body indices were estimated to define the general conformation of the animals: compact index 1: rump width/body length (RW/BL); compact index 2:
\end{abstract}


thoracic circumference/body length (TC/BL); compact index 3: abdomen circumference/body length (AC/BL). Data collected were subjected to analysis of variance (ANOVA) studying the effect of age (20 wk, $45 \mathrm{wk})$, sex (M, F), and their interaction (age x sex). Statistical significance of differences was assessed by the t-test. Considering the main effects, all traits were affected by age and almost all body measurements by sex with the exception of BL, EL, FHW, HL, and TC/BL. At both ages, females showed heavier live weights than males (1,630 vs $1,542 \mathrm{~g}$ and $1,953 \mathrm{vs}$ $1,850 \mathrm{~g}$, at 20 and $45 \mathrm{wk}$ of age, respectively). Significant sex differences were also found for $\mathrm{AC}$ at $45 \mathrm{wk}$ of age: females presented higher $\mathrm{AC}$ value than males (29.5 vs $27.8 \mathrm{~cm} ; \mathrm{P}<0.01)$. Concerning head measurements with increasing age, males showed the highest mean value of FHW and HW than females at 45 and at 20 wk (4.25 vs 4.13 and 3.86 vs $3.87 \mathrm{~mm}, \mathrm{P}<0.05$; 4.64 vs 4.29 and 4.34 vs $4.18 \mathrm{~mm}, \mathrm{P}<0.01$, respectively). The FW results showed significantly higher values for males at 45 and $20 \mathrm{wk}$ of age than females (4.28 vs 3.63 and 3.76 vs $3.62 \mathrm{~mm}, \mathrm{P}<0.01$, respectively). With regards to the indices, only the compact index $1(\mathrm{RW} / \mathrm{BL})$ showed significant differences $(\mathrm{P}<0.01)$ with males at $20 \mathrm{wk}$ being less compact than females. The results showed clear sexual dimorphism for nearly all traits considered, resulting in heavier live weights in females than males at both ages. Considering that some body measurements did not correspond to the breed standards for "coloured dwarf" rabbits and that they showed a high degree of variability, this suggests that through the selection process that other breeds were used in its formation. The use of uncontrolled selection at the commercial scale could lead to this breed becoming in danger of extinction.

Key words: Dwarf rabbit, Morphometric measurements, Age, Gender.

\title{
USE OF SOLAR AND SOCIAL PERCEPTION OF DOMESTIC RABBIT (Oryctolagus cuniculus) IN TWO RURAL COMMUNITIES OF THE STATE OF YUCATAN, MEXICO
}

\author{
Cruz - Bacab, L. ${ }^{1 *}$, Sandoval- Castro, C ${ }^{1}$, Pantoja - Nuñez, G. ${ }^{2}$ \\ ${ }^{1}$ Universidad Autónoma de Yucatán - Campus de Ciencias Biológicas y Agropecuarias \\ ${ }^{2}$ Instituto Tecnológico de Sonora - Depto. De Ciencias Agronómicas y Veterinarias \\ *Corresponding author: veterina@www.uady.mx
}

\begin{abstract}
The necessity for efficient alternatives in animal production in rural areas make it necessary to know the current use of the home garden and the potential for inclusion of new species in this production unit. This paper discusses the current use of home gardens in two rural communities of Yucatan, Mexico (Ucu and Santa Elena), and surveys knowledge of the domestic rabbit (Oryctolagus cuniculus) and its potential inclusion in home gardens. Two-hundred twenty-seven surveys were obtained in Ucu and 98 in Santa Elena. The results show a greater proportion of activities related to agriculture and animal husbandry in Santa Elena than in Ucu $(\mathrm{P}<0.05)$. Similarly, greater interest in raising rabbits was found in Santa Elena as compared to Ucu ( $\mathrm{P}<0.05)$.
\end{abstract}

Key words: Yucatan, rabbit, rural inclusion. 


\title{
THE IMPACT OF INCORPORATION OF ORGANIC SELENIUM INTO MEAT ON GROWTH PERFORMANCE, ANTIOXIDATIVE STATUS, AND IMMUNE RESPONSE IN GROWING RABBITS
}

\author{
Ebeid T. ${ }^{*}$, Zeweil H. ${ }^{2}$, Basyony M. ${ }^{3}$, Badry $_{\text {H. }}{ }^{2}$ \\ ${ }^{1}$ Dept. of Poultry Production, Faculty of Agriculture, Kafrelsheikh University, 33516, Kafr El-Sheikh, Egypt \\ ${ }^{2}$ Dept. of Animal and Fish Production, Faculty of Agriculture (Saba Basha), Alexandria University, Egypt \\ ${ }^{3}$ Dept. of Animal Nutrition, Animal Production Research Institute, Ministry of Agriculture, Egypt \\ *Corresponding author: tarkamin@yahoo.com
}

\begin{abstract}
Thirty California male rabbits, 6 weeks old, were randomly divided into 3 experimental treatments (10 each). Animals were fed ad libitum the basal diet containing $0.13 \mathrm{ppm}$ selenium (Se), supplemented with 0 (control), 0.15 or $0.3 \mathrm{ppm}$ organic Se in the form of a yeast source from 6 to 12 weeks of age. Dietary supplementation of organic Se increased final body weight and daily gain, while feed conversion ratio was reduced in the growing rabbits. Supplementation with 0.15 and $0.3 \mathrm{ppm}$ organic Se increased both hot carcass weight and dressing percentage. Se deposition in hindleg meat significantly increased in proportion to the dietary organic Se concentration. Dietary organic Se had no negative effects on chemical composition in hindleg meat. It is also interesting to note that inclusion of 0.15 or $0.3 \mathrm{ppm}$ Se in the growing rabbits' diets elevated serum total antioxioxidant capacity and reduced the lipid peroxidation expressed as serum malondialdehyde which finally translated into enhancing the immune response. In conclusion, supplemental dietary organic Se enhanced growth performance and carcass weight, increased the Se content in meat, stabilized the antioxidative status, and elevated the humoral immune response in growing rabbits.
\end{abstract}

Key words: Organic Se, Antioxidative systems, Immunity.

\section{INTEGRATION BETWEEN SUPPLEMENTAL VITAMIN E AND ENDOGENOUS ANTIOXIDANT ENZYMES OF DIFFERENT RABBIT GENETIC RESOURCES: 2- EFFECT ON MEAT QUALITY}

\author{
Abdel-Khalek A.M. ${ }^{*}$, Gihan Shaaban F. ${ }^{2}$, El-Refaay W.H. ${ }^{3}$, Azoz A.A. ${ }^{1}$, \\ Selim Nessrin A. ${ }^{1}$, El-Medany Sh.A. ${ }^{3}$, Abd El-Salam Amal B ${ }^{1}$. \\ ${ }^{1}$ Animal Production Research Institute, ARC, Dokki, Giza, 12618, Egypt. \\ ${ }^{2}$ Department of Poultry Science, Faculty of Agriculture, Fayoum University, Fayoum, 63514, Egypt. \\ ${ }^{1}$ Animal Production Research Institute, Dokki, ARC, Egypt. \\ ${ }^{3}$ Regional Centre for Food and Feed, ARC, Egypt. \\ *Corresponding author: aabdelkhalek_apri@yahoo.com
}




\begin{abstract}
Lipid oxidation is a limiting factor of meat quality. Integration between supplemental antioxidants and the activity of endogenous antioxidants' enzymes, as well as, introduction of proper rabbit breed could participate to improve the quality of the rabbit meat. The current study was initiated to explore the effect of the relationship between rabbit breed (exotic; V-line vs. native; Gabali) and dietary vitamin E level; 40 (control), 80, or $120 \mathrm{mg} / \mathrm{kg}$ diet on the activities of endogenous antioxidants' enzymes (glutathione peroxidase; GSH-Px, superoxide dismutase; SOD, and catalase; CAT), lipid oxidative stability and $\alpha$-tocopherol content of the hind legs' muscles (oxidative muscle fibers) kept refrigerated (up to 8 days at $4^{\circ} \mathrm{C}$ ) or frozen (30 days at $-20^{\circ} \mathrm{C}$ ). 36 samples distributed among 6 experimental treatments were used in the study. Results indicate that V-line had higher lipid oxidative stability and $\alpha$-tocopherol content, but lower GSH-Px and CAT activities compared to Gabali breed. The increase in dietary vitamin $\mathrm{E}$ was associated with a linear increase in the oxidative stability and $\alpha$ tocopherol content of the muscle, without affecting antioxidants' enzymes activity. Prolonged storage (irrespective of storage method) decreased the activities of endogenous antioxidants' enzymes, lipid oxidative stability and $\alpha$-tocopherol content of the hind legs' muscles. Conclusively, rabbit breed and supplemental vitamin $\mathrm{E}$ have a clear effect on meat quality as it increased the $\alpha$-tocopherol content and lipid oxidative stability of the meat.
\end{abstract}

Key words: Rabbit meat, vitamin E, breed, antioxidants' enzymes, oxidative stability.

\title{
EFFECTS OF DIETARY VITAMIN E SUPPLEMENTATION ON MEAT QUALITY, VITAMIN E CONTENTS AND OXIDATIVE STABILITY OF RABBIT MEAT
}

\author{
Zhang W. ${ }^{1,2}$, Wang X. P. ${ }^{1}$, Wang C. Y. ${ }^{1}$, Li F. C. ${ }^{1 *}$ \\ ${ }^{1}$ College of Animal Science and Technology, Shandong Agricultural University, Taian, 271018, P. R. China \\ ${ }^{2}$ Jining Vocational Technology College, Jining, 272037, P. R. China \\ *Corresponding author: chlf@sdau.edu.cn
}

\begin{abstract}
One hundred and twenty weaned meat rabbits were randomly allocated to one of six diets. The diets contain $0,40,80,160,320$ and $640 \mathrm{mg} / \mathrm{kg} \alpha$-tocopheryl acetate. Fortyeight rabbits were slaughtered at age of 90 days. Effects of dietary vitamin E (VE) supplementation on meat quality, $\alpha$-tocopherol contents and oxidative stability were evaluated. The $\alpha$-tocopherol contents in the serum, liver and meat increased when the dietary VE levels increased ( $P$ 0.0001). The dietary VE supplementation significantly affected the $\mathrm{pH}$ of the Biceps femoris (BF) 45 min post-mortem and day $1(\mathrm{P}<0.05)$. The dietary VE supplementation significantly increased the tenderness of meat and decreased the contents of malondialdehyde (MDA) in serum, liver and meat ( $\mathrm{p}=0.005$, $\mathrm{p}=0.014$ and $\mathrm{P}<0.0001$ ).
\end{abstract}

Key words: Rabbit meat, vitamin E, meat quality, oxidative stability 


\title{
EFFECTS OF THREE REPRODUCTIVE SYSTEMS ON RABBIT CARCASS AND MEAT QUALITY
}

\author{
Guardia S. ${ }^{1 *}$, Theau-Clément M. ${ }^{2}$, Galliot P. ${ }^{1}$, Souchet C. $^{1}$, Bouchier M. ${ }^{1}$, \\ Bignon L. ${ }^{1}$, Fortun-Lamothe L. ${ }^{3}$ \\ 1 ITAVI, 28 rue du Rocher, 750008 Paris, France \\ ${ }^{2}$ INRA. UR 631 Station d'Amélioration Génétique des Animaux, BP 52627, 31326 Castanet.- \\ Tolosan, France \\ ${ }^{3}$ INRA., UMR 1289, Tissus Animaux Nutrition Digestion Ecosystème et Métabolisme, 31326- \\ Castanet Tolosan, France \\ *Corresponding author: guardia.itavi@tours.inra.fr
}

\begin{abstract}
This study investigated the impact of three reproductive systems on the carcass and meat quality of rabbit kits. The extensive, semi-intensive and intensive systems had previously been studied to investigate doe performance. The extensive system was designed to reduce overlap between lactation and pregnancy (first artificial insemination, $\mathrm{AI}_{1}=16.6$ weeks; reproduction rhythm, $\mathrm{RR}=49 \mathrm{~d}$; weaning age, $\mathrm{WA}=$ 30d; slaughter age, $S A=70 d$ ), the semi intensive system corresponds to the main rabbit breeding system used in France $\left(\mathrm{AI}_{1}=19.6\right.$ weeks; $\left.\mathrm{RR}=42 \mathrm{~d} ; \mathrm{WA}=35 \mathrm{~d} ; \mathrm{SA}=70 \mathrm{~d}\right)$ and the intensive system was designed to increase the maximum number of batches reared per year $\left(\mathrm{AI}_{1}=20.6\right.$ weeks; $\left.\mathrm{RR}=35 \mathrm{~d} ; \mathrm{WA}=32 \mathrm{~d} ; \mathrm{SA}=63 \mathrm{~d}\right)$. The impact of the three reproductive systems and sex effect on carcass quality and composition (carcass yield, perirenal fat, hind part to fore part ratio) and on loin and hind leg meat quality (ultimate $\mathrm{pH}$ and color) were investigated. Animals from the extensive and semi-intensive systems had a higher dressing percentage $(+5 \%$ and $+6 \%$, respectively), heavier carcasses $(+18 \%$ and $+17 \%$, respectively) and more perirenal fat $(+27 \%$ and $+22 \%$, respectively) than animals from the intensive system $(\mathrm{P}<0.001)$, probably due to the earlier slaughter age in the latter. Rabbits from the semi-intensive system had the highest hind part to fore part ratio (1.05 vs 1.03 and 1.02; $\mathrm{P}<0.001)$, and females were heavier (2540 g vs $2501 \mathrm{~g} ; \mathrm{P}<0.001)$ and fatter than males $(1.54 \%$ vs $1.38 \%$; $<<0.001)$. Regarding meat quality, the reproductive system only had a slight effect on meat from loins and hind legs $(\mathrm{P}<0.01)$, however, none of the systems lead to decreased meat quality in terms of ultimate $\mathrm{pH}$ or color. Sex had a very limited impact on meat quality. In conclusion, the semi-intensive and extensive systems resulted in similar carcass quality. In contrast, the intensive system reduced the carcass quality (lower weight and dressing percentage). The impact of the rearing system on meat quality is probably not large enough to affect consumer acceptability.
\end{abstract}

Key words: Rabbit, meat quality, carcass quality, reproductive management, sex effect. 


\title{
EFFECT OF SUPPLEMENTATION OF LINSEED OIL, VITAMIN E AND SELENIUM IN DIET FOR GROWING RABBITS ON PRODUCTIVE AND CARCASS TRAITS
}

\author{
Szendr Z Zs. ${ }^{1}$, Gerencsér Zs. ${ }^{1}$, Szabó A. ${ }^{1}$, Fébel H. ${ }^{2}$, Szín M. ${ }^{3}$, Radnai I. ${ }^{1}$, \\ Dalle Zotte A. ${ }^{4}$, Matics Zs. ${ }^{1}$ \\ ${ }^{1}$ Faculty of Animal Science, Kaposvár University, 40, Guba S. str., H-7400, Kaposvár, Hungary \\ ${ }^{2}$ Research Institute for Animal Breeding and Nutrition, 1, Gesztenyés str., H-2053, Herceghalom, \\ Hungary \\ ${ }^{3}$ Olivia Ltd, Mizse 94, H-6050, Lajosmizse, Hungary \\ ${ }^{4}$ Department of Animal Medicine, Production and Health, University of Padova, Agripolis, Viale \\ dell'Universita 16, 35020 Legnaro (PD), Italy \\ "Corresponding author: szendro.zsolt@ $@$ ke.hu
}

\begin{abstract}
The aim of this experiment was to analyse how additional dietary linseed oil, vitamin E and selenium affect live performances and carcass traits in growing rabbits. The basal diet (B) contained 3\% sunflower oil, while it was substituted with 3\% linseed oil in the experimental feed (S). The vitamin $\mathrm{E}$ and selenium content of the two diets was 60 vs $260 \mathrm{mg} / \mathrm{kg}$ and 0.10 vs. $0.46 \mathrm{mg} / \mathrm{kg}$, respectively. Rabbits were fed with B diet from the age of 18 days. One group was fed with the B diet until 11 weeks of age, while the experimental groups (S1, S2, S3 and S4 groups) were fed with S diet for 1, 2, 3 and 4 weeks, respectively, before the slaughter. Body weight gain, body weight, feed intake and feed conversion were not affected by dietary treatment. Mortality, as compared to the $\mathrm{S} 1$ group (0\%) was higher in the in the B group by $13.4 \%$ and in the S2 and S3 groups (5.6 and $11.1 \%$, resp.). The dressing out percentage was the lowest in the S1 group $(61.7 \%)$, while it was significantly higher $(\mathrm{P}<0.05)$ in the $\mathrm{S} 2$ and $\mathrm{S} 3$ groups $(62.8$ and $62.7 \%$ ). The proportion of the mid part, as compared to the reference carcass was the lowest in the $\mathrm{S} 1$ group and the highest in the $\mathrm{S} 3$ ( 31.3 vs $32.0 \%, \mathrm{P}<0.05)$. The proportion of the hind part was the highest in the S1 group $(\mathrm{P}<0.05)$ and the lowest in the S2, S3 and S4 groups (38.8 vs 37.3; 37.2 and $37.1 \%$ ). The weight of the organs, the proportion of the fore part and that of the perirenal fat was identical in all groups. Comparing these results to the literature, it was found that additional dietary linseed oil, vitamin E and selenium has no or only a slight effect on the live perfomances and carcass traits.
\end{abstract}

Key words: Growing rabbits, linseed oil, vitamin E, selenium, live perfomances, carcass traits.

\section{PHYSICAL, CHEMICAL AND SENSORY QUALITY IN RABBIT BURGERS, REFRIGERATED AND STORED UNDER DIFFERENT CONSERVATION METHODS}

Cossu M. E.*, Lamanna M. L., Picallo A. B., Cumini M. L., Gambetti P., Lazzari G. Dto. Prod. Animal. Facultad de Agronomía, Univ. de Buenos Aires. Av. San Martín 4453, Buenos Aires, Argentina. *Corresponding author: mcossu@agro.uba.ar 


\begin{abstract}
The high quality and safety of raw meat products are important features to be conserved during the storage and distribution. Nowadays, processed products are very popular; however, not enough studies have been carried out to assess rabbit meat burgers quality. In order to introduce rabbit meat into the market of processed meat and verify the best method of packaging that prevents lipid and pigment oxidation, chilled $\left(2 \pm 1{ }^{\circ} \mathrm{C}\right)$ burgers, packed without or with vacuum (Multivax) or modified atmosphere (30\% $\mathrm{CO}_{2}-70 \% \mathrm{~N}_{2}$; MAT) stored in dark (refrigerated chamber) or under fluorescent light (commercial fridge) were analysed at 1, 2, 5, 9, 13 and 15 days after preparation (6 hamburgers/packet/day/dark-light storage). Lipid oxidation (TBARS index), raw color (CIELAB system), and pH (Testo205) were determined. Fatty acids were analysed as methyl esters by gas chromatography. Refrigeration and cooking (grill, $71 \pm 1{ }^{\circ} \mathrm{C}$ ) losses were determined by weight difference. Cooked burgers were also analysed by an analytical panel of 8 trained assessors for overall color, off-odours, flavour and off-flavour. The place of storage influenced $b^{*}$ and $C^{*}$ values (higher in dark refrigeration room) and raw and cooked TBARS (higher under light incidence). Packaging and time influenced physical and sensory quality of burgers until 15 days of storage. The longer time of conservation increased values of the $b^{*}$ parameters, TBARS and water losses. Off-odours/off-flavours increased after 9 days of storage but their perception was low, especially for vacuum-packed burgers. Fatty acid profile was not influenced by place, packaging and time. In conclusion, the light/dark storage showed similar effects on the sensory qualitative traits of burgers while the physical quality was mainly influenced by light incidence, vacuum or MAT packaging and storage time.
\end{abstract}

Key words: processed meat, rabbit, vacuum, modified atmosphere, light.

\title{
EFFECT OF STOCKING DENSITY ON GROWTH PERFORMANCE, MEAT QUALITY AND FIBRE PROPERTIES OF BICEPS FEMORIS MUSCLE OF SLOW- GROWING RABBITS
}

\author{
Volek Z. ${ }^{1 *}$, Chodová D. ${ }^{2}$, Tůmová E. ${ }^{2}$, Volková L. ${ }^{1}$, Kudrnová E. ${ }^{1}$, Marounek M. ${ }^{1}$ \\ ${ }^{1}$ Institute of Animal Science, Přátelství 815, Prague, CZ-104 00, Czech Republic \\ ${ }^{2}$ Czech University of Life Sciences, Kamýcká 129, Prague, CZ-165 21, Czech Republic \\ *Corresponding author: volek.zdenek@ vuzv.cz
}

\begin{abstract}
The aim of the present work was to evaluate the effect of stocking density on growth performance, meat quality and fibre properties of Biceps femoris (BF) muscle of Czech White rabbits. A total of 20 rabbits (40 days old) were randomly allocated to two groups (10 rabbits per treatment) and reared at a different stocking density: group SC (small cage, $40 \times 50 \times 43 \mathrm{~cm}$ ) at the density of $10 \mathrm{rabbits} / \mathrm{m}^{2}(2$ animals $/$ cage $)$ and group LC (large cage, $60 \times 80 \times 43 \mathrm{~cm}$ ) at the density of $4 \mathrm{rabbits} / \mathrm{m}^{2}$ ( 2 animals $/$ cage).
\end{abstract}


Animals were fed ad libitum pelleted feed. Rabbits were weighed every 7 days and feed intake was measured every day. At the end of experiment ( 89 days of age), all rabbits were slaughtered and used for the evaluation of carcass and meat traits. Stocking density had no significant effect on growth performance. There were no significant differences between groups with regard to hot carcass weight or the dressing-out percentage. The proportions of both perirenal and total dissectible fat were significantly lower in rabbits reared at the lower stocking density than in rabbits reared at the higher stocking density. There were no significant differences between groups for ultimate $\mathrm{pH}$ values or proximate chemical composition of hind leg meat. Similarly, meat colour $\left(\mathrm{L}^{*} \mathrm{a}^{*} \mathrm{~b}\right.$ ) $)$ assessed on the BF surface was not affected by stocking density. Hind leg meat of rabbits reared at the lower stocking density contained less lauric $(\mathrm{P}=0.008)$ and myristic acid $(\mathrm{P}=0.033)$. There were significantly higher percentages of $\beta \mathrm{R}$ fibres and $\alpha \mathrm{R}$ fibres and a significantly lower percentage of $\alpha \mathrm{W}$ fibres in rabbits reared at the lower stocking density. The mean cross-sectional area and diameter of $\beta R$ fibres were significantly smaller in rabbits reared at the lower stocking density than in rabbits reared at the higher stocking density. It can be concluded that a lower stocking density affected fatty acid profile and fibre characteristics of BF muscle of rabbits in a beneficial way and could provide an important nutritional benefit to humans.

Key words: Rabbit, Stocking density, Meat, Fatty acid, Fibre muscle

\title{
VALIDATION OF THE RELATION BETWEEN IN VIVO ANTIOXIDANT STATUS AND SHELF LIFE OF RABBIT MEAT BY THE KRL METHOD
}

\author{
Weissman D. ${ }^{1}$, Davoust C. ${ }^{1}$, Picard E. ${ }^{1}$, Troislouches G. ${ }^{1}$, Cousin A. ${ }^{1}$, Launay C. ${ }^{1}$ \\ ${ }^{1}$ INZO, Rue de l'Eglise, BP 50019, 02407 Chierry Cedex, France \\ *Corresponding author: dweissman@inzo-net.com
}

\begin{abstract}
The aim of this study was to test the effect of vitamin E concentration in fattening rabbit diet on antioxidant status of animals and meat quality. A total of 120 rabbits were divided into 3 groups at weaning (36 days of age) till slaughtering (70 days of age) according to their live weight the day before weaning and their litter origin. Each group received a different diet with increasing levels of vitamin E: 5, 35 and $105 \mathrm{ppm}$. Blood samples were taken from 16 rabbits per group at the end of the fattening period to analyze blood and red blood cells antioxidant status by KRL method. Among these 16 rabbits, the two hind legs of 12 rabbits were kept after slaughtering to measure $\mathrm{pH}$, color and water loss. Malondialdehyde (MDA), oxidized glutathione (GSSG) and reduced glutathione (GSH) concentrations in the meat of the 2 hind legs of 4 rabbits per group were measured after 1 and 8 days of storage at $4^{\circ} \mathrm{C}$. Results showed that antioxidant protection of animals significantly increased with vitamin $\mathrm{E}$ level in the diet due to higher antioxidant properties of plasma. After 8 days of storage, MDA was less concentrated in the meat when rabbits were fed higher vitamin $E$ rates showing a
\end{abstract}


slowing down of lipid peroxidation. MDA evolution and GSSG concentration after 8 days of storage showed similar results. Color, water loss and $\mathrm{pH}$ were not modified by vitamin $\mathrm{E}$ level in the diet. As a conclusion, an increase of $30 \mathrm{ppm}$ and $100 \mathrm{ppm}$ in vitamin $\mathrm{E}$ in the diet linearly improves antioxidant status of fattening rabbits and rabbit meat shelf life.

Key words: Antioxidant, Rabbit meat, Vitamin E, Oxidation.

\title{
EFFECTS OF GRADUAL INCORPORATION (40 TO 60\%) OF HARD WHEAT BRAN, IN SIMPLIFIED BRAN- ALFALFA-MAIZE DIETS, ON VIABILITY, GROWTH AND SLAUGHTER TRAITS OF RABBITS OF WHITE POPULATION UNDER ALGERIAN CONTEXT
}

\author{
Lounaouci-Ouyed G..$^{{ }^{*}}$, Berchiche M. ${ }^{2}$, Lebas F. ${ }^{3}$ \\ ${ }^{1}$ Département des Sciences Biologiques, Faculté des Sciences Biologiques et Agronomiques, \\ Université Mouloud Mammeri, Tizi-Ouzou, Algérie \\ ${ }^{2}$ Département des Sciences Agronomiques, Faculté des Sciences Biologiques et Agronomiques, \\ Université Mouloud Mammeri, Tizi-Ouzou, Algérie \\ ${ }^{3}$ Cuniculture, 87A Chemin de Lasserre, 31450 Corronsac, France \\ *Corresponding author: ghanialou@yahoo.fr
}

\begin{abstract}
Five groups of 24 rabbits of Algerian White population, weaned at 28 days of age, with an average live weight of $532 \mathrm{~g}$, were placed in collective cages (4 rabbits/cage) and were used to study under Algerian conditions the effects on viability, growth and slaughter traits, of gradual incorporation of hard wheat bran in pelleted and balanced feeds devoid of soybean meal. The rabbits received ad libitum, from 28 to 84 days of age, one of the 5 experimental diets containing $40 \%$ (B40), 45\% (B45), 50\% (B50), $55 \%$ (B55) or $60 \%$ (B60) of hard wheat bran, complemented by maize, dehydrated alfalfa and a mineral and vitamins premix exclusively. The average protein and ADF levels were $14.4 \%$ and $16.0 \%$ respectively. Throughout the experiment, the health status of rabbits was good (average mortality rate of 8.3\%) without significant effect of treatments. The average liveweight, daily growth and intake reached by the rabbits fed B45 diet were significantly higher than those of the others groups of rabbits (respectively: 2269, 31.6 and 98.7 vs 2047 g, $27.32 \mathrm{~g} / \mathrm{d}$ and $80.6 \mathrm{~g} / \mathrm{d}$. However, the feed conversion ratio of $\mathrm{B} 45$ group was significantly $(\mathrm{P}=0.007)$ deteriorated comparatively to the average FCR of the other groups (3.48 vs 3.26). For the B40, B50, B55 and B60 groups of rabbits, growth performances were similar and the average liveweight $(2047 \mathrm{~g})$ reached at 84 days correspond to a degree of maturity of $56.8 \%$. The average slaughter rate $(66.1 \%)$ and the meat/bone ratio (6.6) were not affected by the amount of hard wheat bran in the diet and were similar for the 5 groups of rabbits. In addition, the moderate crude protein level doesn't seem to be a limiting factor for the growth of the rabbit population used. The absence of soybean meal doesn't create any alteration of growth performance.
\end{abstract}

Key words: Rabbit, hard wheat bran, growth performances, slaughter traits 


\title{
RELATIONSHIPS BETWEEN LIPID METABOLISM TRAITS IN CARCASS AND MUSCLE ADIPOSE TISSUES
}

\author{
Zomeño C.*, Hernández P. \\ Institute for Animal Science and Technology, Universitat Politècnica de València, Camino de Vera \\ s/n. P.O.Box 22012, 46022, Valencia, Spain \\ *Corresponding author: crizose@ posgrado.upv.es
}

\begin{abstract}
The relationships between lipid synthesis and degradation pathways were studied in order to understand the biological mechanisms involved in carcass and muscle fat deposition. A total of 120 animals from three synthetic lines (A, V and R) at two slaughter ages (9 and 13 weeks) were used. Perirenal fat adipose tissue (PF) and two muscles, Longissimus dorsi (LM) and Semimembranosus proprius (SP) were studied. Residual correlations were calculated after line and age effects were removed from the data. There was a relationship between lipogenic activity and fat content in perirenal fat tissue, $r=0.37$ for glucose-6-phosphate dehydrogenase (G6PDH) and $r=0.28$ for malic enzyme (ME). The amount of PF has an influence on its fatty acid (FA) composition, showing positive correlations between PF content and saturated FA (SFA) $(r=0.29)$ and monounsaturated FA (MUFA) percentage $(r=0.33)$ and negative with polyunsaturated FA (PUFA) percentage ( $\mathrm{r}=-0.55)$. Lipogenic enzyme activities were also related to FA composition of PF tissue, with positive correlations between lipogenic enzymes and SFA and negative with MUFA and PUFA. No association was found between IMF content of LM and its lipogenic activity. However, there was a relationship between IMF of LM and lipogenic activity of SP muscle ( $r>0.42)$. As in PF tissue, IMF content was positively related to SFA ( $\mathrm{r}=0.35)$ and MUFA percentages $(\mathrm{r}=0.29)$ and negatively related to PUFA percentages $(\mathrm{r}=-0.43)$. In LM catabolic enzymes were also studied. There was no relationship between IMF and HAD, CS and LDH. Anabolic and catabolic pathways were related in muscle and the coordinated use of both pathways was determinant for IMF deposition. No relationship was observed among glycolytic, oxidative and lipolytic activities in LM. Moreover, the present study showed a lack of relationship between PF and IMF adipose tissues ( $r=-0.02)$. This correlation supports the idea of independence between IMF and carcass fat, suggesting the possibility of increasing intramuscular adipose tissue without increasing overall adiposity carcass.

Key words: Intramuscular fat, Metabolism, Perirenal fat, Residual correlations.
\end{abstract}

\section{RELATIONSHIPS BETWEEN MEAT QUALITY TRAITS IN A LINE OF RABBITS SELECTED FOR GROWTH RATE}

\footnotetext{
Pascual M. ${ }^{1}$, Blasco A. $^{2} *$

${ }^{1}$ Centro de Investigación y Tecnología Animal, Instituto Valenciano de Investigaciones Agrarias, P.O. Box 187, 12400 Segorbe, Castellón, Spain

${ }^{2}$ Institute for Animal Science and Technology, Universitat Politècnica de València, P.O. Box 22012, 46022

Valencia, Spain

*Corresponding author: ablasco@dca.upv.es
} 


\begin{abstract}
Relationships between meat quality traits susceptible to be analyzed at the slaughterhouse level (ultimate $\mathrm{pH}$ and carcass colour), standard meat quality traits (meat colour, water holding capacity) and chemical composition were analyzed. Rabbits belonged to two groups: a selected group from the 23th generation of a line selected for growth rate and a contemporary control group from the 7th generation of selection of the same line. Correlations indicated that slaughterhouse measurements would help predicting meat colour but they would not provide enough information about water holding capacity, meat texture and chemical composition. The principal components analyses showed that the ultimate $\mathrm{pH}$, yellowness of the carcass, saturated fatty acids percentage, polyunsaturated/saturated fatty acids ratio and n-6:n-3 fatty acids ratio were the traits explaining the main variability in meat quality. No differences between groups was observed when projecting the data on the principal component analyses.
\end{abstract}

Key words: Selection for growth rate, Meat quality, Principal component analysis.

\title{
RELATIONSHIP BETWEEN SENSORY EVALUATION AND INSTRUMENTAL MEASUREMENTS OF TEXTURE OF RABBIT MEAT
}

\author{
Martínez M., Blasco A., Hernández P.* \\ Institute for Animal Science and Technology, Universitat Politècnica de València, \\ Camino de Vera s/n. P.O.Box 22012, 46022, Valencia, Spain. \\ "Corresponding author: phernan@dca.upv.es
}

\begin{abstract}
The objective of this study was to evaluate the relationship between sensory texture traits and two instrumental texture assessment methods, Warner-Bratzler shear test (WB) and Texture Profile Analysis (TPA). Animals from three synthetic lines A, V and $\mathrm{R}$ were used in this experiment. Sensory analysis was performed in forty animals per line. A quantitative descriptive analysis was performed by six trained tasters of rabbit meat. The parameters evaluated were: hardness $(\mathrm{H})$, juiciness $(\mathrm{J})$, fibrousness $(\mathrm{F})$ and flouriness $(\mathrm{Fl})$. Sensory analysis was carried out on samples of the Longissimus dorsi muscle, randomizing sex and muscle location. Texture analyses were performed in twenty animals per line. Three parameters were measured for WB: maximum shear force (WB SF), shear firmness (WB FI) and total work performed to cut the sample or the area under the curve obtained (WB W). Four traits were measured for TPA: hardness (TPA H), cohesiveness (TPA CO), springiness (TPA SP) and chewiness (TPA CH). Sensory data were standardized dividing them by the standard deviation of each taster. Sensory and texture data were analysed using model including taster, line and session for sensory data and line and sex for texture. Correlations between the estimated residuals of both models were computed. Sensory hardness was negatively correlated with juiciness (-0.41) and positively with fibrousness $(0.58)$ and it was not correlated with flouriness. A low negative correlation was found between juiciness and
\end{abstract}


fibrousness. High correlations were found among WB measurements. All correlations between WB measurements and sensory analysis traits were low. Correlation between WB SF and sensory hardness was positive (0.26) and WB FI was negatively correlated with $\mathbf{J}$ and $\mathrm{F}$. No correlation was found between WBW and sensory traits. Residual correlation coefficients between sensory analysis traits and TPA parameters were also low. Sensory hardness was only correlated with TPA CO (0.26). Negative correlations were found between juiciness and TPA $\mathrm{H}(-0.32)$ and TPA CH (-0.30) and no correlations were found for F. Sensory flouriness was positively correlated with TPA H (0.36), TPA SP (0.29) and TPA CH (0.34), this sensory trait was not predicted by WB. Low correlations were found between WB and TPA parameters.

The results from this study show that instrumental and sensory evaluations are both required for evaluating rabbit meat tenderness, since correlations between measurements are low.

Key words: Texture, Residual correlations, Warner-Bratzler, TPA, Sensory evaluation.

\title{
EFFECT OF DIFFERENT DIETARY AROMATIC ESSENCES ON MEAT QUALITY OF RABBIT
}

\author{
Cardinali R. ${ }^{1 *}$, Dal Bosco A. ${ }^{2}$, Mugnai C. ${ }^{3}$, Mattioli S. ${ }^{2}$, Ruggeri S. ${ }^{2}$, \\ Dalle Zotte A. ${ }^{4}$, Sartori A. ${ }^{4}$, Cullere M. ${ }^{4}$, Castellini C. ${ }^{2}$ \\ ${ }^{1}$ Mignini e Petrini S.p.A., via dei Pini 306081 Petrignano d'Assisi, Perugia, Italy \\ ${ }^{2}$ Department of Applied Biology, University of Perugia, Borgo XX Giugno 74, 06121 Perugia, Italy \\ ${ }^{3}$ Department of Food Science, University of Teramo, Viale F. Crispi 212, 64100 Teramo, Italy \\ ${ }^{4}$ Department of Animal Medicine, Production and Health, University of Padova, Agripolis, Viale \\ dell'Università 16, 35020 Legnaro (PD), Italy \\ *Corresponding author: rcardinali@inwind.it
}

\begin{abstract}
The effect of dietary supplementation of oregano, rosemary and oregano+rosemary on rabbit growth performance and meat quality was analyzed. Five groups of twenty New Zealand White (NZW) weaned rabbits were submitted to the following dietary treatments: Standard diet (S); Standard diet $+150 \mathrm{ppm}$ vitamin E (E); Standard diet + $0.2 \%$ oregano extract $(\mathrm{O})$; Standard diet $+0.2 \%$ rosemary extract $(\mathrm{R})$; Standard diet + $0.1 \%$ oregano extract $+0.1 \%$ rosemary extract (OR). Each diet contained integrations of: 50 ppm vitamin E, CLA 0.5\% (from soy oil), 3\% Omega Lin ${ }^{\circledR}$ (Mignini \& Petrini) and $0.5 \%$ mixed vitamins. The rabbit were slaughtered at $80 \mathrm{~d}$ of age and slaughter yield and carcass traits were determined. On Longissimus dorsi (LD) muscle, the ultimate $\mathrm{pH}$ was measured, the cooking loss and the Water Holding Capacity (WHC) were estimated, the $\mathrm{L}^{*}, \mathrm{a}^{*}$ and $\mathrm{b}^{*}$ color parameters and the antioxidant status (TBARs) were measured. Slaughter weights, carcass weights and $\mathrm{pH}$ values were not affected by dietary treatment. The cooking loss decreased $(\mathrm{P}=0.002)$ in $\mathrm{O}, \mathrm{R}$ and $\mathrm{O}+\mathrm{R}$ groups, whereas the WHC value increased, mainly in $\mathrm{O}$ group, which showed the highest $(\mathrm{P}=0.04)$ value. The $\mathrm{LD}$ meat color showed a strong $(\mathrm{P}=0.05)$ reduction of $\mathrm{a}^{*}$ for all the antioxidant supplementations; even the $\mathrm{b}^{*}$ value of $\mathrm{R}$ and $\mathrm{O}+\mathrm{R}$ groups $(\mathrm{P}=0.05)$ lowered. The TBARs concentration of meat was slightly affected by dietary treatment. In conclusion, the studied natural extracts showed beneficial effects on color traits of
\end{abstract}


meat; the color parameters highlighted the effectiveness of spice integrations on improving appearance traits of rabbit meat.

Key words: Rabbit, Oregano, Rosemary, Meat quality.

\title{
EFFECT OF DIETARY ALFALFA ON FATTY ACID PROFILE AND OXIDATIVE STATUS OF RABBIT MEAT
}

\author{
Dal Bosco A. ${ }^{1 *}$, Mugnai C. ${ }^{2}$, Roscini V. ${ }^{1}$, Ruggeri S. ${ }^{1}$, Mattioli S. ${ }^{1}$, Castellini C. ${ }^{1}$ \\ ${ }^{1}$ Dept. of Applied Biology, University of Perugia, Borgo XX Giugno 74, 06121 Perugia, Italy \\ ${ }^{2}$ Dept. of Food Science, University of Teramo, v.le F. Crispi 212, 64100 Teramo, Italy \\ *Corresponding author: dalbosco@unipg.it
}

\begin{abstract}
To verify the effect of fresh alfalfa availability on fatty acid profile and oxidative status of rabbit meat. At 50 days of age rabbits (Martini hybrid, $n=40$ ) were divided in two homogeneous groups and fed commercial pelleted feed (Control group) and the same diet plus ad libitum fresh alfalfa (Alfalfa group). At 80 days of age rabbits were slaughtered. Lipid content of meat showed significant $(\mathrm{P}<0.05)$ differences being higher in Control meat, probably due to the lower pellet consumption observed in this group. The same trend was observed by myristic, palmitoleic, oleic and linoleic acid contents. On the contrary, fresh alfalfa feeding increased $(\mathrm{P}<0.05)$ stearic, linolenic, eicosatrienoic, eicosapentaenoic, docosapentaenoic, docosahexaenoic and total polyunsaturated fatty acids. In the Alfalfa group the total monounsaturated fatty acid content was significantly lower $(\mathrm{P}<0.05)$ as well as $\alpha$ - and $\gamma$-tocopherol. Moreover Alfalfa meat showed lower $(\mathrm{P}<0.05) \mathrm{n}-6$ contents, $\mathrm{n}-6 / \mathrm{n}-3$ ratio and trombogenicity index. In conclusion, this specific strategy, accompanied by a good marketing campaign, could improve the economic situation allowing to reach competitive sale price.
\end{abstract}

Key words: Rabbit, meat, alfalfa, fatty acid, lipid oxidation

\section{DIETARY SUPPLEMENTATION OF SPIRULINA (Arthrospira platensis) AND THYME (Thymus vulgaris). PART 5: EFFECT ON RABBIT MEAT APPEARANCE DURING RETAIL DISPLAY}

\author{
Dal Bosco A. ${ }^{*}$, Szendr Zs $^{2}$, Mugnai C. ${ }^{3}$, Kovàcs M. ${ }^{2}$, Ruggeri S. ${ }^{1}$, Mattioli S. ${ }^{1}$, \\ Castellini C. ${ }^{1}$, Dalle Zotte A. ${ }^{4}$, \\ ${ }^{1}$ Dept. of Applied Biology, University of Perugia, Borgo XX Giugno 74, 06121 Perugia, Italy \\ ${ }^{2}$ Kaposvár University, Faculty of Animal Science, Guba S. str. 40, H-7400, Kaposvár, Hungary \\ ${ }^{3}$ Dept. of Food Science, University of Teramo, v.le F. Crispi 212, 64100 Teramo, Italy \\ ${ }^{4}$ Department of Animal Medicine, Production and Health, University of Padova, Agripolis, Viale \\ dell'Università 16, 35020 Legnaro (PD), Italy \\ *Corresponding author: dalbosco@unipg.it
}




\begin{abstract}
The objective of this study was to evaluate the effect of Spirulina and Thyme supplementation (between the ages of 5-11 or 8-11 weeks) on the rabbit meat appearance during retail display. The experiment was conducted at the experimental rabbit farm of the Kaposvár University using progeny of the Institutes' maternal line $(n=294)$. At weaning the rabbits were randomly allocated to 7 treatments $(42$ rabbits/group). Rabbits of the control group (C-C) received a diet throughout the experiment (5-11 weeks of age) without supplementation of spices. The other groups were fed diets with 5\% Spirulina (S), 3\% Thyme (T) or by both spices (ST) for the whole (5-11 wk; treatments: S-S, T-T, ST-ST), or for part of the growing period (8-11 wk; groups: C-S, C-T, C-ST). The $\mathrm{L}^{*}, \mathrm{a}^{*}, \mathrm{~b}^{*}$ colour parameters, $\mathrm{pH}$, water holding capacity and drip loss were determined on fresh Longissimus dorsi (LD) muscle and again on days 3,6 and 9 of storage at $+4{ }^{\circ} \mathrm{C}$ under continuous cool white fluorescent illumination. Spirulina and Thyme had a significant effect only on redness and yellowness of LD muscle. In particular, C-T and T-T treatments showed the lower values at the day 1 of display in the fore part, while at the end of storage the lower values were observed in C-C, C-T and T-T treatments. In the hind part C-S, C-T and T$\mathrm{T}$ treatments showed lower values at the beginning of the storage. Meat samples of C-T and T-T treatments showed a significant reduction of drip loss of LD muscle during display. Based on the results of this study, Thyme seems more effective than Spirulina on improving appearance traits of rabbit meat during retail display.
\end{abstract}

Key words: Spirulina, Thyme, Rabbit meat, Physical characteristics.

\title{
DIETARY SUPPLEMENTATION OF SPIRULINA (Arthrospira platensis) AND THYME (Thymus vulgaris). PART 6: EFFECT ON OXIDATIVE STATUS OF RABBIT MEAT DURING RETAIL DISPLAY
}

\author{
Dal Bosco A. ${ }^{1 *}$, Szendr Zs $^{2}$, Mugnai C. ${ }^{3}$, Kovàcs M. ${ }^{2}$, Ruggeri S. ${ }^{1}$, Mattioli S. ${ }^{1}$, \\ Castellini C. ${ }^{1}$ Dalle Zotte A. ${ }^{4}$ \\ ${ }^{1}$ Department of Applied Biology, University of Perugia, Borgo XX Giugno 74, 06121 Perugia, Italy \\ ${ }^{2}$ Kaposvár University, Faculty of Animal Science, Guba S. str. 40, H-7400, Kaposvár, Hungary \\ ${ }^{3}$ Department of Food Science, University of Teramo, Viale F. Crispi 212, 64100 Teramo, Italy \\ ${ }^{4}$ Department of Animal Medicine, Production and Health, University of Padova, Agripolis, Viale \\ dell'Università 16, 35020 Legnaro (PD), Italy \\ *Corresponding author: dalbosco@unipg.it
}

\begin{abstract}
The objective of this study was to evaluate the effect of Spirulina and Thyme supplementation (between the ages of 5-11 or 8-11 weeks) on the oxidative status of rabbit meat during a simulated retail display. The experiment was conducted at the experimental rabbit farm of the Kaposvár University (Hungary) using progeny of the Institues' maternal line $(\mathrm{n}=294)$. At weaning the rabbits were randomly allocated in 7 groups (42 rabbits/group). Rabbits of the control group (C) received a diet throughout
\end{abstract}


the experiment (5-11 weeks of age) without any supplementation of spices. Experimental groups were fed a diet with 5\% Spirulina (S) or 3\% Thyme (T) or with both spices (ST) for the whole (5-11 wk; groups: S-S, T-T, ST-ST), or for part of the growing period (8-11 wk; groups: C-S, C-T, C-ST). After slaughter, Longissimus dorsi muscles were transported refrigerated to the Department of Applied Biology of Perugia (Italy) to determine the Thiobarbituric Reactive substances, the fatty acid profile and the antioxidant content. At the begin of storage, C-T and T-T samples showed the highest value of $n-3$ fatty acids, whereas S-S and ST-ST those of n-6 fatty acids. S-S group showed the highest amount of PUFA at day 1 of trial. In agreement with these results, the C-T and T-T groups showed the highest content of $\alpha$ tocopherol, at the beginning and end of the storage period. C-T and T-T groups showed significantly lower lipid peroxidation, and at the same time, the lower losses of long chain fatty acids of n-3 series.

Key words: Spirulina, thyme, rabbit meat, retail display, oxidative status.

\title{
DIETARY SUPPLEMENTATION OF SPIRULINA (Arthrospira platensis) AND THYME (Thymus vulgaris). PART 4: EFFECT ON RABBIT CARCASS AND MEAT QUALITY
}

\author{
Dalle Zotte A. ${ }^{1}$, Sartori A. ${ }^{1}$, Cullere M. ${ }^{1}{ }^{*}$, Gerencsér Zs. ${ }^{2}$, Matics Zs. ${ }^{2}$, \\ Dal Bosco A. ${ }^{3}$, Kovàcs M. ${ }^{2}$, Szendr $Z_{\text {s. }}{ }^{2}$ \\ ${ }^{1}$ Department of Animal Medicine, Production and Health, University of Padova, Agripolis, Viale \\ dell'Università 16, 35020 Legnaro (PD), Italy \\ ${ }^{2}$ Faculty of Animal Science, Kaposvár University, 40, Guba S. str., H-7400, Kaposvár, Hungary \\ ${ }^{3}$ Department of Applied Biology, University of Perugia, Borgo XX Giugno 74, 06121 Perugia, Italy \\ *Corresponding author: cux@hotmail.it
}

\begin{abstract}
The aim of the study was to evaluate the effect of the dietary supplementation of 5\% Spirulina (S) and 3\% Thyme (T) leaves and the duration of their supplementation on carcass traits and meat quality of fattening rabbits. Maternal line rabbits $(n=252)$ of both sexes were used. Spirulina and Thyme were supplemented to isonitrogenous and isoenergy diets formulated to cover the requirements of meat producing rabbits. All diets did not include coccidiostatic. Rabbits received the $S$ and $T$ supplementation separately or combined (TS), during the whole growing-fattening period (5th-11th week of age: SS; T-T; ST-ST) or only during fattening (8th-11th week of age: C-S; C-T; C-ST). Seven groups containing 36 rabbits each were used for carcass evaluation: Control (C-C; not supplemented diet) C-S, S-S, C-T, T-T, C-ST, ST-ST. Rabbits were slaughtered at 77 days of age. Carcasses were dissected, carcass yield, fatness and meatiness were determined and $\mathrm{pHu}$ and $\mathrm{L}^{*} \mathrm{a}^{*} \mathrm{~b}^{*}$ colour were measured on Longissimus dorsi (LD) muscle. LD muscle of 15 rabbits per treatment were dissected and frozen; WHC, heme
\end{abstract}


iron and vitamin B12 were analyzed on raw meat whereas proximate composition and cholesterol content were analyzed on both raw and cooked meat. Carcass traits were not affected by dietary treatments, except the scapular fat incidence which showed its lowest value in C-T group $(0.39 \%)$ and its highest value in S-S $(0.56 \%$; $\mathrm{P}<0.05)$. Spirulina and Thyme supplementations didn't affect the rheological traits as well, even though a tendency towards a lower total water loss was found in S-S and C-S (33.1 and 33.4\%, respectively; n.s.) compared to the other groups $(35.2 \pm 0.86 \%)$. Consequently, cooked LD meat of S-S group contained more water (67\%) than the other groups $(66.1 \pm 0.27 \%$; n.s.). S-S and T-T diets reduced the protein content in the cooked LD meat, compared to the $\mathrm{C}-\mathrm{C}$ diet ( 31.3 and 31.5 vs $32.4 \%$; $\mathrm{P}=0.051$ ), and the lowest value for cholesterol content was found in S-S group, in raw and cooked LD meat as well (49.7 and 76.0 $\mathrm{mg} / 100 \mathrm{~g}$ ). In this study the effect of Spirulina supplementation as lipid lowering wasn't confirmed. Based on our results, Spirulina supplement seems promising in enhancing WHC and vitamin B12, and in reducing cholesterol content of rabbit meat, but its inclusion level should be further increased.

Key words: Rabbit, spirulina, thyme, feed, carcass traits, meat quality.

\title{
PROMOTION OF RABBIT MEAT CONSUMPTION IN SPAIN
}

\author{
González-Redondo P. ${ }^{1 *}$, Rodríguez-Serrano, T.M. ${ }^{2}$ \\ ${ }^{1}$ Departamento de Ciencias Agroforestales, Escuela Técnica Superior de Ingeniería \\ Agronómica, Universidad de Sevilla, 41013 Sevilla, Spain \\ ${ }^{2}$ INTERCUN, Organización Interprofesional para implulsar el Sector Cunícola, 20730 Azpeitia \\ (Guipúzcoa), Spain \\ *Corresponding author: pedro@us.es
}

\begin{abstract}
In the last decades, per capita consumption of the rabbit meat has undergone a continuous decline in Spain. For this reason, several actions have been carried out aimed to promote rabbit meat consumption. These actions have been carried out mainly by the Spanish Rabbit Meat Marketing Board (Organización Interprofesional para implulsar el Sector Cunícola, INTERCUN). This paper analyses the effectiveness of these promotional actions to recover the consumption of rabbit meat. The activities aimed at promoting rabbit meat consumption were organised in three campaigns: July 2008 to June 2009, July 2009 to June 2010, and July 2010 to June 2011. There have been two promotional activities. The first were actions intended to promote consumption of rabbit meat among the people by doctors, dieticians, nurses and other professionals who prescribe diets to their patients. The second activity of the campaign has been oriented to the general public, in order to increase the rabbit meat consumption in a more immediate way. This part of the campaign has included celebrities on television, supported with publication of recipes, advertorials and news in mass circulation magazines. The promotional activities carried out by INTERCUN
\end{abstract}


have been effective in halting the decline in production and consumption of rabbit meat because after 2010 the total amount of rabbit meat produced has been increased and the per capita consumption has slowed its pace of decline. INTERCUN considers that, in the future, it will be necessary to intervene in two ways. First by carrying out shortterm promotional activities on the segment of active consumers, and secondly, through medium and long-term actions directed to younger consumers. Moreover, it will be convenient to carry out actions aimed to promote the rabbit meat consumption among schoolchildren.

Key words: Consumption, Promotion, Spanish Rabbit. Meat Marketing Board.

\title{
EFFECT OF DIETARY SUPPLEMENTATION OF CHESTNUT HYDROLYSABLE TANNIN ON DIGESTIVE EFFICIENCY, GROWTH PERFORMANCE AND MEAT QUALITY IN GROWING RABBITS
}

\author{
Dalle Zotte A. ${ }^{1}$, Matics Zs. ${ }^{2}$, Bohatir P. ${ }^{1}$,Sartori A. ${ }^{1}$, Gerencsér Zs. ${ }^{2}$, Szendrö Zs. ${ }^{2}$ \\ ${ }^{1}$ Department of Animal Medicine, Production and Health, University of Padova, Agripolis, Viale \\ dell'Università 16, 35020 Legnaro (PD), Italy \\ ${ }^{2}$ Faculty of Animal Science, Kaposvár University, 40, Guba S. str., H-7400, Kaposvár, Hungary \\ *Corresponding author: antonella.dallezotte@unipd.it
}

\begin{abstract}
The aim of the study was to evaluate the effect of the dietary supplementation of chestnut hydrolysable tannin on the feed digestibility and nutritive value, mortality and growth performance,fatty acid profile and TBARS of cooked Longissimus dorsi (LD) meat. From the age of 18 days the rabbits were fed pellets supplemented with coccidiostat (CC) or with tannin ( $400 \mathrm{~g} / 100 \mathrm{~kg}$ : T400). At weaning (35 d of age) within both groups 5 dietary sub-groups were formed: medicated-free $(\mathrm{C} 0)$, containing coccidiostatic (CC), or supplemented with increasing levels of chestnut tannin (T200, T400 and T600). Rabbits fed the 5 diets ad libitum until slaughter at 11 weeks of age. The coefficient of total tract apparent digestibility (CTTAD) of nutrients was not affected by the tannin inclusion, substantially, with exception of CTTAD of $\mathrm{Ca}$, lower in T400 vs $\mathrm{C} 0$ and $\mathrm{CC}(\mathrm{P}<0.05)$, although the DP-to-DE ratio was lowest in $\mathrm{CC}$ and T600 ( $\mathrm{P}<0.001)$. Dietary tannin significantly modified theCTTAD of FA classes.At weaning, the live weight of $\mathrm{CC}$ rabbits was significantly higher than that of the T400 rabbits (974 vs $940 \mathrm{~g}, \mathrm{P}<0.05$ ). The other variables related to growth performance, health status and carcass traits were not affected by the tannin supplementation. The T400 diet fed before weaning seemed to be more effective than the 3 tannin levels administered during fattening period on FA profile change in the LD muscle.T400 diet fed before weaning increased SFA and MUFA $(\mathrm{P}<0.01)$ and decreased PUFA $(\mathrm{P}<0.05)$, decreasing the $\mathrm{n}-6 / \mathrm{n}-3$ ratio $(\mathrm{P}<0.01)$, however. When tannin-supplemented diets were fed during fattening, only $\mathrm{T} 600$ diet showed significantlyhigher $(\mathrm{P}<0.05)$ SFA and MUFA contents compared to CC diet. In conclusion, the dietary inclusion of
\end{abstract}


chestnut hydrolysable tannin doesn't provides improvements in health status, diet nutritive value, growth performance and carcass traits. Dietary hydrolysable tannin supplementation may play a role on lipid metabolism.

Key words: Chestnut hydrolysable tannin, feed, digestibility, live performance, meat quality.

\title{
EFFECT OF SUPPLEMENTATION OF LINSEED OIL, VITAMIN E AND SELENIUM IN DIET ON MEAT QUALITY OF GROWING RABBITS
}

\author{
Matics Zs. ${ }^{1}$, Gerencsér Zs. ${ }^{1}$, Szabó A. ${ }^{1}$, Fébel H. ${ }^{2}$, Szin M. ${ }^{3}$, Radnai I. ${ }^{1}$, \\ Szendr Zs. ${ }^{1}$ \\ ${ }^{1}$ Faculty of Animal Science, Kaposvár University, 40, Guba S. str., H-7400, Kaposvár, Hungary \\ ${ }^{2}$ Research Institute for Animal Breeding and Nutrition, 1, Gesztenyés str., H-2053, Herceghalom, \\ Hungary \\ ${ }^{3}$ Olivia Ltd, Mizse 94, H-6050, Lajosmizse, Hungary \\ *Corresponding author: matics.zsolt@ke.hu
}

\begin{abstract}
The objective of our study was to examine the fatty acid (FA) profile and the selenium (Se) and vitamin $\mathrm{E}$ contents of meat from rabbits fed on a diet enriched with linseed oil, vitamin E and Se. Supplemented diets were enriched with $180 \mathrm{mg}$ vitamin E/kg, whereas Se content was increased from 0.1 to $0.46 \mathrm{mg} / \mathrm{kg}$ and $3 \%$ linseed oil replaced the same amount of sunflower oil. Rabbits were weaned at the age of 5 weeks, and the supplementation (S) was fed for 1 (S1), 2 (S2), 3 (S3) or 4 weeks (S4) in the preslaughter period. The control group (C) was fed a non-supplemented diet throughout the study. Rabbits were slaughtered at 11 weeks of age and Longissimus dorsi (MLD) meat and thigh (HL) were sampled. The $\sum \mathrm{n}-6$ FA content of HL of S4 was significantly lower than the other groups $(\mathrm{P}<0.01)$; this decrease was continuous and statistically significant $(\mathrm{P}<0.001)$ in the MLD for all groups. The n-3 FA content increased, compared to the C group, of 2.5, 4.8, 4.8 and 3.6-fold in the HL, and of 2.0, 2.8, 3.1 and 3.7-fold in the MLD, for groups S1, S2, S3 and S4, respectively. The larger increment was found between groups C and S4 for C20:5 n-3 (increased by 5.9 and 5.7-fold), which was followed by $\mathrm{C} 18 \mathrm{n}-3$ (increased by 4.0 and 4.7 -fold), by C22:5 n-3 (increased by 2.8 and 3.1-fold), and by C22:6 n-3 (increased by 2.0 and 2.5fold) in the HL and MLD, respectively. The $n-6 / n-3$ ratio decreased after 2 weeks of $S$ feeding from 14.8 and 13.6 to 4.5 and 4.2, and in the S4 group to 2.3 and 2.4, for HL and MLD respectively. The vitamin E content increased significantly from $\mathrm{C}$ and S3 and S4 only in the MLD, whereas in the HL its concentration was lower in the S3 group compared to $\mathrm{C}$ and $\mathrm{S} 1$. In the meat of the $\mathrm{S}$ diet-fed-rabbits the Se concentration increased parallelly with the feeding time interval. Compared to the C group, S1, S2, S3 and S4 groups the Se increment was of 1.4, 1.6, 1.8 and 2.0-fold in the HL, and of $1.4,1.4,1.6$ and 2.0-fold in the MLD. Results have proven that 2-3 weeks of dietary supplementation of linseed oil, vitamin E and Se increases significantly their content in the rabbit meat, improving the functional value of the rabbit meat.
\end{abstract}

Key words: Rabbits, meat quality, fatty acids, vitamin E, selenium. 


\title{
DISTRIBUTION AND ELIMINATION OF GRISEOFULVIN RESIDUE IN RABBIT TISSUES
}

\author{
Gao Shu-xia, Yang Li-ping, Zhang Xiu-ling, Sun Hai-tao, Jiang Wen-xue* \\ Institute of Animal Science and Veterinary Medicine, Shangdong Academy of Agricultural \\ Sciences; Shandong Provincial Key Laboratory of Animal Disease Control and Breeding, N0.8, Sangyuan \\ Rd, Licheng District, 250100, Jinan, China \\ *Corresponding author: jwx0127@163.com
}

\begin{abstract}
The distribution and elimination of griseofulvin residue in rabbit tissues were studied in order to provide basis for the safety assessment of griseofulvin used for prevention and treatment of rabbit fungal dermatopathy. Forty-two rabbits (70 days old) were fed for 14 days with pelleted feed containing $0.8 \mathrm{~g}$ griseofulvin $/ \mathrm{kg}$. The liver, kidney, muscle, skin and brain were collected from 6 rabbits per drug withdrawal day $(1,3,5,7,9,12$ and 21). The concentrations of griseofulvin in rabbit tissues were determined by HPLC. Results showed that after continuous administration, the griseofulvin concentration in liver tissue was the highest $(134.61 \mathrm{ng} / \mathrm{g})$, followed by kidney tissue $(54.09 \mathrm{ng} / \mathrm{g})$. The griseofulvin residue in brain was not detected. Along with the drug withdrawal time extension, the griseofulvin concentration in muscle, liver, kidney and skin tissue was gradually eliminated. At the $21^{\text {st }}$ day of drug withdrawal, the griseofulvin residue in liver and kidney tissue could still be detected $(12.36 \mathrm{ng} / \mathrm{g}$ and $3.39 \mathrm{ng} / \mathrm{g}$, respectively). The elimination rate of griseofulvin in the liver tissue was found to be the fastest. We suggest that griseofulvin should be used with caution in the rabbit farming practice.
\end{abstract}

Key words: Griseofulvin, rabbit, distribution, residue. 


\title{
GERMAN REGULATIONS AND GUIDELINES ON RABBIT HOUSING
}

\author{
Hoy St. ${ }^{1}$ \\ ${ }^{1}$ Dept. of Animal Breeding and Genetics, Justus Liebig University, Bismarckstrasse 16, D-35390, \\ Giessen, Germany \\ Steffen.Hoy@agrar.uni-giessen.de
}

\begin{abstract}
In May 2007 Guidelines of the German branch of World Rabbit Science Association (WRSA) for the housing of rabbits under the aspects of animal protection and welfare were published which were revised in 2009. The Guidelines are very similar to the Dutch regulation on rabbit housing. There are no European rules regarding rabbit housing, apart from those on laboratory animals (EC Directive 2010/63). In June 2011, a draft of a directive in addition to the Animal Welfare regulations in Farm Animals in Germany was published by the Federal Ministry of Food, Agriculture and Consumer Protection. The aim of this directive is to describe minimum requirements for the housing of rabbits giving the rabbit owners (for farm and pet rabbits) and veterinarians clear and unambiguous legal definitions concerning housing and management. However, the rules are only focused on rabbits which are kept for economical purposes. But, animal welfare is indivisible and the housing of rabbits for scientific purposes and of pet or home rabbits as well should also be included in the directive. Notwithstanding the general requirements for housing conditions for farm animals ( $\$ 3$ Animal Welfare Regulations in Farm Animals) much stronger requirements are intended concerning some factors of housing, e.g. the area of walls through which daylight may illuminate the stable, space allowance, number of waterers. The draft of the German Federal Ministry required a non-perforated lying area. But, this may result in hygienic problems. Non-perforated floors very quickly lead to an accumulation of faeces resulting in an increasing health risk because of the contamination with E. coli and coccidia. The Federal Ministry wishes to offer an additional spatially separated and darkened area. But, this makes the required twice daily animal control very difficult and is not necessary. There is also the wish to have tubes or similar hiding places. But, this increases the risk to identify sick animals too late which have retreated into these areas. Poorer animal health control may not be in the interest of animal welfare regulation. The continuous supply of hay or straw on a perforated floor as required by the draft of the Federal Ministry leads to a more or less polluted perforated floor and to an inadequate separation of animals from their faeces. The minimum requirements for breeding and growing rabbits following the Guidelines of the German group of WRSA are summarized in two tables. Enriched cages should be used. The space for a breeding doe in single housing ranges between 2,000 and $4,800 \mathrm{~cm}^{2}$ depending on body weight and the use of an elevated seat. If an elevated platform is used the floor space of the cage plus the space of the elevated seat plus the nest box space are added to available surface. The rabbits shall have permanent access to water of good quality. There are some guidelines regarding the animal:feeding place-ratio, the light programme, the concentrations of ammonia and carbon dioxide in maximum and the frequency of daily
\end{abstract}


controls of animal health and the technical function of feed and water supply and of microclimate.

Key words: Breeding \& Growing rabbits, Animal Protection, Regulation, Guidelines.

\title{
THE EFFECT OF HIGH ENVIRONMENTAL TEMPERATURE ON DOE PERFORMANCE DURING LACTATION
}

\author{
Piles M. ${ }^{1}$, Bakr M.H. ${ }^{1}$, Tusell L. ${ }^{1}$, Blas E. ${ }^{2}$, Sánchez J.P. ${ }^{1}$, Ramon J. ${ }^{1}$, Rafel O. ${ }^{1}$ \\ ${ }^{1}$ Rabbit Breeding Program. IRTA, Torre Marimon s/n, 08140, Caldes de Montbui, Spain \\ ${ }^{2}$ Institut of Animal Science and Technology, Polytechnic University of Valencia, Camino de Vera \\ $\mathrm{s} / \mathrm{n}, 46022$, Valencia, Spain \\ *Corresponding author: miriam.piles@irta.es
}

\begin{abstract}
The general objective of this research was to study the effect on doe performance during lactation of high ambient temperature exposure from early development stages. Specifically, the effect on following traits was analyzed: daily milk yield (DMY); milk composition [dry matter (DM), crude protein $(\mathrm{CP})$ and gross energy (GE)]; average daily feed (ADFC) and water (ADWC) consumptions, and doe live weight (LW). The study was performed comparing the performance of two groups of contemporary does reared under the same management and feeding but different environmental temperature. At 60 days of age, 80 females (and 15 more for reposition) were randomly distributed in two identical and adjoining rooms. In one room, the temperature was permanently kept within the thermo-neutral zone (between 18 to $22{ }^{\circ} \mathrm{C}$ ), which was considered as comfort conditions (C). In the second room, the environmental temperature pattern attempted to simulate the characteristic daily temperature cycle of summer in Mediterranean countries (minimum $24^{\circ} \mathrm{C}$ and maximum $30^{\circ} \mathrm{C}$ for at least 2 hours), which was considered as heat conditions $(\mathrm{H})$. Despite both rooms differed in temperature being $\mathrm{H}$ room out of the boundaries of the thermo-neutral zone at any time of day, no significant differences were found for DMY, milk composition and ADWC during the lactation period. However, the high environmental temperature led to a lower ADFC (-9.4\%) and LW (-6.2\%) with respect to results obtained under C conditions. Based on these results, it could be concluded that both milk yield and composition seems not to be affected when animals are exposed to heat stress from early stages of development, despite there is a relevant decrease of doe feed consumption during lactation. High environmental temperature in this period seems not to affect ADWC. Thus, reducing feed intake rather than increasing water intake could be the main animal's mechanism to overcome high environmental temperature, at least for the pattern of temperature applied in this study, which could only produce moderate stress in the doe.
\end{abstract}

Key words: Feed consumption, Heat stress, Milk Yield \& Composition, Water consumption 


\title{
PRODUCTION AND BEHAVIOUR OF GROWING RABBITS DEPENDING ON THE SEX-COMPOSITION OF THE GROUPS
}

\author{
Szendr Zs. ${ }^{1}{ }^{*}$, Gerencsér Zs. ${ }^{1}$, Odermatt M. $^{2}$, Dalle Zotte A. ${ }^{3}$, Zendri F. ${ }^{3}$, Radnai \\ I. $^{1}$, Nagy I. ${ }^{1}$, Matics Zs. ${ }^{1}$ \\ ${ }^{1}$ Faculty of Animal Science, Kaposvár University, 40, Guba S. str., H-7400, Kaposvár, Hungary \\ ${ }^{2}$ Olivia Ltd, Mizse 94, H-6050, Lajosmizse, Hungary \\ ${ }^{3}$ Department of Animal Science, University of Padova, Agripolis, Viale dell'Universita 16, \\ 35020 Legnaro (PD), Italy \\ *Corresponding author: szendro.zsolt@ke.hu
}

\begin{abstract}
The objective of this study was to analyse the effects of the sex-composition of group on the production and behaviour of growing rabbits. Altogether 168 growing rabbits were evaluated between the ages of 5 and 11 weeks. Seven rabbits were placed to each pen $(0.9 \times 0.5 \mathrm{~m})$. The rabbits placed to the same pen were full sibs (FS), only females $(\mathrm{F})$, only males $(\mathrm{M})$, or mixed sexes (FM). Body weights and feed intake were measured weekly; average daily gain and feed conversion ratio were calculated. Mortality was also continuously registered. Using infrared cameras, 24-hour recording was performed at the ages of 7,9 and 11 weeks. The rabbits with visible injuries were counted in all pens at the ages of $6,7,8,9,10$ and 11 weeks. The sex-composition of the groups had no effect on the production (weight gain, body weight, feed intake, feed conversion ratio, mortality). No differences were found on behavioural patterns. Lesions on the body caused by the aggressive animals were initially observed at the age of 7 weeks. It was more frequent for the $\mathrm{F}$ group at the ages of 7 and 9 weeks, but on the contrary, at the age of 11 weeks the occurrence of the lesions was $40.5 \%$ in the $\mathrm{M}$ group, which was higher than that of the other groups (23.8-28.6\%). Based on the results it could be concluded that housing the growing rabbits segregated by sex, especially only males, was disadvantageous.
\end{abstract}

Key words: Growing rabbits, Group-housing, Sex-composition, Production, Behaviour

\section{STUDY ON REPEATABILITY OF SIRE BEHAVIORAL TYPES IN F1 BUCKS OF NEW ZEALAND WHITE AND TERMOND WHITE RABBITS}

\author{
Gacek L. ${ }^{1}$, Brzozowski M. ${ }^{2}$, Głogowski R. ${ }^{2}$ \\ ${ }^{1}$ National Research Institute of Animal Production, Experimental Station Chorzelów \\ ${ }^{2}$ Warsaw University of Life Sciences, Faculty of Animal Sciences \\ *Corresponding author: marian_brzozowski@sggw.pl
}




\begin{abstract}
The aim of the study was to estimate the repeatability of the behavior type of the father in male progeny in F1 generation of two breeds of rabbits. Termond white (TW) and New Zealand white (NW) bucks were divided with empatic test to Timid, Tame and Aggressive behavior patterns. In the next phase, the sons of previously selected males were estimated with the same testing procedures within both breeds. No significant differences in behavior types in F1 were observed, regardless of the fathers pattern. Moreover, the differences between breeds were also not significant.
\end{abstract}

Key words: Termond White rabbit; New Zealand White rabbit; behavioral test.

\title{
PHYTODERIVATES IN RABBIT DIET AND IMMUNE RESPONSES
}

\author{
Daniela Beghelli1*, Ssa. Raffaella Cardinali2, Sara Caterbi3, Onelia Bistoni3, \\ Alessia Alunno3, Roberto Gerli3, Cesare Castellini2 \\ 1School of Environmental Sciences. University of Camerino. Via Gentile III da Varano. 62032 Camerino, Italy \\ 2 Department of Applied Biology. Borgo XX Giugno, 74. University of Perugia. 06121 Perugia. Italy. \\ 3 Rheumatology Unit - Department of Clinical \& Experimental Medicine. University of Perugia. Via del \\ Giochetto. 06132 Perugia. Italy. \\ 2 Mignini e Petrini spa, via dei Pini 306081 Petrignano d'Assisi Perugia, Italy \\ *Corresponding author:daniela.beghelli@unicam.it
}

\begin{abstract}
In order to investigate the effects of some dietary phytoderivates (Origanum vulgare L. and Rosmarinus officinalis L.) on rabbit peripheral lymphocyte proliferation and subsets populations, a total of $100 \mathrm{New}$ Zealand mixed-sex rabbits were weaned at 30 days of age and immediately split into homogeneous groups submitted to the following dietary treatments: 1) Standard diet (Ctrl); 2) Standard diet +150 ppm Vit E (Vit E); 3) Standard diet $+0.2 \%$ oregano $(\mathrm{O})$; 4$)$ Standard diet $+0.2 \%$ rosemary $(\mathrm{R})$ and 5 ) Standard diet $+0,1 \%$ oregano $+0.1 \%$ rosemary $(\mathrm{OR})$. Blood samples were collected from rabbits at 30 days (Time $0, n .10$ rabbits) and 90 days of age (Time 1 ; n.5 animals/diet group). A diet effect on lymphocyte proliferation test was observed in the "O" group, where its response to pokeweed mitogen (PWM) and interleukin-2 (IL-2) at Time 1 resulted significantly higher than that of the other experimental diet groups (PWM, P<0,001 and IL-2, P< 0,000), with the exception of "OR" group whose IL-2 mitogen response was as significant higher as that of "O" group. Furthermore, the basal mitogenesis values revealed higher responses at Time 1 in the "Vit E" and "O", but the addition of mitogens induced significant increased responses only in the "O" group. No diet effects were registered on the lymphocyte subsets. The lymphocyte proliferation test in the control group showed a general reduction of leukocytes response with age, in particular it was observed a significant reduced response to PWM and PHA mitogens $(\mathrm{P}<0,021)$. Age effects were also recorded on lymphocyte subsets with a significant increase of $\mathrm{CD}^{+} \%$ with age $(\mathrm{P}<0,000)$. These results seem to encourage the
\end{abstract}


integration of rabbit diet with oregano for its positive effect on adaptive immune response (a better in vitro reactivity of B cells).

Key words: Lagomorpha; dietary phytoderivates; immune responses

\title{
DIGESTIBLE VALUE OF TWO RABBIT FEEDSTUFFS IN TWO CLIMATIC ENVIRONMENTS
}

\author{
Alagón G. ${ }^{1}$, Arce O.N. ${ }^{2}$, Martínez-Paredes E. ${ }^{3}$,Ródenas L. ${ }^{3}$, Pascual J.J. ${ }^{3}$, Cervera C. ${ }^{3}$ \\ ${ }^{1}$ Facultad de Agronomía y Zootecnia, Universidad Nacional de San Antonio Abad del Cusco. Perú. \\ ${ }^{2}$ Facultad de Ciencias Agrarias y Veterinarias, Universidad Técnica de Oruro. Bolivia. \\ ${ }^{3}$ Instituto de Ciencia y Tecnología Animal, UniversitatPolitècnica de València, Camino de Vera, 14, \\ Valencia 46071, Spain. \\ *Corresponding author:jupascu@dca.upv.es
}

\begin{abstract}
A digestibility trial was performed with 72 rabbits 35 days old in order to determine the digestible energy (DE) and digestibleprotein (DP)content of dried distillers grains with solubles (DDGS) and beet pulp, using the substitution methodology and calculation procedures. Half of rabbits were housed in a conventional farm $(\mathrm{CF})$ with temperatures ranged from 18 to $20^{\circ} \mathrm{C}$ and half in a climatic chamber (CC) set up to perform a daily sigmoid curve with a temperature ranging from 25 to $36^{\circ} \mathrm{C}$. Animals submitted to heat challenge showed significantly lower daily feed intake $(-20 \%)$ and increased apparent digestible coefficients for main nutrients increased (from 2 to 7 points of percentage) in comparison to those kept in normal conditions, and independently of the diet. As heat stress had a similar effect on the different diets, digestible values for the feedstuffs calculated by substitution were less affected by the climatic environment, being the $\mathrm{DE}$ values of 11.6 and $11.7 \mathrm{MJ} / \mathrm{kg}$ of dry matter (DM) for DDGS and 15.0 and $14.2 \mathrm{MJ} / \mathrm{kg}$ DM for beet pulp at the CC and CF housing, respectively. The DP values obtained for the DDGS were 177 and $165 \mathrm{~g} / \mathrm{kg} \mathrm{DM}$ at the CC and CF housing, and 67 and $45 \mathrm{~g} / \mathrm{kg}$ DM for beet pulp. Only the DP value of beet pulp significantly increased in heat stress conditions $(+49 \%$; $\mathrm{P}<0.05)$ due to the low crude protein content of this feedstuff, butit should have lowrelevanceat feed formulation level.
\end{abstract}

Key words: Rabbit, Digestibility, Heat stress, DDGS, Beet pulp.

\section{LOCATION PREFERENCE OF LACTATING RABBIT DOES AND THEIR KITS IN PENS WITH ELEVATED PLATFORM}

\author{
Mikó A. ${ }^{1}$, Matics Zs. ${ }^{1}$, Gerencsér Zs. ${ }^{1}$, Radnai I. ${ }^{1}$, Odermatt M. ${ }^{2}$, Nagy I. ${ }^{1}$, \\ Szendr Zs. ${ }^{1}$ \\ ${ }^{1}$ Kaposvár University, Faculty of Animal Science, 7401 Kaposvár, POBox 16, Hungary \\ ${ }^{2}$ Olivia Ltd, 6050 Lajosmizse, Mizse 94, Hungary \\ *Corresponding author: miko.annamaria@ke.hu
}




\begin{abstract}
In this study, the location preferences of rabbit does and their kits were analyzed in two types of pens with elevated platforms (wire-mesh or plastic-mesh). The experiment was conducted at the Kaposvár University. Crossbred rabbit does $(n=31)$ were randomly allocated into two groups. PP: pen with plastic-mesh platform (102.5 x 52.5 x $97 \mathrm{~cm}$ ), the pen floor was wire-mesh, which size of $41.5 \times 52.5 \mathrm{~cm}$, and it was disposed at the $25 \mathrm{~cm}$ from the base $(\mathrm{n}=15)$. PW: pen with wire-mesh platform $(102.5$ x $38 \times 61 \mathrm{~cm}$ ), the pen floor was wire-mesh, which size of $28.5 \times 38 \mathrm{~cm}$, and it was disposed at $26.5 \mathrm{~cm}$ from the base. A plastic footrest $(40 \times 25 \mathrm{~cm})$ was on the lower level $(\mathrm{n}=16)$. The lighting schedule was 16 hours light (06:00-22:00) and 8 hours dark (22:00-06:00). Locations of does and their kits were observed with infrared cameras. 24-hour video recordings were performed. The location of rabbit does and kits were registered at every $30 \mathrm{~min}$ from kindling till weaning, twice a week on the same days. In PP pens, during the active period (23:00-4:30), the does spent more time on the platform than during the light (resting) period (6:00-17:00). Opposite tendencies were observed under the platform, the preferences of this part of pens were 2.5-3.5 times higher between 5:00 and 17:00 hours than during the dark period (23:00-5:00). The effect of the parts of the day was smaller in the PW pens. On average the does spent by $25.2 \%$ more time on the platform when they were placed to PP pens compared to the PW pens. After the kits left the nest boxes the does chose the platform more frequently, then after day 21, when the kits started to visit the platform, the does' platform preference decreased. Usage of the wire-mesh platform by kits was significantly lower than that of the plastic platform. From the aspect of animal welfare cages/pens enriched with platforms can be considered advantageous especially when the platform is made from plastic-mash.
\end{abstract}

Key words: Rabbit does, Kits, Housing, Elevated platform, Behaviour, Welfare.

\title{
HAEMATOLOGICAL PARAMETERS AS INDICATORS OF TRANSPORT STRESS IN RABBITS
}

\author{
Giammarco M.*, Vignola G., Mazzone G., Fusaro I., Lambertini L. \\ Dipartimento di Scienze degli Alimenti, Università di Teramo, Viale Crispi 212, 64100 Teramo, Italy \\ *Corresponding author: mgiammarco@unite.it
}

\begin{abstract}
The purpose of our investigation was to evaluate the effect of transport to the slaughterhouse on some haematological stress indicators in rabbits. All the animals used came from the same farm and were randomly chosen from those that reached the end of their productive cycle ( 82 days old). A total of four journey session were performed. Each journey lasted 100 minutes. Moreover, for each journey, the same lorry driven by the same transport operator, was used. In order to assess stress condition, blood samples from 80 male rabbits (20 animals per journey session) were collected two days before each transport session and at the de-bleeding in the
\end{abstract}


slaughterhouse. Haematological and biochemical variables were analyzed: packed cell volume (PCV) did not differ significantly after transport while a significant neutrophilia $(\mathrm{P}<0.001)$, lymphocytopaenia $(\mathrm{P}<0.001)$ with a significant increase in the $\mathrm{N} / \mathrm{L}$ ratio were observed in all transported rabbits. A significant increase $(\mathrm{P}<0.001)$ in serum glucose concentration following transport, was found. Furthermore, total protein, albumin and osmolality increased significantly in all rabbits. These findings underlined a moderate dehydration caused by transport that was evidenced also by the increasing in $\mathrm{Na}$ and $\mathrm{K}$ serum concentrations. A significant upsurge in serum aspartate aminotransferase (AST) $(\mathrm{P}<0.01)$, alanine aminotransferase $(\mathrm{ALT})(\mathrm{P}<0.001)$ and creatine kinase $(\mathrm{CK})$ activities $(\mathrm{P}<0.001)$ were recorded in all rabbits after transport.

A twofold increase in serum corticosterone concentration $(6.23$ vs. $14.88 \mathrm{ng} / \mathrm{mL}$; $\mathrm{P}<0.01)$ evidenced the stress condition experienced by all rabbits during transport. The altered levels of some of the analyzed blood variables, lead to the conclusion that, as in other species, haematological parameters may be usefully employed to highlight the stress condition of rabbits during transport.

Key words: Rabbit, transport, stress indicators, welfare

\title{
GNAWING BLOCKS AS CAGE ENRICHMENT AND DIETARY SUPPLEMENT FOR DOES: PERFORMANCE, INTAKE,AND BEHAVIOUR
}

\author{
Maertens L. ${ }^{1}$, S. Buijs ${ }^{1}$, C. Davoust ${ }^{2}$ \\ ${ }^{1}$ Institute for Agricultural and Fisheries Research (ILVO) - Animal Sciences Unit, 9090 Melle, Belgium \\ ${ }^{2}$ Adresse actuelle, INZO SAS, Rue de l'église - BP 50019, 02407 Chierry Cedex, France \\ Email address corresponding author: Luc.maertens@ilvo.vlaanderen.be
}

\begin{abstract}
One hundred and five pregnant rabbit does housed in conventional wire cages received during one complete reproductive cycle no enrichment (controls) or one of three different gnawing blocks hanged up with a wire at the wall of the cage. The three different blocks had the same basal components but additionally wood mash (WM), wood mash + chicory pulp (CP) or wood mash and inulin syrup (I) were respectively incorporated. Weight development during the lactation was comparable except in does that received the WM blocks. These females had a significant lower weight $(\mathrm{P}<0.05)$ at different time points compared to controls. Litter weight or kit weight was not significantly different at any of the time points measured but again the treatment with WM blocks had the lowest weight. The consumption of blocks during the whole reproduction cycle (42 days) was 11.0; 6.8 and $4.4 \mathrm{~g}$ /day/cage for $\mathrm{WM}, \mathrm{CP}$ or I enriched blocks, respectively. A very large variability in consumption of blocks was observed between females. This varied between 1 and 5 (I or CP group) or even 1 and 9 blocks (WM group) per reproductive cycle. In each group 5 females were observed for 1 hour 3 days before the expected parturition and at 2 time points during the lactation. Although the presence of a block did not significantly increase the total
\end{abstract}


number of behavioural transitions, locomotion and intake behaviour were significantly $(\mathrm{P}<0.05)$ increased when a gnawing block was available. The period of observation influenced the frequency of many behavioural transitions and was before parturition significantly higher than post parturition, respectively 56.1 vs. 13.7 (Week $1, \mathrm{P}<0.01$ ) and 25.1 (Week 2, $\mathrm{P}<0.01$ ). Based on the consumption pattern, the hardness and behaviour this gnawing blocks could be considered as cage enrichment and those with the chicory pulp fitted best with the objective.

Key words: Gnawing blocks, does, performance, intake, behaviour.

\title{
INDIVIDUAL HOUSING OF YOUNG DOES IN DIFFERENT SIZED CAGES: IMPACT ON WELFARE, ECONOMIC COSTS AND PRODUCTIVE DATA
}

\author{
Bignon L. ${ }^{1}$, Bouchier M. ${ }^{1}$, Coutelet G. ${ }^{2}$, Galliot P. $^{3}$, Souchet C. $^{3}$, Fortun- \\ Lamothe $\mathrm{L}^{4}$ \\ ${ }^{1}$ ITAVI, Centre INRA de Tours, 37380, Nouzilly, France \\ ${ }^{2}$ ITAVI, Service économie, 4 rue de la Bienfaisance, 75008, Paris, France \\ ${ }^{3}$ ITAVI, Station expérimentale cunicole, 29 Bergerie Nationale, 78120, Rambouillet, France \\ ${ }^{4}$ INRA, UMR 1289, TANDEM, BP 52627, F-31326, Castanet-Tolosan Cedex, France \\ *Corresponding author: Bignon.itavi@tours.inra.fr
}

\begin{abstract}
Young does are the first link in the production chain for rabbit meat due to their future role as breeders. Housing could be one of the factors influencing reproductive performance. Young does are currently housed in small unfurnished cages $(25 \mathrm{x} 46 \mathrm{x}$ $30 \mathrm{~cm}$ ), which may influence their welfare and is also an important factor for consumers. To date, very few studies have investigated this topic, thus the aim of this study was to evaluate the impact of different sized individual cages on welfare and productive data of young does. Three cage sizes were compared: 25 x 46 x $28.5 \mathrm{~cm}$ (standard, STD); $33 \times 68.5 \times 40 \mathrm{~cm}$ (intermediate, IS); $38 \times 90 \times 60 \mathrm{~cm}$ with a platform of $35 \times 25 \mathrm{~cm}$ at $30 \mathrm{~cm}$ (large size, LS). The study involved two groups of 30 tenweek-old Hyplus females. The does were placed in individual cages at 11 weeks of age, inseminated at 17.6 weeks and studied until the weaning of their first litter. From 11 to 21 weeks of age, does remained in individual cages (STD: $n=19$, IS: $n=19$ and LS: $\mathrm{n}=17)$ and at 21 weeks they were transferred to maternity cages $(45 \times 100 \times 60$ $\mathrm{cm}$ with platform of $45 \times 25$ at $30 \mathrm{~cm}$ ). Behaviour was observed five minutes every hour over $24 \mathrm{~h}$ by focal sampling using a cam recorder for eight cages per series (16 cages per cage size). Analyses of the recordings enabled different behaviours to be counted and the duration of each to be calculated. Productive data were assessed from the weight of females at date of artificial insemination, the number of live kits, and total litter weight at birth and at weaning. The economic impact for the rabbit farm of changing the cages of young does was calculated. Doe activity was significantly greater in the largest cage $(8.3 \pm 2.6 \%, 12.2 \pm 4.6 \%$ and $15.9 \pm 4.6 \%$ respectively for STD, IS and LS; $p<0.0001)$. Lying time was the same in the intermediate and large cage and significantly less than in the standard cage $(63.8 \pm 8.2 \%, 57.5 \pm 9.7 \%, 52.0 \pm 8.8$;
\end{abstract}


respectively for STD, IS and LS; $\mathrm{p}<0.05$ ). The cage size had no significant effect on productive data except for total litter weight at birth ( $28 \%$ higher in the LS compared to the STD cages; $\mathrm{P}<0.01)$. It is only when the intermediate-sized cages are stacked on two levels that there is no economic impact. In conclusion, considering both economic and welfare perspectives, the intermediate-sized cage could be recommended. However, these preliminary results need to be investigated further.

Key words: Replacement breeding rabbit, individual housing, behaviour, productive data, economic

\title{
GNAWING BLOCKS IN RABBIT CAGES: IMPACT ON THE BEHAVIOUR AND PERFORMANCE OF DOES AND FATTENING RABBITS
}

\author{
Bignon L. ${ }^{1}$, Travel A. ${ }^{1}$, Galliot P. ${ }^{2}$, Souchet C. $^{2}$, Davoust C. $^{3}$, Weissman D. ${ }^{3}$ \\ 1 Itavi, Centre INRA de Tours, 37380, Nouzilly, France \\ 2ITAVI, Station expérimentale cunicole, 29 Bergerie Nationale, 78120, Rambouillet, France \\ 3INZO, Rue de l'Eglise BP 50 019, 02407 Château-Thierry, France \\ *Corresponding author: Bignon.itavi@ tours.inra.fr
}

\begin{abstract}
Welfare is of increasing importance to consumers and an enriched environment may be beneficial to farm animals. When over expressed, gnawing is considered as a stereotypic response to an unsuitable environment. Cage enrichment with a gnawing element could thus alleviate this problem, but may also lead to increased hygiene problems. The aim of this study was to investigate the effect of adding a nutritional block in the cages of fattening rabbits (on restricted or non-restricted diets) and does. For does, two groups of 40 animals (including 10 nullipartum) were individually housed from seven days prior to birth until weaning 36 days later with or without a block containing pharmaceutical quality wood fibre and trace elements. For fattening rabbits, four groups of 15 cages with seven rabbits in each were compared. Two groups (30 cages) were fed ad libitum whilst the other two received restricted diet at $80 \%$ of the ad libitum level. Half of the cages received nutritional blocks from 36 to 64 days of age. Under all conditions two cages per group (8 cages) were observed using scan sampling for oral behaviours. The total weight of young rabbits, block and feed consumption were measured once a week for each cage. Mortality was recorded daily. Twenty litters per group of does were weighed at three different ages, before and after suckling, to measure milk consumption. Block availability did not significantly impact doe milk production or significantly modify female and young rabbit behaviour (except for the time young rabbits spent grooming). Mortality of fattening rabbits was not affected. Feed restricted rabbits showed significantly lower body weight and higher nutritional block intake. Over the whole period, rabbit body weight and average daily gain were higher for cages with blocks $(\mathrm{p}<0.10)$. In conclusion, nutritional blocks appear to enhance the rabbit environment. However, these preliminary results need
\end{abstract}


further investigation to balance the improved growth performance with the increased cost of adding nutritional blocks.

Key words: Doe, fattening rabbits, gnawing element, nutritional blocks, behaviour.

\title{
HOW FAR MAY RABBIT CAGE'S SPACE RECOMMENDATIONS REACH: THE GAP BETWEEN SCIENCE AND REGULATIONS
}

\author{
Villagrá, A. ${ }^{1 *}$, Olivas, I. ${ }^{1}$, Estellés, F. ${ }^{2}$, Blas, E. ${ }^{2}$, Rodríguez, T. $^{3}$, Rosell, J. $^{4}$, \\ Pascual, J.J. ${ }^{2}$ \\ ${ }^{1}$ Centro de Tecnología Animal CITA-IVIA, Polígono La Esperanza 100, 12400, \\ Segorbe (Castellón), Spain \\ ${ }^{2}$ Institute of Animal Science and Technology, UniversitatPolitècnica de València, Camino de Vera \\ 14, 46022, Valencia, Spain \\ ${ }^{3}$ Asociación Española de Cunicultura (ASESCU), Apartado de Correos 57, 08360 Canet de Mar, \\ Barcelona, Spain \\ ${ }^{4}$ Private consultant \\ "Corresponding author: villagra_ara@gva.es
}

\begin{abstract}
Animal welfare is a major concern in livestock production. The impact of housing conditions on animal well-being is under study in several species such as chickens, laying hens, or pigs and, some European Directives have been developed in order to protect animal welfare. In these Directives aspects related to housing conditions have been regulated. Several attempts have been done to propose a European Directive for rabbit farming in terms of welfare protection, but any agreement have been reachedfor now. One of the main hot spots is related to cages design. Strong efforts are being made nowadays in order to reach a compromise to define cages characteristics which really benefit rabbits' welfare. In this context, the main aim of this work is to develop a critical review about rabbit does space needs in relation to cages design. It becomes necessary to determine the behavioural needs of rabbits in terms of welfare, so that the space requirements can be known. This might lead to define appropriate housing conditions, although the needs of the animal can change according to age, learning, diurnal rhythm, season and genetic relations. In general, regarding the height of the cages (as well as width), few papers have been found and a European Food Safety Authorities' report recognises, that in the absence of scientific evidence concerning these needs of rabbits, it may be important for growing rabbits to be able to sit and stand with ears erect, as well as rear up occasionally. Regarding the use of platforms, enriching the cage with raised platforms aims at satisfying the doe's need for isolation from the litter, rather than stimulating exercise. Nevertheless, the use of platforms may cause hygiene problems which have to be solved. Therefore, elevated platforms might be considered as environmental enrichment elements and not as structural needs. The patent general lack of information in the topic must be considered when new housing conditions are being proposed, and only those aspects which could lead to real
\end{abstract}


improvement of rabbit's welfare have to be taken into account. The authors propose a cage size for lactating does of $45 \times 75 \times 38 \mathrm{~cm}$ (height, length and width) with a minimum surface of $3,500 \mathrm{~cm}^{2}$ (nest-box not included).

Key words: Welfare, cage, space requirements, platform, does.

\title{
EFFECT OF DIFFERENT LIGHTING SCHEDULES (16L:8D OR 12L:6D) ON NURSING BEHAVIOUR OF RABBIT DOES
}

\author{
Matics Zs. ${ }^{1}$, Gerencsér Zs. ${ }^{1}$, Mikó A. ${ }^{1}$, Radnai I. ${ }^{1}$, Odermatt M. ${ }^{2}$, Nagy I. ${ }^{1}$, \\ Szendr Zs. ${ }^{1}$ \\ ${ }^{1}$ Kaposvár University, Faculty of Animal Science, H-7400, Kaposvár, Guba S. str. 40. (Hungary) \\ ${ }^{2}$ Olivia Ltd, H-6050 Lajosmizse, Mizse 94. (Hungary) \\ *Corresponding author: matics.zsolt@ke.hu
}

\begin{abstract}
The objective of the experiment was to compare the nursing behaviour of rabbit does in a routine (16L:8D) and in a proportionally shorter (18h, 12L:6D) lighting schedule. The experiment was conducted at the Experimental rabbit farm of the Kaposvár University. Thirteen week old crossbred female rabbits were randomly housed in two identical rooms in flat deck cages. The two rooms only differed in the lighting schedule: $24 \mathrm{~h}$ group: 16 hours light and 8 hours dark ( $=9$ does), $18 \mathrm{~h}$ group: 12 hours light and 6 hours dark $(\mathrm{n}=8$ does). $42 \mathrm{~d}$ reproductive rhythm and one batch system was applied. Number of kits/litter was equalised to ten, and rabbit does could nurse their kits freely. We examined the nursing behaviour of the does (duration, number of events per day, distribution of nursing events) at the second lactation, during a 144 hours period from the beginning of the lighting period on day $4^{\text {th }}$ of lactation to the beginning of the lighting period on the $10^{\text {th }}$ day. Infrared cameras were used for observation. 138 nursing events were evaluated during the examined period. The daily number of nursing events were not lower in group 18h compared to the group $24 \mathrm{~h}$ (1.29 \pm 0.35 and $1.41 \pm 0.29$, respectively; $\mathrm{P}=0.470$ ). In a 24 hours period, the percentage with $\geq 2$ nursing was $41.5 \%$ and $27.1 \%$ in groups $24 \mathrm{~h}$ and $18 \mathrm{~h}$, respectively. In routine lighting schedule (24h group, 16L:8D) $77.6 \%$ of the nursing events took place during the dark period and in the two hours after light switch on and does nurse their kits most frequently during the first two hours of the light period (28.9\%). This tendency could not be observed in the $18 \mathrm{~h}$ group. Only a small part of the nursing events was recorded during the dark period (19.4\%) and in the two hours after light switch on $(16.1 \%)$. Even if the rabbit does, who were born and grew up in 16L:8D (24h) lighting schedule, were housed in 12L:6D (18h) schedule their nursing events were still based on 24 hours intervals and lighting schedule. Contrary to our hypothesis, applying a "reduced day" $(12 \mathrm{~L}: 6 \mathrm{D}=18 \mathrm{~h})$ instead of the routine $16 \mathrm{~L}: 8 \mathrm{D}$ lighting schedule did not increase the number of nursing events per 24 hours. Based on the distribution of nursing events in 24 hours period, it seems, that $18 \mathrm{~h}$ rabbit does
\end{abstract}


nursed their kits according to the lighting schedule (16L:8D) which was applied during their growing period.

Key words: Rabbit does, lighting schedule, nursing behaviour.

\title{
FREE CHOICE OF RABBIT DOES BETWEEN CAGES OF DIFFERENT SIZES
}

\author{
Mikó A. ${ }^{1}$, , Szendr Zs. ${ }^{1}$, Matics Zs. ${ }^{1}$, Radnai I. ${ }^{1}$, Odermatt M. ${ }^{2}$, Nagy I. ${ }^{1}$, \\ Gerencsér Zs. ${ }^{1}$ \\ ${ }^{1}$ Kaposvár University, Faculty of Animal Science, 7401 Kaposvár, POBox 16, Hungary \\ ${ }^{2}$ Olivia Ltd, 6050 Lajosmizse, Mizse 94, Hungary \\ *Corresponding author: miko.annamaria@ke.hu
}

\begin{abstract}
The aim of this study was to observe the location preference of non-pregnant, pregnant and lactating rabbit does between cages of different sizes. Ten non-pregnant and 9 pregnant and lactating does were observed. The does could move freely between a small $(57.5 \times 38 \times 30 \mathrm{~cm})$ and a large cage $(57.5 \mathrm{~cm} \times 76 \times 30 \mathrm{~cm})$, through swing doors. The two cages were separated by a wire net wall, while the cage-blocks were separated with non-transparent plate walls, excluding any visual contact between the does which could influence their cage choice. Using infrared cameras, 24-hour recordings were performed. After one-day adaptation period, the preference of nonpregnant does was recorded for 5 days. The pregnant and lactating does were placed to the cages 7 days prior to the expected kindling date. The nest boxes were opened 3 days prior to the estimated kindling. The location preferences of the pregnant and lactating does were continuously monitored until the kits reached the age of 3 weeks. Litter size was standardized to ten at birth. By analyzing the video recordings, the actual location of the does was registered at each half hour, 48 times a day. The data of non-pregnant does was evaluated according the different day parts (23:00-05:00, 05:00-11:00, 11:00-17:00, and 17:00-23:00). For the pregnant and lactating does the observation was started from the day of parturition. Location preference was first evaluated independently of the place of kindling (in the small or large cage), and its influence on the does' location preference was also analyzed. Non-pregnant (63\%) and pregnant rabbit does $(74.1 \%)$ spent significantly $(\mathrm{P}<0.001)$ more time in the large cage than in the small cage (37 and $25.9 \%$, respectively). Cage preference seemed to be proportional to the cage sizes $(1 / 3$ and $2 / 3)$ thus cage choice may be considered as random. Therefore, the difference of location preference was also tested between the observed and expected frequencies $33.3 \%$ and $66.6 \%$ for the smaller and larger cages, respectively). In the group of the non-pregnant does part of the day influenced the preference of rabbits. In the active period (23:00-5:00), they spent substantially more time $(72.2 \%)$ in the large cage and less time in the small one $(27.8 \%)$ than in other times of the day $(\mathrm{P}<0.001)$. Although, parturition and lactation influenced the does' location preference, the effect of place of kindling was the largest on the cage choice. Compared to the expected frequencies $(33.3 \%$ and $66.6 \%)$ the observed cage choices
\end{abstract}


were 14.3 and $85.7 \%$ and 29.7 and $70.3 \%$ if kindlings took place in the small and large cages, respectively. Based on the results the rabbit does show higher preference for large cages but this preference was lower when the kindling took place there.

Key words: Cage size, rabbit does, ethology, welfare, housing.

\title{
EFFECT OF TEMPERATURE ON BREEDING RABBIT BEHAVIOUR
}

\author{
Rafel, O. ${ }^{2}$, Catanese, B. ${ }^{1}$, Rodriguez, P. $^{1}$, Fuentes, C. $^{1}$, Llonch, P. $^{1}$, Mainau, E. ${ }^{1}$, \\ Piles, M. ${ }^{2}$, Velarde, A. ${ }^{1}$, Ramón, J. ${ }^{2}$, López-Béjar, M. $^{3}$, Dalmau, A. ${ }^{1}$ \\ ${ }^{1}$ Animal Welfare Program. IRTA. Finca Camps i Armet s/n. 17121. Monells. Girona. Spain \\ ${ }^{2}$ Rabbit Breeding Program. IRTA. Torre Marimon s/n, 08140, Caldes de Montbui, Spain \\ ${ }^{3}$ Dpt. Animal Health and Anatomy, Faculty of Veterinary, Universitat Autònoma de Barcelona, \\ 08193 Bellaterra, Spain \\ Corresponding autor: antonio.dalmau@irta.es
}

\begin{abstract}
The aim of the study was to assess activity, position and behaviour parameters as indicators of heat stress in rabbits subjected to a circadian heat stress cycle. Ten does (80-105 days old) and 6 bucks (180 days old) individually housed in commercial wire cages were observed during 12 days 12 hours a day by means of videocameras using scan sampling at 5 minutes interval. Rabbits were divided in two buildings. Five females and three males were housed at $18.4^{\circ} \mathrm{C}$ mean temperature (control group) and the rest at $20.1^{\circ} \mathrm{C}, 17$ hours a day, and at $27.9^{\circ} \mathrm{C}$ the rest 7 hours (heat stress group). Position in relation to the corridor (watching it, avoiding it or perpendicular), activity (lying, sitting, prostrated or moving) and behaviour (grooming, exploring, resting, feeding and drinking) were assessed. Statistical analyses were performed with Genmod of SAS. No differences were found between treatments in feeding and drinking behaviour and animals moving. The presence of resting behaviour, watching the corridor and be prostrated was higher $(\mathrm{P}<0.05)$ in heat stress than control treatment and the contrary $(\mathrm{P}<0.05)$ was observed for lying, sitting and exploring. In the case of grooming, a clear compensation could be observed, rabbits reducing this activity in the heat stress period but increasing it just before and after this period in comparison to control animals. It is concluded that rabbits change their behaviour in moderate thermal stress, animals prostrated being a good indicator for the assessment of these conditions. Key words: activity, behaviour, heat, Oryctolagus cuniculus, rabbits, welfare
\end{abstract}

\section{USE OF INFRARED THERMOGRAPHY TO ASSESS HEAT STRESS IN RABBITS}

\author{
Rafel, O. ${ }^{2}$, De Lima, V. ${ }^{1}$, Piles, M. ${ }^{2}$, Velarde, A. ${ }^{1}$, Ramón, J. ${ }^{2}$, López-Béjar, M. ${ }^{3}$, \\ Dalmau, A. ${ }^{1}$ \\ ${ }^{1}$ Animal Welfare Program. IRTA. Finca Camps i Armet s/n. 17121. Monells. Girona. Spain \\ ${ }^{2}$ Rabbit Breeding Program. IRTA. Torre Marimón. 08140. Caldes de Montbui,
}




\author{
Barcelona Spain \\ ${ }^{3}$ Dpt. Animal Health and Anatomy, Faculty of Veterinary, Universitat Autònoma de Barcelona, \\ 08193 Bellaterra, Spain \\ Corresponding autor: antoni.dalmau@irta.es
}

\begin{abstract}
The aim of the study was to ascertain if infrared thermography (IRT) can be used to assess heat stress in rabbits by comparing different body areas. The study was carried out during three trials in two rooms with 65 animals each. Room A was maintained at $20^{\circ} \mathrm{C}-28^{\circ} \mathrm{C}$ and room $\mathrm{B}$ reached values above $30^{\circ} \mathrm{C}$. In the first trial, twenty rabbits were photographed during 24 hours, every hour. In the second and the third trials, all animals of both rooms were assessed once. A thermographic camera (Fluke Ti25, Fluke Corporations, Seattle, USA) was used. The pictures were used to assess maximum and minimum temperatures in the eyes, nose, external ear and internal ear. Statistical analyses were carried out with SAS and significance was fixed at $\mathrm{P}<0.05$. According to the results, eyes, nose, internal and external ear maximum and minimum temperatures are suitable to detect differences in heat stress in rabbits. Maximum eye temperature show a lower range of variation in comparison to other body areas and there were found difficulties in taking a good internal ear picture. Minimum eyes and maximum or minimum nose temperatures are suggested to assess heat stress in rabbits. IRT can be used to assess differences in thermal stress of animals in the same or different buildings.
\end{abstract}

Key words: Animal welfare, heat stress, infrared thermography, rabbit,

\title{
EXAMINATION OF FREE CHOICE OF GROWING RABBITS AMONG DIFFERENT FLOOR-TYPES
}

\author{
Gerencsér Zs. ${ }^{{ }^{*}}$, Odermatt M. ${ }^{2}$, Radnai I. ${ }^{1}$, Mikó A. ${ }^{1}$, Matics Zs. ${ }^{1}$, Nagy I. ${ }^{1}$, \\ Szendr Zs. ${ }^{1}$ \\ ${ }^{1}$ Kaposvár University, Faculty of Animal Science, Guba S. str. 40, H-7400, Kaposvár, Hungary \\ ${ }^{2}$ Olivia Ltd, 6050 Lajosmizse, Mizse 94, Hungary \\ *Corresponding author: gerencser.zsolt@ke.hu
}

\begin{abstract}
Location preference of growing rabbits was evaluated depending on the different floor types (plastic-mesh, wire-mesh and deep-litter). The experiment was conducted at the experimental rabbit farm of Kaposvár University using growing rabbits of maternal line of the Pannon Rabbit Breeding Programme ( $\mathrm{n}=129)$. At weaning (at the age of 5 wk), the rabbits were placed to one of the 3 pens each with a basic area of $3.8 \mathrm{~m}^{2}$ $(1.9 \times 2.0 \mathrm{~m})\left(43 \mathrm{rabbits} / \mathrm{pen}, 12 \mathrm{rabbits} / \mathrm{m}^{2}\right)$. The floor of the pens was partly wire-mesh $(1 / 3)$, plastic-mesh (1/3) and deep-litter (1/3). With infrared cameras, 24h video recording was made once a week, between 5 and 11 weeks of age. The number of rabbits in each location in the pens was recorded every 30 minutes. The $24 \mathrm{~h}$ observations were divided into four 6-h periods starting at 5:00 h. The average temperature in the room was $10.5^{\circ} \mathrm{C}$. The frequencies at the different locations were
\end{abstract}


compared by means of Chi-square test, testing the difference between observed and expected $(33.3 \%)$ frequencies. The rabbits showed the highest preference for plasticmesh $(\mathrm{P}<0.001)$, at every age they spent more time there (70 and 52\%, at the ages of 5.5 and $10.5 \mathrm{wk}$, respectively) than the expected value (33.3\%) in case of random choice of floor type. Between the ages of 5.5 and 9.5 weeks the preference of the wiremesh floor was significantly lower than $33.3 \%(20-27 \%$; $\mathrm{P}<0.001)$, but at the age of 10.5 weeks it was not significantly different from value of $33.3 \%$ ( $P>0.1)$. Deep-litter was the least frequently chosen floor type at all ages ( 8 and 14\%, at the ages of 5.5 and $10.5 \mathrm{wk}$, respectively; $\mathrm{P}<0.001)$. Similar tendencies were observed when the location preference was evaluated separately for the different day parts. Based on the results it can be concluded that at the temperature of $10^{\circ} \mathrm{C}$ the growing rabbits showed the highest and lowest preferences for the plastic-mesh and for deep-litter, respectively.

Key words: Growing rabbits, Preferences, Floor type.

\title{
MORPHOLOGY RELATED WELFARE INDEXES IN PURE BREED FANCY RABBITS
}

\author{
Marelli S.P. ${ }^{\mathbf{1}}$, Redaelli V. ${ }^{\mathbf{1}}$, Giovine G. ${ }^{\mathbf{1}}$, Martino P.A. ${ }^{2}$, Luzi F. ${ }^{1}$ * \\ ${ }^{1}$ Dept. of Animal Science, University of Milan, via Celoria 10, 20133, Milan, Italy \\ 2 DIPAV, University of Milan, via Veloria, 10, 20133, Milan, Italy \\ *Corresponding author: fabio.luzi@unimi.it
}

\begin{abstract}
The aim of this research was to evaluate fancy rabbits welfare conditions through the analysis of morphology related indexes: Body Condition Score (BCS), Pet Size O meter (PSOM), Footpad Injuries (FI). 172 (93 males; 79 females) adult (age $\geq 6$ months) pure breed (14 breeds) pedigree rabbits were sampled, animal were kept in standard environmental condition (2 rabbitries) and fed the same diet (ME 2400 $\mathrm{Kcal} / \mathrm{kg}$; CP $15 \%$ ). Rabbits were singularly cage housed with a slatted plastic floor $(80 * 50 * 40 \mathrm{~cm}: \mathrm{W} * \mathrm{D} * \mathrm{H})$ and a solid floor with straw litter for giant breeds $(120 * 80 * 60$ $\left.\mathrm{cm}: \mathrm{W}^{*} \mathrm{D} * \mathrm{H}\right)$ in both rabbitries. Animal were singularly analyzed: identification, sexing, weighing, scoring for BCS according to the method of Cardinali et al., 2008 (04: very skinny-fat), scoring for PSOM according to Pet Food Manufactures Association (PFMA) method (1-5: very thin-obese), scoring for FI according to Rommers and Meijrhof, 1996 method (0-3: coated foot sole-horny skin +deep crackers $>2.5 \mathrm{~cm})$. SAS® statistic package 9.2 version was applied to data analysis: measurements and scoring were analysed using the procedures means and npar1way procedure (ANOVA, Kruskal-Wallis), breed, breed*sex, size (4 sizes according to Italian Standard of Purebred Rabbits: Heavy (H), Medium (M), Light (L), Dwarf (D)) were considered as sources of variance. Recorded animal weight is in accordance to the standard one, the effect of Breed is significant, giant breeds are the closest to breed standard weight, even if the standard does not divide animal weight by sex: in many breeds females were heavier than male in $\mathrm{D}$ and $\mathrm{H}$ breeds in particular. Very good BCS (3 were recorded for all the analysed rabbits), Breed significantly influence BCS this is due to the particular morphological traits of one of the analysed breeds the Hare
\end{abstract}


an extreme dolichomorphic rabbit, no differences in breed*sex on BCS were recorded. All the rabbits' BCS ranged between 3 and 4, size significantly influence BCS: $\mathrm{H}$ and $M$ breeds showed the highest BCS values $M$ breeds values are influenced by the presence of the Hare breed, D breeds are the lowest group due to weight control and restricted feeding for show purpose. PSOM varied significantly according to Breed*sex variance in one breed in particular (Lynx) female are clearly fatter than males this could be due to feed characteristics that should be less energetic for light breeds, two meat-type breeds (Wien-Blue and Fauve de Bourgogne) showed high PSOM scores underlining their feed conversion ability. Statistically significant differences were recorded in FI, rabbit size influence the presence of injuries, with $\mathrm{H}$ breeds being the more affected even if reared on litter solid floor.

Key words: Fancy breeds welfare, BCS, PSOM, Footpad Injuries, rabbit breeds.

\title{
GROWTH PERFORMANCES AND BEHAVIOR OF GROWING RABBITS HOUSED ON CAGES, CLOSED PARKS OR OPEN-AIR SYSTEM
}

\author{
Pinheiro V. ${ }^{1 *}$, Mourão J.L. ${ }^{1}$, Monteiro D. ${ }^{1}$, Silva, S. ${ }^{1}$ \\ 1 - UTAD; CECAV - Department of Animal Science, University of Trás-os-Montes e Alto Douro, P. O. \\ Box 1013, 5000-911 Vila Real, Portugal \\ *Corresponding author: vpinheir@utad.pt
}

\begin{abstract}
The study was carried to investigate the effect of housing systems on growth and behavior of growing rabbits. Were used 120 rabbits hybrid NZXC from weaning at 35 days of age to slaughter at 84 days. Rabbits were randomly assigned to three types of housings: cages $(\mathrm{Cg}), 10$ collective cages of wire for 4 animals with $0.03 \mathrm{~m}^{2}(0.5 \mathrm{x} 0.6$ $\mathrm{m})$; closed parks $(\mathrm{Cp}), 10$ pens with the area of $0.525 \mathrm{~m}^{2}(1.05 \times 0.5 \mathrm{~m})$ with straw litter in the floor and (4 animals per pen); open-air system (Op), 2 outdoor pens with $80 \mathrm{~m}^{2}$ $(10 \times 8 \mathrm{~m})(20$ animals per pen). The feed intake and live weight were controlled weekly. At 84 days of age, in each treatment 10 rabbits were randomly chosen and subject to an open-field test and 10 rabbits per treatment were slaughtered and the samples of blood were collected for measurement of hematocrit and corticosterone levels. The open-air system rabbits had a significantly lower final live weight (less 424 $\mathrm{g}$ or $14 \%)$ than the $\mathrm{Cg}$ ones. Op rabbits showed lower weight gain $(33.1 \mathrm{~g} / \mathrm{d}$ vs. 41.8 $\mathrm{g} / \mathrm{d})$ and pellet feed intake (111.5 vs. $139.6 \mathrm{~g} / \mathrm{d})$ during the fattening period than $\mathrm{Cg}$ rabbits. Closed parks allowed similar growth and feed intake to the cages and better values than open-air system. The corticoterone and hematocrit levels were higher in rabbits housed in cages, which may indicate a worse welfare. Despite the difficulty of interpretation of locomotor activity in open-field tests, the results found in this work showed that animals reared in the open-air system walked a greater distance $(\mathrm{P}<0.05)$, than animals of other types of housing. The housing type of rabbit during the fattening
\end{abstract}


period affects the growth performances, being worse in open-air system, and the behavior, being worse in cage system.

Key words: Rabbits, growth, behavior, cages, parks, open air

\title{
EFFECT OF GROUP-HOUSING OF YOUNG DOES DURING REARING ON REPRODUCTION PERFORMANCE AND AGGRESSION: A PILOT STUDY
}

\author{
Rommers J.M. , B. Kemp ${ }^{1}$ \\ Wageningen University and Research Centre, Livestock Research \\ PO Box 65, 8200 AB Lelystad, The Netherlands \\ Tel: +31320293509, fax: +31320238050, email: Jorine.Rommers@wur.nl \\ ${ }^{1}$ Wageningen University, Adaptation Physiology group, P.O. Box 338, 6700 AH Wageningen, The \\ Netherlands \\ Email address corresponding author: Jorine.Rommers@ wur.nl
}

\begin{abstract}
An experiment was performed to investigate the effect of housing young does in small groups of two animals during the last three weeks before insemination on receptivity, reproduction performance and aggressive behavior. Seventeen litters of four sisters were used. Two sisters of a litter were housed individually and two sisters were housed together in cages during the last three weeks before first insemination. No influence of housing conditions was found on receptivity and kindling percentage. However, young does housed in groups produced smaller litters than young does that were single housed (9.0 \pm 0.6 vs. $7.2 \pm 0.5$, respectively). At weaning no differences in number of kits weaned and weaning weights between treatments were found anymore. At the end of rearing, one animal in group-housing had small superficial bites at the head. Based on the results of this experiment, group- housing of sisters at the end of the rearing period does not affect receptivity or skin lesions, but decreased total litter size. Further research is needed to investigate the effect of group housing of young does in larger (non-related) groups on aggression.
\end{abstract}

Key words: Rearing, rabbit does, welfare, reproduction, housing.

\section{FEAR LEVEL AND BEHAVIOUR OF GROWING RABBITS HOUSED IN INDIVIDUAL, BICELLULAR AND COLLECTIVE CAGES}

\author{
Filiou E. ${ }^{1}$, Trocino A. ${ }^{2}$, Tazzoli M. ${ }^{1}$, Xiccato G. ${ }^{1}$ \\ ${ }^{1}$ Department of Comparative Biomedicine and Food Science, University of Padova, \\ Viale dell'Università 16, I-35020 Legnaro, Padova, Italy \\ ${ }^{2}$ Department of Agronomy, Food, Natural Resources, Animal and Environment (DAFNAE), University of Padova \\ Viale dell'Università 16 - I-35020 Legnaro, Padova, Italy \\ *Corresponding author: Angela Trocino. angela.trocino@unipd.it
}




\begin{abstract}
During growth (from 27 to $75 \mathrm{~d}$ of age), 384 rabbits were kept into 72 individual cages (72 rabbits), 48 bicellular cages ( 2 rabbits/cage; 96 rabbits) and 24 collective cages ( 9 rabbits/cage; 216 rabbits). To evaluate the effect of the housing system on fear level and behavioural pattern of rabbits at two ages (39-45 $\mathrm{d}$ and 66-73 $\mathrm{d}$ of age), the tonic immobility test and the open field test were performed and behaviour was videorecorded. At the tonic immobility test, the number of attempts to induce immobility was lower (1.38) and the duration of immobility was higher (47.8 sec) in rabbits from individual cages than in those from bicellular (1.72 number of attempts and $25 \mathrm{sec}$ of immobility) and collective cages (1.99 number of attempts and $25.0 \mathrm{sec}$ of immobility) $(0.05<\mathrm{P}<0.01)$. During the open field test, rabbits from individual and bicellular cages showed higher latency (38.8 and 40.3 vs. $27.0 \mathrm{sec})$, lower number of total $(73.3,81.7$ and 91.9) and central displacements (3.6 and 2.8 vs. 5.4), ran for a shorter time (11.8 and $13.6 \mathrm{sec}$ vs. $17.7 \mathrm{sec})$ and bit less some parts of the pen $(5.5$ and $9.1 \mathrm{sec}$ vs. 28.2 sec) compared to rabbits kept in collective cages. During the 24 hours, rabbits in individual and bicellular cages spent less time for allo-grooming $(0.34 \%$ and $0.19 \%$ vs. $1.44 \%)$, moving $(0.74 \%$ and $0.60 \%$ vs. $1.32 \%)$ and running $(0.08 \%$ and $0.03 \%$ vs. $0.21 \%)$ than rabbits in collective cages $(0.01<\mathrm{P}<0.001)$. The lowest numbers of rearing and hops were observed in rabbits kept in bicellular cages. In conclusions, rabbits in individual cages exhibited the highest fear level, a reactive coping strategy and an incomplete behavioural pattern; rabbits housed in collective cages showed the lowest fear levels, had proactive coping strategy and the possibility of expressing more behaviours; rabbits in bicellular cages exhibited a not consistent pattern of fear in the tonic immobility and open field tests and a less defined coping strategies. These rabbits were likely in a less stressful condition compared to animals in individual cages since locomotory possibilities were even more limited, but social contacts were allowed.
\end{abstract}

Key words: Housing system, fear level, behaviour, growing rabbits. 


\title{
RESPONSE OF MALE RABBITS TO T-2 EXPOSURE
}

\author{
Rajli, V. ${ }^{1}$, Cseh, S. ${ }^{2}$, Tornyos, G. ${ }^{1}$, Keresztes, Zs. ${ }^{2}$, Matics, Zs. ${ }^{1}$, Huszenicza, Gy. ${ }^{2}$, \\ Kulcsár, M. ${ }^{2}$, Kovács, M. ${ }^{*}$ \\ ${ }^{1}$ Kaposvár University Faculty of Animal Science, 7400 Kaposvár, Guba S. u. 40. Hungary \\ ${ }^{3}$ SZIU Faculty of Veterinary Science, 1078 Budapest, István u. 2., Hungary \\ *Corresponding author: kovacs.melinda@ke.hu
}

\begin{abstract}
In several studies it has been concluded that the major factors with regard to male subfertility or infertility can be attributable to environmental factors, like mycotoxins, as frequently occurring dietary toxins. In a pilot study we examined the subsequent effect of T-2 toxin applied in high dose (4 mg/animal) for 3 days on the male reproductive processes in rabbits. One day of T-2 toxin treatment dramatically decreased voluntary feed intake which also remained lower during the first 2 weeks after the withdrawal of the toxin. Body weight of the contaminated rabbits decreased by $88 \%$ on days 17 and 29 compared to controls. The subsequent effect of T-2 toxin applied to rabbits in high dose manifested a decrease in sperm motility, an increase in the number of spermatozoa with morphological abnormalities, and decrease in the testosterone level even after 48 days following a 3-day long acute toxicosis. In another study male rabbits were exposed to 0 (control), $0.05,0.1$ or $0.2 \mathrm{mg} /$ animal/day T-2 toxin by gavage for 63 days. T-2 toxin in $0.1 \mathrm{mg}$ and 0.2 daily doses significantly decreased feed intake, which returned to normal values after the $2^{\text {nd }}$ and $3^{\text {rd }}$ week, respectively for each group. None of the sperm quality parameters examined showed significant difference between groups, except the ratio of spermatozoa with cytoplasmic droplets, which increased in animals treated with the highest dose of T-2. The two lower doses applied via feed (i.e. mixed into the feed to get 0.33 and $0.66 \mathrm{ppm}$ T-2 containing diets) had no significant effect on feed intake, body weight, and any spermatological parameters. According to the results of the two chronic experiments the two lower doses may be tolerated by adult male rabbits without any detrimental changes in reproductive parameters.
\end{abstract}

Key words: T-2 toxin, reproduction, male, rabbit.

\section{BLOOD HAPTOGLOBIN RESPONSE IN RABBITS WITH EXPERIMENTALLY INDUCED Staphylococcus aureus INFECTION}

\footnotetext{
Petrov V. ${ }^{1 *}$, Denev S. ${ }^{2}$, Georgieva T. M. ${ }^{3}$, Dishlyanova E. ${ }^{3}$, Dinev I. ${ }^{4}$

${ }^{1}$ Department of Veterinary Microbiology, Infection and Parasitic Diseases, Faculty of Veterinary Medicine, Trakia University, 6000 Stara Zagora, Bulgaria.

${ }^{2}$ Department of Biochemistry and Microbiology, Faculty of Agriculture, Trakia Unuiversity, 6000 Stara Zagora, Bulgaria;

${ }^{3}$ Department of Pharmacology, Animal Physiology and Physiological Chemistry, Faculty of Veterinary Medicine, Trakia University, 6000 Stara Zagora, Bulgaria.
} 
${ }^{4}$ Department of General and Clinical Pathology, Faculty of Veterinary Medicine, Trakia University, 6000 Stara Zagora, Bulgaria.

*Corresponding author: V.Petrov. vlado72@abv.bg

\begin{abstract}
Staphylococcus aureus is a common pathogenic bacterium which can induce severe skin infections in rabbits leading to important economic losses. The objectives of the present study included investigation of the variation profiles of blood concentrations of haptoglobin (Hp) which is considered a moderate positive APP during a 21-day-long period after inoculation and their comparison with clinical signs in order to improve diagnosis. The Hp concentrations were determined in plasma specimens from 7 male New Zealand White, 5 month-old rabbits subcutaneously injected with 100 L of bacterial suspension of a field S. aureus strain (density: $8 \times 10^{8} \mathrm{cfu} / \mathrm{mL}$ ) and from 6 untreated rabbits (controls). In parallel, rectal temperature and other clinical signs (skin lesions) were recorded. Abscesses and sometimes phlegmons were formed at the injection site within 48-72 hs in all infected animals and the inoculated germ was reisolated from these lesions. The mortality rate in inoculated rabbits was $28.6 \%$. A marked hyperthermia was observed in the inoculated rabbits after the 6 hrs and until 72 hs post-infection. Additionally, Hp concentrations were dramatically increased in infected rabbits compared to the controls between day one and 7 post-infection. These two parameters were positively but moderately correlated. Because of the great fluctuations of the body temperature in healthy rabbits, the simultaneous determination of the blood Hp concentrations may help to characterize the inflammation intensity in rabbits with experimental staphylococcal infection.
\end{abstract}

Key words: Rabbits, Staphylococcus aureus, inflammation, haptoglobin

\title{
EFFECTS OF EXPERIMENTALLY INDUCED Staphylococcus aureus INFECTION ON BLOOD PROTEIN FRACTIONS IN OBESE RABBITS
}

\author{
Georgieva T.M. ${ }^{1}{ }^{*}$, Denev S. ${ }^{2}$, Petrov V. ${ }^{3}$, Dinev I. ${ }^{4}$, Saco Y. ${ }^{5}$, Pato R. ${ }^{5}$, Bassols A. ${ }^{5}$ \\ ${ }^{1}$ Department of Pharmacology, Animal Physiology \& Physiological Chemistry, Faculty of Veterinary \\ Medicine, \\ Trakia University, 6000 Stara Zagora, Bulgaria \\ ${ }^{2}$ Department of Biochemistry \& Microbiology, Faculty of Agriculture, Trakia University, 6000 Stara \\ Zagora, Bulgaria ${ }^{3}$ Department of Microbiology, Infection and Parasitic Diseases, Faculty of Veterinary \\ Medicine, \\ Trakia University, 6000 Stara Zagora, Bulgaria \\ ${ }^{4}$ Department of General and Clinical Pathology, Faculty of Veterinary Medicine, \\ Trakia University, 6000 Stara Zagora, Bulgaria \\ ${ }^{5}$ Department of Biochemistry and Molecular Biology, Faculty of Veterinary Medicine, \\ Barcelona University, Barcelona, Spain \\ *Corresponding author: T.M. Georgieva. teodoramirchevag@ abv.bg
}




\begin{abstract}
Staphylococcus aureus causes suppurative inflammation and is frequently isolated from infected sites in rabbits. The aims of the study was to investigate the variations of blood protein fractions during a 7 days long period after subcutaneous inoculation of S. aureus in fattening obese castrated rabbits. Male New Zealand White rabbits $(n=6)$ were castrated at 2.5 months of age, fattened for 1.5 month and subcutaneously inoculated with a S. aureus field strain (suspension concentration: $8 \times 10^{8} \mathrm{cfu} / \mathrm{mL}$, injection volume: 100 L) when they were 4 months old. General health status, water/food intake, rectal temperature and skin lesions at the inoculation site as well as proteinemia, albuminemia and globulinemia were determined for 21 days whereas plasma protein fractions were analysed by electrophoresis for 7 days after the bacterial challenge. Lethargy, a strong decrease in food consumption and a marked hyperthermia were observed during the first $6 \mathrm{~h}$ whereas abscesses were formed in all rabbits at the inoculation sites within $48-96 \mathrm{~h}$ and consecutive invasive suppurative phlegmons persisted until the 7 and the 14 days in 4 rabbits. The inoculated germ was re-isolated from these lesions. Significant hypoalbuminemia and hyperglobulinemia

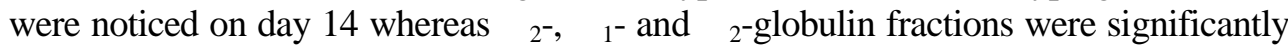
increased from day 2 to day 7, after inoculation compared to the basal values. The simultaneous determination of the blood protein fractions may help to characterize the inflammation intensity in rabbits with experimental staphylococcal infection.
\end{abstract}

Key words: Staphylococcus aureus, Inflammation, Abscess, Albumin, Globulins

\title{
ON-FARM CAUSES OF MORTALITY IN FEMALE RABBITS
}

\author{
Rosell J. M. ${ }^{1 *}$, de la Fuente L. F. ${ }^{2}$ \\ ${ }^{1}$ Cunivet Service, P.O. Box 518, 43080-Tarragona, Spain \\ ${ }^{2}$ Depto. de Producción Animal, Facultad de Veterinaria, Avda. Profesor Pedro Cármenes \\ s/n, Universidad de León, 24071-León, Spain \\ *Corresponding author: jmrosellp@cunivetservice.com
}

\begin{abstract}
On-farm causes of mortality in female rabbits were collected from 1,000 necropsies of 803 dead and 197 moribund-euthanized rabbit does. Data were gathered on 488 visits to 173 doe farms, in Spain and Portugal during 2006-2011. The median size of the 173 doe farms was 600 does (minimum to maximum: 60-2,580 does), and 45 bucks (minimum to maximum: 14-180 bucks) on 45 farms/173 doe farms; there were no bucks on 128 farms. Our estimation of the causes of mortality was based on a population of 369,589 females at risk over a period of 6 years. The mortality risk per year $\times 100$ females (MR) was estimated, considering the relationship between necropsied does and the population at risk on each visit. We found alterations of the respiratory tract compatible with cause of death in $31.1 \%$ of does (MR). MR due to
\end{abstract}


digestive causes was $22 \%$ (15.7\% enteritis-diarrhoea, and $6.3 \%$ mucoid enteropathy, similar to Epizootic Rabbit Enteropathy), followed by metritis, pyometra and mummified fetuses $(\mathrm{MR}=11.4 \%)$, hemorrhagic septicemia $(8.4 \%)$, pregnancy toxaemia/ketosis $(8.4 \%)$, uterine torsion $(7.5 \%)$, mastitis (chronic, but mainly acute; $\mathrm{MR}=5.5 \%)$, viral hemorrhagic disease $(4.1 \%)$. There were also miscellaneous health events $(14.7 \%)$, and unknown conditions (cadaver with autolysis included; MR= $3.7 \%$ ). Among the miscellaneous health events there were hepatopathies (abscesses and cholecystitis included; $\mathrm{MR}=1.9 \%)$, uterine prolapse $(1.9 \%)$, toxicosis caused by ionophore antibiotics in feed (1.5\%), or nephropathies (1.4\%). It would be very useful if this information were complemented with laboratory analyses. Knowledge of the apparent causes of disease and death in does is necessary for preparing better adapted prevention protocols.

Key words: Animal Welfare, Females, Diseases, Mortality, Rabbits.

\title{
CALCINOSIS IN FEMALE RABBITS
}

\author{
Rosell J.M. ${ }^{1 *}$, Garriga R. ${ }^{2}$, Martínez J. ${ }^{3}$, Domingo M. ${ }^{3,4}$, de la Fuente L.F. \\ ${ }^{1}$ Cunivet Service, P.O. Box 518, 43080-Tarragona, Spain \\ ${ }^{2}$ Federació d'Associacions de Cunicultors de Catalunya (FACC), C. Ull de Llebre 13, 08734- \\ Olèrdola, Barcelona, Spain \\ ${ }^{3}$ Dept. de Sanitat i Anatomia Animals, Facultat de Veterinària, Universitat Autònoma de \\ Barcelona, \\ 08193-Bellaterra, Barcelona, Spain \\ ${ }^{4}$ Centre de Recerca en Sanitat Animal (CReSA), UAB-IRTA, Campus de la Universitat Autònoma \\ de Barcelona, 08193-Bellaterra, Barcelona, Spain \\ ${ }^{5}$ Depto. Producción Animal, Facultad de Veterinaria, Avda. Profesor Pedro Cármenes s/n, \\ Universidad de León, 24071-León, Spain \\ *Corresponding author: jmrosellp@ cunivetservice.com
}

\begin{abstract}
Soft tissue mineralization was determined in female rabbits on commercial farms. Does received vitamin $\mathrm{D}_{3}$ supplementation subcutaneously, in drinking water, or both, at the beginning of every new reproductive cycle. Records $(n=708)$ were obtained from onfarm necropsies of 245 dead and 463 euthanized rabbit does, sorted according to the age in months and the monthly extra dose of vitamin $\mathrm{D}_{3}$ received. Data were gathered on 248 visits with necropsies on 101 doe farms in Spain, between August 2010 and December 2011. Producers administered extra doses of vitamin $\mathrm{D}_{3}$ on $75 \%$ of the evaluated rabbitries; doses ranged between 1,000 and 125,000 IU per month. Median size of the 101 farms was 600 does (minimum to maximum: 90-7,000 does). The population at risk (in this study, females from 1st AI), was 190,481 does. Median age was 16 months (minimum to maximum: 5 to 59 months), and 6 kindlings (minimum to maximum: 1 to 34 kindlings), besides 57 females on their 1st pregnancy. Does with the most severe calcinosis were anorectic, emaciated $(\mathrm{BCS}=1 / 9)$, with extreme weight loss $(\mathrm{BW}=2.2 \mathrm{~kg})$, and died. At necropsy, 71 of 708 does $(10 \%)$ presented variable scores of mineralization in the aorta, stomach, kidney, heart and other soft organs. The
\end{abstract}


presence of calcium was confirmed on histopathological examination by von Kossa special stain. Calcinosis was assessed with the lesions in the aorta, on a 4-point linear scale, by trained and experienced veterinarians, according to images supporting this study. Using an ANOVA (proc CATMOD) we found that oral or mainly subcutaneous treatment with extra doses of vitamin $\mathrm{D}_{3}$, was an enabling risk factor for calcinosis $(\mathrm{P}<$ 0.0001 ). The Odds ratio was 6.04 for $>1,000 \mathrm{IU}$ of vitamin $\mathrm{D}_{3}$ per month, 11.40 for $>$ $10,000 \mathrm{IU}$ and 13.66 for $>25,000 \mathrm{IU}$. Age was a predisposing risk factor only in females receiving vitamin $D_{3}$ treatment not in untreated does. Based on this retrospective study, we recommend the prudent use of vitamin $\mathrm{D}_{3}$ in commercial rabbit production.

Key words: Animal Welfare, Calcinosis, Diseases, Rabbit, Vitamin $\mathrm{D}_{3}$.

\title{
SALMONELLA SER. TYPHIMURIUM ISOLATED FROM RABBIT FARMS: CHARACTERIZATION AND EPIDEMIOLOGICAL IMPLICATIONS
}

\author{
Camarda A. ${ }^{1}$, Pugliese N. ${ }^{1}$, Circella E. ${ }^{1}$, Caroli A. ${ }^{1}$, Legretto M. ${ }^{1}$, Pazzani C. ${ }^{2}$ \\ ${ }^{1}$ Dipartimento di Sanità Pubblica e Zootecnia. ${ }^{2}$ Dipartimento di Genetica e Microbiologia, \\ Università degli Studi di Bari “Aldo Moro", Italy. \\ Corresponding Author: Antonio Camarda, Dipartimento di Sanità Pubblica e Zootecnia \\ Università di Bari, Strada provinciale per Casamassima Km 3, 70010 Valenzano-Bari, \\ Italy - Tel./Fax: +39080 4679910 - Email: a.camarda@ veterinaria.uniba.it
}

\begin{abstract}
Salmonella enterica infections are not common in rabbits, but, whenever they occur, they induce high morbidity and mortality and they also raise concern in terms of public health impact. Moreover, the worldwide spread of multidrug resistant strains complicates the treatment of infection in both rabbits and humans. Despite those premises, knowledge about salmonelloses in rabbits is still poor. In this study four S. Typhimurium strains were isolated from as many rabbit farms, and they were characterized for antimicrobial susceptibility, resistance genes, class 1 integrons and Pulsed-Field Gel Electrophoresis (PFGE). The results showed that a group of strains were circulating in Basilicata, and that it was indistinguishable from human isolates for PFGE profile, multidrug resistance pattern and genetic features, as they harbored the Salmonella Genomic Island 1 (SGI1) which characterized the S. Typhimurium strains which are widespread among humans all over the world. Our data suggest that molecular characterization is a useful tool to promptly recognize Salmonella strains which are potentially harmful to rabbits or humans.
\end{abstract}

Key words: Salmonella typhimurium, PFGE, Resistance genes. 


\title{
A RT-PCR BASED STRATEGY TO IDENTIFY RABBIT HAEMORRAGIC DISEASE VIRUS
}

\author{
Pugliese N., Circella E., Caroli A., Legretto M., Camarda A. \\ Dipartimento di Sanità Pubblica e Zootecnia, Università degli Studi di Bari “Aldo Moro", Italy. \\ Corresponding Author: Antonio Camarda, Dipartimento di Sanità Pubblica e Zootecnia, \\ Università di Bari, Strada provinciale per Casamassima Km 3, 70010 Valenzano-Bari, \\ Italy - Tel./Fax: +39080 4679910 - Email: a.camarda@ veterinaria.uniba.it
}

\begin{abstract}
Rabbit Hemorrhagic Disease Virus (RHDV) and European Brown Hare Syndrome Virus (EBHSV) are two virus belonging to the Lagovirus genus. They cause a hemorrhagic disease in rabbits and hares, respectively. The high mortality (up to $100 \%$ ), and the great contagious potential of the viruses make them very dangerous for both wild and domestic animals. The viruses have a number of variants, and recently a new RHDV variant has been widely circulating among rabbits, mainly in France. The variability of viruses may cause some problems in the molecular diagnosis. We set up a RT-PCR based method which could widen the efficacy of the existing molecular techniques, as it could detect simultaneously the variants of RHDV, including the French variants, and the EBHSV, furthermore discriminating the two viral species.

Key words: Rabbit Hemorrhagic Disease Virus, European Brown Hare Syndrome Virus, detection, RT-PCR

\section{SALMONELLOSIS IN RABBITS. FIELD AND LABORATORY RESULTS DURING 1999-2011}

\author{
Saco M. ${ }^{1 *}$, Pérez de Rozas A. ${ }^{2}$, Aloy N. ${ }^{2}$, González J. ${ }^{2}$, Rosell J.M. ${ }^{3}$ Badiola J.I. ${ }^{2,4}$ \\ ${ }^{1}$ Laboratori de Sanitat Ramadera de Barcelona, Via de Circulació Nord, tramo $6^{\circ}$, esquina calle 3 , \\ Zona Franca, 08040 Barcelona, Spain \\ ${ }^{2}$ Centre de Recerca en Sanitat Animal (CReSA), UAB-IRTA, Campus de la Universitat \\ Autònoma de Barcelona, 08193 Bellaterra, Barcelona, Spain \\ ${ }^{3}$ Cunivet Service, P.O. Box 518, 43080 Tarragona, Spain \\ ${ }^{4}$ Institut de Recerca i Tecnologia Agroalimentàries (IRTA), Barcelona, Spain. \\ *Corresponding author: montserrat.saco@gencat.cat
}

\begin{abstract}
In this study, we evaluated the incidence risk of salmonellosis on 394 commercial rabbit farms in Spain (374) and Portugal (21). Data were gathered on 2,269 visits performed by a trained veterinarian, during 2008-2011. The median size of the farms was 740 does (minimum to maximum: 40-9,000 does), and 50 bucks (minimum to maximum: 8-544 bucks). Refrigerated samples obtained from on-farm necropsies of aborted does, kits and runt growing rabbits were analyzed for isolation and typing of
\end{abstract}


Salmonella spp. Clinical incidence risk was $4 \%$, the same result as in a precedent retrospective study performed by the same practitioner, on 868 rabbit farms during 1997-2007. From the perspective of the Associations for managing Animal Health in food-producing animals, it was useful to point out the diffusion of infected young breeders and semen from selection breeder's centers and artificial insemination centers, respectively, to production farms.

Key words: Animal Welfare, Public Health, diseases prevention, rabbit, salmonellosis.

\title{
EFFECT OF HIGH TEMPERATURE ON BLOOD LYMPHOCYTE POPULATIONS IN TWO DIFFERENT GENETIC RABBIT LINES.
}

\author{
Ferrian S. ${ }^{1}$, Guerrero I. ${ }^{1}$, Blas E. ${ }^{2}$, García-Diego F.J. ${ }^{2}$, Viana D. ${ }^{\text {, Pascual J.J. }}$, \\ Corpa J.M. ${ }^{*} *$ \\ ${ }^{1}$ Dpt. Animal Production and Health, Veterinary Public Health and Science and Food \\ Tecnology, Veterinary School, Universidad CEU Cardenal Herrera. Moncada (Valencia). Spain. \\ ${ }^{2}$ Institute for Animal Science and Technology. Polytechnic University of València. Camino de \\ Vera, 14. 46071. Valencia. Spain. \\ * Correspondign autor: jmcorpa@uch.ceu.es
}

\begin{abstract}
Stress is generally considered an important factor affecting the productivity of farm animals, as it is able to suppress the immune system and may lead to an increase in the occurrence of diseases in the presence of pathogens. In fact, it has been described that chronic heat stress can affect negatively the immune response in several production animal species, since they are genetically different and they show different ability to deal successfully with environmental challenges. Therefore, rabbits from different genetic lines subjected to heat stress also develop different immune system responses. The present study aimed to determine and compare the ability of rabbit does from two different genetic lines selected by different productive criteria (one selected for productive longevity (LP) and one for litter size at weaning (V, using two generations of the same line: V16, V36), to deal with heat stress in terms of their abovementioned selection criteria. The results pointed out that animals from the LP line showed a higher number of total lymphocytes (in blood). Furthermore, while the animals from line LP were able to modulate their immune response based on the total numbers of lymphocytes throughout the gestation-lactation cycle, animals from lines V16 and V36 did not show such ability to adapt to different situations, since the total cell number remained constant or decreased, reaching very low values in the second parturition. These results may suggest that, regarding immune response to thermal challenges, selecting by prolificacy criteria may have a negative impact on breeding rabbits.

Key words: Lymphocyte populations; heat stress; genetic origin; litter size, longevity.
\end{abstract}




\title{
SCREENING OF VIRULENCE GENES IN Staphylococcus
} aureus ISOLATE FROM RABBITS

\author{
Viana D. ${ }^{1}$, Selva L. ${ }^{1}$, García-Quirós A. ${ }^{1}$, Penadés M. ${ }^{1}$, Penadés J.R. ${ }^{2,3}$, \\ Corpa J.M. ${ }^{\text {* }}$ \\ ${ }^{1}$ Dept. de Producción y Sanidad Animal, Salud Pública Veterinaria y Ciencia y Tecnología de los \\ Alimentos (Histología y Anatomía Patológica), CEU-Cardenal Herrera University, 46113 Moncada \\ (Valencia), Spain \\ ${ }^{2}$ Dept. de Ciencias Biomédicas, CEU-Cardenal Herrera University, 46113 Moncada (Valencia), \\ Spain \\ ${ }^{3}$ Centro de Investigación y Tecnología Animal. Instituto Valenciano de Investigaciones Agrarias \\ (IVIA), Apdo. 187, Polígono La Esperanza, 100, 12400, Segorbe (Castellón), Spain \\ *Corresponding author: jmcorpa@uch.ceu.es
}

\begin{abstract}
Staphylococcus aureus is a versatile pathogen that can survive in diverse host environments and produce a wide range of diseases both in humans and animals. This versatility depends on its ability to modulate gene expression and the synthesis of virulence determinants. Therefore, this study aimed to investigate the distribution of bacterial virulence determinants in the most prevalent $\mathrm{S}$. aureus strain types causing lesions in rabbits. Sixty-nine S. aureus strains were isolated from rabbit does with different chronic purulent lesions from 30 Spanish industrial rabbitries. Genotyping characterization of the strains was performed based on the analysis of the polymorphic regions of the coa, spa and clfB genes, as well as Multylocus Sequence Typing (MLST) on one strain of each of the most frequent genotypes. The isolates were also analyzed for the presence of forty virulence genes by PCRs and Southern blot, in order to determine their relationship with the genotype and the type of infection respectively. The great majority of isolates belonging to the same genotype were related to the same virulence factors, even though certain virulence factors were variable inside a genotype. However, the type of infection could not be related to any combination of virulence factors.
\end{abstract}

Key words: Screening, virulence genesm, staphylococcus aureus, isolate.

\section{STRAINS OF Staphylococcus aureus AND PATHOLOGY ASSOCIATED WITH NATURAL CHRONIC AND EXPERIMENTAL ACUTE SUPPURATIVE MASTITIS}

\author{
Guerrero I., Penades M., García Quirós A., Viana D., Selva L., Ferrian S., \\ Corpa J.M. * \\ ${ }^{1}$ Dept. de Produccion y Sanidad Animal, Salud Pública Veterinaria y Ciencia y Tecnología de los \\ Alimentos (Histología y Anatomía Patológica), Universidad CEU Cardenal Herrera, 46113 Moncada \\ (Valencia), Spain \\ *Corresponding author: jmcorpa@uch.ceu.es
}




\begin{abstract}
Staphylococcal mastitis is one of the main causes of culling of adult rabbit does from commercial rabbitries. The aims of this work were: 1) to provide a detailed description of the spectrum of gross and microscopic lesions observed in chronic natural cases of staphylococcal mastitis in adult does, 2) to determine whether there is a correlation between the different Staphylococcus aureus genotypes and the pathology observed and 3) to study the host immune response after an experimental infection with this bacterium.

The results showed that the different lesions observed were independent of the bacterial genotype. A broad spectrum of different pathological stages could be established based on the histomorphological characteristics and the cellular composition of the lesions. There were two major types of pathologies, one focused on the mammary gland structures (with variations which could suggest possible stages of infection) and one focused on periglandular tissue. Mammary glands were histologically grouped into four different types: abscesses (66.3\%), suppurative mastitis (lobular pattern) (7.9\%), cellulitis (19.6\%) and mixed (6.2\%). In the experimental infection, the important role of the individual immune response was considered after observing that animals inoculated with the same bacterial strain showed histological lesions of different level of severity.
\end{abstract}

Key words: Staphylococcus aureus; Mastitis; Rabbit; Natural infection; Experimental infection

\title{
PATHOLOGY AND DIAGNOSIS OF LEPORID HERPESVIRUS-4
}

\author{
Sunohara-Neilson J. ${ }^{1}$, Carman S. ${ }^{2}$, Nagy E. ${ }^{1}$, Turner PV. ${ }^{1 *}$ \\ ${ }^{1}$ Dept. of Pathobiology, University of Guelph, 50 Stone Rd W, N1G2W1, Guelph, ON, Canada \\ ${ }^{2}$ Animal Health Laboratory, University of Guelph, 50 Stone Rd W, N1G2W1, Guelph, ON, \\ Canada \\ *Corresponding author: pvturner@uoguelph.ca
}

\begin{abstract}
Leporid herpesvirus-4 is a novel alphaherpesvirus that has been identified as the cause of mortality in commercial and pet rabbits in North America. Experimental intranasal inoculation of laboratory rabbits has been conducted to determine the clinical course of infection, pathologic findings, virus shedding and development of serum antibodies. Rabbits show peak clinical signs between 3-7 days post infection (dpi) and include respiratory distress, serous nasal and ocular discharge and mild weight loss. Virus can be isolated from nasal secretions during this period and polymerase chain reaction (PCR) can be used to identify the virus. The main histopathologic findings are suppurative, ulcerative rhinitis ( $3 \mathrm{dpi}$ ), multifocal-to-coalescing splenic necrosis (5 dpi) and fibrinosuppurative bronchopneumonia $(7 \mathrm{dpi})$. Characteristic herpesviral intranuclear inclusion bodies are present in these tissues at 3 and 5 dpi. Rabbits begin
\end{abstract}


to recover at $8 \mathrm{dpi}$, and the presence of neutralizing antibodies can be demonstrated at 11 dpi. In the acute phase of the disease, LHV-4 can be diagnosed based on histopathologic findings or virus isolation from nasal secretions. Serology is useful for diagnosis in convalescent animals.

Key words: Herpesvirus, Oryctolagus cuniculi, histopathology, nasal shedding, pneumonia

\title{
ANTIMICROBIAL RESISTANCE-RELATED GENE PROFILES OF RABBIT ENTEROPATHOGENIC ESCHERICHIA COLI STRAINS ISOLATED FROM COLIBACILLOSIS OUTBREAKS IN NORTHERN ITALY
}

\author{
Badagliacca P. ${ }^{1 *}$, Agnoletti F. ${ }^{2}$, Tonelli A. ${ }^{1}$, Masson L. ${ }^{3}$ \\ ${ }^{1}$ Istituto "G. Caporale", Campo Boario, 64100 Teramo, Italy \\ ${ }^{2}$ Istituto Zooprofilattico Sperimentale delle Venezie, Viale Brigata Treviso 13/A, 31100, Treviso, \\ Italy \\ ${ }^{3}$ Biotechnology Research Institute, National Research Council of Canada, 6100 Royalmount, Montreal, \\ QC, Canada H4P 2R2 \\ *Corresponding author: p.badagliacca@izs.it
}

\begin{abstract}
A DNA microarray, designed to detect a large set of resistance genes to antimicrobials belonging to Aminoglycosides, $\beta$-lactams, Tetracyclines, Sulfonamides, Phenicols, Quinolones and Rifamicines families as well as Erythromycin, Trimetoprim, Olaquindox, Quaternary ammonium compound resistant determinants and mobile genetic elements such as Class 1, 2, 3 Integrons and transposon Tn21, was applied to genotyping twenty-six rabbit enteropathogenic E. coli strains coming from 14 rabbitries, located in Northern Italy. Each strain was positive at least for one family of antimicrobial resistance genes. The main frequent genes encoding for the Aminoglycoside resistance were aac(3)-IV (20 out of 26 strains), aadA1 (24 strains), strA and strB (16 and 21 strains). At least one $\beta$-lactamase encoding gene was detected in 15 out of 26 strains. Within this family, the blaCMY-2 plasmid-borne gene was the most frequent one. Relatively few antimicrobial resistance genes related to Phenicols, Erythromycin, Quinolones and Olaquindox antimicrobials were detected. Among mobile genetic elements, only the Class 1 integron genes were detected in 14 out of 26 strains, six of which have shown to be associated with the tnpM gene, confirming an important circulation of the transposon Tn21, never described in rabbit E. coli. The presence of mobile elements supporting the multidrug resistance to Aminoglycoside, Tetracycline and Sulfa-Trimethoprim antimicrobial families was discussed as well as the importance of the plasmid-carried aac(3)-IV gene as potential gene cassette in Apramicyn-resistant E. coli strains. The detection of blaCMY-2 was reputed an indicator of the involvement of rabbit E.coli in the transfer of class $\mathrm{C} \beta$-lactamases which hydrolyse broad and extended-spectrum cephalosporins (cephamycins).
\end{abstract}

Key words: Antimicrobial resistance, Genotyping, Escherichia coli, Integron, Microarray. 


\title{
NUTRIONNALY INDUCED ENTEROPATHY IN THE GROWING RABBIT: IMPACT ON CAECAL MICROBIAL ACTIVITY AND METABOLIC PROFILE
}

\author{
Nadia Laurent-Bennegadi ${ }^{* 1}$, Dominique Licois ${ }^{2}$, Thierry Gidenne ${ }^{3,4,5}$ \\ 1: Esitpa, Chaire d'Agronomie, 3 rue du Tronquet, CS 40118, 76134 Mont Saint Aignan, France \\ 2: UR 1286 IASP, INRA 37380, Nouzilly, France \\ ${ }^{3}$ INRA, UMR1289 Tissus Animaux Nutrition Digestion Ecosystème et Métabolisme, F-31326 Castanet- \\ Tolosan, France \\ ${ }^{4}$ Université de Toulouse, INPT ENSAT, UMR1289 Tissus Animaux Nutrition Digestion Ecosystème et \\ Métabolisme, F-31326 Castanet-Tolosan, France \\ ${ }^{5}$ ENVT, UMR1289 Tissus Animaux Nutrition Digestion Ecosystème et Métabolisme, F-31076 Toulouse, \\ France \\ E-mail address: nlaurent@esitpa.org*
}

\begin{abstract}
Caecal microbial activity, metabolic and mineral blood profiles were studied according to the health status of growing rabbits (diarrhoeic vs. healthy). Conventional rabbits $(n=359)$ were housed in collective cages and 80 rabbits in individual cages. A standard fibre-diet $\mathrm{SF}\left(\mathrm{ADF}=19 \mathrm{~g} \cdot \mathrm{kg}^{-1} \mathrm{DM}\right)$ or a deficient-fibre diet $\mathrm{DF}\left(\mathrm{ADF}=9 \mathrm{~g} \cdot \mathrm{kg}^{-1} \mathrm{DM}\right)$ as a model to reproduce non-specific enteropathy were distributed ad libitum from weaning (28 days) to 70 days of age. In agonising rabbits, dry matter and total volatile fatty acids concentration in the caecum decreased, as well as bacterial pectinasic activity, while caecal ammonia concentration, minor VFAs proportions, $\mathrm{C}_{3}: \mathrm{C}_{4}$ ratio and $\mathrm{pH}$ increased.

Regarding the blood profile, glucose, potassium and albumin plasma decreased in diarrhoeic rabbits compared to healthy ones, while urea and total cholesterol showed a two-fold increase. Thus the metabolic profile of the rabbit affected by a non specific enteropathy is similar to that previously described for rabbit specific enteropathy such coccidiosis or colibacillosis.
\end{abstract}

Key words: Blood parameters, caecal fermentation, diarrhoea, fibre deficiency, growing rabbits.

\section{ANALYSIS OF MYXOMATOSIS OUTBREAKS ON SPANISH RABBIT FARMS}

\author{
Dalton K.P. ${ }^{1 *}$, I. Nicieza ${ }^{1}$, J. Gullón ${ }^{2}$, M. Inza ${ }^{3}$, M. Petralanda ${ }^{3}$, Z. Arroita ${ }^{3}$, F. \\ Parra'. \\ ${ }^{1}$ Departamento de Bioquímica y Biología Molecular, Edificio Santiago Gascón, Campus El \\ Cristo,Universidad de Oviedo, 33007 Oviedo, Asturias, Spain ${ }^{2}$ COGAL Cogal, S. Coop. Gallega 36530 \\ Rodeiro, Pontevedra, Spain. ${ }^{3}$ Federacion de Cunicultores de Euskadi, C/ Juan XXIII, 16 B-3, 20730- \\ Azpeita, Gipuzkoa, Spain. \\ *Corresponding author: daltonkevin@uniovi.es
}




\begin{abstract}
Myxomatosis is a fatal disease caused by myxoma virus (MV), a member of the poxviridae. Although effective vaccines are available, outbreaks on Spanish rabbit farms cause large economic losses. In order to study the causes of these outbreaks we have focused our attention on characterizing circulating viruses and analyzing the immune response of vaccinated rabbits in both rabbitry and laboratory conditions. Using a network of veterinary surgeons and technicians we received samples suspected of containing myxoma virus from 22 affected rabbitries. Firstly we used PCR to confirm the presence of myxoma virus, we next targeted 3 genomic regions by PCR to obtain sequence data in order to typify the virus present. In a selected number of samples the virus was isolated by cultivation in tissue culture. Using the sequence data we selected a virus isolate as representative of the current circulating field viruses causing outbreaks on Spanish rabbit farms. The viral strain Granada -05/09 was characterized for its virulence in New Zealand white rabbits and shown to be of virulence grade A (maximum virulence grade).Next, we measured seroconversion in vaccinated rabbits under both farm and laboratory conditions. Using anti-MV antibody levels as an indicator of immune response we compared methods of vaccine administration (intradermic or subcutaneous). In laboratory rabbits we tested the efficacy of a current vaccine strain against the MV Granada -05/09 strain. Our findings indicate that MV vaccines are capable of protecting against currently circulating strains but the levels of seroconversion after vaccination vary greatly and depend on the method (route) of vaccine administration.
\end{abstract}

Key words: Myxoma virus, characterization, sequence, antibody response.

\title{
CROSS-SECTIONAL STUDY OF COLIBACILLOSIS IN PORTUGUESE RABBIT FARMS
}

\author{
Calhoa I. ${ }^{1}$, Pinheiro V. ${ }^{2 *}$, Monteiro J.M. ${ }^{3}$, Coelho AC. ${ }^{1}$ \\ ${ }^{1}$ Dept. de Ciências Veterinárias, CECAV, Universidade de Trás-os-Montes e Alto Douro (UTAD), 5001- \\ 801 Vila Real, Portugal \\ ${ }^{2}$ Dept. de Zootecnia, CECAV, Universidade de Trás-os-Montes e Alto Douro (UTAD), 5001-801 Vila \\ Real, Portugal \\ ${ }^{3}$ Sumicor Portugal, Lda., Apartado 74, 4481-911 Vila do Conde, Portugal \\ *Corresponding author: vpinheir@utad.pt
}

\begin{abstract}
A cross-sectional study was carried out between 2007 and 2011 in Portuguese rabbit farms to investigate farm characteristics related to colibacillosis. In seven $(17.1 \%)$ farms, one or more animals were positive to E. coli. All positive farms were from the North of Portugal. Five positive (71.6\%) farms had less than 900 female's rabbits, and 2 positive $(28.6 \%)$ had more than 900 females. In six positive farms $(85.7 \%)$, ammonia levels were less than $5 \mathrm{ppm}$ and four $(57.1 \%$ ) farms had humidity levels between $55 \%$ and $80 \%$. This study provides preliminary data in colibacillosis in farms. Differences were observed between the farms. More extensive investigations are required with
\end{abstract}


multiple farms and replicates to confirm our findings and assess the role of each of these factors.

Key words: Rabbits, colibacillosis, farms, Portugal.

\title{
VISCERAL OBESITY INDUCED BY A HIGH-CALORIE DIET LEADS TO DYSLIPIDEMIA, INSULIN RESISTANCE AND IMPAIRS ADRENAL FUNCTION IN MALE RABBITS
}

\author{
Mokrani Zoulikha ${ }^{1,2}$, Soltani Yacine ${ }^{* 1,3}$, Hadj Bekkouche Fatima ${ }^{1,4}$ \\ ${ }^{1}$ Laboratory of Biology and Physiology of Organisms, Faculty of Biological Sciences, USTHB, BP32, El \\ Alia, BabEzzouar, 16111, Algiers, Algeria \\ email: mokranizoulikha@yahoo.fr \\ 3 email: ysoltani@usthb.dz \\ 4 email: illoulfa@yahoo.fr
}

\begin{abstract}
The nutritional status and obesity alter the HPA axis function. The aim was to study the impact of a diet induced obesity on hormonal pituitary- adrenal axis, as well as structural changes that appeared in affect the adrenal gland. Two groups of adult male New Zealand White rabbits $(n=16)$ were maintained on high-calorie $(454 \mathrm{Kcal} /$ day $)$ and standard diets $(258 \mathrm{kcal} /$ day) for 15 weeks. Plasma triglycerides (TG), total cholesterol (Tchol), HDL-c, LDL-c, glucose ACTH, cortisol, insulin and levels cortisol within adrenal and periadrenal fat (PAF) were measured. We show that high-calorie diet induced a significant increase of body weight, visceral adipose tissue (VAT) and adrenal. Increased TG, Tchol an LDL-c and decreased LDL-c were associated to hyperglycemia (HG) and hyperinsulinemia (HI) in obese rabbits. Plasma ACTH was increased in obese compared to controls rabbits, but PAF cortisol increases more significantly than within adrenal and plasma. Adrenal gland of obese rabbits shows a reduction in the thickness of the zona reticularis, while fasciculata and medullary zones were enlarged, with a proliferation of pyknotic nuclei; the medulla shows a vasodilatation and a high density of connective fibers that grew through the cortex until they reach the glomerulosa zone. We suggested that high-calorie diet induced visceral obesity and led to disrupt metabolic parameters that onset dyslipidemia and development of insulin resistance. High-calorie diet seems also to induce a nutritional stress that stimulates the secretion of ACTH and cortisol by the adrenal axis and an overproduction of cortisol from PAF, probably by stimulating $11 \beta$-HSD1 activity. These disturbances may be involved in the fibrosis of the medulla and the intense pyknosis in the fasciculata and medulla in obese rabbits which could be related to an apoptotic process.
\end{abstract}

Key words: Obesity, dyslipidemia, insulin resistance, adrenal axis. 


\title{
DEVELOPMENT OF AN ELISA USING RECOMBINANT OMPA PROTEIN FOR THE DETECTION OF PASTEURELLA MULTOCIDA INFECTIONS IN RABBITS
}

\author{
Liu Y., Pang AN., Bao GL*.,Wei Q., Xiao CW., Ji QA. \\ Animal Husbandry and Veterinary Institute, Zhejiang Academy of Agricultural Sciences \\ NO.145 shiqiao road, 310021, Hangzhou, China \\ *Corresponding author: baoguolian@163.com
}

\begin{abstract}
Pasteurella multocida, a gram-negative bacillus, is the causative agent of snuffles in rabbits, a disease which could incur much economic loss in the rabbit industry. Vaccination is not commercially available because of a lack of efficacy, antibiotics may be effective for resolving the symptoms in sick animals but usually do not clear the bacteria from colonized animals. Hence the detection of P. multocida in clinically healthy rabbit colonies is important for the control of this disease. An indirect enzymelinked immunosorbent assay (ELISA) has been developed to facilitate early detection of Pasteurella multocida infections in rabbits. The antigen used was a recombinant protein, ompA, which was expressed in Escherichia coli as an N-terminal HIS fusion protein. The rompA-based ELISA successfully detected ompA antibodies in the sera of rabbits immunized with bacterin preparations of the C51-2-499 strain. Antibodies to ompA were also detected in the sera of $40 \%(42 / 106)$ which were collected from three different farms, but few of the rabbits $(19 \%)$ were PCR positive. The rompA-HIS antigen did not cross-react with antibodies in sera from rabbits which were infected with other gram-negative and gram-positive bacterial pathogens, including E.coli, Bordetella bronchiseptic, Pseudomonas aeruginosa and staphylococcus. The rompA based ELISA may be useful for the diagnosis of Pasteurella multocida infections in sick rabbits as well as for screening for carriers in research rabbit colonies.
\end{abstract}

Key words: Pasteurella multocida ELISA ompA. 